NIST Special Publication 260-182

\title{
Re-Certification of SRM 2492: Bingham Paste Mixture for Rheological Measurements
}

Alex Olivas

Chiara F. Ferraris

William F. Guthrie

Blaza Toman 
Page left intentionally blank 


\title{
Re-Certification of SRM 2492: Bingham Paste Mixture for Rheological Measurements
}

\author{
Alex Olivas \\ Chiara F. Ferraris \\ Materials and Construction Research Division \\ Engineering Laboratory \\ William F. Guthrie \\ Blaza Toman \\ Statistical Engineering Division \\ Information Technology Laboratory
}

10.6028/NIST.SP.260-182

August 2015

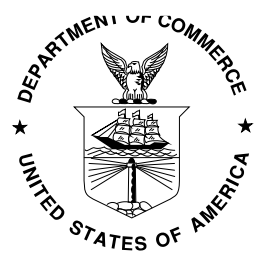

U.S. Department of Commerce

Penny Pritzker, Secretary

National Institute of Standards and Technology Willie May, Under Secretary of Commerce for Standards and Technology and Director 
Certain commercial entities, equipment, or materials may be identified in this document in order to describe an experimental procedure or concept adequately. Such identification is not intended to imply recommendation or endorsement by the National Institute of Standards and Technology, nor is it intended to imply that the entities, materials, or equipment are necessarily the best available for the purpose.

National Institute of Standards and Technology Special Publication 260-182 Natl. Inst. Stand. Technol. Spec. Publ. 260-182, 120 pages (June 2015)

10.6028/NIST.SP.260-182

CODEN: NSPUE2 


\section{$\underline{\text { Abstract }}$}

Rheological measurements are often performed using a rotational rheometer. In this type of rheometer, the tested fluid is sheared between two surfaces, one of which is rotating [1]. Usually, an angular velocity is imposed on the fluid (through the rotating surface) and this angular velocity determines the shear rate the fluid is subjected to. The response of the material is monitored by the measurement of the resultant torque on the shaft of the rheometer; this torque can then be converted to shear stress. In order to calibrate a rheometer, a standard oil of known viscosity should be tested in the rheometer to verify that the instrument is operating correctly. However, these standard oils are expensive; which makes it impractical for use in calibrating with the rheometer with a large capacity as needed for concrete.

Additional, these standard oils that are not suspensions (i.e. they do not have solid particles suspended in the media), and thus using them may not capture some issues that may occur in a suspension rheology. Therefore, a relatively inexpensive, reference material is needed that incorporates aggregates for concrete rheometers. As concrete and mortar are non-Newtonian, the reference material should also be non-Newtonian. This report follows the development and serves as re-certification of a Standard Reference Material (SRM) for cement paste [2]. A multiscale approach will be utilized to develop SRMs for mortar and concrete in the future. The SRM 2492 will be the matrix fluid for a mortar SRM that will in turn become the matrix fluid for a concrete SRM.

The report SP 260-174 Rev.2012 [2] describes how this SRM 2492, a "Bingham Paste Mixture for Rheological Measurements” was developed and provides all the details on the various ingredients. After an inter-laboratory study under the sponsorship of the American Concrete Institute (ACI) committee 238, Workability of Fresh Concrete, it was found that the instructions provided to prepare the SRM were inadequate to obtain reproducible data in all laboratories. Thus after establishing a better preparation method, new instructions were drafted and it was found that the certified values were no longer valid. Thus, it was necessary to redo a series of testing to obtain a new certified value. This report provides all measurements obtained, the calculation of the new rheological characteristics and the statistical analyses.

This is report is the third edition of the report and is based on new data using a different method for preparing the mixture (see section 3.3) that was developed with feedback from customers. Thus, sections and appendices were added or modified. The certificate is available only online.

This report complements the previous report SP-260-174 Rev.2012 


\section{Acknowledgements}

The authors would also like to thank some key persons at NIST whom this certification could not have been completed without: Drs. Nicos Martys, Kenneth Snyder, Jason Averill (NIST) and Raissa Ferron (University of Texas - Austin) for their valuable comments. Brian Lang (NIST) provided the corn syrup analysis.

Dr. Ferraris would like to personally thank also Dr. Zhuguo Li (Yamaguchi University) and Dr. Min-Hong Zhang (National University of Singapore) whose collaboration during their stay at NIST led to the basis of this SRM. 


\section{Table of Contents}

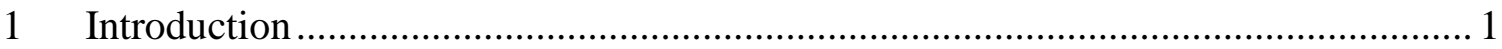

2 Description of Rheological Measurements ............................................................... 2

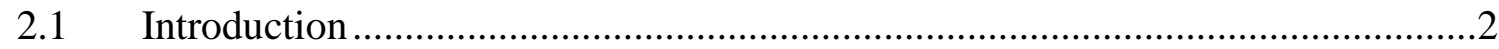

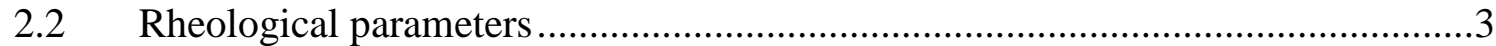

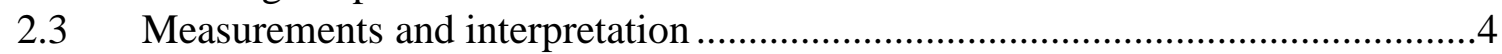

2.3.1 Experimental set-up ...................................................................................

2.3.2 Calculation of the rheological parameters from the measurements ....................5

2.3.3 Calibration with oil ........................................................................................6

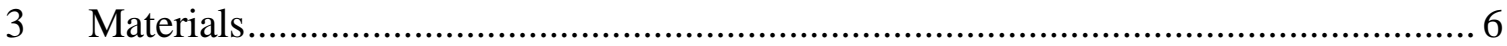

3.1 Characteristics of the Limestone and Corn Syrup ………....................................6

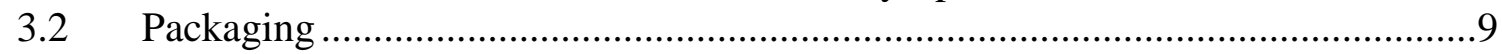

3.3 New preparation method of the SRM ………...................................................

3.3.1 Quality control of the corn syrup solution …………......................................10

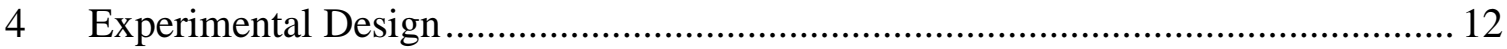

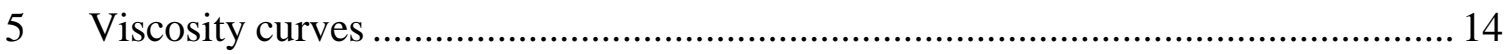

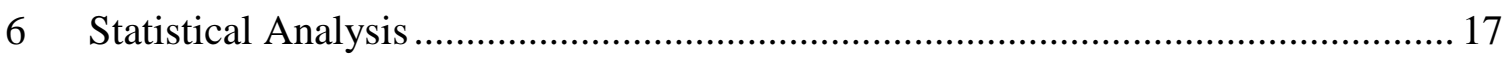

6.1 Reanalysis of Rheological Quantities for SRM2492 ..........................................17

6.2 Statistical Analysis of Viscosity curves ...........................................................20

6.2.1 Viscosity versus shear rate ............................................................................20

6.2.2 Bingham parameters from log scale viscosity curves .......................................22

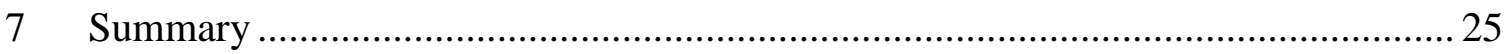

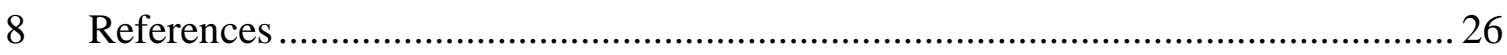

9 Appendices ............................................................................................... 1

Appendix A: Statistical analysis for re-certification Bingham calculations..............A-1

Appendix B: Data for re-certification calculations...................................

Appendix C: Viscosity Curve Data .................................................

Appendix D: Viscosity Curve Certified and Reference Values...........................D-1 


\section{List of Figures}

Figure 1: Bingham model and calculation of the plastic viscosity and yield stress..............4

Figure 2: Parallel Plate Rheometer .............................................................................

Figure 3: Particle size distribution of the 12 limestone containers. .....................................8

Figure 4: Density of the 12 limestone containers........................................................8

Figure 5: Log- vs. linear-scale measurement intervals. ..............................................15

Figure 6: Viscosity curves for five samples of SRM2492 at age $=1$ day.......................15

Figure 7: Viscosity curves for five samples of SRM2492 at age $=3$ days.......................16

Figure 8: Viscosity curves for five samples of SRM2492 at age $=7$ days.......................16

Figure 9: Average viscosity curves for each day measured from the statistical analysis. ...22

\section{List of Tables}

Table 1: Measured (a) and average (b) data for PSD of limestone.

Table 2: Viscosity measurements of corn syrup solution with vibrational viscometer, and the corresponding temperature. (code of mix is explained in section 4)

Table 3: Randomized order of testing for 12 selected units (boxes) where I under the Box \# column corresponds to materials stored in the SRM inventory and F corresponds to a materials stored in the division storage.

Table 4: SRM testing schedule.

Table 5: Yield Stress and Plastic Viscosity Values from linear shear rate scale (certified values are shown in bold type and reference values are shown in regular type).

Table 6: Yield Stress and Plastic Viscosity Values from logarithmic shear rate scale (certified values are shown in bold type and reference values are shown in regular type)........24 


\section{Introduction}

A National Institute of Standards and Technology (NIST) Standard Reference Material $^{\circledR}$ (SRM) meets specific certification criteria ${ }^{1}$ and is issued with a certificate of analysis that reports the results of its characterization and provides information regarding the appropriate use(s) of the material. An SRM is prepared and used for three main purposes: 1) to help develop accurate methods of analysis; 2) to calibrate measurement systems used to facilitate exchange of goods, institute quality control, determine performance characteristics, or measure a property at the state-of-art limit; and 3) to ensure the long-term adequacy and integrity of measurement quality assurance programs. NIST provides over 1 300 different SRMs to industry and academia. Every NIST SRM is provided with a certificate of analysis that gives the official characterization of the material's properties. In addition, supplementary documentation, such as this report, describing the development, analysis, and use of SRMs, is also often provided to ensure effective use of these materials.

There are several SRMs related to the cement industry but none are related to the rheological properties of cement paste, mortar or concrete. The existing calibration oils are too expensive to fill a concrete rheometer; therefore, a need exists in the industry for an inexpensive non-Newtonian reference material specifically designed for concrete. SRM 2492, the first step for concrete rheological SRM production, was developed as described in a previous report [2]. After the certification of SRM 2492, American Concrete Institute (ACI) Committee 238, Workability of Fresh Concrete, organized an inter-laboratory study, where it was found that the certified values were not easily reproducible by laboratories other than NIST. Therefore, a new preparation method of the SRM was developed to ensure reproducible values are obtained universally. The values given in this report were obtained through testing performed at NIST using a commercial rheometer with a serrated parallel plate geometry system.

The objective of this report is to correct and re-certify the values of the SRM 2492: "Bingham Paste Mixture for Rheological Measurements." A brief description of the methodology and all measurements used are provided along with the statistical analysis.

This is report is the third edition of the report and is based on new data using a different method for preparing the mixture (see section 3.3) that was developed with feedback from customers. Thus, sections and appendices were added or modified. The certificate is available only online.

This report complements the previous report SP-260-174 Rev.2012

\footnotetext{
${ }^{1}$ http://www.nist.gov/srm/program info.cfm
} 


\section{Description of Rheological Measurements}

\subsection{Introduction}

Rheological measurements are commonly performed using a rotational rheometer. In this type of rheometer, the test fluid is sheared between two surfaces, one of which is rotating while the other is stationary [1]. The rate of the rotating surface is precisely controlled by a computer, while measuring the torque resulting from the material response. Commercial Laboratory rheometers are mainly designed for homogeneous liquids (e.g., oils) containing no particles. The equipment manufacturers recommend the use of a standard oil of known viscosity to verify that the rheometer is operating correctly. The dynamic viscosities of the standard oils are determined by reference to the water viscosity established by an international consensus in 1953 [3], as described in International Organization for Standardization (ISO)-3666 [4]. In 1954, NIST [3] conducted a study to compare two rheological devices, the Bingham viscometer and the Cannon Master viscometer (both based on capillary flow) that are still used today for determining the viscosity values of standard oils.

It is not economically practical to use the standard oils (sold in $100 \mathrm{~mL}$ containers) in concrete rheometers due to the large volumes of oil needed (often around $7 \mathrm{~L}$ to $20 \mathrm{~L}$ depending on the design). In 2003, an international round-robin used an oil of a known viscosity (29.5 Pa $s \pm 0.6 \mathrm{~Pa} \cdot \mathrm{s})$ to calibrate concrete rheometers [5, 6, 7]. It was shown that not all rheometers were able to measure rheological properties of this oil, due to the lack of specific shear patterns and slippage on the shearing surfaces. In the case of fresh concrete, the geometry of the rheometer needs to accommodate aggregates, at least $25 \mathrm{~mm}$ in diameter. The complex geometry of the rheometer results in unknown shear patterns and test results that cannot be quantitatively characterized in fundamental units; therefore, calibration of such large and non-standard rheometers is impossible using the traditional measurement protocols.

The results of the interlaboratory study revealed the need for a new reference material for calibrating concrete rheometers. Concrete is a non-Newtonian suspension, thus any reference material mixture should also be a non-Newtonian, chemically stable suspension. Ideally such a material must be inexpensive, reproducible and repeatable with respect to both its physical and chemical properties, and readily allow the inclusion of aggregates similar as used in concrete. Given the constraints, the new strategy was to develop a granular mixture similar to concrete. The ACI Committee 238 on "Workability of Fresh Concrete" considered this approach and recommended the use of an oil of known viscosity in which particles could be added. The calculation of the viscosity of the mixture would be a combination of experimental measurements and computerized modeling. Thus, spherical particles would simplify the computerized model. Moreover, the particle specific gravity should match that of the oil to avoid sedimentation during testing as the medium has no yield stress. Given these constraints, hollow plastic spheres were an excellent candidate material. Unfortunately, their cost was prohibitive. Therefore, this idea was deemed impractical and thus, was abandoned as a viable strategy. Instead, a multiscale approach was considered to be the next best option.

The multiscale approach consists of developing a paste, followed by a wellcharacterized mortar and a well-characterized concrete. A mortar is produced by adding sand 
to the cement paste, while a concrete is produced by adding coarse aggregates to the mortar. The rheological parameters of the mortar and concrete would be determined from the paste through a combination of measurements and computer simulation. The simulation is designed to calculate the viscosity of the suspensions (mortar or concrete) from the medium viscosity (cement paste) with various aggregate concentrations, aggregate size distribution, and particle shape. Therefore, the first step is to develop a paste reference material. This report presents a new paste SRM that was produced based on a preliminary study [8].

A non-Newtonian reference material for cement paste should have the following characteristics: 1) no particle segregation for the duration of the test; 2) linear Bingham stress response to shear rates over a large range such as cement paste; 3) rheological and chemical properties unchanged over at least several days, with no chemical reactions between the medium and the particles; 4) a yield stress sufficient to avoid segregation of added sand and coarse aggregates; and 5) the linear response should be reversible, implying no structural breakdown or build-up, flocculation or deflocculation during the test (i.e., no hysteresis).

\subsection{Rheological parameters}

The primary output of rheological measurements is either a shear stress-shear rate plot or a plot of the rotational speed of the rotating surface versus the torque. In cases where the geometry of the rheometer does not permit a direct calculation of the shear stress and shear rate in fundamental units, the rotational speed is plotted against torque [9].

The viscosity [1] is defined as the ratio of the shear stress over the shear rate at a given shear rate and temperature. For a Newtonian fluid, the viscosity is constant across all shear rates and is the slope of a line with zero intercept fit to the shear stress-shear rate data. Most granular mixtures are non-Newtonian (i.e. Viscosity is shear-rate dependent). One common type of non-Newtonian fluids exhibits a yield stress. This yield stress can be estimated from the shear stress and shear rate in several ways. The most common method used for cement-based materials is the curve fitting the shear stress-shear rate curve with the Bingham test equation $[9,10,11]$.

The Bingham equation (Eq. 1) assumes a linear relationship between shear stress and shear rate, where the plastic viscosity $\eta_{p l}$ is the slope and the yield stress $\tau_{B}$ is the intercept of the curve at zero shear rate. The point of zero shear rate is generally not measured, so it is determined by an extrapolation (Figure 1). The Bingham rheological parameters, yield stress and plastic viscosity, will characterize the flow curve within a range of shear rates, as shown in Figure 1 and equation (1).

$$
\sigma=\sigma_{B}+\eta_{p l} \dot{\gamma}
$$

where $\sigma=$ shear stress, $\sigma_{B}=$ yield stress, $\eta_{p l}=$ plastic viscosity, and $\dot{\gamma}=$ shear rate. 


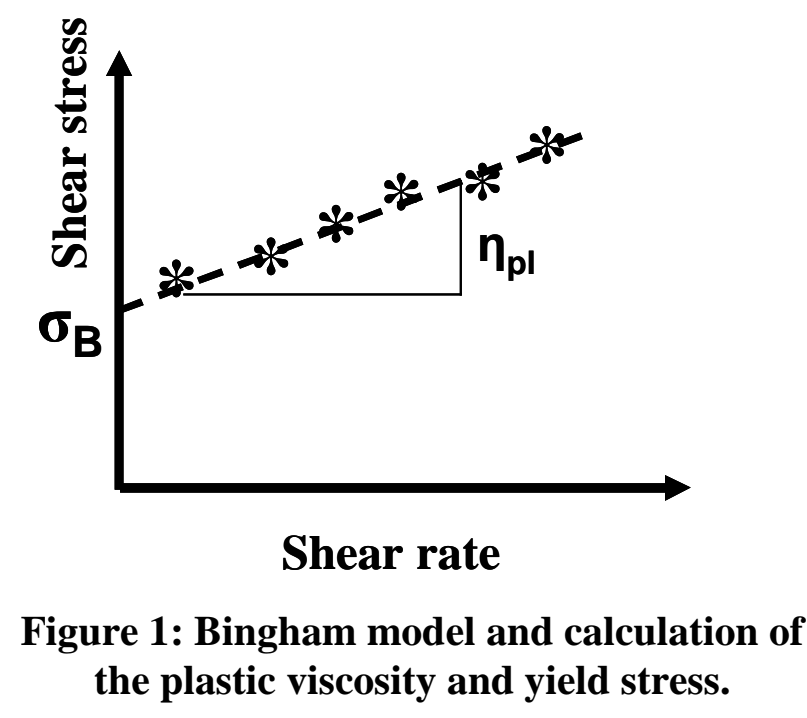

\subsection{Measurements and interpretation}

\subsubsection{Experimental set-up}

Conventional rotational rheometers often have different geometries. Nevertheless, the measurement always involves the material being sheared between two surfaces [1]. The geometry used in this report is serrated parallel plates as shown in Figure 2. The plates were $35 \mathrm{~mm}$ in diameter. Figure 2A shows the actual plates while Figure 2B shows a schematic of a parallel plate rheometer. To shear a granular material, precautions need to be taken to avoid slippage of the shearing surface. Both plate in the device used had serrated surfaces as shown in Figure 2C. As this SRM contains water, precautions also need to be taken to avoid evaporation during the measurement. This is achieved by creating a small enclosure around the shearing plates as shown in Figure 2D. Finally, a wet sponge was placed in the enclosure to maintain a high relative humidity environment. This set-up is identical to the one used in the previous report [2], but the current rheometer is a newer model.

The gap between the two parallel plates was $0.600 \mathrm{~mm} \pm 0.001 \mathrm{~mm}$ (one standard deviation). A smaller gap could cause the particles to jam while a larger gap might lead to the material not staying between the plates. The temperature of the rheometer was maintained at $23{ }^{\circ} \mathrm{C} \pm 0.5^{\circ} \mathrm{C}$ during all tests via controlled water bath. A measured volume of $1.2 \mathrm{~mL}$ of material was placed in the rheometer and the gap adjusted to $0.6 \mathrm{~mm}$ automatically. Then the material was nominally sheared at $0.01 \mathrm{~s}^{-1}$ for $150 \mathrm{~s}$ before starting the Bingham test. The Bingham test consisted of increasing the nominal shear rate from 0.1 $\mathrm{s}^{-1}$ to $50 \mathrm{~s}^{-1}$ (15 points in total) and then decreasing shear rate from $50 \mathrm{~s}^{-1}$ to $0.1 \mathrm{~s}^{-1}$ (20 points in total). Both linear and logarithmic scales were used (Section 4 and Section 5). At each point the shear rate was maintained at the desired value until a stable value (less than $5 \%$ changes automatically determined by the computer) of the torque was reached, but for a time not to exceed $30 \mathrm{~s}$, to limit the duration of the testing time. The hysteresis $(\mathrm{Pa} / \mathrm{s})$ was defined as the area between the up (increasing shear rate) and down (decreasing shear rate) curves of a shear stress vs. shear rate graph. 


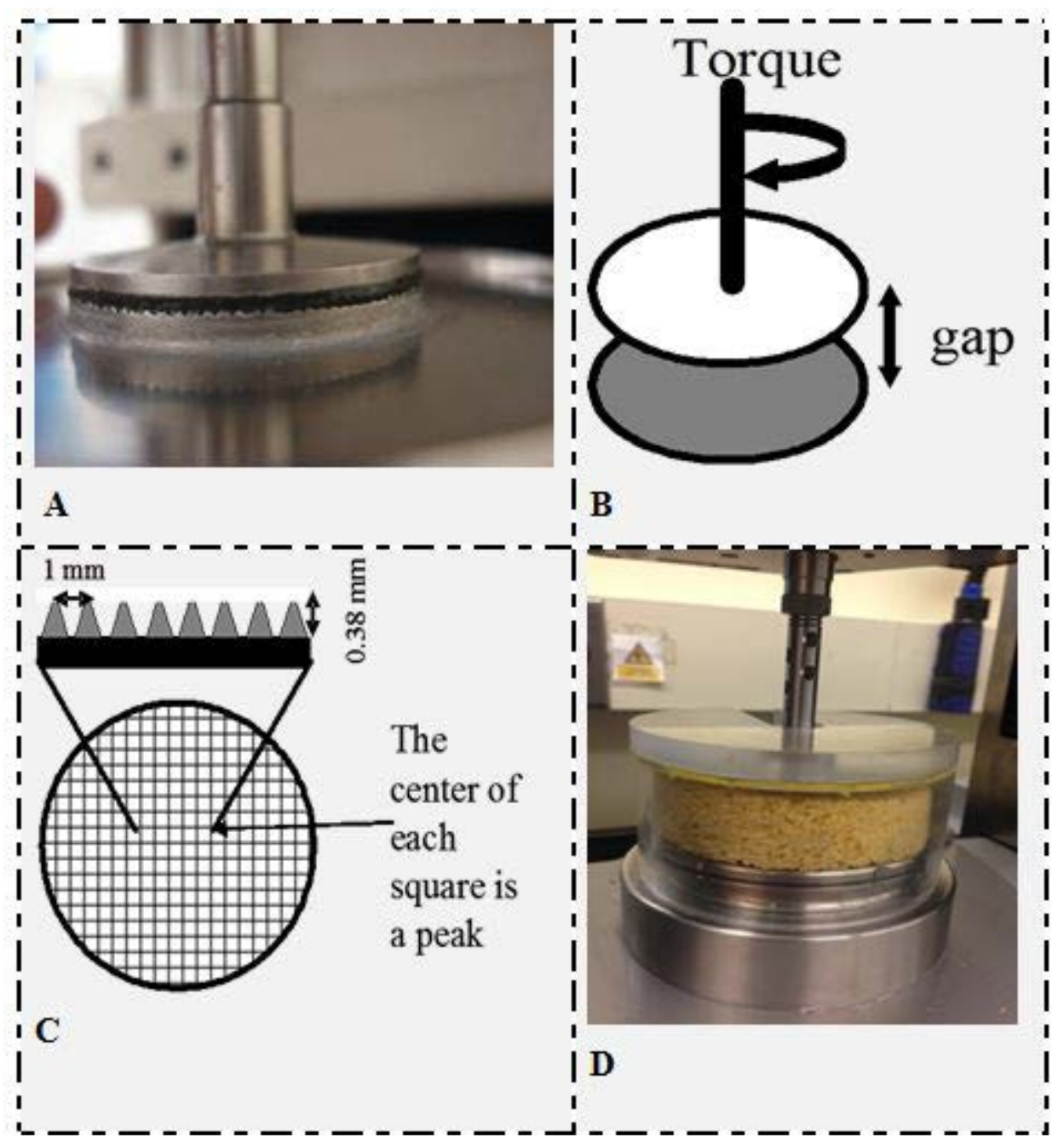

Figure 2: Parallel Plate Rheometer: a) actual serrated plates used; (b) schematic of system showing top plate is subjected to torque; (c) details about serrations of the plates; (d) evaporation trap for sample

\subsubsection{Calculation of the rheological parameters from the measurements}

The rotational speed is controlled and the torque is measured. The computer software calculates the shear rate and shear stress automatically from the rotational speed and measured torque. The shear rate is calculated as follows:

$$
\dot{\gamma}_{R}=\frac{R}{h} \cdot 2 \pi \cdot n
$$

Where: $\quad \dot{\gamma}_{R}=$ shear rate at the outer edge [1/s]

$\mathrm{R}=$ radius of shear $[\mathrm{mm}](17.5 \mathrm{~mm}$ in our case $)$

$\mathrm{h}=$ gap or distance between the plates $[\mathrm{mm}](0.600 \mathrm{~mm} \pm 0.001 \mathrm{~mm})$

$\mathrm{n}=$ speed of rotation of the top plate, revolution/s [1/s] 
The shear stress calculation from the torque accounts for the non-Newtonian properties [9]:

$$
\tau=\frac{T}{2 \cdot \pi \cdot R^{3}}\left(3+\frac{d \ln T}{d \ln \dot{\gamma}_{R}}\right)
$$

Where: $\quad \tau=$ shear stress $[\mathrm{Pa}]$

$\mathrm{T}=$ torque at the outer edge [N.m]

$\mathrm{R}=$ radius of shear $[\mathrm{mm}](17.5 \mathrm{~mm}$ in our case $)$

$\dot{\gamma}_{R}=$ shear rate $[1 / \mathrm{s}]$

This non-Newtonian approximation is used because the shear rate is not constant in the radial direction (i.e. shear rate is zero in the center of the plate and then reaches a maximum value at the outer edge), thus the torque at the outer edge of the plate is used to approximate the shear stress. This is considered a better approximation of the paste behavior and was used to calculate the certified values.

\subsubsection{Calibration with oil}

Accurate rheological error assessment, including the correction of the zeroing of the plates, requires a standard oil. The measurement protocol for making these assessments is described in the previous report [2]. After calculating the shear rate and shear stress from the torque and angular velocity, these values were corrected for plate roughness and zeroing error (due to the instrument) as outlined by Ferraris et al. [10]. This correction consists of modifying the gap by $0.22 \mathrm{~mm}[11,13,14]$. Further details on the uncertainty of the method can be found in ref. [10].

\section{Materials}

\subsection{Characteristics of the Limestone and Corn Syrup}

The mixture is composed of a corn syrup aqueous solution and limestone (further details about the preparation of the mixture is provided in Section 3.4). A commercial source of $100 \%$ glucose corn syrup was identified, and the purity was confirmed by testing done at NIST. The limestone powder is a micro-limestone flour. Analyses were conducted on samples of the limestone powder to determine its particle size distribution (PSD), as well as its mineralogical, chemical, and physical properties. The same materials were used as those described in the previous report [2], which provides detailed characterization of these materials.

Two methods were used in our characterization process to measure the density of the limestone. In addition to using the current standard method, ASTM C188-14 (Le Chatelier method), a helium pycnometer was also used to provide more consistency. A study at NIST compared the two methods for the limestone and other powders, which concluded by proposing that the helium pycnometer be a new standard method for density measurements of hydraulic cement [15]. The pycnometer provides more efficient density measurements since the testing fluid is a gas (helium) rather than a liquid (kerosene or alcohol for example); therefore, the pycnometer is capable of filling more air voids. The helium pycnometer measured the average density of the limestone to be $2724 \mathrm{~kg} / \mathrm{m}^{3} \pm 15 \mathrm{~kg} / \mathrm{m}^{3}$, while the Le 
Chatelier method recorded a value of $2608 \mathrm{~kg} / \mathrm{m}^{3} \pm 35 \mathrm{~kg} / \mathrm{m}^{3}$. The density by helium pycnometer is used as it is more repeatable. This is an update to the limestone density reported previously [2]. The particle size distribution (PSD) and densities for all 12 mixes used during the re-certification process are shown on Figure 3 and 4, respectively. The PSD data measured using a laser diffraction device [12] and the calculated averages are presented in Table 1 (a) and (b). (I and F represent limestone storage location, explained in Section 4). It should be noted that there is no difference in the PSD or the density measured on the samples from the two storage areas (See Table $1 b$ ).

Table 1: Measured (a) and average (b) data for PSD of limestone. The d values represent the size of the particles at which $10 \%(0.1), 50 \%(0.5)$

(a) and $90 \%(0.9)$ of the sample by volume is finer.

\begin{tabular}{|c|c|c|c|c|c|c|c|}
\hline Box \# & $\begin{array}{l}\text { Mix } \\
\text { Code }\end{array}$ & NIST Code & $d(0.1)$ & $d(0.5)$ & $d(0.9)$ & span & $\begin{array}{c}\text { SSA } \\
{\left[\mathrm{m}^{\wedge} 2 / \mathrm{g}\right]}\end{array}$ \\
\hline I1 & A & PSD3-126BD & 2.47 & 17.49 & 57.79 & 3.16 & 0.345 \\
\hline I2 & B & PSD3-130BD & 2.51 & 17.06 & 55.55 & 3.11 & 0.343 \\
\hline I3 & $\mathrm{C}$ & PSD3-127AD & 2.39 & 17.18 & 55.94 & 3.12 & 0.354 \\
\hline I4 & D & PSD3-127BD & 2.41 & 16.99 & 54.73 & 3.08 & 0.353 \\
\hline I5 & $\mathbf{E}$ & PSD3-127CD & 2.51 & 17.78 & 57.87 & 3.11 & 0.340 \\
\hline I6 & $\mathbf{F}$ & PSD3-123AD & 2.54 & 17.18 & 57.08 & 3.18 & 0.336 \\
\hline F1 & $\mathbf{G}$ & PSD3-122DD & 2.43 & 16.33 & 56.55 & 3.31 & 0.357 \\
\hline $\mathbf{F} 2$ & $\mathbf{H}$ & PSD3-129AD & 2.32 & 16.38 & 56.31 & 3.30 & 0.364 \\
\hline F3 & $\mathbf{I}$ & PSD3-146AD & 2.78 & 17.71 & 59.05 & 3.18 & 0.324 \\
\hline F4 & $\mathbf{J}$ & PSD3-129BD & 2.41 & 17.28 & 58.95 & 3.27 & 0.350 \\
\hline F5 & $\mathbf{K}$ & PSD3-130CC & 2.66 & 18.43 & 60.07 & 3.12 & 0.327 \\
\hline F6 & $\mathbf{L}$ & PSD3-129CD & 2.43 & 17.68 & 58.85 & 3.19 & 0.347 \\
\hline
\end{tabular}

(b)

\begin{tabular}{|r|c|c|c|c|c|}
\cline { 2 - 6 } \multicolumn{1}{|c|}{} & $\mathbf{d}(\mathbf{0 . 1})$ & $\mathbf{d}(\mathbf{0 . 5})$ & $\mathbf{d}(\mathbf{0 . 9})$ & span & $\begin{array}{c}\text { SSA } \\
{[\mathbf{m} \wedge \mathbf{2} / \mathbf{g}]}\end{array}$ \\
\hline Total Avg & 2.49 & 17.29 & 57.40 & 3.18 & 0.35 \\
SD & 0.1 & 0.6 & 1.6 & 0.1 & 0.01 \\
COV & $5 \%$ & $3 \%$ & $3 \%$ & $2 \%$ & $3 \%$ \\
\hline Lab Inventory (I) \\
Avg & 2.47 & 17.28 & 56.49 & 3.13 & 0.35 \\
SD & 0.1 & 0.3 & 1.3 & 0.0 & 0.0 \\
COV & $3 \%$ & $2 \%$ & $2 \%$ & $1 \%$ & $2 \%$ \\
\hline \multicolumn{6}{|c|}{} \\
\hline Division Storage (F) & 2.50 & 17.30 & 58.30 & 3.23 & 0.34 \\
\hline Avg & 0.2 & 0.8 & 1.5 & 0.1 & 0.0 \\
COV & $7 \%$ & $5 \%$ & $3 \%$ & $2 \%$ & $5 \%$ \\
\hline
\end{tabular}




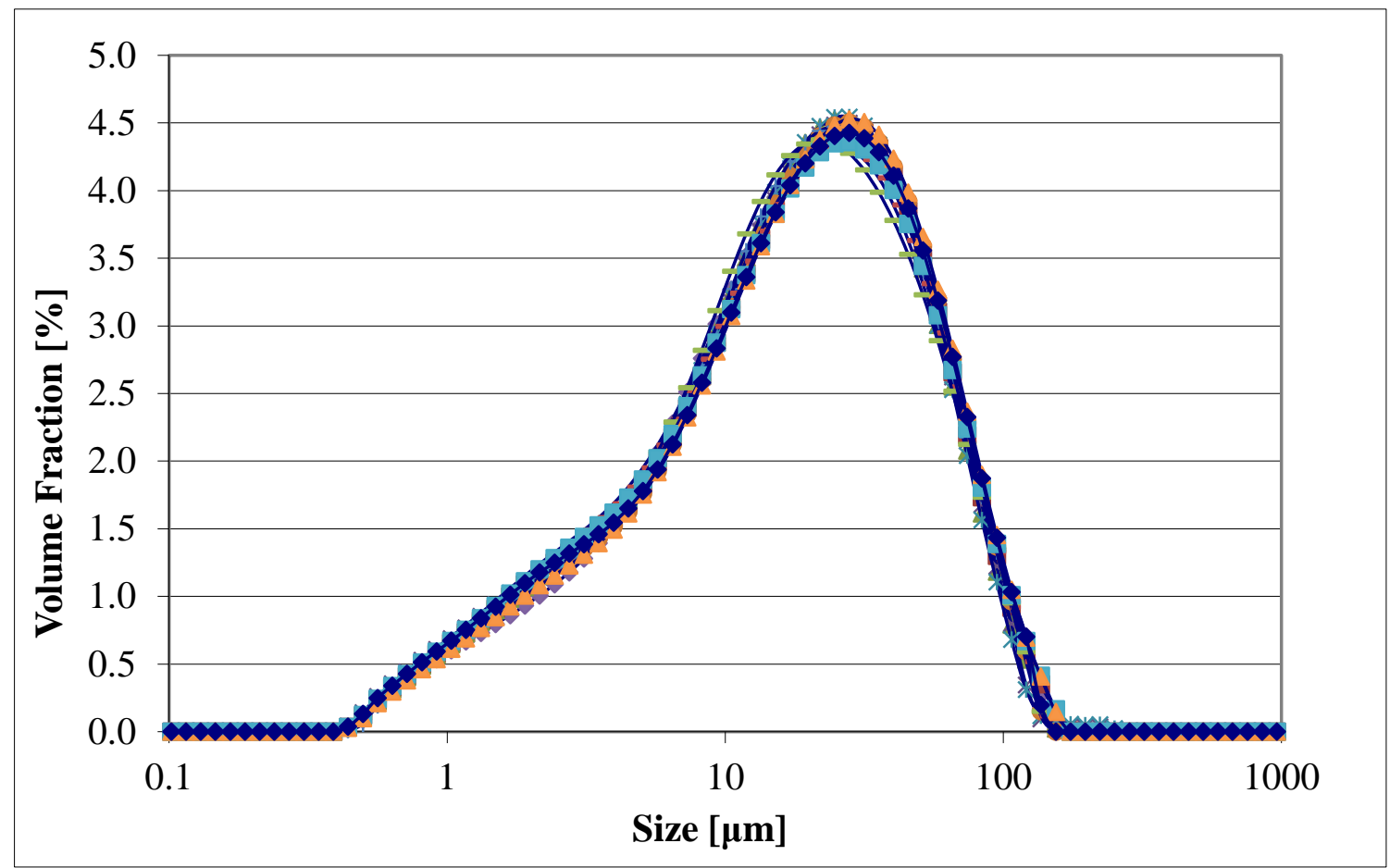

Figure 3: Particle size distribution of the 12 limestone containers.

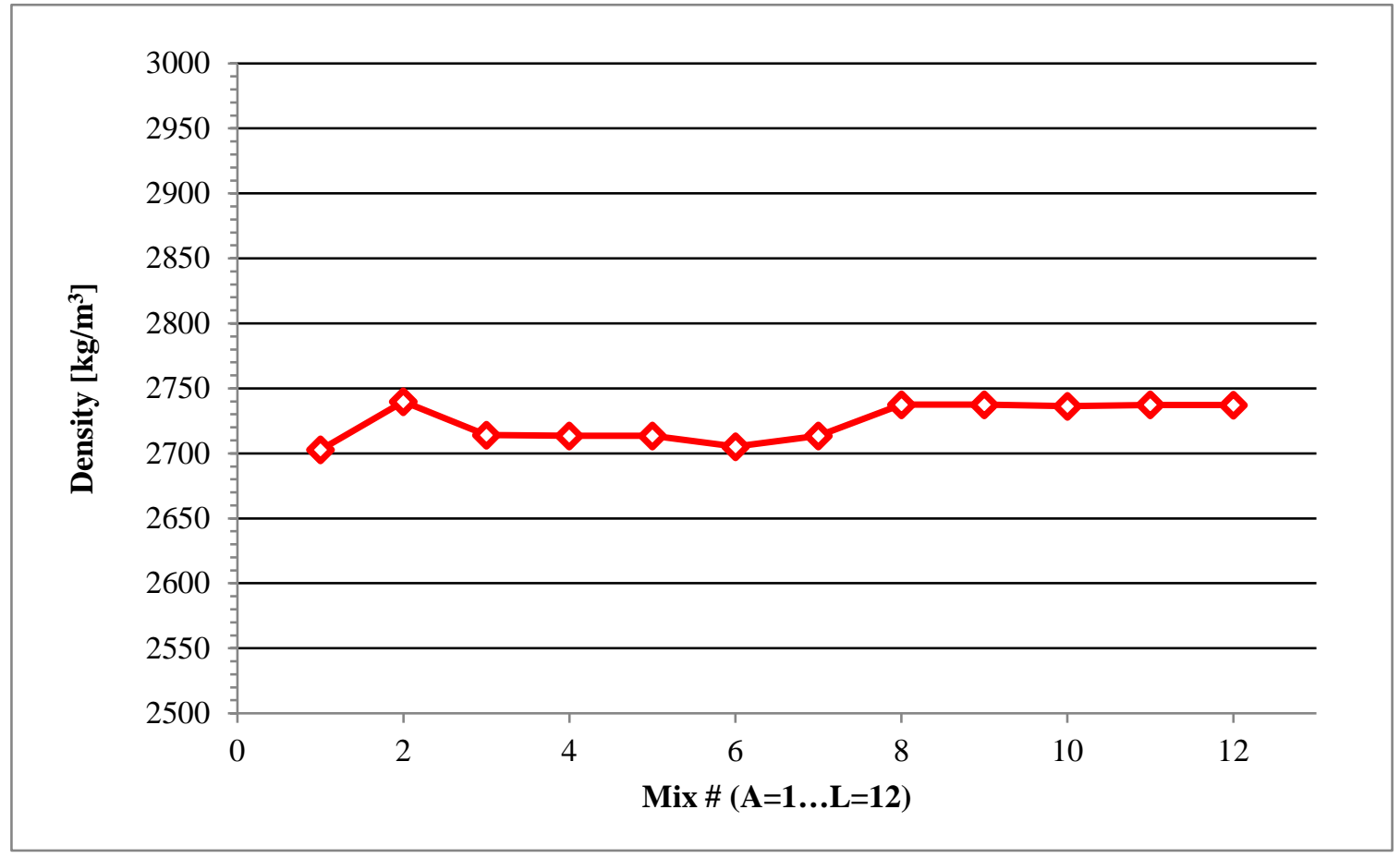

Figure 4: Density of the 12 limestone containers, measured with helium pycnometer. 
Rheological characterization of the corn syrup was performed using a viscometer, as explained later in Section 3.3.1. Some variation in viscosity for the SRM packaged corn syrup was detected. Further investigation revealed that two shipments of corn syrup were received by NIST and used for the preparation of the SRM. Both shipments came from the same manufacturer; therefore the viscosity was not expected to change due to shipment date.

A vibrational viscometer and rheometer were used to test twelve mixtures during this re-certification process, and the results helped quantify any difference in viscosity values for the corn syrups (Section 3.3.1).

\subsection{Packaging}

The previous report [2] described the packaging scheme that was executed for the SRM materials. The packaged SRM contains enough material to make two batches of paste. No further packaging was performed for this re-certification.

\subsection{New preparation method of the SRM}

The re-certification of SRM 2492 originates from the discovery, during an interlaboratory study sponsored by ACI committee 238, that other laboratories could not obtain the same certified value as NIST. Therefore, the mixing procedure was modified in order to enhance the reproducibility.

The mixture composition of the SRM is provided below:

- Corn Syrup: $200 \mathrm{~g}$

- Distilled water: $63.16 \mathrm{~g}$

- Limestone: $458.1 \mathrm{~g}$

A prepared mixture of SRM has a shelf life of about 7 days. Therefore, it should not be prepared too far in advance of its usage. The SRM mixture is prepared by using a high shear blender as described in ASTM C1738. The modification of how to introduce the corn syrup to the high shear blender was implemented as follows:

Place the correct amount of corn syrup in a wide mouth plastic jar (volume about $140 \mathrm{~mL}$ ), then introduce the measured room temperature water to the jar, and mix with a spatula by hand until the mixture is homogeneous. On average it will take five minutes to dilute the visible glucose chains of the corn syrup in the water. Assuring the syrup is diluted prior to adding it into the high shear blender results in a more effective transfer of the corn syrup into the mixture. Thus, this method assures that the mixture composition is as proposed.

Fifteen minutes after the corn syrup solution has been mixed, introduce it in the mixer and proceed as described in ASTM C1738 to complete mixing the SRM. The water bath and the rheometer should be maintained at $23^{\circ} \mathrm{C} \pm 2{ }^{\circ} \mathrm{C}$. The delay of $15 \mathrm{~min}$ ( $\pm 1 \mathrm{~min}$ ) after mixing the corn syrup and before introducing it in the mixer was dictated by the viscosity measurements done at NIST (Section 3.3.1) to verify the homogeneity of the corn syrup solution and ensure that the temperature is stable at $23^{\circ} \mathrm{C} \pm 2{ }^{\circ} \mathrm{C}$. 
Store the prepared SRM mixture in a sealed plastic jar maintained at $23{ }^{\circ} \mathrm{C} \pm 2{ }^{\circ} \mathrm{C}$. It is recommended to use a plunger mixer to remix the prepared SRM before each use for at least $60 \mathrm{~s}$ at $300 \mathrm{RPM}$ (31 rad/s). The plastic jar should be low moisture vapor transmission rate (MVTR), i.e., less than $5 \cdot 10^{-6} \mathrm{~g} \cdot \mathrm{m} / \mathrm{m}^{2} \cdot \mathrm{d}\left(1 \mathrm{~g}-\mathrm{mil} / 100 \mathrm{in}^{2} / \mathrm{d}\right)$ such as polypropylene. Also, when not in use the jar should be closed with a lid and sealed with wax paper. This would prevent any evaporation of the water in between testing.

\subsubsection{Quality control of the corn syrup solution}

During the development of the SRM and the round-robin sponsored by ACI Committee 238, it was found that the introduction of the corn syrup in the blender was problematic, i.e. difficult to ensure that all the corn syrup was being used as some was left on the walls of the container. It was determined that the new method of premixing the corn syrup in water should improve the process. To verify this assumption, the quality of the solution was monitored by measuring its temperature and its viscosity prior to the introduction in the blender.

To measure the viscosity of the solution a vibrational viscometer was used. The viscometer consists of a rod that is immersed in the fluid to be measured. The rod vibrates at a high frequency, and it measures the damping due to the fluid. The amplitude is small and the power consumed is then converted to viscosity [16]. The viscosity measured is the kinematic viscosity of the fluid. The temperature can also be measured at the same time using a thermocouple. The data are shown in Table 2.

An observation during this quality control process showed that the corn syrup viscosity varied depending on the date received. The two different shipments are labelled CS-A and CS-B; CS-A was received prior to CS-B and typically had a higher viscosity than CS-B. Most corn syrup bottles in the SRM 2492 packages consist of CS-A since this shipment was exhausted; this created the need to order exceCS-B. Unfortunately, the SRM as packaged cannot distinguish which corn syrup (CS-A or CS-B) was used. The statistical analysis takes this into account.

Twenty-minute observations found the average kinematic viscosity of all the mixtures prepared for this report to be $159 \mathrm{cP} \pm 5 \mathrm{cP}(1000 \mathrm{cP}=1 \mathrm{~Pa} \cdot \mathrm{s})$ (see Table 2$)$. It was discovered that the viscosity readings stabilized after allowing the solution to sit for 15 min post handmixing. Therefore, the average viscosity calculated for each mix only considers the 15 min and 20 min values since this gives the most accurate viscosity readings. The consistency of the data, with a coefficient of variation of only $3 \%$, served as quality assurance that no new sources of error were introduced with the new SRM preparation method. The temperature was on average $23.0{ }^{\circ} \mathrm{C} \pm 0.5{ }^{\circ} \mathrm{C}$ (one standard deviation) for $10 \mathrm{~min}$ and $15 \mathrm{~min}$ and was $22.8{ }^{\circ} \mathrm{C} \pm 0.5 \circ \mathrm{C}$ after $20 \mathrm{~min}$. These patterns showed that the temperature slightly decreases with time after mixing, although it is within the standard deviation. 
Table 2: Viscosity measurements of corn syrup solution with vibrational viscometer, and the corresponding temperature. (code of mix is explained in section 4)

\begin{tabular}{|c|c|c|c|c|c|c|c|c|}
\hline \multicolumn{9}{|c|}{ Viscosity of Corn Syrup + Distilled Water } \\
\hline Time after mixing & \multicolumn{2}{|c|}{10 mins } & \multicolumn{2}{|c|}{15 mins } & \multicolumn{2}{|c|}{20 mins } & \multirow{2}{*}{\begin{tabular}{|c|} 
Avg. \\
Viscosity
\end{tabular}} & \multirow{2}{*}{$\begin{array}{l}\text { Std. } \\
\text { Dev. }\end{array}$} \\
\hline Mix & Viscosity [cP] & Temp. $\left[{ }^{\circ} \mathrm{C}\right]$ & Viscosity [cP] & Temp. $\left[{ }^{\circ} \mathrm{C}\right]$ & Viscosity [cP] & Temp. $\left[{ }^{\circ} \mathrm{C}\right]$ & & \\
\hline A & 165.81 & 22.3 & 163.17 & 22.4 & \multicolumn{2}{|l|}{163.07} & 163.1 & 0.0 \\
\hline $\mathbf{B}$ & 156.37 & 23.5 & 154.88 & 23.5 & \multicolumn{2}{|l|}{155.10} & 155.0 & 0.1 \\
\hline $\mathbf{C}$ & 162.59 & 22.8 & 159.23 & 22.8 & \multicolumn{2}{|l|}{158.80} & 159.0 & 0.2 \\
\hline $\mathbf{D}$ & 164.14 & 22.7 & 160.87 & 22.8 & \multicolumn{2}{|l|}{161.10} & 161.0 & 0.1 \\
\hline $\mathbf{E}$ & 156.80 & 23.7 & 152.33 & 23.7 & \multicolumn{2}{|l|}{151.80} & 152.1 & 0.3 \\
\hline $\mathbf{F}$ & 170.14 & 22.5 & 167.47 & 22.4 & \multicolumn{2}{|l|}{167.48} & 167.5 & 0.0 \\
\hline G & 168.56 & 23.5 & 162.22 & 23.3 & \multicolumn{2}{|l|}{160.70} & 161.5 & 0.8 \\
\hline $\mathbf{H}$ & 163.52 & 22.4 & 160.03 & 22.3 & \multicolumn{2}{|l|}{159.93} & 160.0 & 0.0 \\
\hline $\mathbf{I}$ & 154.23 & 23.5 & 151.58 & 23.5 & \multicolumn{2}{|l|}{152.02} & 151.8 & 0.2 \\
\hline $\mathbf{J}$ & 156.29 & 23.1 & 155.01 & 23.2 & \multicolumn{2}{|l|}{154.69} & 154.9 & 0.2 \\
\hline $\mathbf{K}$ & 165.77 & 22.7 & 162.70 & 22.7 & \multicolumn{2}{|l|}{162.71} & 162.7 & 0.0 \\
\hline \multirow[t]{4}{*}{$\mathbf{L}$} & 165.13 & 23.0 & 161.08 & 23.0 & \multicolumn{2}{|l|}{161.52} & 161.3 & 0.2 \\
\hline & & & & & & Total Avg. & 159.1 & \\
\hline & & & & & & Std. Dev. & 4.6 & \\
\hline & & & & & & COV & $3 \%$ & \\
\hline
\end{tabular}




\section{Experimental Design}

Twelve units of the SRM, as packaged for sale, were randomly selected for testing. Each unit contains two batches of SRM, but only one batch was tested from each selected unit. The order of testing for the 12 units (boxes) was randomized (see Table 3). Half of the 12 units had been stored in the division storage (F), while the other half were stored in the SRM lab inventory (I). Location F was a normal laboratory with no particular temperature controls other normal building operation. Location I was in temperature controlled environment where all NIST SRMs are kept before shipment to customers.

Rheological results were analyzed from batches stored in both storage locations to observe any difference due to storage location. After analyzing the rheological measurements presented in this report, it was concluded that the storage location had no effect on the rheological behavior of our materials. This conclusion verified that the data of importance to this study, repeatable Bingham behavior, was observed regardless of where the SRM units were stored prior to testing with a rheometer. The data analysis showed that all rheological results were identical within small percentage of error, as described later in the statistical analysis section.

Each mixture (batch) was tested at $1 \mathrm{~d}, 3 \mathrm{~d}$ and $7 \mathrm{~d}$ after mixing. Each reported value was the average of 3 consecutive tests run back-to-back using a new paste SRM sample loaded in the rheometer from the same batch. The rheometer protocol is provided in Section 2.3.1. Schedule codes were assigned to the box numbers in order to compliment the three testing values ( $1 \mathrm{~d}, 3 \mathrm{~d}, 7 \mathrm{~d}$ ) and complete a testing schedule, as shown in Table 4 . The testing days labelled with the prefix " $M$ " represent the mixing day for the respective mixture and are color coded green. The remaining testing days are prefixed with the corresponding schedule code and followed by the age of the mixture being tested. The mixure age are also distinguished by the color code shown in Table 4.

Table 3: Randomized order of testing for 12 selected units (boxes)

\begin{tabular}{|c|c|c|c|}
\hline Box \# & $\begin{array}{c}\text { Order of } \\
\text { Testing }\end{array}$ & $\begin{array}{c}\text { Schedule } \\
\text { Code }\end{array}$ & \\
\hline I1 & 4 & $A$ & Legend for \\
I2 & 8 & $B$ & Box \#: \\
I3 & 3 & $C$ & $I$ \#: \\
I4 & 5 & $D$ & box is from \\
I5 & 6 & $E$ & inventory \\
I6 & 2 & $F$ & stored in \\
F1 & 1 & $G$ & SRM div. \\
F2 & 12 & $H$ & F \#: \\
F3 & 9 & $I$ & box is from \\
F4 & 10 & $J$ & division \\
F5 & 7 & $K$ & storage \\
F6 & 11 & $L$ & \\
\hline
\end{tabular}


Table 4: SRM testing schedule.

Holidays and days on which testing was not executable were considered.

The testing days labelled with the prefix " $\mathrm{M}$ " represent the mixing day for the respective mixture as named in Table 1 column 3 . Color codes distinguish the age of the mixtures as blue (1 d), orange (3 d), yellow (7 d) and green (mixing day).

\begin{tabular}{|c|c|c|c|c|c|}
\hline & $\begin{array}{r}\mathbf{F} \\
\text { Conside } \\
\end{array}$ & $\begin{array}{l}\text { ll Testir } \\
\text { ing Holi }\end{array}$ & $\begin{array}{l}\text { chec } \\
S \&\end{array}$ & days & \\
\hline & $\mathrm{M}$ & $\mathrm{T}$ & $\mathrm{W}$ & $\mathrm{T}$ & $\mathrm{F}$ \\
\hline W1 & $\overline{\mathrm{MG}}$ & G1 & $\mathrm{F} 1$ & G3 & F3 \\
\hline 2/3/2014 & & MF & & & \\
\hline & $\mathrm{M}$ & $\mathrm{T}$ & $\mathrm{W}$ & $\mathrm{T}$ & $\mathrm{F}$ \\
\hline W2 & G7 & F7 & C1 & & $\mathrm{C} 3$ \\
\hline 2/10/2014 & & MC & & & \\
\hline & $\mathrm{M}$ & $\mathrm{T}$ & $\mathrm{W}$ & $\mathrm{T}$ & $\mathrm{F}$ \\
\hline W3 & & MA & C7 & & A3 \\
\hline 2/17/2014 & HOLIDAY & & A1 & & \\
\hline & $\mathrm{M}$ & $\mathrm{T}$ & $\mathrm{W}$ & $\mathrm{T}$ & $\mathrm{F}$ \\
\hline W4 & MD & A7 & E1 & D3 & E3 \\
\hline $2 / 24 / 2014$ & & D1 & & & \\
\hline $2 / \angle 4 / \angle 014$ & & $\mathrm{ME}$ & & & \\
\hline & $\mathrm{M}$ & $\mathrm{T}$ & $\mathrm{W}$ & $\mathrm{T}$ & $\mathrm{F}$ \\
\hline W5 & & E7 & K1 & & K3 \\
\hline 3/3/2014 & $\begin{array}{l}\text { SNUW } \\
\text { DAY }\end{array}$ & D7 (8) & & & \\
\hline & & MK & & & \\
\hline & $\mathrm{M}$ & $\mathrm{T}$ & $\mathrm{W}$ & $\mathrm{T}$ & $\mathrm{F}$ \\
\hline W6 & MB & K7 & I1 & B3 & I3 \\
\hline 3/10/2014 & & B1 & & & \\
\hline & & MI & & & \\
\hline & $\mathrm{M}$ & $\mathrm{T}$ & $\mathrm{W}$ & $\mathrm{T}$ & $\mathrm{F}$ \\
\hline W7 & & I7 & $\mathrm{J} 1$ & & J3 \\
\hline 3/17/2014 & $\begin{array}{l}\text { SNOW } \\
\text { DAY }\end{array}$ & B7 (8) & & & \\
\hline & & $\mathrm{MJ}$ & & & \\
\hline & $\mathrm{M}$ & $\mathrm{T}$ & $\mathrm{W}$ & $\mathrm{T}$ & $\mathrm{F}$ \\
\hline W8 & Water & $\mathrm{J} 7$ & $\overline{\mathrm{H} 1}$ & & H3 \\
\hline 3/24/2014 & Bath & MH & L1 & & L3 \\
\hline $3 / 24 / 2014$ & Frozen & ML & & & \\
\hline & $\mathrm{M}$ & $\mathrm{T}$ & $\mathrm{W}$ & $\mathrm{T}$ & $\mathrm{F}$ \\
\hline W9 & & H7 & & & \\
\hline 3/31/2014 & & L7 & & & \\
\hline
\end{tabular}




\section{Viscosity curves}

As an alternative to fitting experimental data to the Bingham equation, one may represent rheological data in terms of a viscosity profile that depicts the viscosity of the material vs. shear rate. While the two Bingham parameters describe the onset of flow (yields stress) and flow at larger shear rates (plastic viscosity), the viscosity depicted in the viscosity curves is the ratio of the shear stress to shear rate for each shear rate tested. The plot of the viscosity versus shear rate provides a complete representation of the flow behavior. Nonetheless, the raw data used for calculating both the plastic viscosity and apparent viscosity are the same. Individual viscosity curves for each mixture tested in this section can be found in Appendix C.

Not only do viscosity curves portray the viscosity of the material in relation to a specific shear rate over the entire range of shear rates tested, but, research has shown that the viscosity curves of a suspension composed of solid inclusions embedded in a nonNewtonian matrix fluid follow the same form as the original embedding fluid [23, 24]. Since SRM 2492 is the first step in developing an SRM for concrete, it's advantageous to use viscosity curves when moving forward towards the development of the mortar and concrete SRM. The curves allow us to portray flow behavior in a simple macroscopic manner, regardless of the existence of a complex microscopic inter-particle flow [25].

When constructing viscosity curves, it is useful to present shear rates using equal increments according to a logarithmic scale. Acquiring data in log scale allows the viscosity at low shear rates to be illustrated better. Therefore, five of the twelve mixtures tested for SRM 2492 re-certification had additional measurements performed using points of shear rates in logarithmic intervals instead of linear. Figure 5 shows an example of the difference between obtaining data with a log and linear shear rate intervals. Due to the lack of data in the low shear rates for a linear scale graph, these data could not be used to fully represent viscosity curves as shown by the low shear rates on the blue curve of Figure 5.

The five trials measured in log-scale showed that our SRM does exhibit reproducible flow behavior in the low shear rate regime (red curve in Figure 5). Each mix was tested at 1 d, $3 \mathrm{~d}$ and $7 \mathrm{~d}$, and the respective viscosity curves for each are shown in Figures 6-8. The curves shown portray both the data for the steps up and down, as explained in Section 4. The average viscosity curve for each day was combined into Figure 9 to portray that there is repeatable behavior as the SRM age approaches its shelf life. The individual viscosity curves recorded at each day ( $1 \mathrm{~d}, 3 \mathrm{~d}$, and $7 \mathrm{~d}$ ) and the data tables for Figures 6-8 can be found in Appendix C.

In conclusion, the flow behavior of SRM 2492 can be described using viscosity curves, preferably with shear rates measured uniformly on a log-scale. Current research shows that viscosity curves for non-Newtonian suspensions have simple scaling laws that relate the flow of the suspension to that of the embedding fluid of the suspension. For example, the viscosity curves of spherical solid inclusions suspended in a non-Newtonian fluid medium can be rescaled to collapse onto the viscosity curve of the fluid medium [25]. This is very helpful to proceed forward to the development of mortar and concrete SRMs, which are currently under development. 


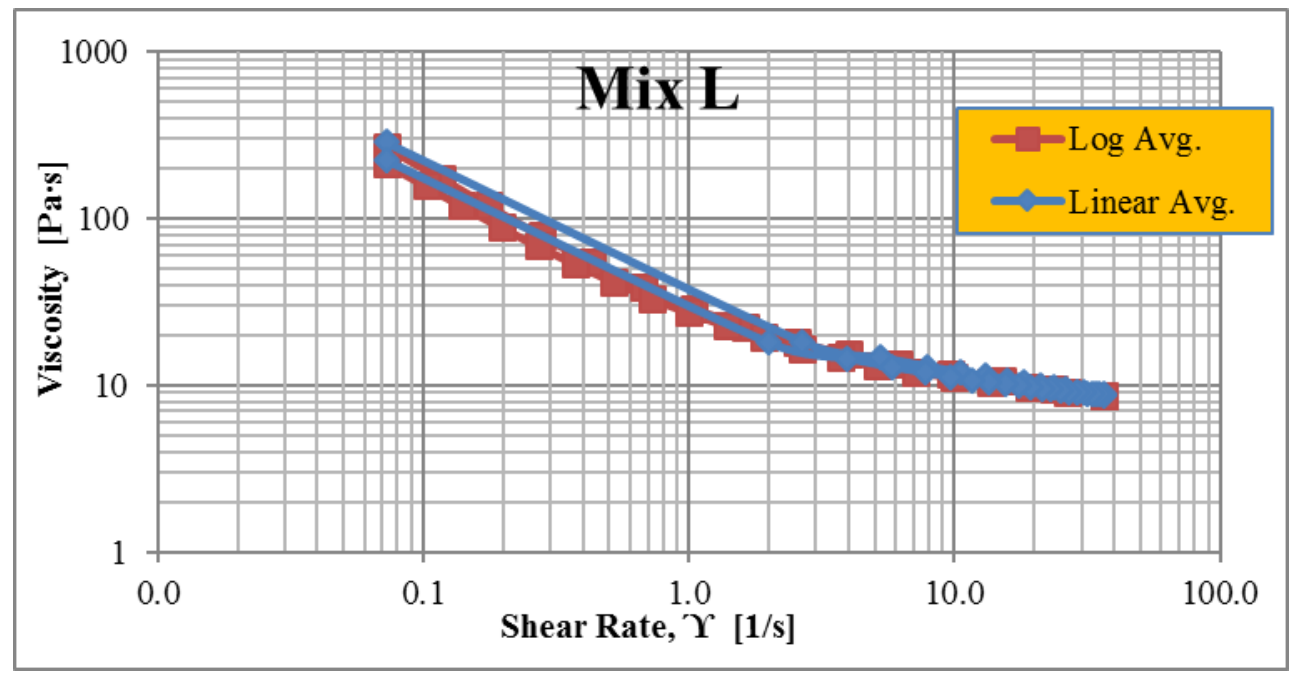

Figure 5: Represents one sample of the mixes using both equal log- and linear-scale measurement intervals. The log interval data is able to provide more data in the low shear rate region $\left(<1.0 \mathrm{~s}^{-1}\right)$ than the linearinterval data.

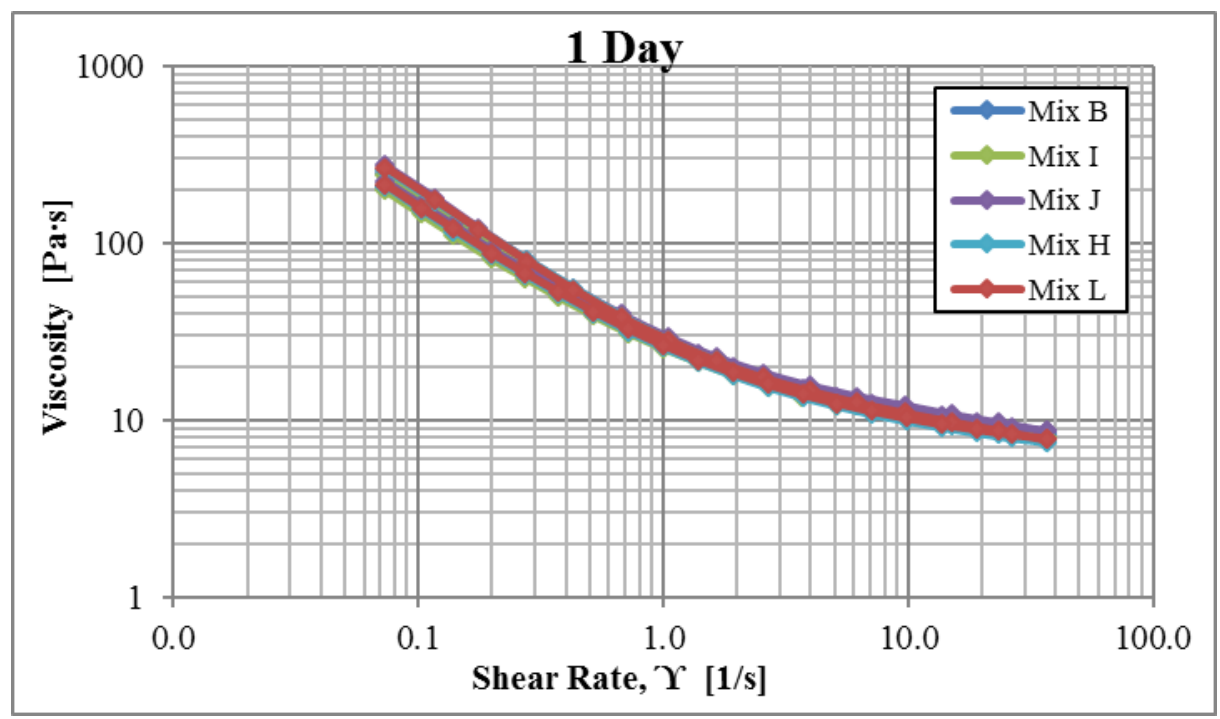

Figure 6: Viscosity curves for five samples of SRM2492 at age $=1$ day 


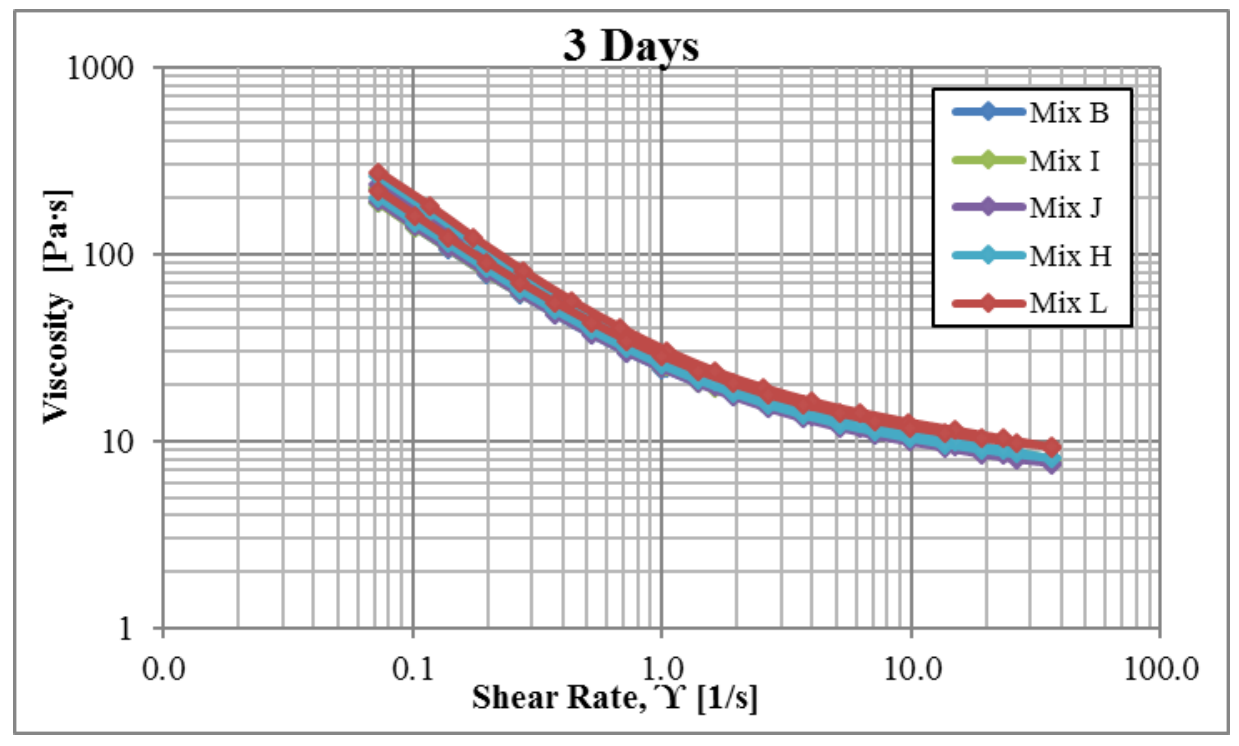

Figure 7: Viscosity curves for five samples of SRM2492 at age $=3$ days.

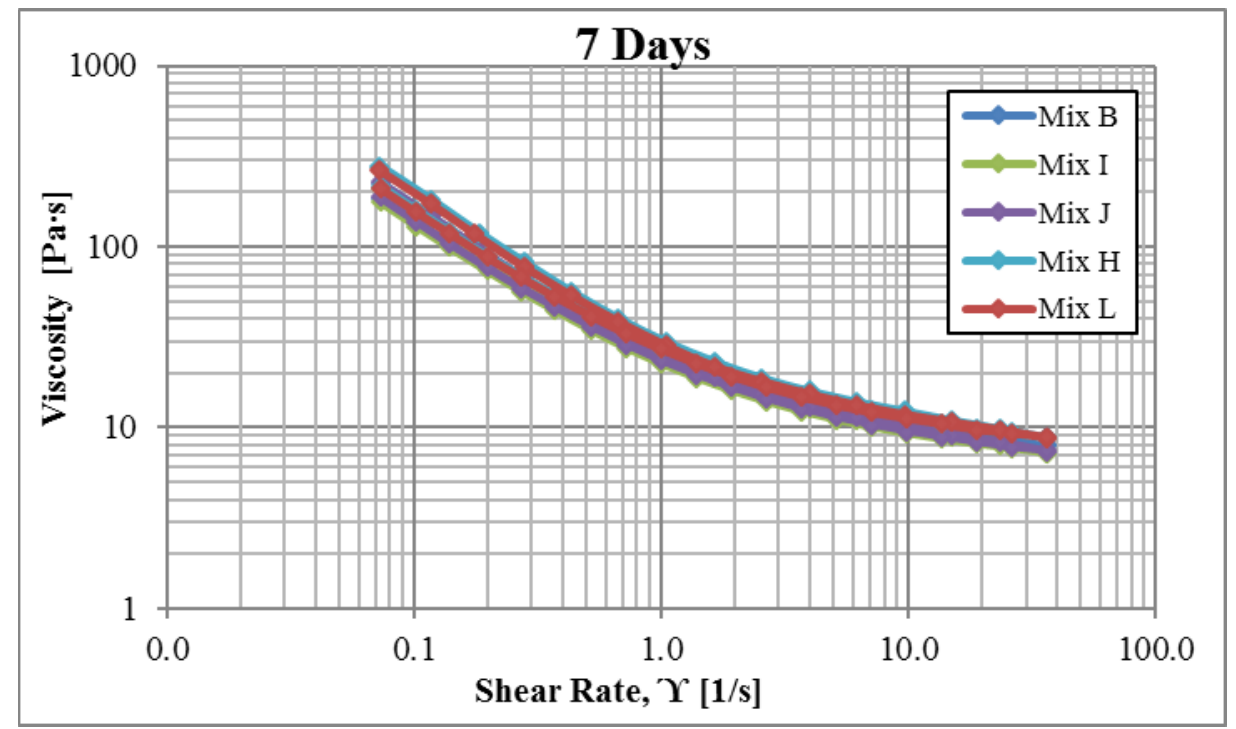

Figure 8: Viscosity curves for five samples of SRM2492 at age = 7 days. 


\section{Statistical Analysis}

\subsection{Reanalysis of Rheological Quantities for SRM2492}

This section summarizes the reanalysis of various rheological quantities for SRM 2492 under the Bingham model after the mixing procedure for the material was changed to improve the consistency of results between laboratories. The data used for this analysis was collected using a nested design with measurements made at three different sample ages within each of twelve units of the SRM (See Section 4). One sample was prepared for each unit, using corn syrup from the single bottle associated with the unit and limestone from one of the two single-use bottles of limestone powder associated with the unit.

With this design a hierarchical linear regression model can be fit to the data to assess random variability associated with units and measurements. In addition, the run order of the measurements is an implicit factor whose potential effect was addressed by randomization of the run order.

Results derived from the raw data were recorded for two quantities, plastic viscosity and yield stress, from tests carried out on the samples at three different ages $(1 \mathrm{~d}, 3 \mathrm{~d}$, and 7 d). The data are shown in Table A-1 (Appendix A). The full viscosity curves associated with these samples are shown in Appendix B. For this analysis, the summary of the viscosity curves made assuming the Bingham model was carried out prior to transmission of the data to the Statistical Engineering Division for analysis. As a result, no assumption checking or validation of the appropriateness of the Bingham model for this data is included in the statistical analysis described here.

The first step in the analysis of the data was an exploratory data analysis. In this analysis plots of the data were examined for evidence of measurement drift, outliers, factor effects, and any other features that might impact further analysis for certification. These plots are shown in Figure A-1 through Figure A-8 (in Appendix A) and were made using the software package $R$ [17]. While a few potentially outlying points were observed in this data, these were not associated with any recognized problems associated with sample preparation or measurement, so no data were omitted when doing further analysis.

Based on the exploratory plots, a hierarchical linear regression model was then fit to the data using maximum likelihood as implemented in the R package lme4 [18]. This model allowed for random variation between units and measurements but assumed a single fixed rate of change, $\beta_{1}$, between each response, denoted generically here as $y_{i j}$, and age, denoted by $A_{i j}$. The random errors associated with each unit are denoted by $\delta_{i}$ and the random errors associated with each measurement are denoted by $\varepsilon_{i j}$. The variances associated with each

source of random error, unit and measurement, are denoted $\sigma_{U}^{2}$ and $\sigma_{M}^{2}$, respectively. All random errors are assumed to be mutually independent of one another.

$$
\begin{aligned}
y_{i j}=\beta_{0}+\beta_{1} A_{i j}+ & \delta_{i}+\varepsilon_{i j}, \quad i=1, \cdots, 12, j=1, \cdots, 3 \\
& \delta_{i} \sim N\left(0, \sigma_{U}^{2}\right) \\
\varepsilon_{i j} & \sim N\left(0, \sigma_{M}^{2}\right)
\end{aligned}
$$


Residual plots from the fit of the model are shown in Figure A-9 through Figure A-14 (Appendix A) and indicate the model fits the data reasonably well. Normal probability plots of the residuals suggested some potential for error distributions with lighter tails than the normal distribution. To investigate this further a comparison of hierarchical models with normal error distributions and p-generalized normal error distributions [19] was made using Bayesian methods. However, the results of this comparison indicated that there was not enough distributional information in the data to clearly distinguish between these two models and the simpler model using normal error distributions was adopted. Output from these models is given in Table A-2 and Table A-3 (Appendix A).

Finally, to determine the certified values and their associated uncertainties, the hierarchical regression model [20, 21, 22] with normal error distributions was refit using Bayesian methods to quantify the contributions to the overall uncertainty from random errors associated with units and measurements. A Bayesian analysis [20, 21, 22]was used because it makes fitting the hierarchical regression model relatively easy and provides uncertainty estimates that have a clear statistical interpretation with no need for approximation or use of asymptotic results.

In order to fit the Bayesian model, prior assessments of the values of each parameter in the model must be provided. The prior assessment for each parameter is specified as probability distribution for the parameter's unknown value. These distributions are called prior distributions because they are specified independently of the data (i.e. before the data is observed or used). For this analysis, essentially non-informative prior distributions were used. Such distributions are relatively flat and have very large variances so that they will not provide any quantitative information on the values of the parameters as part of the model. In this case shifted and scaled beta distributions [23] with hyper-parameters $\alpha_{H}=1$ and $\beta_{H}=1$ were used (i.e. shifted and scaled uniform distributions). The ranges and locations of the prior distributions for each parameter were set so that they completely covered all the parameter values expected.

Fitting the model with a range of different prior distributions confirmed that the results were not sensitive to the parameters chosen for the prior distributions. The check on prior sensitivity also was carried out using shifted and scaled beta distributions, but for different combinations of the hyper-parameters, with $\alpha_{H_{i}} \in\{0.8,1.2\}$ and $\beta_{H_{i}} \in\{0.8,1.2\}$. The same shifting and scaling values used in the original model fit with uniform priors were used throughout the prior sensitivity check. The two hyper-parameters used for each of the four primary parameters in the model, $\beta_{0}, \beta_{1}, \sigma_{U}$ and $\sigma_{M}$, were assigned using a supersaturated $U E\left(s^{2}\right)$ optimal experiment design [24] to study the combined effects of eight factors in four runs. The alternative prior specifications and the associated results from the fit of each model are shown in Table A-4 and Table A-5 (Appendix A).

A probability distribution for each measurement, given with respect to the parameters in the model, is also specified. In this case the random errors associated with each factor were modeled as following a normal distribution. Then, based on the model and the observed data, the prior distributions for each parameter are updated using Bayes' Theorem to obtain new distributions for each parameter given the information in the data. Finally, these new distributions, called posterior distributions, are used to obtain uncertainty intervals about each quantity of interest. 
The Bayesian model was fit using Markov Chain Monte Carlo simulation as implemented in the software package OpenBUGS [25, 26]. Diagnostic plots (not included in this memo) show that the Markov Chains had converged by the 5000th iteration of the simulation. Then 5000 additional iterations were run for each of 4 parallel Markov chains for model validation and to estimate the parameter values. Box plots and scatter plots (not shown here) of the posterior predictive residuals from the model for each data point again indicate the models fit the data reasonably well.

Assuming that the hierarchical model does provide an adequate description of the measurement process, proposed certified values for each of the different rheological quantities at sample ages of 1 day through 7 days were determined from predictive distributions for a randomly selected unit. Use of the predictive distribution was chosen for this purpose because it accounts for uncertainty from potential heterogeneity between units and thus is more robust than an assessment that assumes under certain conditions that the material is homogenous. The proposed certified and reference values with expanded uncertainties at the 95\% probability level are given in Table 5 . The bold values show the levels of age where data were collected, while no data were collected at the ages shown in regular type. However, the values at all seven age levels were predicted using the same linear model fit to the data. It should be noted that these calculation are for shear rates above $1 \mathrm{~s}^{-1}$ as shown in Figure 5.

Table 5: Yield Stress and Plastic Viscosity Values from linear shear rate scale (certified values are shown in bold type and reference values are shown in regular type).

\begin{tabular}{|c|c|c|c|c|c|}
\hline Parameter & $\begin{array}{c}\text { Age } \\
\text { [days] }\end{array}$ & $\begin{array}{c}\text { Certified } \\
\text { Value } \\
\text { [Pa] }\end{array}$ & $\begin{array}{c}\text { Standard } \\
\text { Uncertainty } \\
\text { [Pa] }\end{array}$ & $\begin{array}{c}\text { Coverage } \\
\text { Factor } \\
k\end{array}$ & $\begin{array}{c}\text { Expanded } \\
\text { Uncertainty } \\
\text { [Pa] }\end{array}$ \\
\hline \multirow{7}{*}{$\begin{array}{l}\text { Yield } \\
\text { Stress }\end{array}$} & 1 & 25.61 & 1.69 & 2.05 & 3.47 \\
\hline & 2 & 25.28 & 1.70 & 2.04 & 3.48 \\
\hline & 3 & 24.93 & 1.69 & 2.03 & 3.44 \\
\hline & 4 & 24.58 & 1.67 & 2.05 & 3.43 \\
\hline & 5 & 24.23 & 1.68 & 2.04 & 3.43 \\
\hline & 6 & 23.88 & 1.73 & 2.06 & 3.55 \\
\hline & 7 & 23.53 & 1.73 & 2.04 & 3.54 \\
\hline \multirow{7}{*}{$\begin{array}{c}\text { Plastic } \\
\text { Viscosity }\end{array}$} & 1 & 7.74 & 0.74 & 2.00 & 1.47 \\
\hline & 2 & 7.81 & 0.75 & 2.00 & 1.50 \\
\hline & 3 & 7.89 & 0.74 & 2.01 & 1.49 \\
\hline & 4 & 7.94 & 0.74 & 2.01 & 1.49 \\
\hline & 5 & 8.00 & 0.74 & 2.00 & 1.48 \\
\hline & 6 & 8.08 & 0.74 & 2.01 & 1.49 \\
\hline & 7 & 8.13 & 0.74 & 2.00 & 1.49 \\
\hline
\end{tabular}




\subsection{Statistical Analysis of Viscosity curves}

\subsubsection{Viscosity versus shear rate}

This section summarizes the statistical analysis of viscosity curves for SRM 2492 for use in further computational analyses of the subsequently planned SRMs in the series (mortar and concrete). The data used for this analysis included the data from both Appendices B and C.

With the enlarged set of data based on the results shown in both Appendix B and Appendix C, a hierarchical linear regression model in sample age can be fit to the data to assess random variability associated with units, mixes prepared from each unit, and individual measurements. This is similar to the analysis shown in Section 6.1, except with one extra variance component that can now be estimated because the data in Appendix $\mathrm{C}$ is based on some of the same units as the data shown in Appendix B. Unlike the analysis in Section 5.1, however, the analysis in this Section does not assume the Bingham model necessarily describes the relationship between shear stress versus shear rate. As a result, reduction of the raw shear stress vs. shear rate curves was done as part of the analysis described here rather than being done prior to the transmission of the data to Statistical Engineering Division staff, as in the analysis of Section 5.1.

The reduction from the raw data to the data used to fit the hierarchical regression models was carried out by fitting smoothing splines to each shear rate, shear stress curve using the software package $R$ [17]. These spline models do not require a functional form to be specified and have the flexibility to fit almost any reasonably smooth curve well. The spline models were fit by the direction of the change in shear rate for each trace, as well as by unit, mix, and age (102 spline fits). The spline models were then used to predict the shear stress a consistent set of 38 shear rates over the range of interest. These shear rates were chosen so that the change in viscosity would never be more than about $5 \mathrm{~Pa} \cdot \mathrm{s}$ between points and so that shear rates would never be more than $5 \mathrm{~s}^{-1}$ apart (doing so many measurements would not have taken too long). Although there appears to be a small systematic hysteresis, the two spline functions fit for each run, one for each direction of change in shear rate, were averaged to obtain one curve. This was done since the size of this effect was negligible compared to the variation between the curves associated with different units and mixes. Similarly, the uncertainties in the spline fits themselves are negligible relative to the between-mix and between-unit variability. The random variation in the spline fits is part of the variation observed between-measurements, however, so it is still implicitly accounted for.

The next step in the analysis of the data was an exploratory data analysis, as done in the analysis of Section 5.1, except the analysis was repeated for the data associated with each level of shear rate. While a few potentially outlying points were observed in this data, as before, these were not associated with any recognized problems associated with sample preparation or measurement, so no data were omitted when doing further analyses. 
Based on the exploratory plots, a hierarchical linear regression model was then fit to a selection of the data sets for different shear rates using maximum likelihood as implemented in the $R$ package lme4 [18]. This model allowed for random variation between units and measurements but assumed a single fixed rate of change, $\beta_{1}$, between each response, denoted generically here as $y_{i j k}$, and age, denoted by $A_{i j k}$. The random errors associated with each unit are denoted by $\delta_{i}$, the random errors associated with each mix within a given unit are denoted by $\phi_{(i) j}$, and the random errors associated with each measurement are denoted by $\varepsilon_{(i j) k}$. The variances associated with each source of random error, unit, mix, and measurement, are denoted $\sigma_{U}^{2}, \sigma_{M i x}^{2}$, and $\sigma_{M}^{2}$, respectively. All random errors are assumed to be mutually independent of one another.

$$
\begin{aligned}
y_{i j k}=\beta_{0}+\beta_{1} A_{i j k}+\delta_{i}+\phi_{(i) j}+\varepsilon_{(i j) k}, & i=1, \cdots, 12, j=1, \cdots, n_{i}, n_{i}=1,2, k=1, \cdots, 3 \\
\delta_{i} & \sim N\left(0, \sigma_{U}^{2}\right) \\
\phi_{(i j) k} & \sim N\left(0, \sigma_{M i x}^{2}\right) \\
\varepsilon_{(i j) k} & \sim N\left(0, \sigma_{M}^{2}\right)
\end{aligned}
$$

Residual plots from the fit of the model were similar to those shown in Appendix A, covering the Bingham model analysis, and indicated the model fits the data reasonably well. The analysis of the residuals is a graphical check on the assumptions underlying the fit of the model. The residuals look qualitatively similar to the way they would look if the model truly fit the data, but they are not perfect.

Finally, to determine the certified values and their associated uncertainties, the hierarchical regression model with normal error distributions was refit using Bayesian methods, as in the analysis of Section 5.1, to quantify the contributions to the overall uncertainty from random errors associated with units, mixes, and measurements.

Again, as for the analysis in Section 5.1, shifted and scaled beta prior distributions with hyper-parameters $\alpha_{H}=1$ and $\beta_{H}=1$ were used to fi the Bayesian model. However, the ranges and locations of the prior distributions for each parameter were set so that they completely covered all practical parameter values that could be possible across all shear rates considered.

Fitting the model with a range of different prior distributions confirmed that the results were not sensitive to the parameters chosen for the prior distributions. The check on prior sensitivity also was carried out using shifted and scaled beta distributions, but for different combinations of the hyper-parameters, with $\alpha_{H_{i}} \in\{0.8,1.2\}$ and $\beta_{H_{i}} \in\{0.8,1.2\}$. The same shifting and scaling values used in the original model fit with uniform priors were used throughout the prior sensitivity check. However, the two hyper-parameters used for each of the five primary parameters in the model, $\beta_{0}, \beta_{1}, \sigma_{U}, \sigma_{\text {Mix }}$ and $\sigma_{M}$, were not assigned using a supersaturated $U E\left(s^{2}\right)$ optimal experiment design [24] as illustrated in Section 6.1.

A probability distribution for each measurement, given with respect to the parameters in the model, is also specified. In this case the random errors associated with each factor were modeled as following a normal distribution. Then, based on the model and the observed data, the prior distributions for each parameter are updated using Bayes' Theorem to obtain new distributions for each parameter given the information in the data. Finally, these new 
distributions, called posterior distributions, are used to obtain uncertainty intervals about each quantity of interest.

As before, the Bayesian model was fit using Markov Chain Monte Carlo simulation as implemented in the software package OpenBUGS $[25,26]$. Unlike the analysis of Section 5.1, however, the fits were carried out using the BRugs $R$ package [30] to run OpenBUGS so that all 38 models could be fit using an $R$ script that automatically looped through the data sets. For the fits made in $R$ a single Markov chain was used with a burn-in of 5000 runs and then 30000 runs to compute the samples used to obtain the results, thinning each run by a factor of 100. Diagnostic plots fit directly in OpenBUGS for some of the data sets throughout the range of shear rates show that the Markov Chains had converged by the 5000th iteration of the simulation. Then 5000 additional iterations were run for each of 4 parallel Markov chains for model validation. Box plots and scatter plots of the posterior predictive residuals from the model for each data point again indicate the models fit the data reasonably well.

Assuming that the hierarchical model does provide an adequate description of the measurement process at each shear rate, proposed certified values for each of the different rheological quantities at sample ages of $1 \mathrm{~d}$ through $7 \mathrm{~d}$ were determined from predictive distributions for a randomly selected unit, as for the analysis of Section 5.1. The proposed certified values with expanded uncertainties at the $95 \%$ probability level are given in appendix D and in Figure 9.

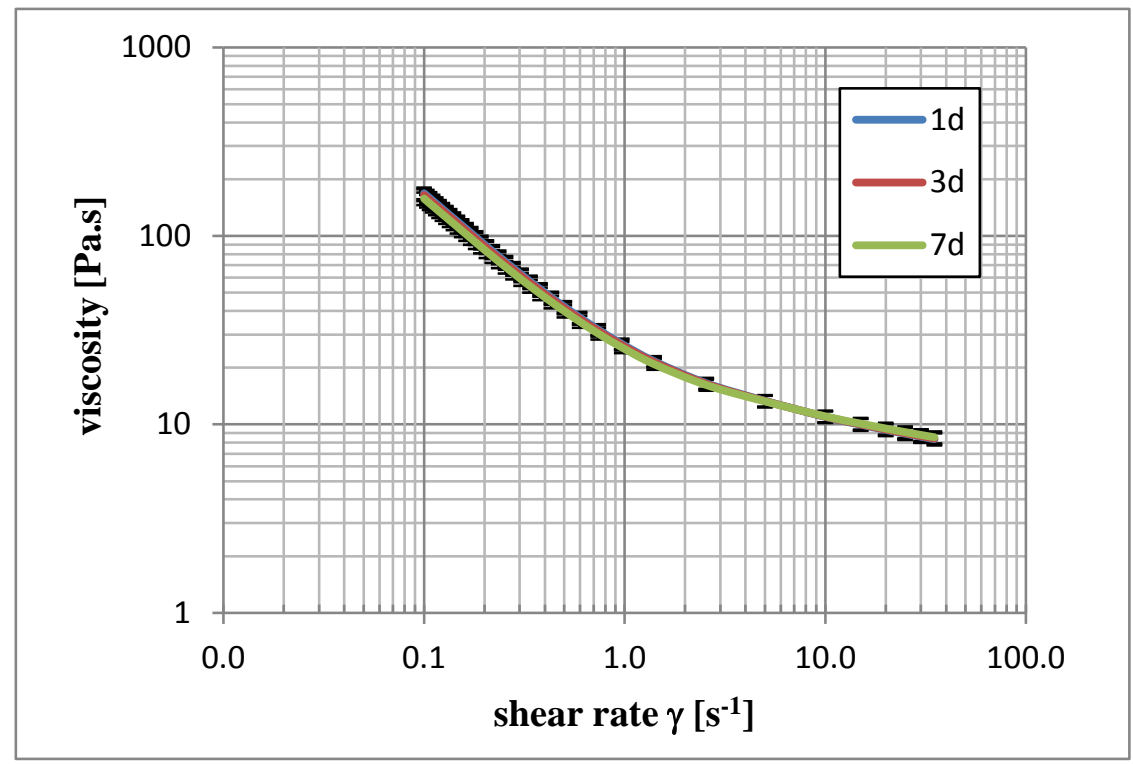

Figure 9: Average viscosity curves for each day measured from the statistical analysis.

\subsubsection{Bingham parameters from log scale viscosity curves}

Using the data developed in Section 6.2.1 and shown in Table D-1 through D-7 (Appendix D), it is again possible to calculate the Bingham parameters (plastic viscosity and yield stress) and they are shown in Table 6 . The shear stress, $\sigma$, not shown in the Tables D1 to $\mathrm{D}-7$, for each shear rate, $\dot{\gamma}$, was calculated using the viscosity, $\eta$, using the following relationship:

$$
\sigma[\mathrm{Pa}]=\dot{\gamma}[1 / \mathrm{s}] * \eta[\mathrm{Pa} \cdot \mathrm{s}]
$$


The shear stress standard uncertainty, $u(\sigma)$, was computed from the standard uncertainty of the viscosity, $u(\eta)$

$$
u(\sigma)=\text { shear rate } * u(\eta)
$$

The standard and expanded uncertainty of the Bingham parameters was obtained by parametric Monte Carlo [31] by generating 10000 samples of shear stress values for each shear rate using a Gaussian distribution with the mean given by the shear stress value and the standard deviation given by the corresponding uncertainty. For each of the 10000 random samples of the shear stress values, a linear regression produced a slope and intercept. The standard deviation of these 10000 estimates is the standard uncertainty of the Bingham parameters. The coverage factors were computed using the $95 \%$ probability intervals of the samples.

It is interesting to note that Table 6 uncertainty is lower than shown in Table 5 and that the values of plastic viscosity and yield stress are not the identical. The plastic viscosity is within the uncertainty of the values of Table 5, while the yield stress is lower. Thus, it can be inferred that using a logarithmic scale for the measurements and using both the up and down data in the statistical analysis provides a lower uncertainty in the data.

Both tables will be provided to the SRM certificate. Customers may select the precision and type of scale best suited for their tests. Performing more measurements points lengthen the total duration of test and thus it might not advisable due to the material tested setting time or rheological properties evolution versus time. 
Table 6: Yield Stress and Plastic Viscosity Values from logarithmic shear rate scale (certified values are shown in bold type and reference values are shown in regular type).

\begin{tabular}{|c|c|c|c|c|c|}
\hline $\begin{array}{l}\text { Bingham } \\
\text { Parameter }\end{array}$ & $\begin{array}{c}\text { Age } \\
\text { [days] }\end{array}$ & $\begin{array}{c}\text { Certified } \\
\text { Value } \\
\text { [Pa] } \\
\end{array}$ & $\begin{array}{c}\text { Standard } \\
\text { Uncertainty } \\
\text { [Pa] } \\
\end{array}$ & $\begin{array}{c}\text { Coverage } \\
\text { Factor } \\
k \\
\end{array}$ & $\begin{array}{c}\text { Expanded } \\
\text { Uncertainty } \\
\text { [Pa] }\end{array}$ \\
\hline \multirow{7}{*}{$\begin{array}{l}\text { Yield } \\
\text { Stress }\end{array}$} & 1 & 17.48 & 0.52 & 1.96 & 1.02 \\
\hline & 2 & 17.29 & 0.51 & 1.96 & 1.00 \\
\hline & 3 & 17.07 & 0.51 & 1.96 & 1.00 \\
\hline & 4 & 16.87 & 0.51 & 1.96 & 1.00 \\
\hline & 5 & 16.67 & 0.52 & 1.96 & 1.02 \\
\hline & 6 & 16.47 & 0.52 & 1.96 & 1.02 \\
\hline & 7 & 16.26 & 0.52 & 1.96 & 1.02 \\
\hline \multirow{7}{*}{$\begin{array}{c}\text { Plastic } \\
\text { Viscosity }\end{array}$} & 1 & 8.15 & 0.32 & 1.96 & 0.63 \\
\hline & 2 & 8.18 & 0.32 & 1.96 & 0.63 \\
\hline & 3 & 8.23 & 0.32 & 1.96 & 0.63 \\
\hline & 4 & 8.27 & 0.32 & 1.96 & 0.63 \\
\hline & 5 & 8.30 & 0.32 & 1.96 & 0.63 \\
\hline & 6 & 8.34 & 0.33 & 1.96 & 0.65 \\
\hline & 7 & 8.38 & 0.33 & 1.96 & 0.65 \\
\hline
\end{tabular}




\section{Summary}

A new paste reference material was developed that consists of three components mixed to form a suspension: water, corn syrup and fine limestone. The uniqueness of this material is that similar to cement paste, it is a suspension that is comprised of a fine powder in a liquid. The user needs to prepare the mixture according to the proportions defined in the certificate, and mix it using ASTM C1738 with the modification for introduction of the corn syrup to the blender as described in Section 3.3 of this report (and will also be described on the certificate).

This report provides the development of the certified Bingham values or yield stress and plastic viscosity (section 6.1), and the viscosity curves composed of the viscosity vs shear rate relationship (section 6.2). In both cases an extensive statistical analysis allows the determination of the values with their uncertainty. All the results obtained are provided in the appendixes.

Currently, research on the addition of fine and coarse aggregates to develop SRMs for characterizing the performance of mortar and concrete rheometers is under way. 


\section{References}

1. Hackley V. A., Ferraris C.F, "The Use of Nomenclature in Dispersion Science and Technology", NIST Recommended Practice Guide, SP 960-3, (2001) http://www.nist.gov/public_affairs/practiceguides/SP960-3.pdf

2. National Institute of Standards and Technology (2012). Certification of SRM2492: Bingham Paste Mixture for Rheological Measurements. (NIST Special Publication 260-174). U.S. Department of Commerce.

3. Swindells J.F. , Hardy R.C., Cottington R.L., Precise Measurements with Bingham Viscometers and Cannon Master Viscometers, J. of Res. of the National Institute of Standards and Technology, 52 \#3 (1954) 105-115

4. ISO/TR 3666:1998, “Viscosity of Water,” Technical report. (1998)

5. Ferraris C.F., Brower L., editors, Comparison of Concrete Rheometers: International Tests at MB (Cleveland OH, USA) in May 2003, NISTIR 7154, (2004) (http://ciks.cbt.nist.gov/ ferraris/PDF/DraftRheo2003V11.4.pdf)

6. Brower L., Ferraris C.F., Comparison of Concrete Rheometers, Concrete International, Vol. 25 \#8, (2003) 41-47

7. Ferraris C.F. , Brower L., editors, Comparison of concrete rheometers: International tests at LCPC (Nantes, France) in October 2000, NISTIR 6819, (2001) (http://fire.nist.gov/bfrlpubs/build01/PDF/b01074.pdf)

8. Ferraris, C.F., Li, Z., Zhang, M-H., Stutzman P. "Development of a Reference Material for the Calibration of Cement Paste Rheometers” Accepted for publication to ASTM-Advances in Civil Engineering Materials, June 2012

9. Collyer A.A., Clegg D.W., "Rheological Measurements”, Chapman \& Hall, London, 1998

10. Ferraris C.F, Geiker M., Martys N. S. and Muzzatti N., "Parallel-plate Rheometer Calibration Using Oil and Lattice Boltzmann simulation”, J. of Advanced Concrete Technology, vol. 5 \#3, October 2007, pp. 363-371

11. Ferraris C.F., Concrete Rheology: Knowledge and challenges, Key note speaker, 2nd International RILEM Symposium on Advances in Concrete Through Science and Engineering (Quebec, Canada), (2006)

12. AASHTO- T-353-14, "Particle Size Analysis of Hydraulic Cement and Related Materials by Light Scattering”

13. Davies G.A., Stokes J.R., "On the gap error in parallel plate rheometry that arises from the presence of air when zeroing the gap”, J. of Rheology $49 \# 4$ (2005) 919922.

14. Sanchez-Perez J., Archer L.A., "Interfacial Slip Violations in Polymer Solutions: Role of Microscale Surface Roughness”, Langmuir 19 (2003) 3304-3312.

15. Helsel M., Ferraris C.F., “Comparative study on measurement of the density of cement and limestone”, under review for publication.

16. Rao, M.A. Rizvi S.S.H. Datta A. K., “Engineering properties of foods” CRC Press, p. 81, 2005 
17. R Development Core Team, R: A Language and Environment for Statistical Computing. R Foundation for Statistical Computing, Vienna, Austria, 2011, http://www.R-project.org.

18. Bates, D., Maechler, M.,Bolker, B., Walker, S. (2014) Linear Mixed-Effects Models Using Eigen and S4, http://cran.r-project.org/web/packages/lme4/.

19. Domínguez-Molina, J.A. and González-Farías, G, and Rodríguez-Dagnino, R.M. (2002) A Practical Procedure to Estimate the Shape Parameter in the Generalized Gaussian Distribution, Centro de Investigación en Matemáticas, México Report, 37 p. http://www.cimat.mx/reportes/enlinea/I-01-18_eng.pdf.

20. Lee, P. (2012) Bayesian Statistics: An Introduction, 4th ed., Wiley, 486 p.

21. Gelman. A., Carlin, J.B., Stern, H.S., Dunson, D.B., Vehtari, A. Rubin, D.B. (2013) Bayesian Data Analysis, 3rd ed., Chapman \& Hall/CRC, 675 p.

22. Congdon, P. (2007) Bayesian Statistical Modelling, 2nd ed., Wiley, 596 p.

23. "Beta Distribution”, NIST/SEMATECH e-Handbook of Statistical Methods, http://www.itl.nist.gov/div898/handbook/eda/section3/eda366h.htm, May 18, 2015.

24. Jones, B. and Majumdar, D. (2014) “Optimal Supersaturated Designs”, Journal of the American Statistical Association, to appear. http://dx.doi.org/10.1080/01621459.2014.938810.

25. Lunn, D., Spiegelhalter, D., Thomas, A. and Best, N. (2009) “The BUGS Project: Evolution, Critique and Future Directions (with discussion)”, Statistics in Medicine, pp 3049-3082.

26. OpenBUGS website, http://www.openbugs.net.

27. Roscoe R. (1952). "The viscosity of suspensions of rigid spheres," British Journal of Applied Physics, 3, 267-269.

28. Kataoka T., Kitano T., Sasahara M., and Nishijima K. (1978). "Viscosity of particle filled polymer melts." Rheologica Acta, 17, 149-155.

29. Liard, Maxime and Martys, Nicos S. and George, William L. and Lootens, Didier and Hebraud, Pascal, "Scaling laws for the flow of generalized Newtonian suspensions.” Journal of Rheology (1978-present), 58, 1993-2015 (2014), DOI: http://dx.doi.org/10.1122/1.4896896

30. BRugs R Package: http://cran.r-project.org/web/packages/BRugs/.

31. BIPM, IEC, IFCC, ILAC, ISO, IUPAC, IUPAP and OIML 2008 Evaluation of Measurement Data - Supplement 1 to the Guide to the Expression of Uncertainty in Measurement - Propagation of Distributions Using a Monte Carlo Method JCGM $101: 2008$ 


\section{Appendices}

\section{Appendix A: Statistical analysis for re-certification Bingham calculations}

This Appendix provides all the graphs needed for the interpretation of the results and the extraction of the proposed re-certified values. See Table 3 for re-certified values.

\section{Appendix B: Data for re-certification calculations}

This Appendix provides all the data obtained from each test that was performed and used for the calculations. The results calculated with these data were generated using a NonNewtonian approach. Also included are the graphs needed for interpretation of the results.

\section{Appendix C: Viscosity Curve Data}

This Appendix provides the viscosity curves (in Log-scale form) for selected mixes.

The curves portray the viscosity of the material at each shear rate, rather than the plastic viscosity found by Bingham approximation.

\section{Appendix D: Viscosity Curve Certified and Reference Values}

This Appendix provides the results from statistical analysis of viscosity curves, listed as certified and reference values 


\section{Appendix A: Statistical analysis for re-certification calculations}

This Appendix provides all the graphs needed for the interpretation of the results and the extraction of the proposed re-certified values. See Table 3 for re-certified values. 
Unit $=1$

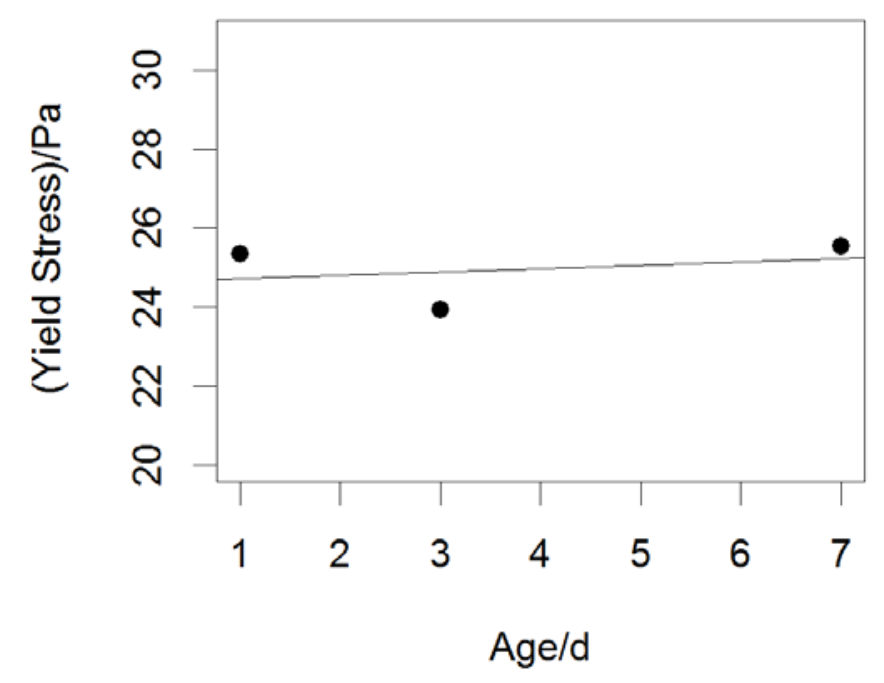

Unit $=3$

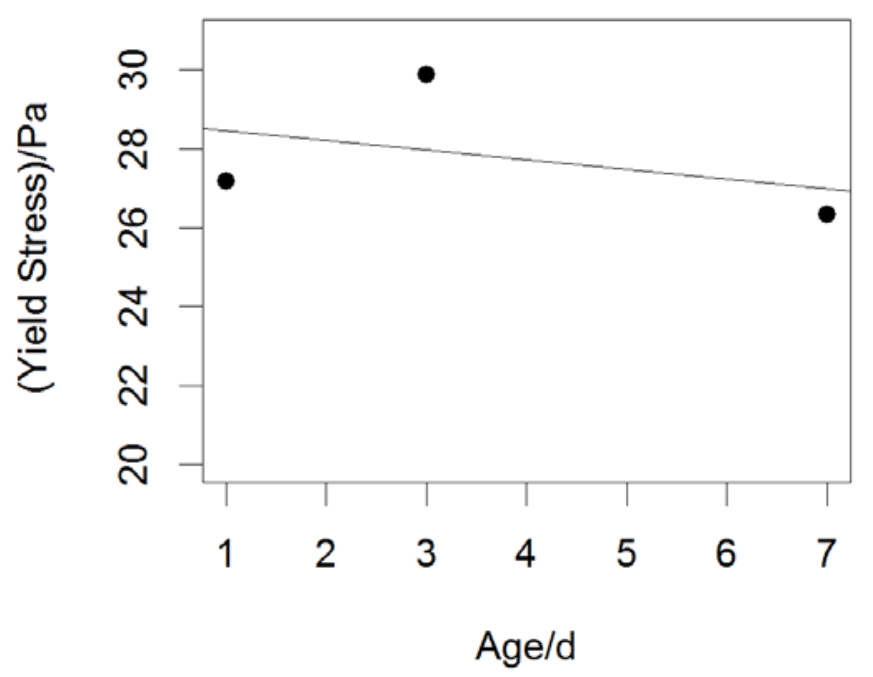

Unit $=2$

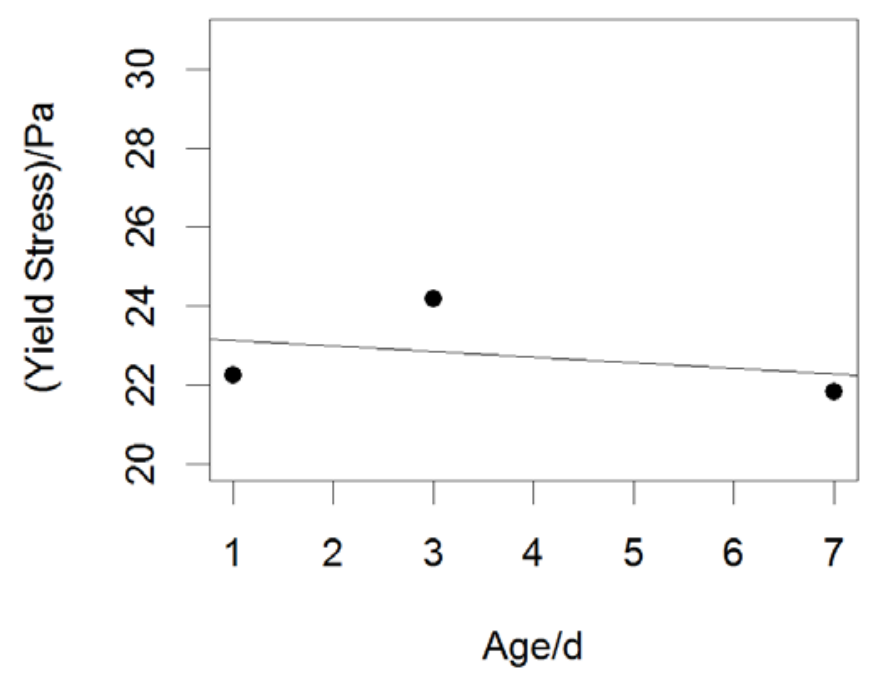

Unit $=4$

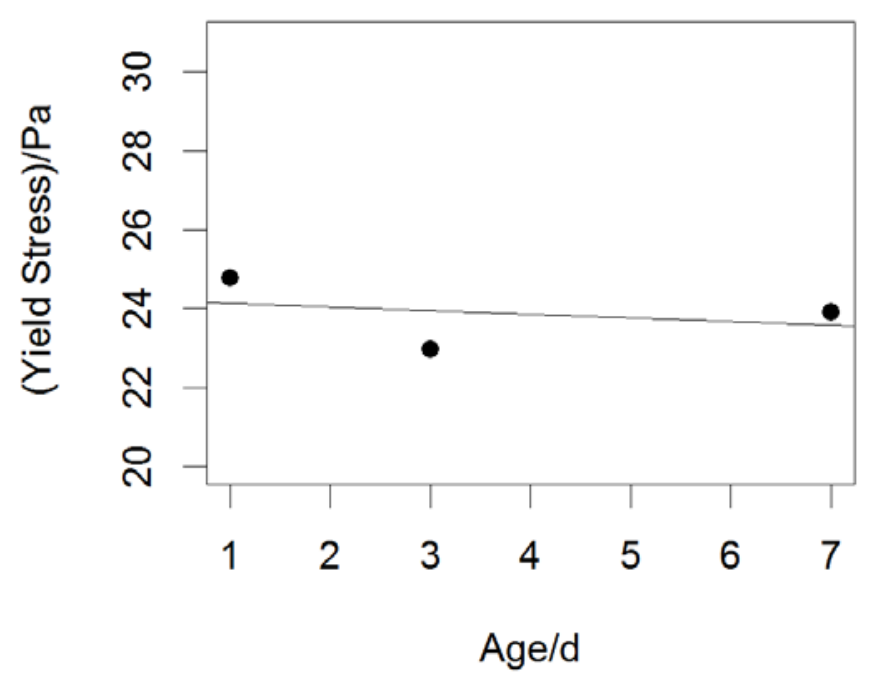

Figure A-1: Yield Stress by unit - Units 1 through 4. 


\section{Unit $=\mathbf{5}$}

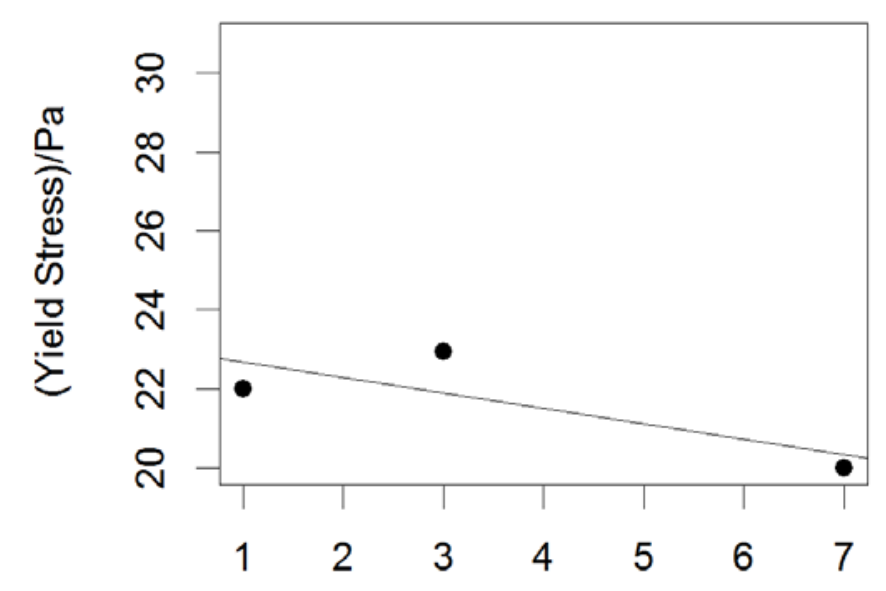

Age/d

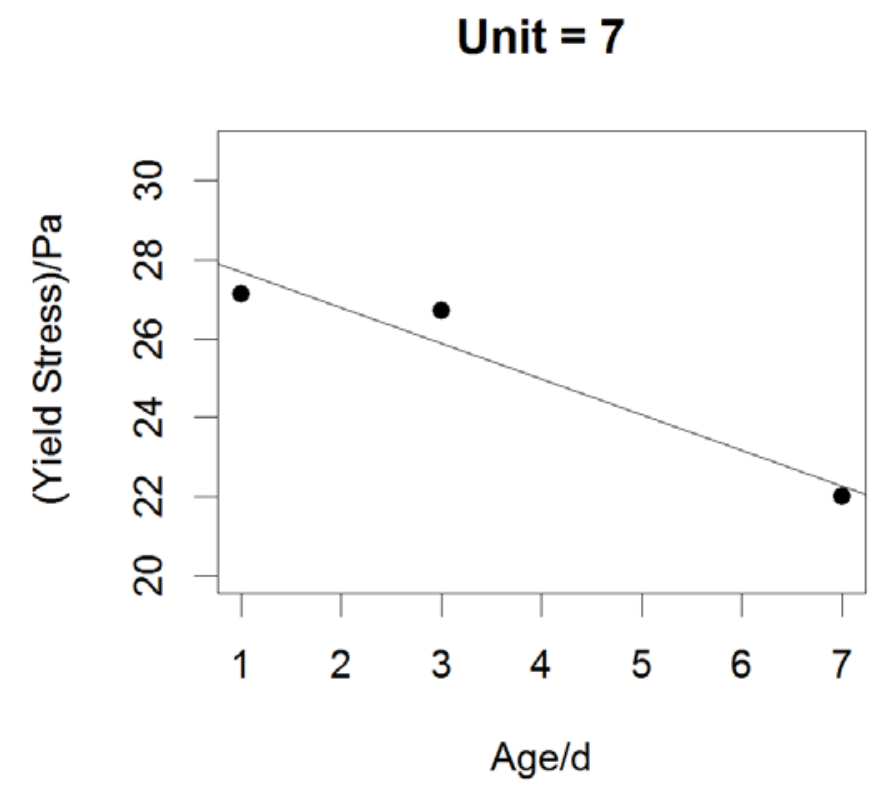

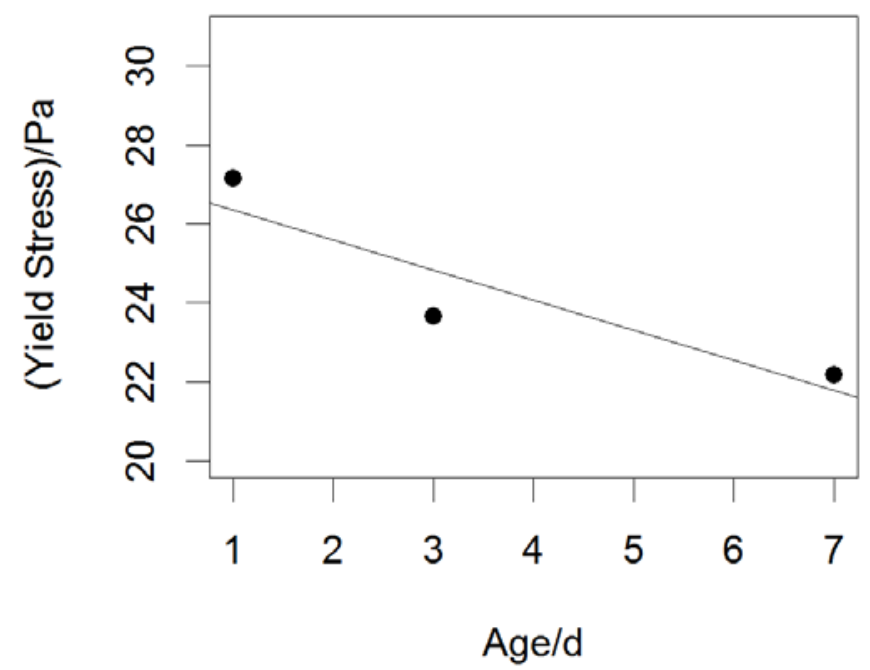

Unit $=8$

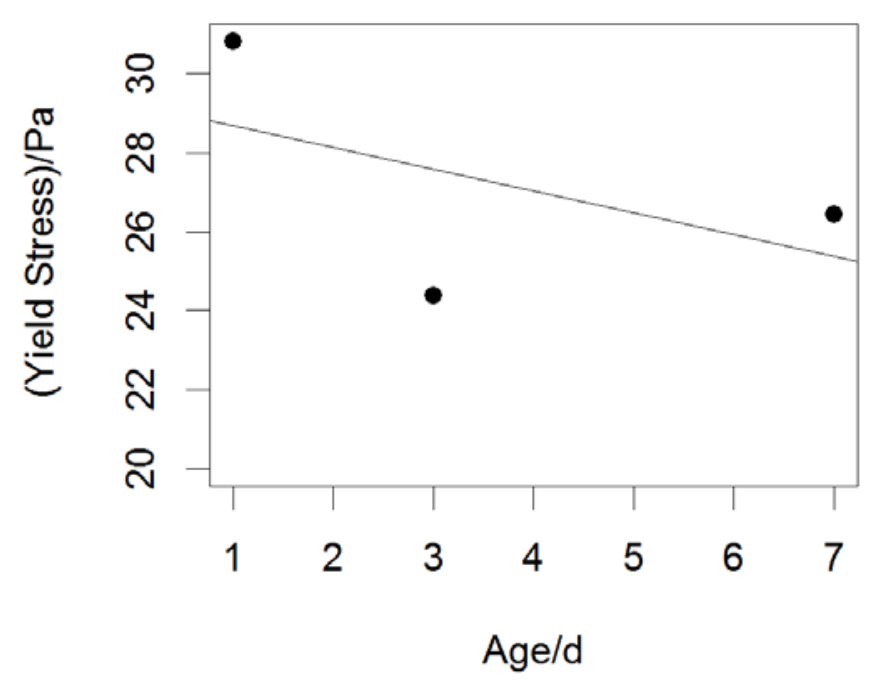

Figure A-2: Yield Stress by unit - Units 5 through 8. 
Unit $=9$

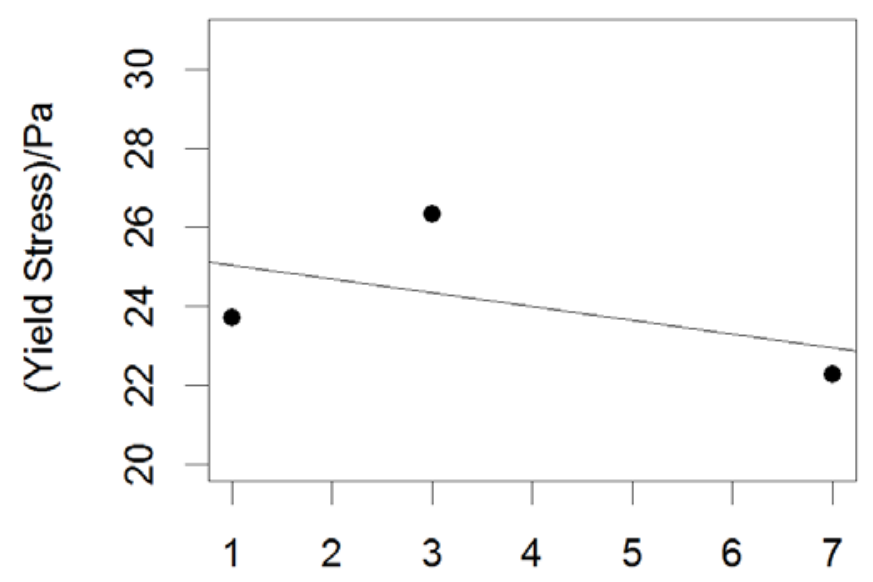

Age/d

Unit $=11$

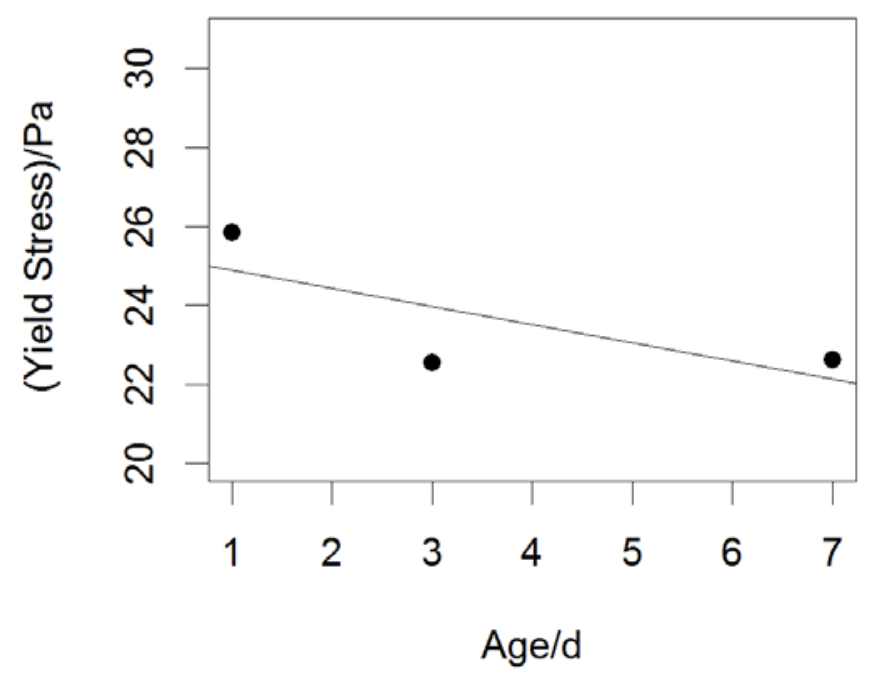

Unit $=10$

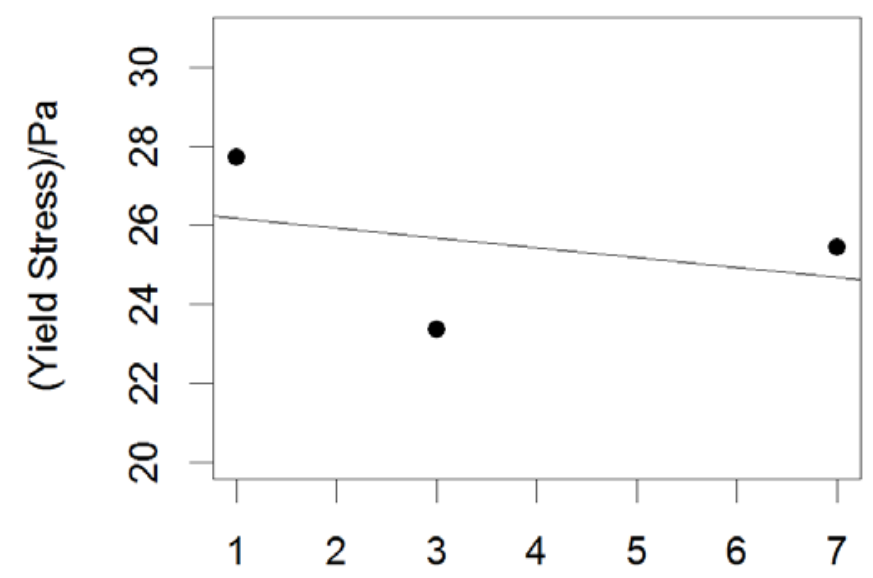

Age/d

Unit $=12$

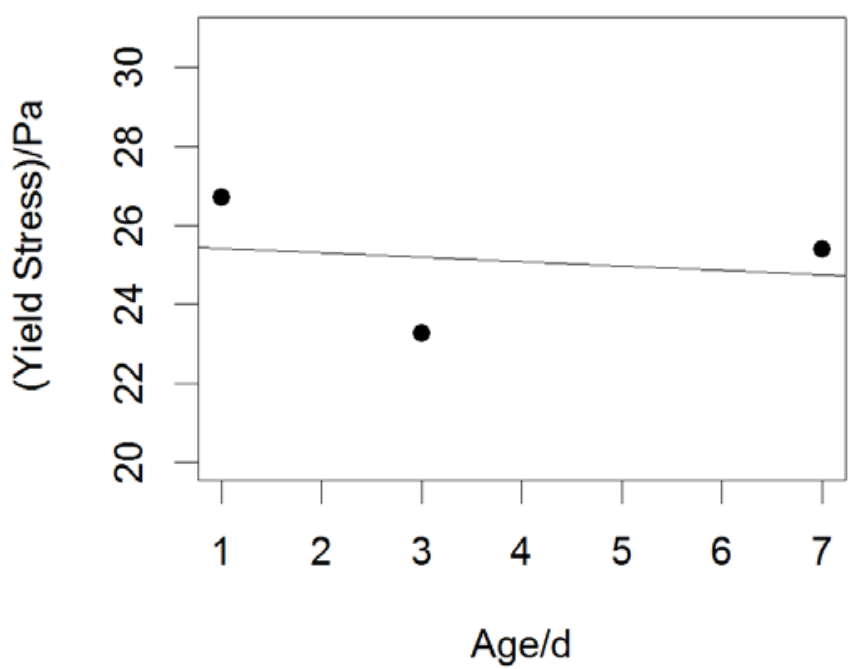

Figure A-3: Yield Stress by unit - Units 9 through 12. 


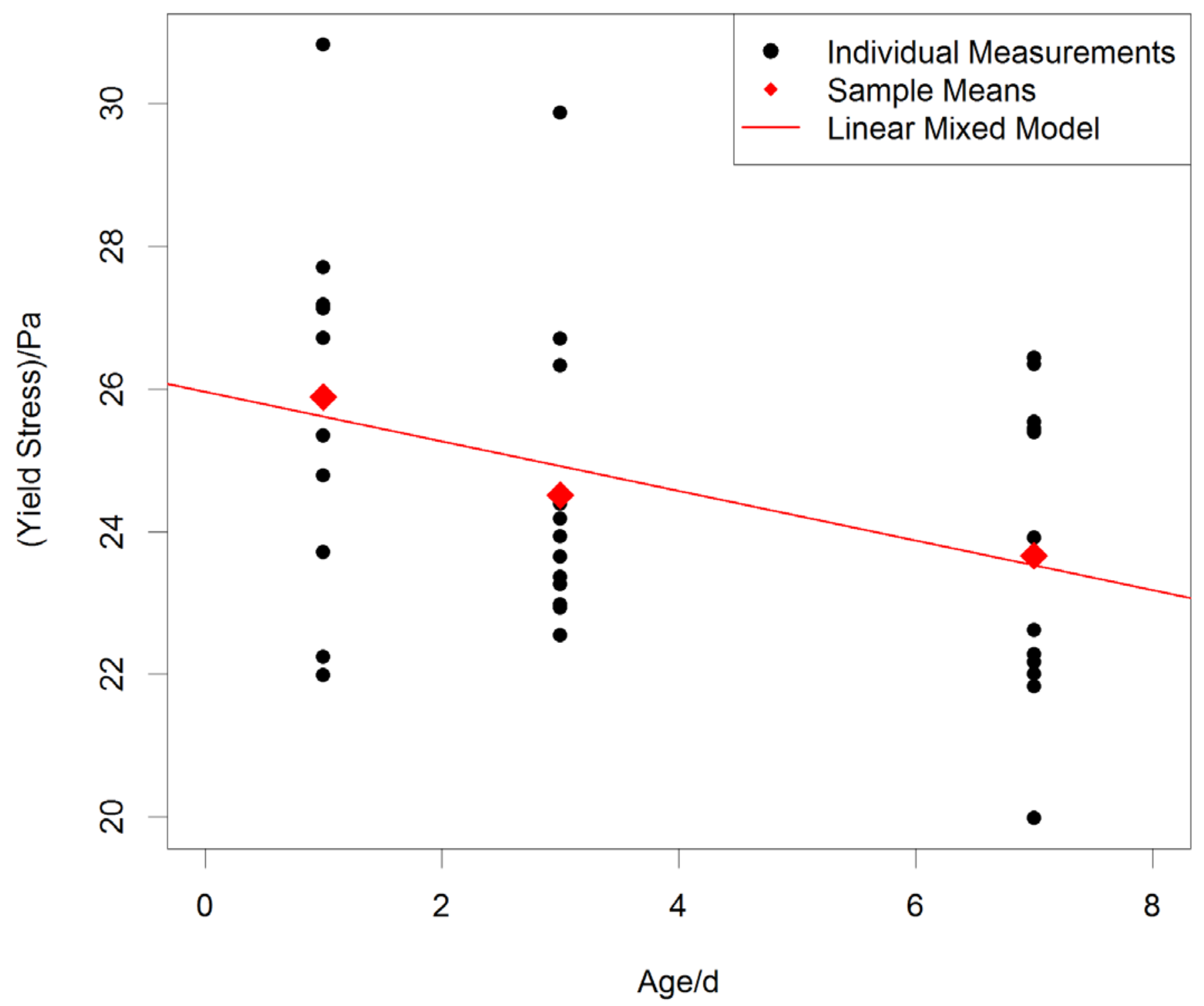

Figure A-4: Yield Stress versus Age with Linear Mixed Model. 
Unit $=1$

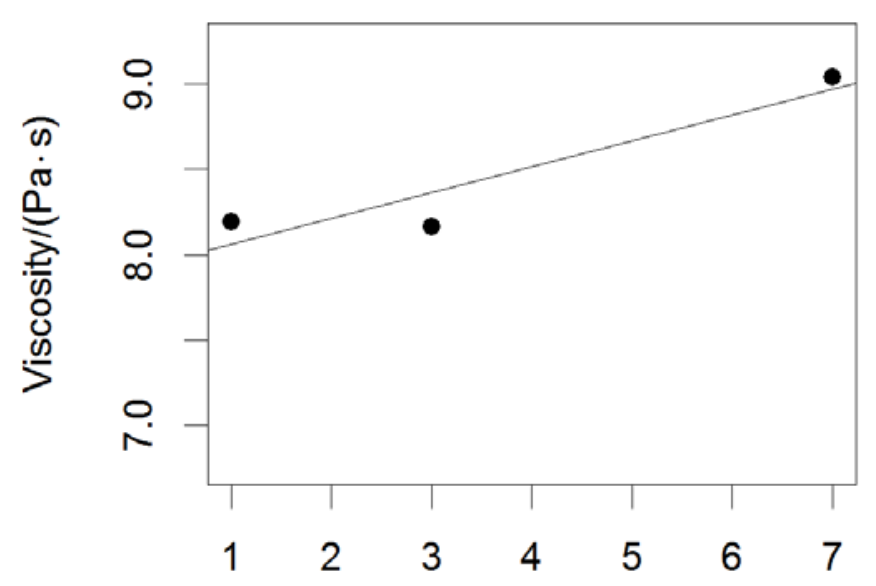

Age/d

\section{Unit $=3$}

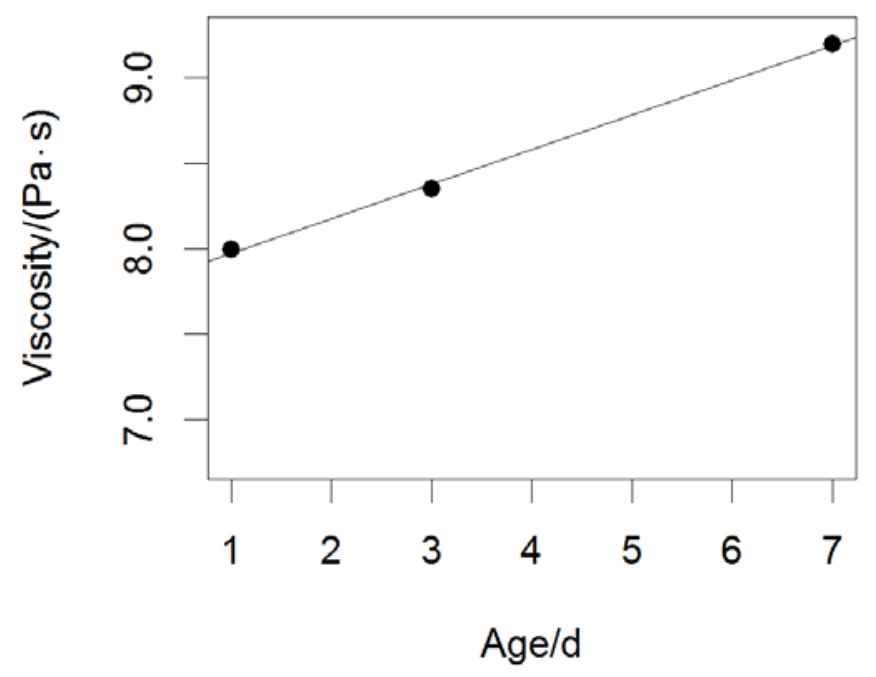

Unit $=2$

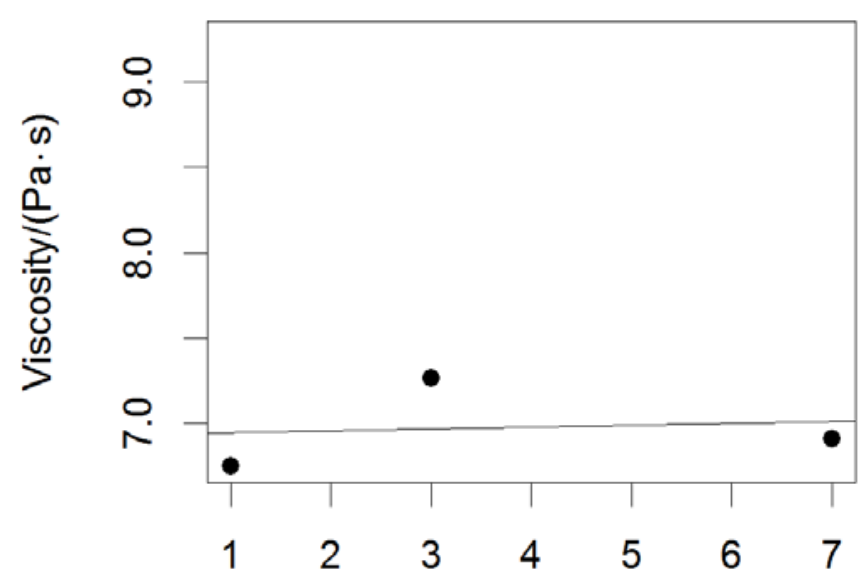

Age/d

Unit $=4$

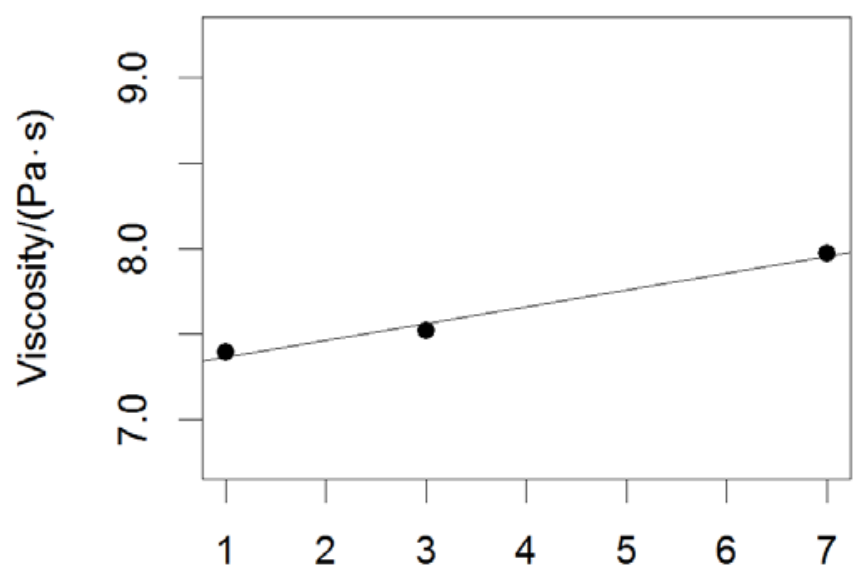

Age/d

Figure A-5: Plastic Viscosity by Unit - Units 1 through 4. 


\section{Unit $=5$}

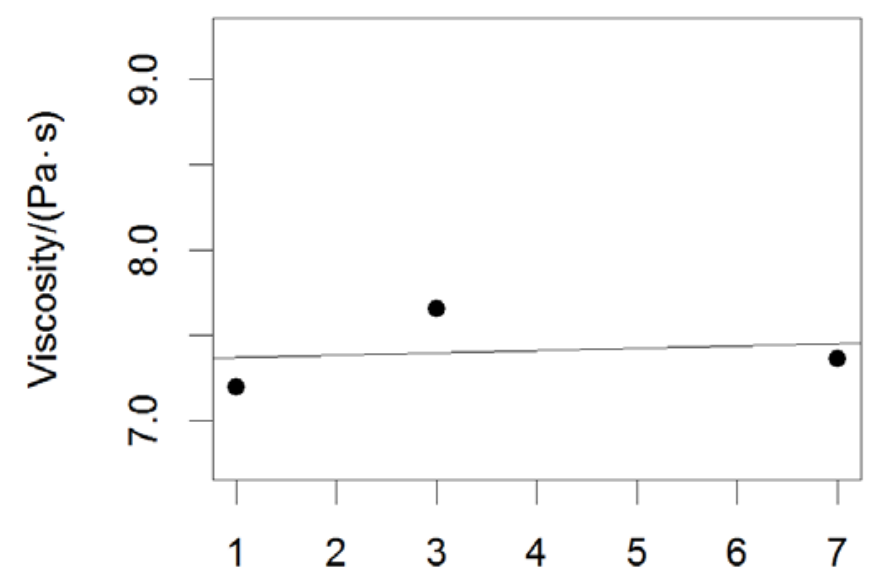

Age/d

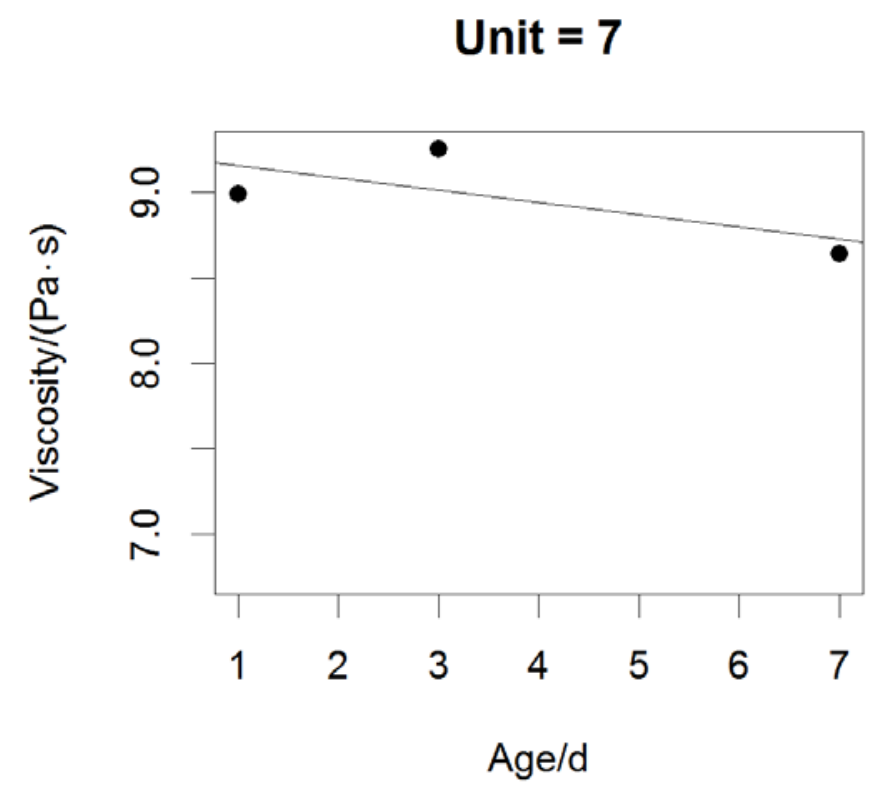

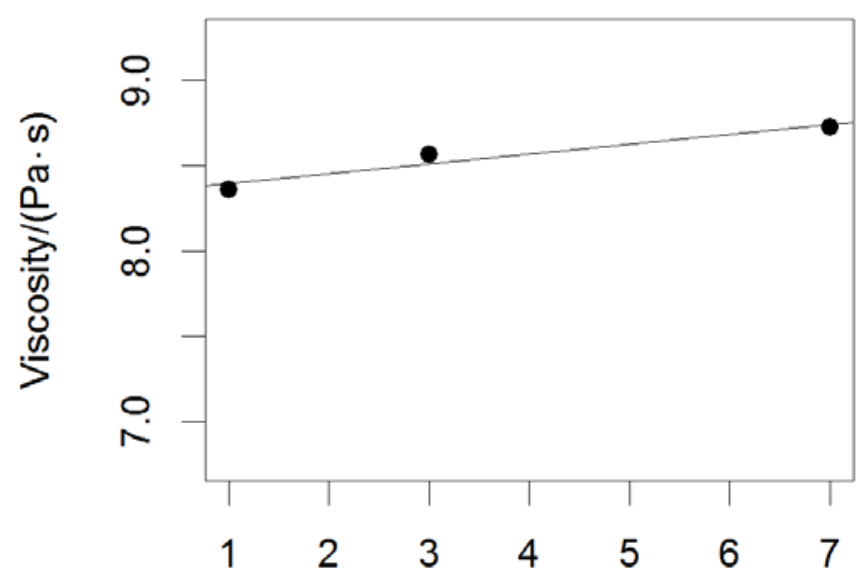

Age/d

Unit $=8$

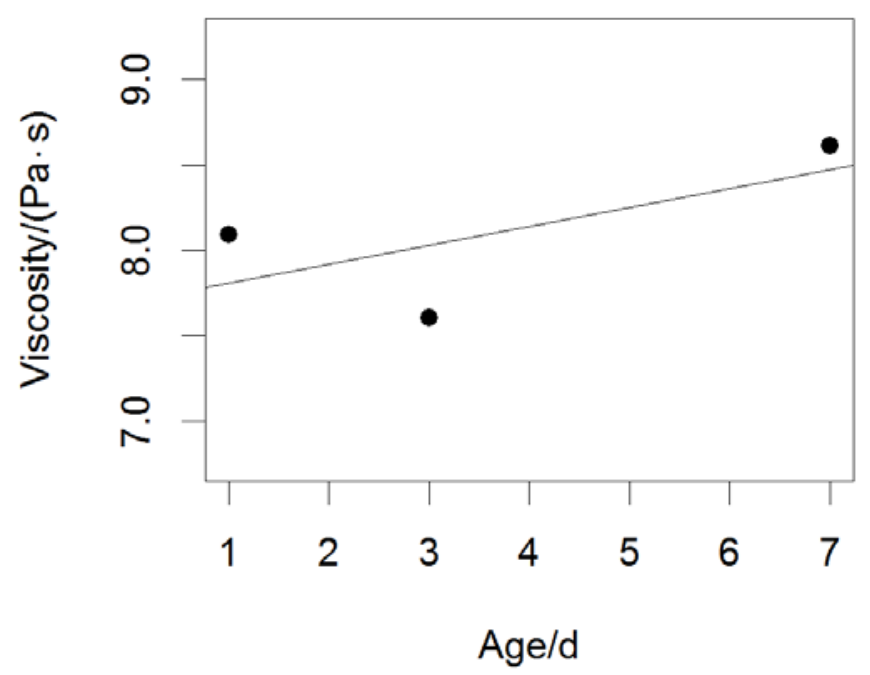

Figure A-6: Plastic Viscosity by Unit - Units 5 through 8. 
Unit $=9$

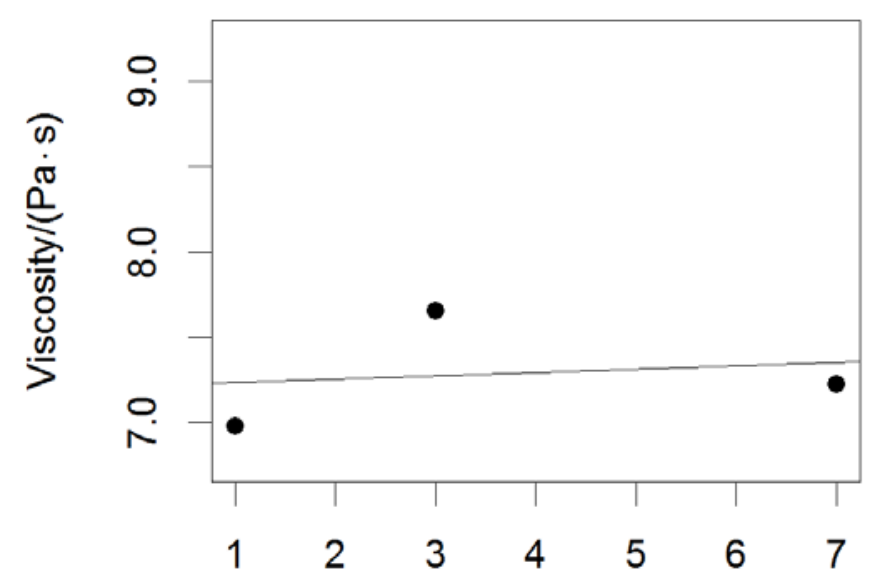

Age/d

\section{Unit $=11$}

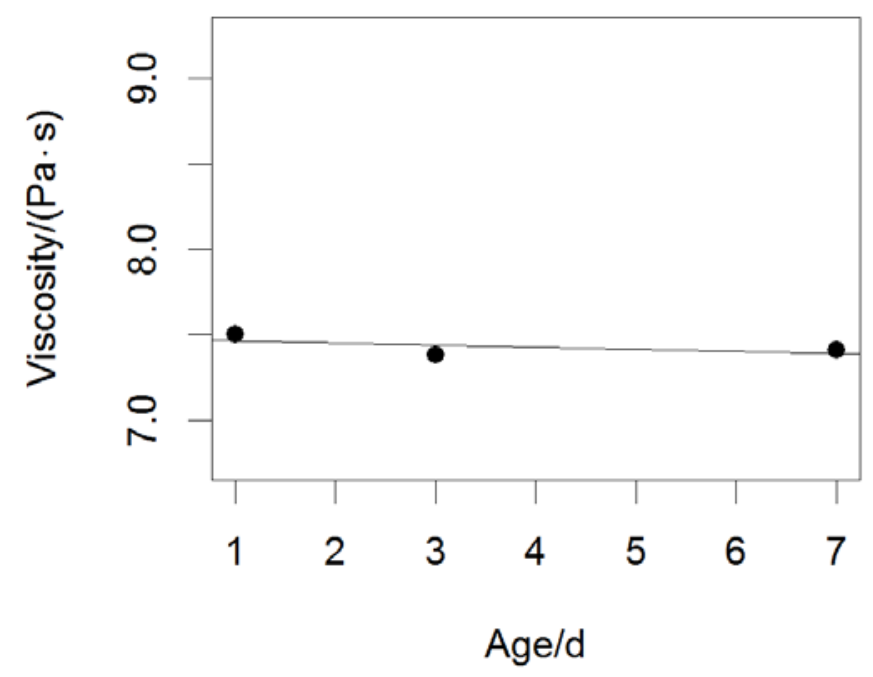

Unit $=10$

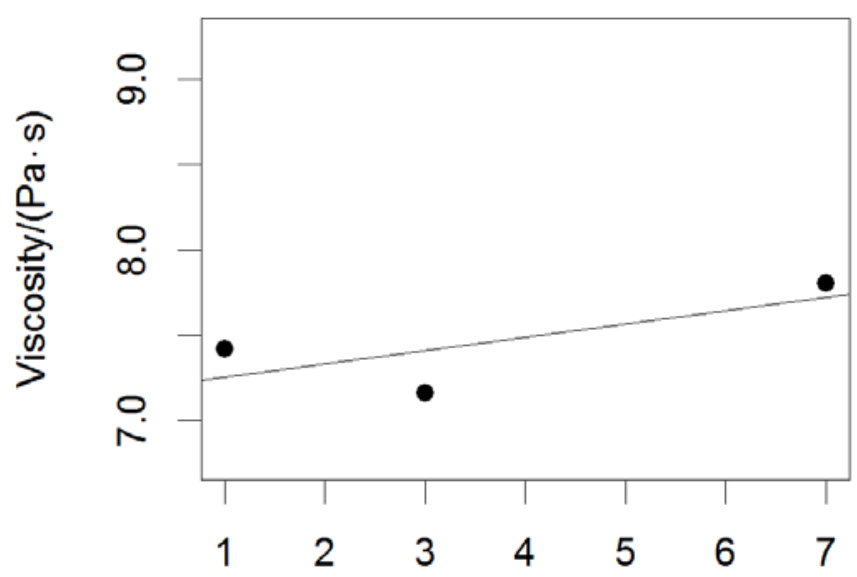

Age/d

Unit $=12$

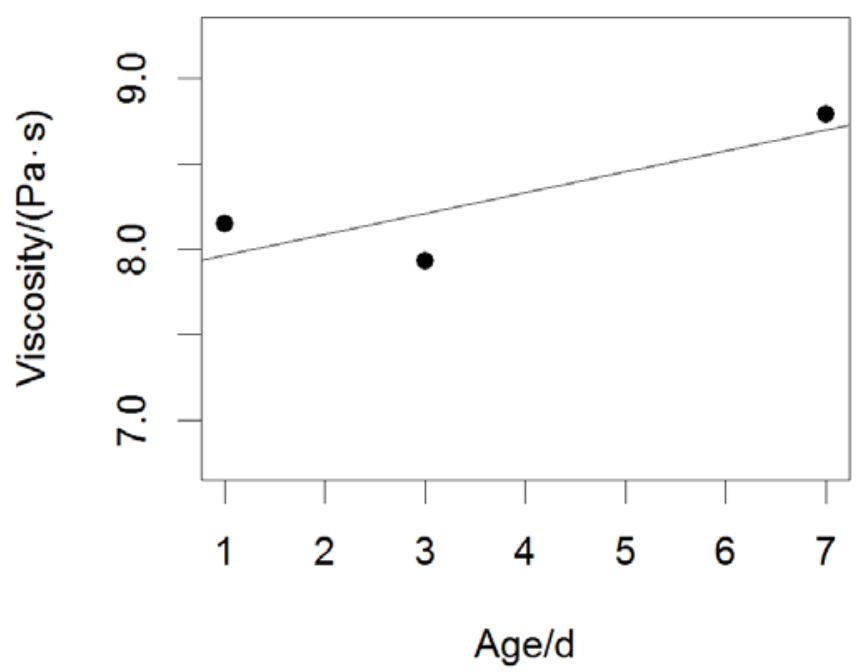

Figure A-7: Plastic Viscosity by Unit - Units 9 through 12. 


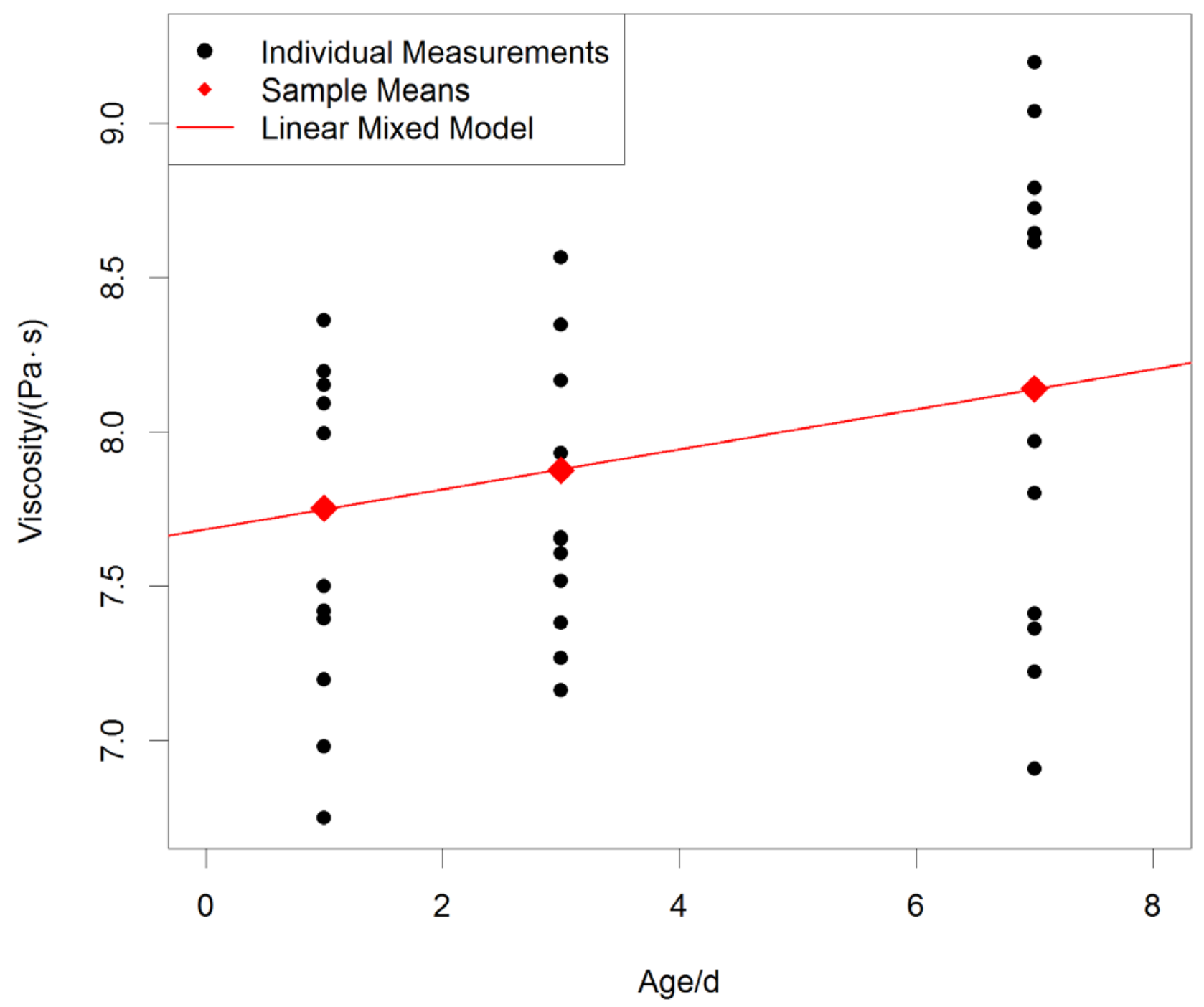

Figure A-8: Plastic Viscosity versus Age with Linear Mixed Model. 


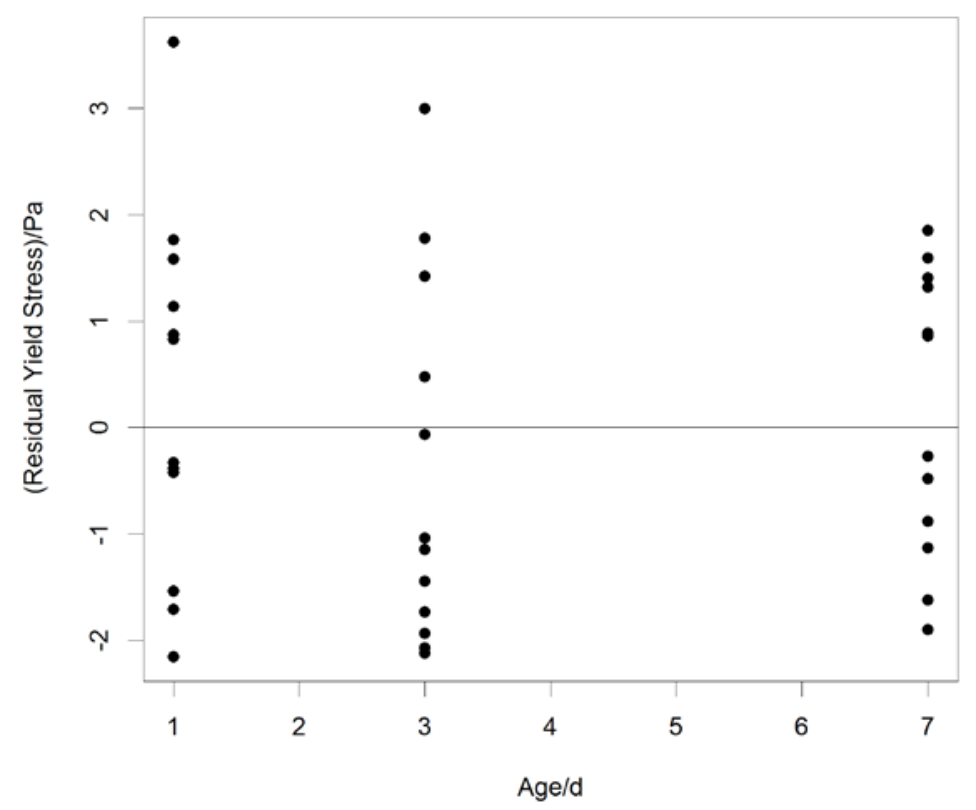

Figure A-9:Residual Yield Stress versus Age.

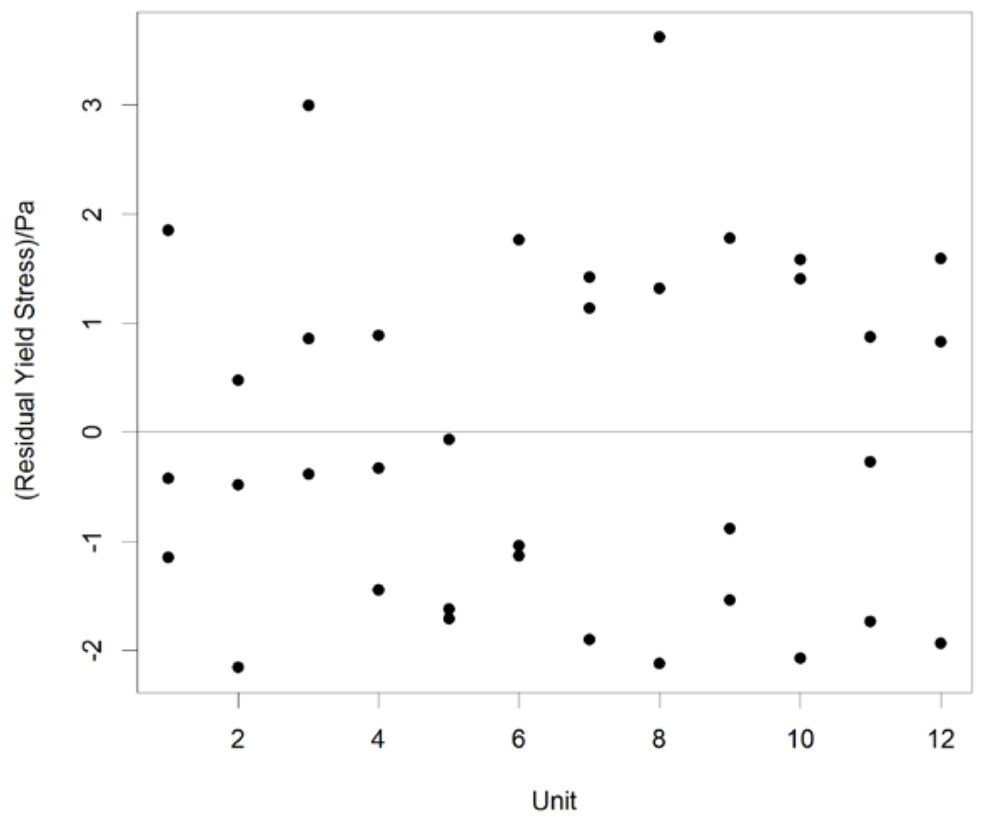

Figure A-10: Residual Yield Stress versus Unit. 


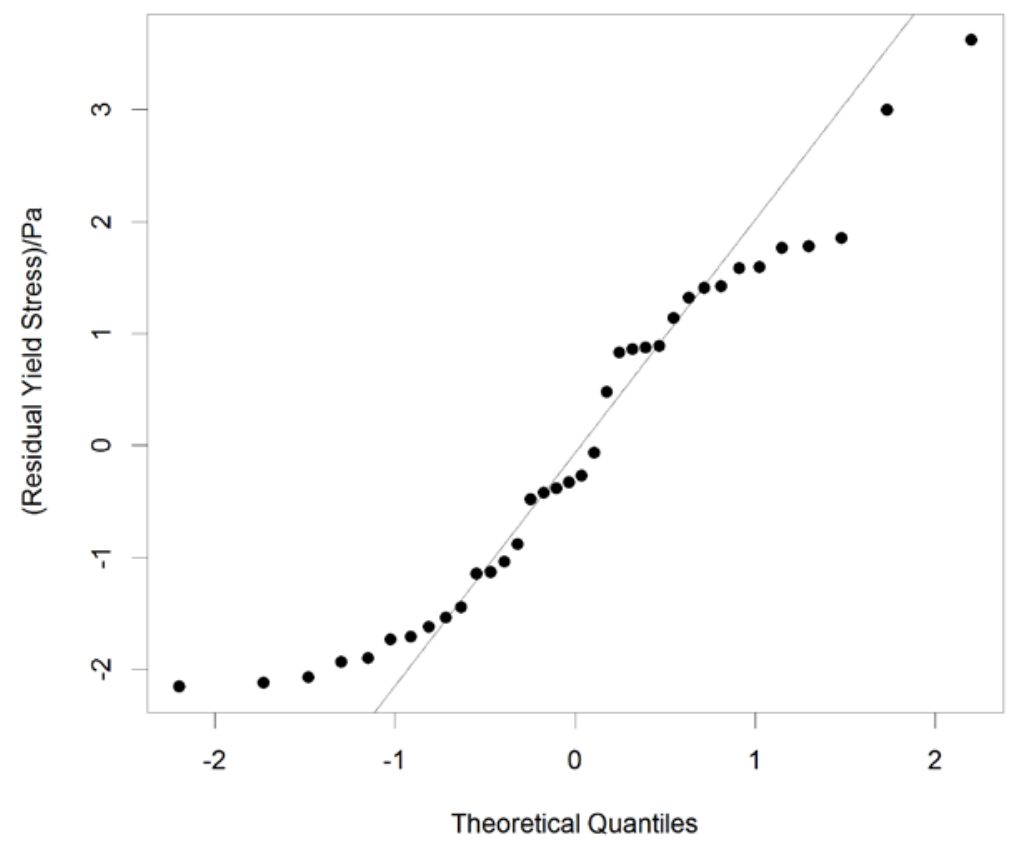

Figure A-11: Normal Probability Plot of Yield Stress Residuals.

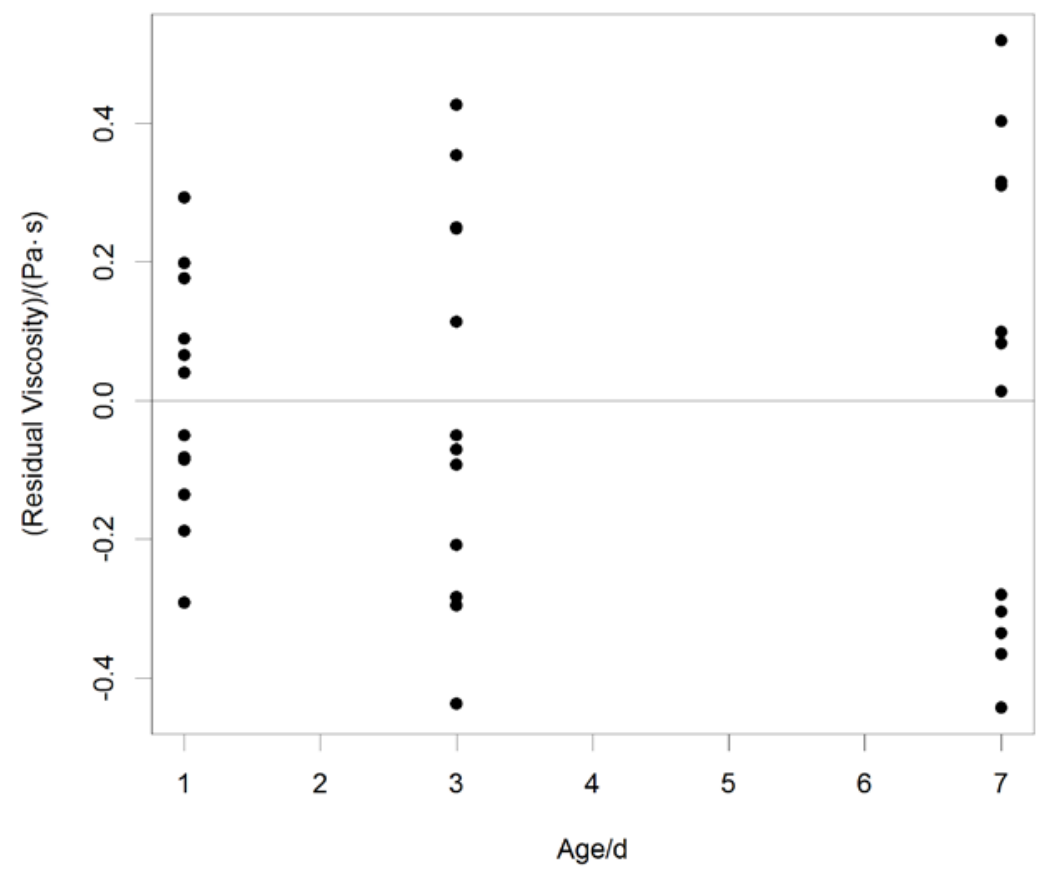

Figure A-12: Residual Plastic Viscosity versus Age. 


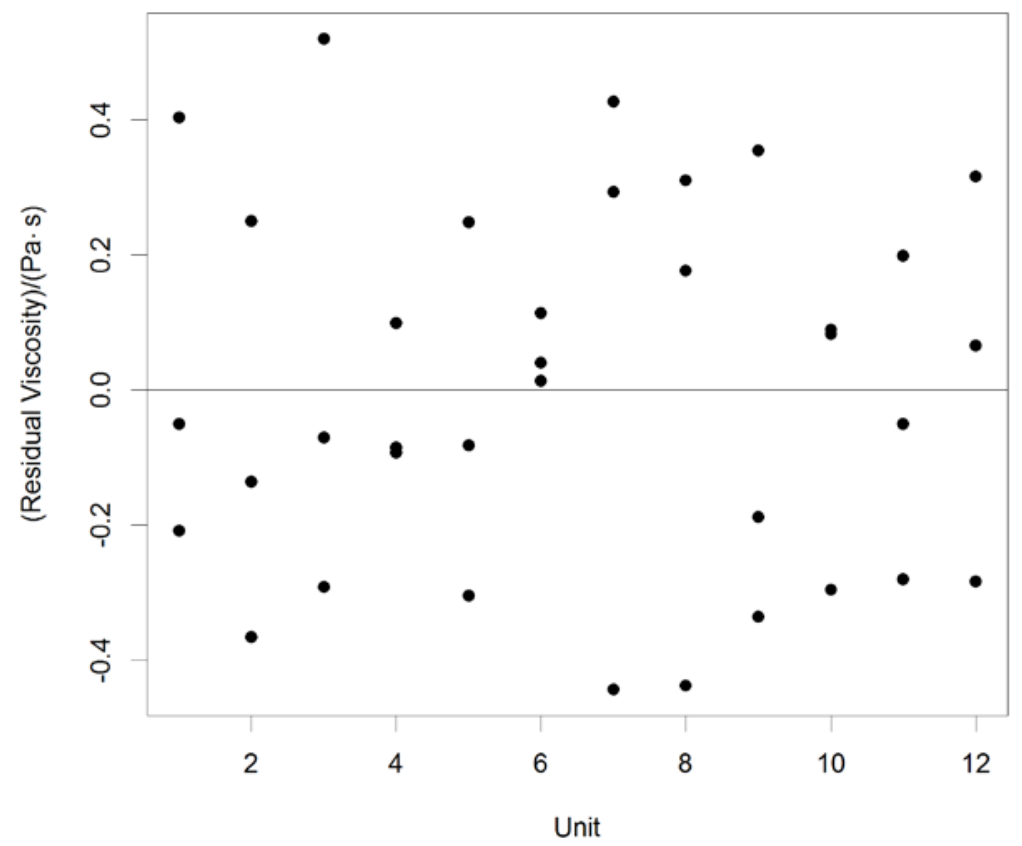

Figure A-13: Residual Plastic Viscosity versus Unit.

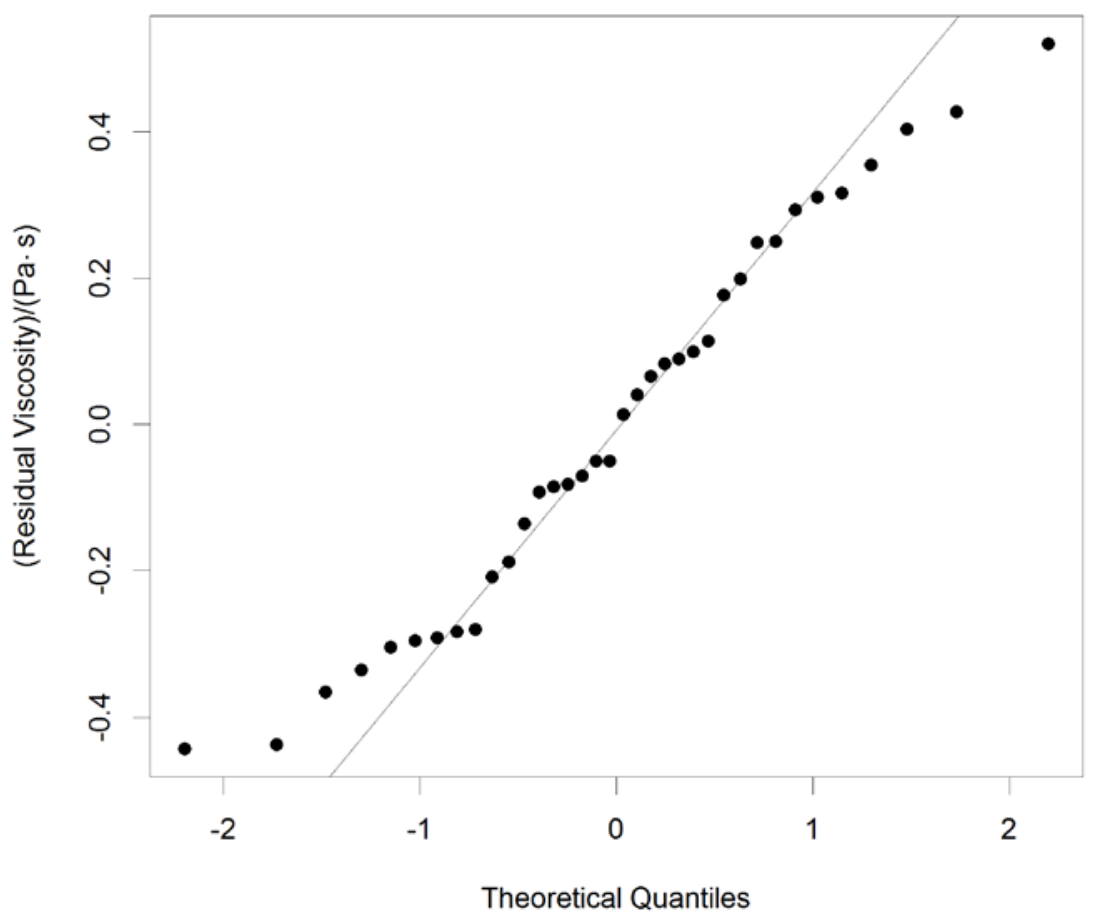

Figure A-14: Normal Probability Plot of Viscosity Residuals. 
Table A-1: Raw Data for Rheological Quantities in SRM 2492.

\begin{tabular}{|c|c|c|c|}
\hline Unit & Age & Yield Stress & $\begin{array}{c}\text { Plastic } \\
\text { Viscosity }\end{array}$ \\
\hline & days & {$[\mathrm{Pa}]$} & {$[\mathrm{Pa} \cdot \mathrm{s}]$} \\
\hline 1 & 1 & 25.345 & 8.195 \\
\hline 1 & 3 & 23.929 & 8.166 \\
\hline 1 & 7 & 25.535 & 9.038 \\
\hline 2 & 1 & 22.244 & 6.751 \\
\hline 2 & 3 & 24.176 & 7.267 \\
\hline 2 & 7 & 21.831 & 6.910 \\
\hline 3 & 1 & 27.185 & 7.996 \\
\hline 3 & 3 & 29.868 & 8.346 \\
\hline 3 & 7 & 26.342 & 9.197 \\
\hline 4 & 1 & 24.781 & 7.395 \\
\hline 4 & 3 & 22.973 & 7.517 \\
\hline 4 & 7 & 23.917 & 7.968 \\
\hline 5 & 1 & 21.986 & 7.197 \\
\hline 5 & 3 & 22.935 & 7.658 \\
\hline 5 & 7 & 19.989 & 7.364 \\
\hline 6 & 1 & 27.143 & 8.362 \\
\hline 6 & 3 & 23.646 & 8.564 \\
\hline 6 & 7 & 22.165 & 8.724 \\
\hline 7 & 1 & 27.124 & 8.991 \\
\hline 7 & 3 & 26.708 & 9.254 \\
\hline 7 & 7 & 21.999 & 8.643 \\
\hline 8 & 1 & 30.824 & 8.092 \\
\hline 8 & 3 & 24.387 & 7.607 \\
\hline 8 & 7 & 26.436 & 8.615 \\
\hline 9 & 1 & 23.707 & 6.982 \\
\hline 9 & 3 & 26.329 & 7.654 \\
\hline 9 & 7 & 22.277 & 7.223 \\
\hline 10 & 1 & 27.707 & 7.420 \\
\hline 10 & 3 & 23.358 & 7.164 \\
\hline 10 & 7 & 25.447 & 7.802 \\
\hline 11 & 1 & 25.851 & 7.501 \\
\hline 11 & 3 & 22.550 & 7.381 \\
\hline 11 & 7 & 22.622 & 7.411 \\
\hline 12 & 1 & 26.714 & 8.150 \\
\hline 12 & 3 & 23.258 & 7.931 \\
\hline 12 & 7 & 25.394 & 8.790 \\
\hline
\end{tabular}


Table A-2: Output from Fit of Linear Mixed Model for Yield Stress.

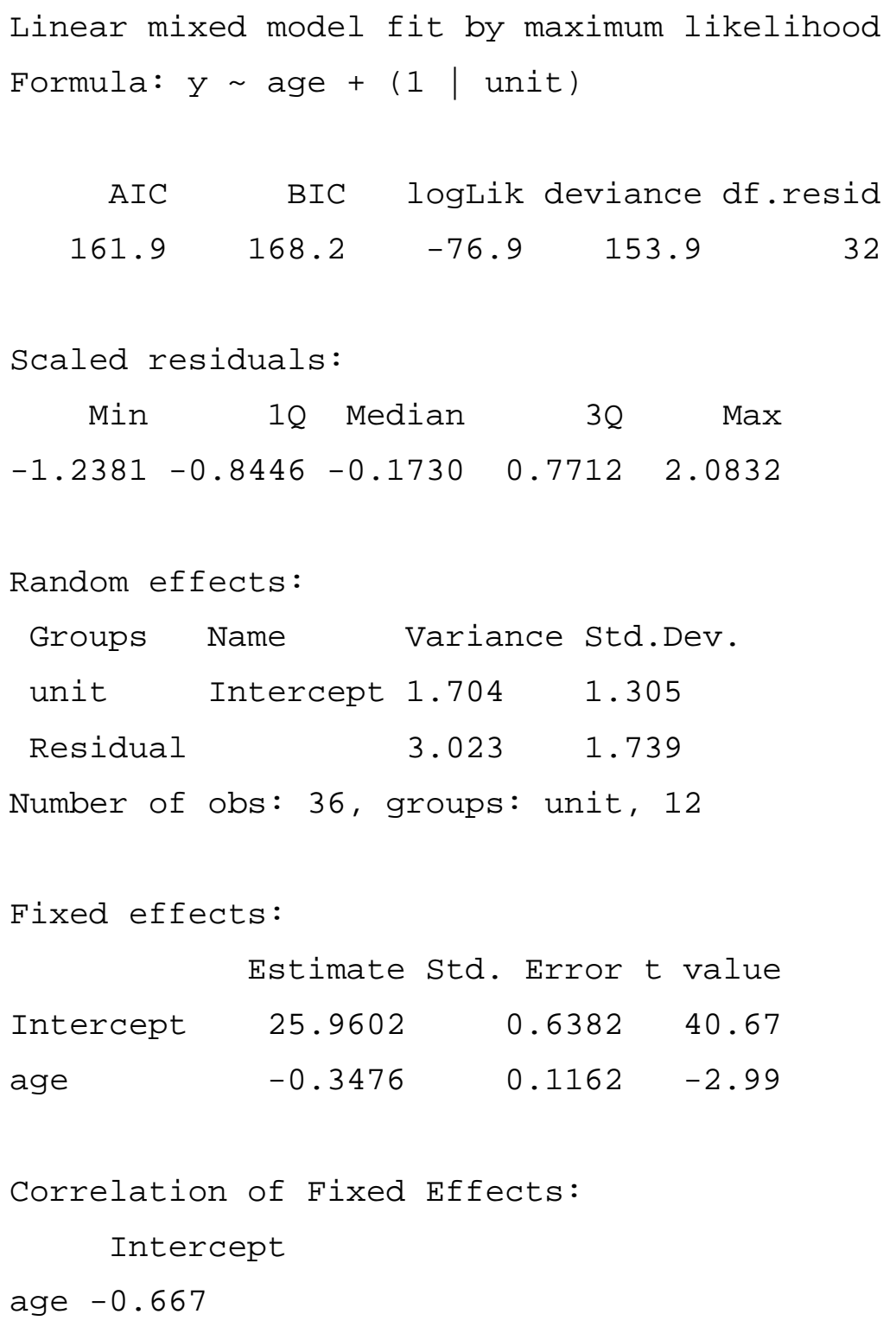


Table A-3: Output from Fit of Linear Mixed Model for Plastic Viscosity.

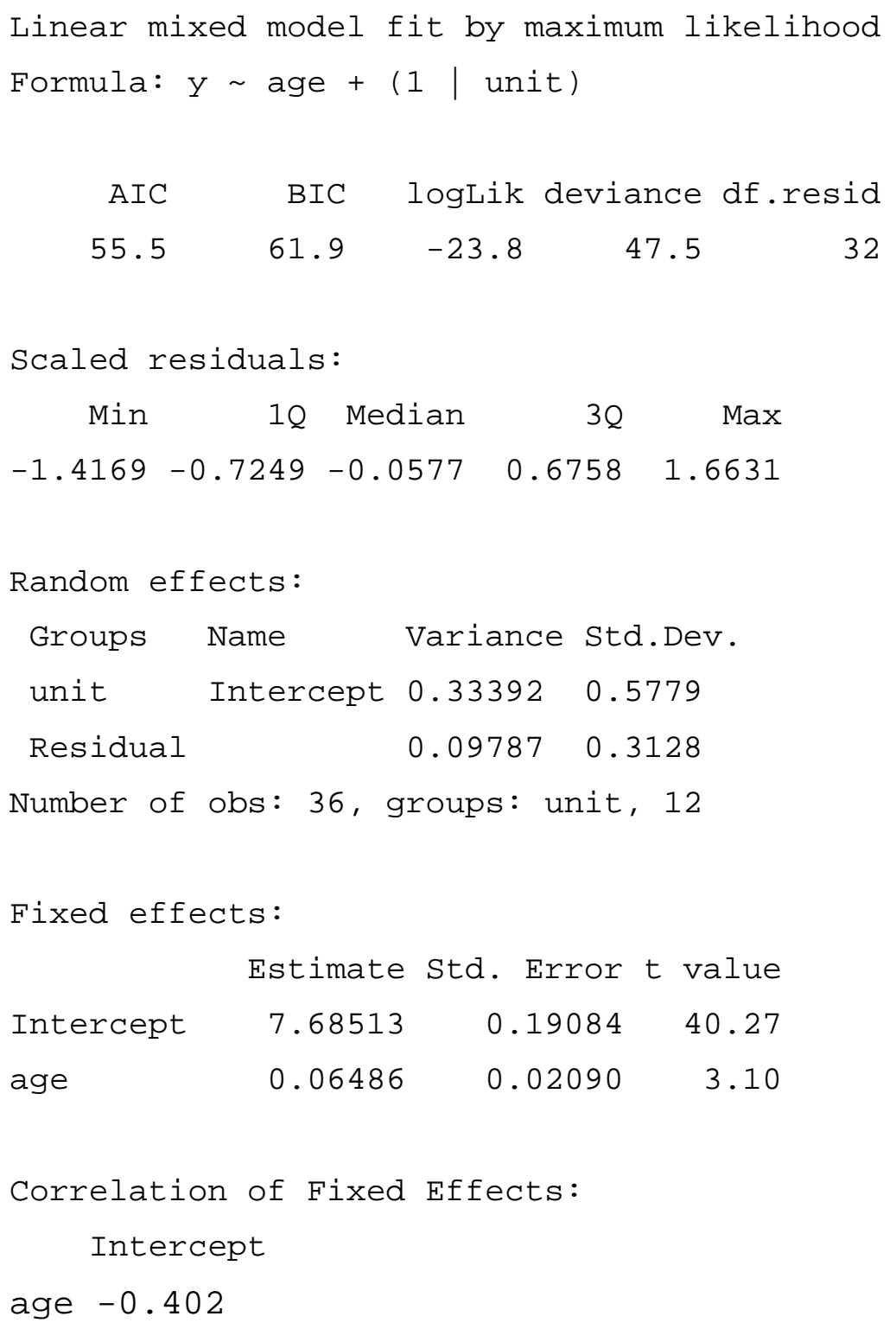


Table A-4: Output from Models for Yield Stress with Different Priors.

\begin{tabular}{|c|c|c|c|c|}
\hline Model & Parameter & Prior & $\begin{array}{r}\text { Posterior } \\
\text { Mean }\end{array}$ & $\begin{array}{l}\text { Posterior } \\
\text { Standard } \\
\text { Deviation }\end{array}$ \\
\hline \multirow{4}{*}{1} & beta0 & $10 * \operatorname{Beta}(1.0,1.0)+20$ & 25.97 & 0.74 \\
\hline & beta1 & $6 * \operatorname{Beta}(1.0,1.0)-3$ & -0.35 & 0.13 \\
\hline & sigma.U & 10*Beta(1.0,1.0) & 1.46 & 0.63 \\
\hline & sigma.M & $10 * \operatorname{Beta}(1.0,1.0)$ & 1.91 & 0.31 \\
\hline \multirow{4}{*}{2} & beta0 & $10 * \operatorname{Beta}(1.2,1.2)+20$ & 25.94 & 0.72 \\
\hline & beta1 & 6*Beta(1.2,0.8)-3 & -0.34 & 0.13 \\
\hline & sigma.U & $10 * \operatorname{Beta}(0.8,0.8)$ & 1.40 & 0.64 \\
\hline & sigma.M & $10 * \operatorname{Beta}(0.8,1.2)$ & 1.91 & 0.31 \\
\hline \multirow{4}{*}{3} & beta0 & $10 * \operatorname{Beta}(1.2,0.8)+20$ & 26.00 & 0.73 \\
\hline & beta1 & 6*Beta(0.8,0.8)-3 & -0.35 & 0.13 \\
\hline & sigma.U & 10*Beta(0.8,1.2) & 1.38 & 0.65 \\
\hline & sigma.M & $10 * \operatorname{Beta}(1.2,0.8)$ & 1.94 & 0.32 \\
\hline \multirow{4}{*}{4} & beta0 & $10 * \operatorname{Beta}(0.8,1.2)+20$ & 25.92 & 0.72 \\
\hline & beta1 & $6 * \operatorname{Beta}(0.8,1.2)-3$ & -0.34 & 0.13 \\
\hline & sigma.U & 10*Beta(0.8,1.2) & 1.39 & 0.64 \\
\hline & sigma.M & $10 * \operatorname{Beta}(0.8,1.2)$ & 1.92 & 0.32 \\
\hline \multirow{4}{*}{5} & beta0 & $10 * \operatorname{Beta}(0.8,0.8)+20$ & 25.97 & 0.73 \\
\hline & beta1 & $6 * \operatorname{Beta}(1.2,1.2)-3$ & -0.35 & 0.13 \\
\hline & sigma.U & 10*Beta(0.8,0.8) & 1.40 & 0.66 \\
\hline & sigma.M & $10 * \operatorname{Beta}(1.2,0.8)$ & 1.94 & 0.32 \\
\hline
\end{tabular}


Table A-5: Output from Models for Plastic Viscosity with Different Priors.

\begin{tabular}{|c|c|c|c|c|}
\hline Model & Parameter & Prior & $\begin{array}{r}\text { Posterior } \\
\text { Mean }\end{array}$ & $\begin{array}{l}\text { Posterior } \\
\text { Standard } \\
\text { Deviation }\end{array}$ \\
\hline \multirow{4}{*}{1} & beta0 & $3 * \operatorname{Beta}(1.0,1.0)+6$ & 7.686 & 0.230 \\
\hline & beta1 & $6 * \operatorname{Beta}(1.0,1.0)-3$ & 0.065 & 0.023 \\
\hline & sigma.U & $10 * \operatorname{Beta}(1.0,1.0)$ & 0.684 & 0.184 \\
\hline & sigma.M & $10 * \operatorname{Beta}(1.0,1.0)$ & 0.339 & 0.055 \\
\hline \multirow{4}{*}{2} & beta0 & $3 * \operatorname{Beta}(1.2,1.2)+6$ & 7.684 & 0.224 \\
\hline & beta1 & 6*Beta(1.2,0.8)-3 & 0.065 & 0.023 \\
\hline & sigma.U & $10 * \operatorname{Beta}(0.8,0.8)$ & 0.676 & 0.183 \\
\hline & sigma.M & $10 * \operatorname{Beta}(0.8,1.2)$ & 0.339 & 0.054 \\
\hline \multirow{4}{*}{3} & beta0 & $3 * \operatorname{Beta}(1.2,0.8)+6$ & 7.700 & 0.225 \\
\hline & beta1 & 6*Beta(0.8,0.8)-3 & 0.064 & 0.023 \\
\hline & sigma.U & $10 * \operatorname{Beta}(0.8,1.2)$ & 0.676 & 0.185 \\
\hline & sigma.M & $10 * \operatorname{Beta}(1.2,0.8)$ & 0.341 & 0.055 \\
\hline \multirow{4}{*}{4} & beta0 & $3 * \operatorname{Beta}(0.8,1.2)+6$ & 7.670 & 0.227 \\
\hline & beta1 & $6 * \operatorname{Beta}(0.8,1.2)-3$ & 0.065 & 0.023 \\
\hline & sigma.U & $10 * \operatorname{Beta}(0.8,1.2)$ & 0.675 & 0.184 \\
\hline & sigma.M & $10 * \operatorname{Beta}(0.8,1.2)$ & 0.337 & 0.054 \\
\hline \multirow{4}{*}{5} & beta0 & $3 * \operatorname{Beta}(0.8,0.8)+6$ & 7.687 & 0.226 \\
\hline & beta1 & 6*Beta(1.2,1.2)-3 & 0.065 & 0.023 \\
\hline & sigma.U & $10 * \operatorname{Beta}(0.8,0.8)$ & 0.677 & 0.184 \\
\hline & sigma.M & $10 * \operatorname{Beta}(1.2,0.8)$ & 0.341 & 0.055 \\
\hline
\end{tabular}




\section{Appendix B: Data for re-certification calculations}

This Appendix provides all the data obtained from each test that was performed and used for the calculations. The results calculated with these data were generated using a NonNewtonian approach. The viscosity was also calculated as a ratio rather than only a Bingham approximation, as described in Section 6. Also included are the graphs needed for interpretation of the results.

\section{Legend of the tables}

$\mathrm{SR}={ }^{\prime} \Upsilon=$ Shear Rate

SS $=\tau=$ Shear Stress

$\eta=$ Viscosity

$\mathrm{R} 2=\mathrm{r}^{2}$ calculated using a Pearson function to determine the linearity of the data 
Table B-1: 1 Day values for Mix A (NIST Code SR-84)

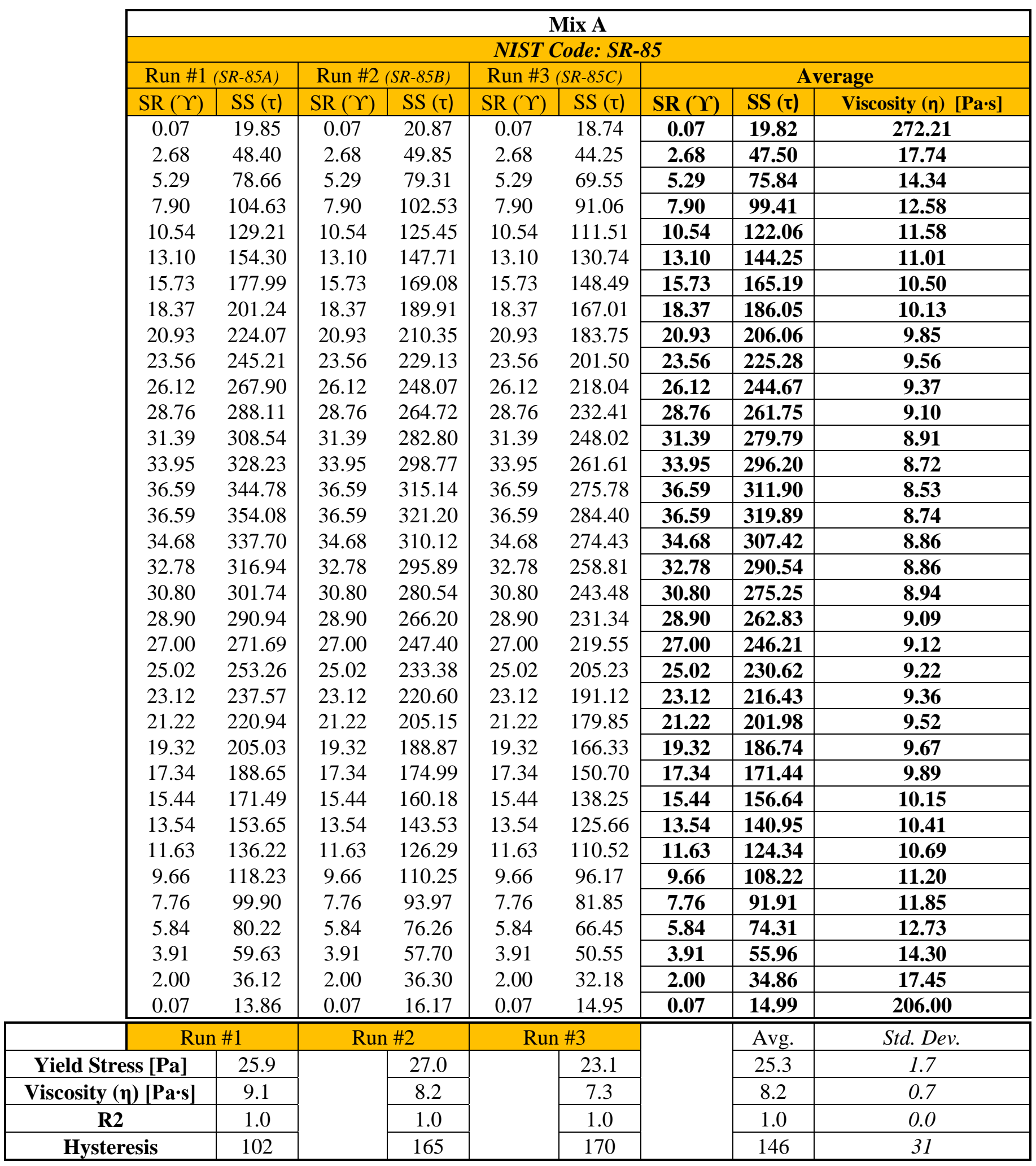


Table B-2: 3 Day values for Mix A (NIST Code: SR-84)

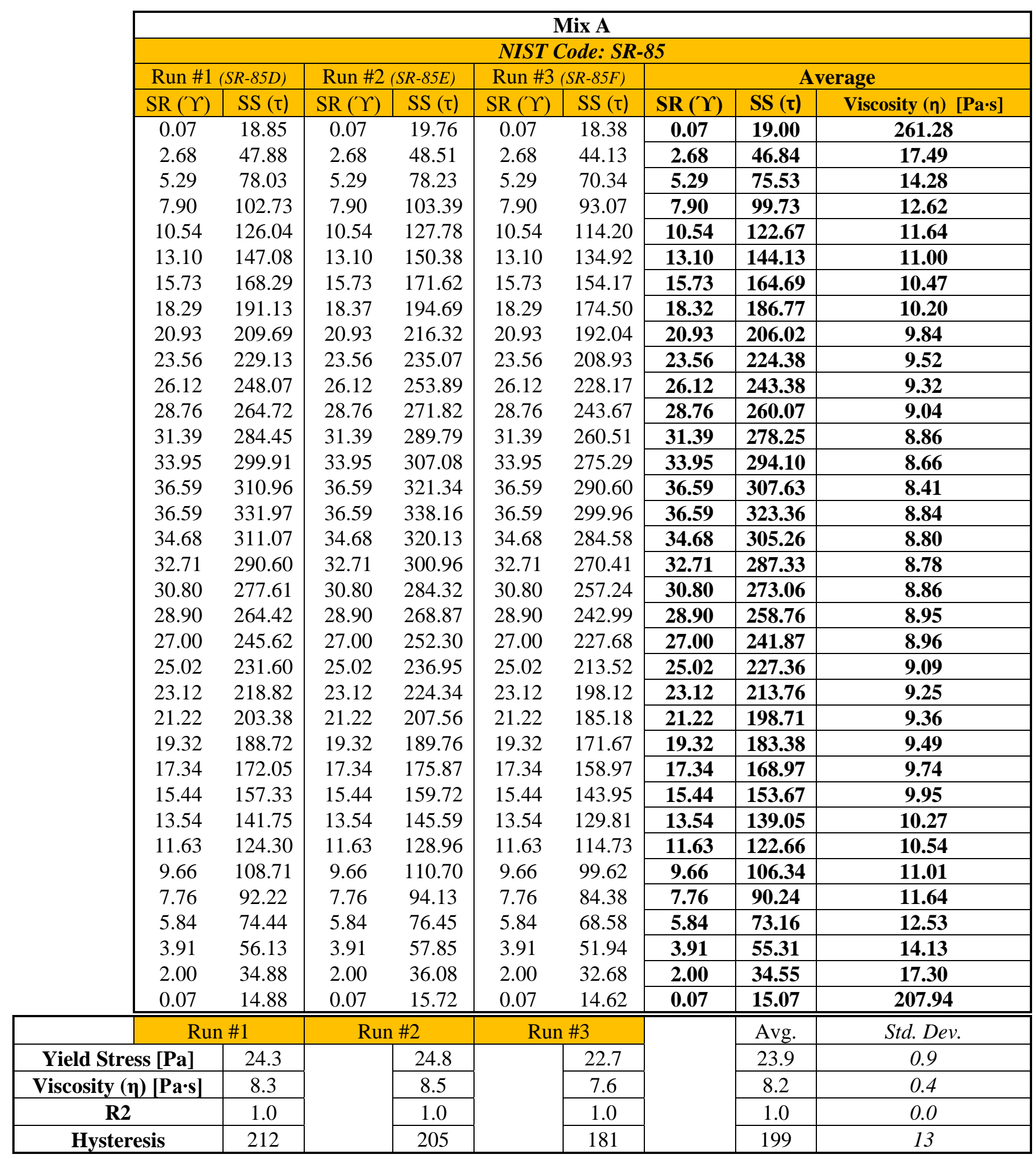


Table B-3: 7 Day values for Mix A (NIST Code: SR-84)

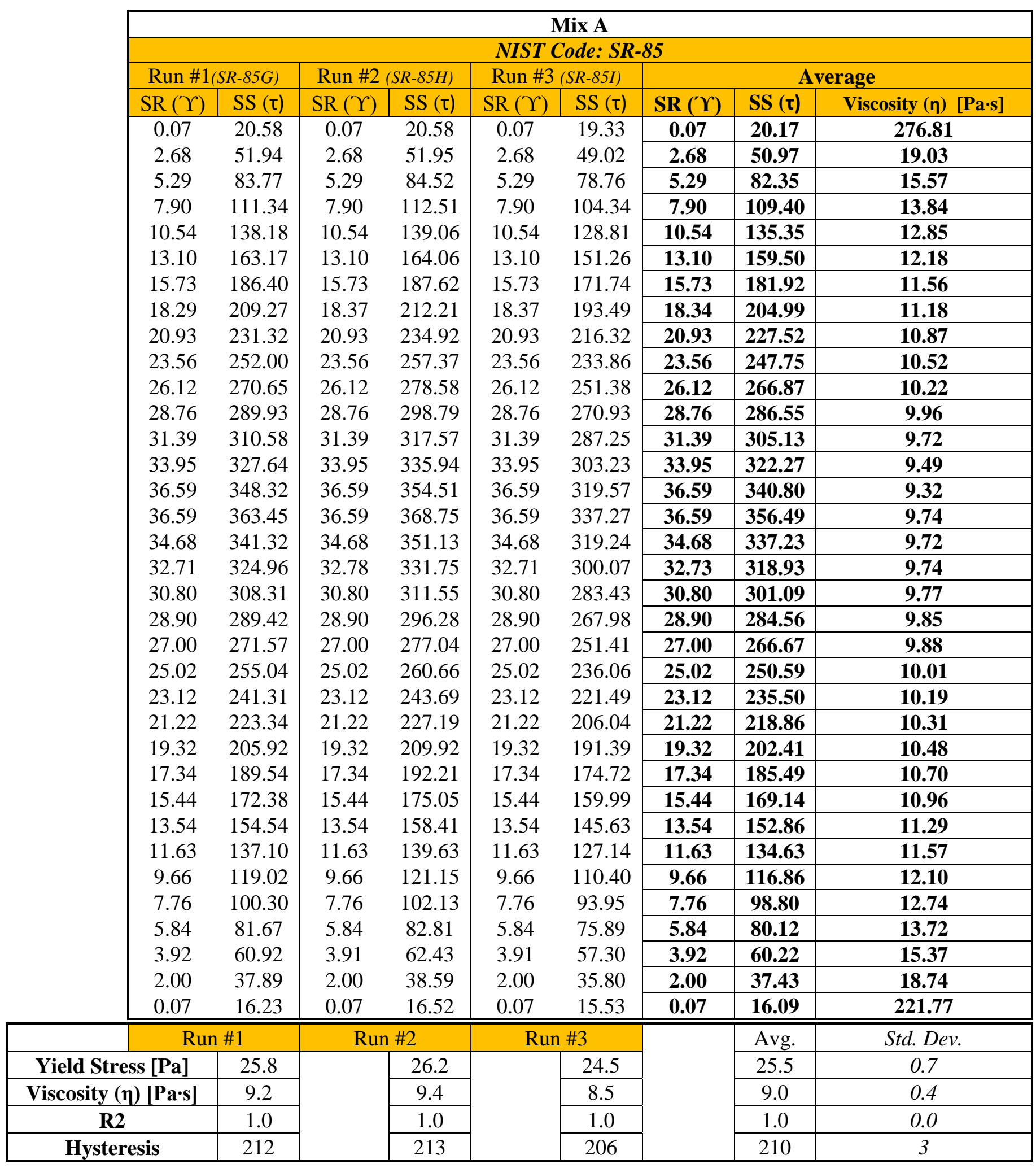




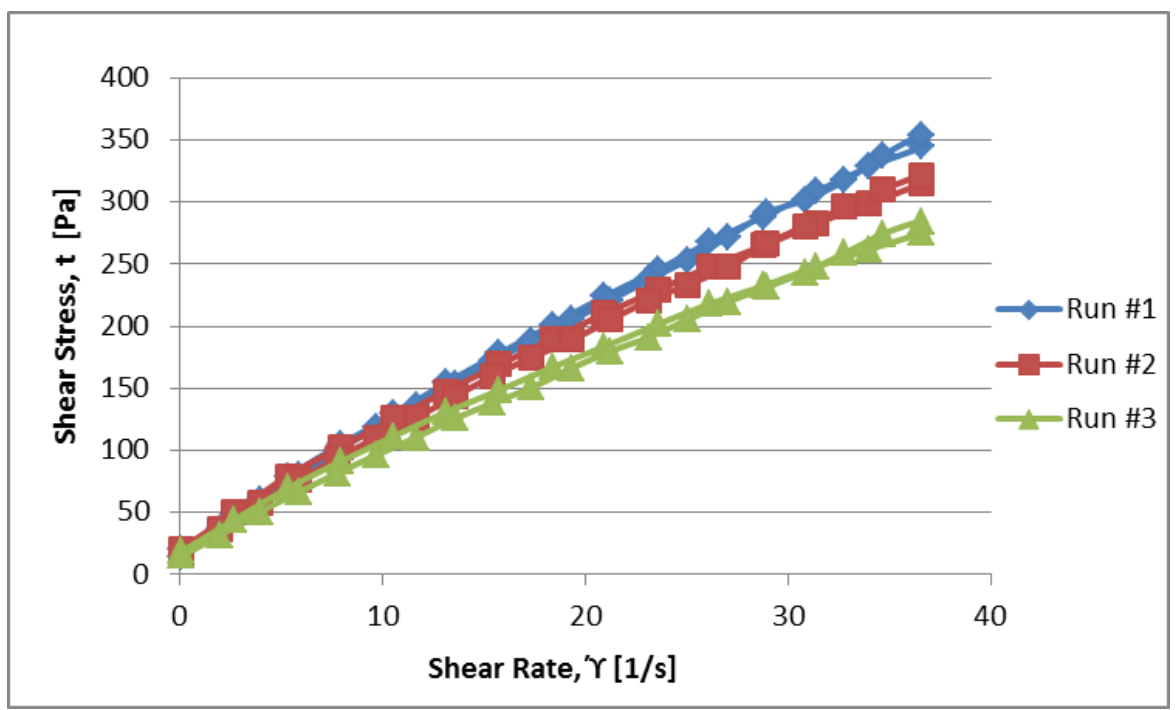

Figure B-1: 1 Day values for Mix A (NIST Code: SR-85)

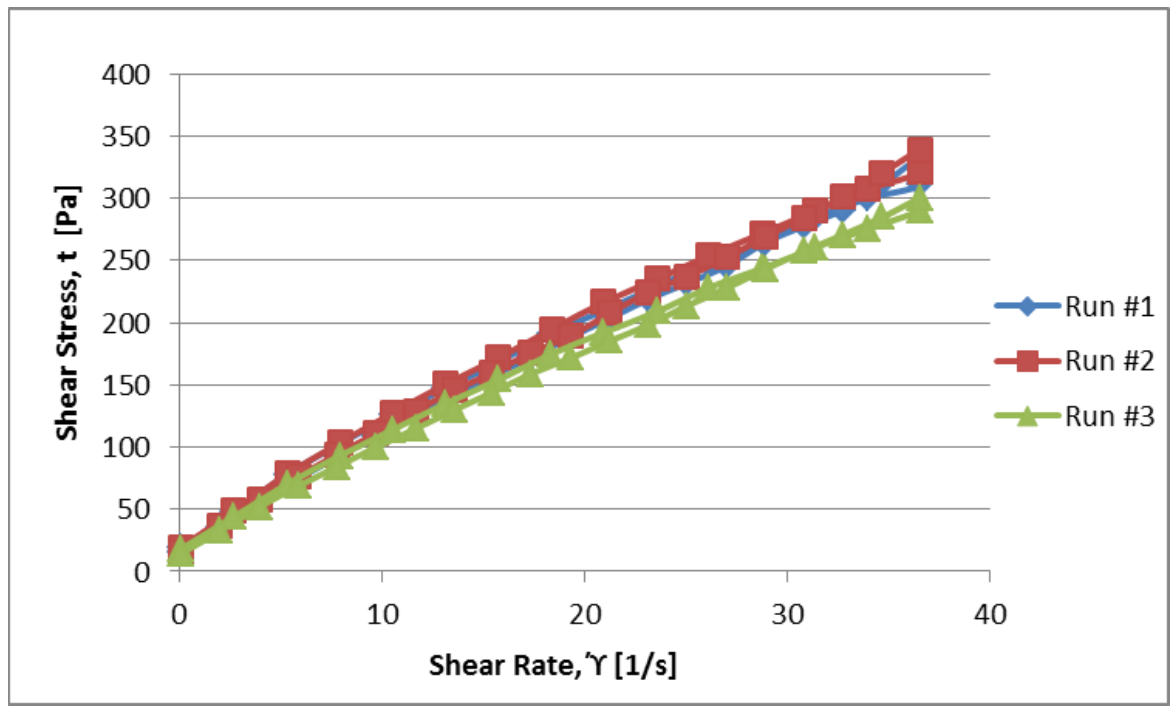

Figure B-2: 3 Day values for Mix A (NIST Code: SR-85)

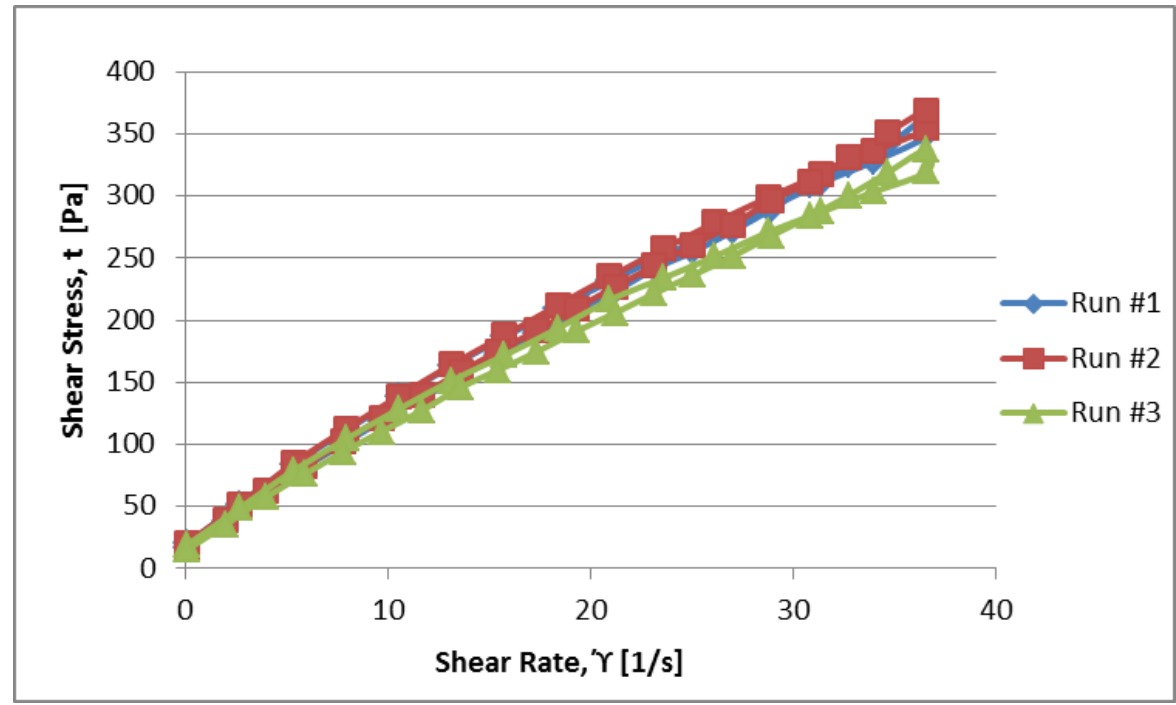

Figure B-3: 7 Day values for Mix A (NIST Code: SR-85)

B - 5 
Table B-4: 1 Day values for Mix B (NIST Code: SR-92)

\begin{tabular}{|c|c|c|c|c|c|c|c|c|}
\hline \multicolumn{9}{|c|}{ Mix B } \\
\hline \multicolumn{9}{|c|}{ NIST Code: SR-93 } \\
\hline \multicolumn{2}{|c|}{ Run \#1 (SR-93A) } & \multicolumn{2}{|c|}{ Run \#2 (SR-93B) } & \multicolumn{2}{|c|}{ Run \#3 (SR-93C) } & \multicolumn{3}{|c|}{ Average } \\
\hline SR (' & $\mathrm{SS}(\tau)$ & SR ('Y) & $\mathrm{SS}(\tau)$ & SR (' () & $\mathrm{SS}(\tau)$ & SR ('T) & SS ( $\tau)$ & Viscosity $(\eta)[P a \cdot s]$ \\
\hline 0.07 & 17.23 & 0.07 & 17.63 & 0.07 & 16.70 & 0.07 & 17.19 & 235.91 \\
\hline 2.68 & 39.03 & 2.68 & 40.42 & 2.68 & 36.36 & 2.68 & 38.60 & 14.41 \\
\hline 5.29 & 63.89 & 5.29 & 65.80 & 5.29 & 57.72 & 5.29 & 62.47 & 11.81 \\
\hline 7.90 & 84.72 & 7.90 & 86.49 & 7.90 & 75.39 & 7.90 & 82.20 & 10.40 \\
\hline 10.54 & 104.90 & 10.54 & 105.54 & 10.54 & 92.86 & 10.54 & 101.10 & 9.60 \\
\hline 13.10 & 124.62 & 13.10 & 124.43 & 13.10 & 110.40 & 13.10 & 119.82 & 9.15 \\
\hline 15.73 & 141.52 & 15.73 & 142.32 & 15.73 & 127.28 & 15.73 & 137.04 & 8.71 \\
\hline 18.37 & 158.71 & 18.29 & 162.89 & 18.29 & 143.29 & 18.32 & 154.96 & 8.46 \\
\hline 20.93 & 177.70 & 20.93 & 176.78 & 20.93 & 158.41 & 20.93 & 170.97 & 8.17 \\
\hline 23.56 & 195.56 & 23.56 & 192.57 & 23.56 & 172.97 & 23.56 & 187.03 & 7.94 \\
\hline 26.12 & 210.66 & 26.12 & 209.30 & 26.12 & 188.50 & 26.12 & 202.82 & 7.76 \\
\hline 28.76 & 226.45 & 28.76 & 223.79 & 28.76 & 201.86 & 28.76 & 217.37 & 7.56 \\
\hline 31.39 & 240.61 & 31.39 & 238.07 & 31.39 & 214.89 & 31.39 & 231.19 & 7.37 \\
\hline 33.95 & 257.45 & 33.95 & 251.77 & 33.95 & 229.23 & 33.95 & 246.15 & 7.25 \\
\hline 36.59 & 269.59 & 36.59 & 262.74 & 36.59 & 242.38 & 36.59 & 258.24 & 7.06 \\
\hline 36.59 & 277.32 & 36.59 & 275.55 & 36.59 & 250.26 & 36.59 & 267.71 & 7.32 \\
\hline 34.68 & 263.24 & 34.68 & 261.46 & 34.68 & 237.44 & 34.68 & 254.05 & 7.32 \\
\hline 32.71 & 250.25 & 32.71 & 245.83 & 32.71 & 223.00 & 32.71 & 239.70 & 7.33 \\
\hline 30.80 & 238.18 & 30.80 & 235.03 & 30.80 & 213.29 & 30.80 & 228.83 & 7.43 \\
\hline 28.90 & 225.11 & 28.90 & 224.22 & 28.90 & 201.27 & 28.90 & 216.87 & 7.50 \\
\hline 27.00 & 211.08 & 27.00 & 207.97 & 27.00 & 189.90 & 27.00 & 202.99 & 7.52 \\
\hline 25.02 & 198.10 & 25.02 & 196.31 & 25.02 & 180.01 & 25.02 & 191.47 & 7.65 \\
\hline 23.12 & 185.77 & 23.12 & 185.77 & 23.12 & 166.86 & 23.12 & 179.47 & 7.76 \\
\hline 21.22 & 172.70 & 21.22 & 172.70 & 21.22 & 156.29 & 21.22 & 167.23 & 7.88 \\
\hline 19.32 & 158.92 & 19.32 & 158.92 & 19.32 & 145.28 & 19.32 & 154.37 & 7.99 \\
\hline 17.34 & 145.93 & 17.34 & 147.40 & 17.34 & 133.47 & 17.34 & 142.27 & 8.20 \\
\hline 15.44 & 134.70 & 15.44 & 133.53 & 15.44 & 123.25 & 15.44 & 130.49 & 8.45 \\
\hline 13.54 & 120.54 & 13.54 & 120.46 & 13.54 & 110.89 & 13.54 & 117.30 & 8.67 \\
\hline 11.63 & 106.83 & 11.63 & 106.53 & 11.63 & 97.87 & 11.63 & 103.74 & 8.92 \\
\hline 9.66 & 93.59 & 9.66 & 92.93 & 9.66 & 85.46 & 9.66 & 90.66 & 9.39 \\
\hline 7.76 & 79.55 & 7.76 & 79.07 & 7.76 & 72.62 & 7.76 & 77.08 & 9.94 \\
\hline 5.84 & 64.59 & 5.84 & 64.35 & 5.84 & 59.36 & 5.84 & 62.76 & 10.75 \\
\hline 3.91 & 49.16 & 3.91 & 48.79 & 3.91 & 45.44 & 3.91 & 47.80 & 12.21 \\
\hline 2.00 & 31.32 & 2.00 & 31.06 & 2.00 & 29.12 & 2.00 & 30.50 & 15.27 \\
\hline 0.07 & 14.48 & 0.07 & 14.11 & 0.07 & 13.78 & $\mathbf{0 . 0 7}$ & 14.13 & 195.59 \\
\hline \multicolumn{2}{|c|}{ Run \#1 } & \multicolumn{2}{|c|}{ Run \#2 } & \multicolumn{2}{|c|}{ Run \#3 } & & Avg. & Std. Dev. \\
\hline ess [Pa] & 22.3 & & 22.6 & & 21.8 & & 22.2 & 0.3 \\
\hline ty $(\eta)$ & 7.0 & & 7.0 & & 6.3 & & 6.8 & 0.3 \\
\hline$\underline{z}$ & 1.0 & & 1.0 & & 1.0 & & 1.0 & 0.0 \\
\hline resis & 131 & & 144 & & 55 & & 110 & 39 \\
\hline
\end{tabular}


Table B-5: 3 Day values for Mix B (NIST Code: SR-92)

\begin{tabular}{|c|c|c|c|c|c|c|c|c|c|}
\hline & \multicolumn{9}{|c|}{ Mix B } \\
\hline & \multicolumn{9}{|c|}{ NIST Code: SR-93 } \\
\hline & \multicolumn{2}{|c|}{ Run \#1 (SR-93E) } & \multicolumn{2}{|c|}{ Run \#2 (SR-93F) } & \multicolumn{2}{|c|}{ Run \#3 (SR-93G) } & \multicolumn{3}{|c|}{ Average } \\
\hline & SR $(' \Upsilon)$ & $\mathrm{SS}(\tau)$ & SR ('Y) & $\mathrm{SS}(\tau)$ & SR (' () & $\mathrm{SS}(\tau)$ & SR ('Y) & SS ( $\tau)$ & Viscosity (n) [Pa·s] \\
\hline & 0.07 & 16.07 & 0.07 & 15.66 & 0.07 & 17.69 & 0.07 & 16.47 & 225.57 \\
\hline & 2.68 & 38.58 & 2.68 & 37.04 & 2.68 & 41.99 & 2.68 & 39.20 & 14.64 \\
\hline & 5.29 & 65.56 & 5.29 & 61.03 & 5.29 & 68.23 & 5.29 & 64.94 & 12.28 \\
\hline & 7.90 & 87.22 & 7.90 & 80.72 & 7.90 & 90.80 & 7.90 & 86.25 & 10.91 \\
\hline & 10.54 & 107.91 & 10.54 & 99.30 & 10.54 & 112.40 & 10.54 & 106.54 & 10.11 \\
\hline & 13.10 & 128.27 & 13.10 & 118.14 & 13.10 & 131.37 & 13.10 & 125.93 & 9.61 \\
\hline & 15.73 & 147.96 & 15.73 & 136.95 & 15.73 & 151.51 & 15.73 & 145.47 & 9.25 \\
\hline & 18.29 & 168.28 & 18.37 & 155.46 & 18.29 & 170.92 & 18.32 & 164.89 & 9.00 \\
\hline & 20.93 & 186.87 & 20.93 & 172.19 & 20.93 & 189.25 & 20.93 & 182.77 & 8.73 \\
\hline & 23.56 & 205.08 & 23.56 & 188.73 & 23.56 & 210.14 & 23.56 & 201.32 & 8.54 \\
\hline & 26.12 & 224.20 & 26.12 & 203.96 & 26.12 & 226.39 & 26.12 & 218.18 & 8.35 \\
\hline & 28.76 & 240.98 & 28.76 & 218.46 & 28.76 & 241.89 & 28.76 & 233.78 & 8.13 \\
\hline & 31.39 & 257.71 & 31.39 & 234.38 & 31.39 & 258.73 & 31.39 & 250.27 & 7.97 \\
\hline & 33.95 & 275.63 & 33.95 & 251.22 & 33.95 & 273.51 & 33.95 & 266.79 & 7.86 \\
\hline & 36.59 & 292.15 & 36.59 & 263.39 & 36.59 & 288.83 & 36.59 & 281.46 & 7.69 \\
\hline & 36.59 & 292.37 & 36.59 & 266.19 & 36.59 & 298.19 & 36.59 & 285.58 & 7.81 \\
\hline & 34.68 & 278.37 & 34.68 & 253.47 & 34.68 & 282.80 & 34.68 & 271.55 & 7.83 \\
\hline & 32.71 & 268.03 & 32.71 & 244.31 & 32.71 & 265.99 & 32.71 & 259.45 & 7.93 \\
\hline & 30.80 & 254.69 & 30.80 & 232.06 & 30.80 & 254.09 & 30.80 & 246.95 & 8.02 \\
\hline & 28.90 & 239.36 & 28.90 & 217.92 & 28.90 & 242.10 & 28.90 & 233.12 & 8.07 \\
\hline & 27.00 & 227.55 & 27.00 & 207.39 & 27.00 & 224.57 & 27.00 & 219.84 & 8.14 \\
\hline & 25.02 & 215.30 & 25.02 & 194.27 & 25.02 & 211.73 & 25.02 & 207.10 & 8.28 \\
\hline & 23.12 & 199.90 & 23.12 & 183.22 & 23.12 & 200.07 & 23.12 & 194.40 & 8.41 \\
\hline & 21.22 & 186.96 & 21.22 & 171.81 & 21.22 & 185.81 & 21.22 & 181.53 & 8.55 \\
\hline & 19.32 & 173.45 & 19.32 & 158.03 & 19.32 & 170.78 & 19.32 & 167.42 & 8.67 \\
\hline & 17.34 & 159.28 & 17.34 & 145.04 & 17.34 & 156.61 & 17.34 & 153.64 & 8.86 \\
\hline & 15.44 & 146.90 & 15.44 & 132.46 & 15.44 & 144.24 & 15.44 & 141.20 & 9.15 \\
\hline & 13.54 & 132.51 & 13.54 & 120.70 & 13.54 & 129.85 & 13.54 & 127.69 & 9.43 \\
\hline & 11.63 & 116.40 & 11.63 & 106.71 & 11.63 & 113.53 & 11.63 & 112.21 & 9.65 \\
\hline & 9.66 & 101.68 & 9.66 & 92.62 & 9.66 & 98.72 & 9.66 & 97.67 & 10.11 \\
\hline & 7.76 & 86.34 & 7.76 & 78.83 & 7.76 & 83.88 & 7.76 & 83.02 & 10.70 \\
\hline & 5.84 & 70.30 & 5.84 & 64.03 & 5.84 & 67.88 & 5.84 & 67.40 & 11.54 \\
\hline & 3.91 & 53.13 & 3.91 & 48.52 & 3.91 & 51.34 & 3.91 & 50.99 & 13.03 \\
\hline & 2.00 & 33.24 & 2.00 & 30.55 & 2.00 & 32.47 & 2.00 & 32.08 & 16.06 \\
\hline & 0.07 & 14.56 & 0.07 & 13.66 & 0.07 & 14.61 & 0.07 & 14.28 & 196.23 \\
\hline & \multicolumn{2}{|c|}{ Run \#1 } & \multicolumn{2}{|c|}{ Run \#2 } & \multicolumn{2}{|c|}{ Run \#3 } & & Avg. & Std. Dev. \\
\hline Yield Str & ess [Pa] & 25.9 & & 23.8 & & 22.8 & & 24.2 & 1.3 \\
\hline $\begin{array}{r}\text { Viscos } \\
{[\mathrm{Pa}} \\
\end{array}$ & $\begin{array}{l}\text { ty }(\eta) \\
s]\end{array}$ & 7.5 & & 6.8 & & 7.6 & & 7.3 & 0.3 \\
\hline $\mathbf{R}$ & & 1.0 & & 1.0 & & 1.0 & & 1.0 & 0.0 \\
\hline Hyste & esis & 17 & & 46 & & 147 & & 70 & 56 \\
\hline
\end{tabular}


Table B-6: 7 Day values for Mix B (NIST Code: SR-92)

*Data was taken at 8 days due to snow on day 7.

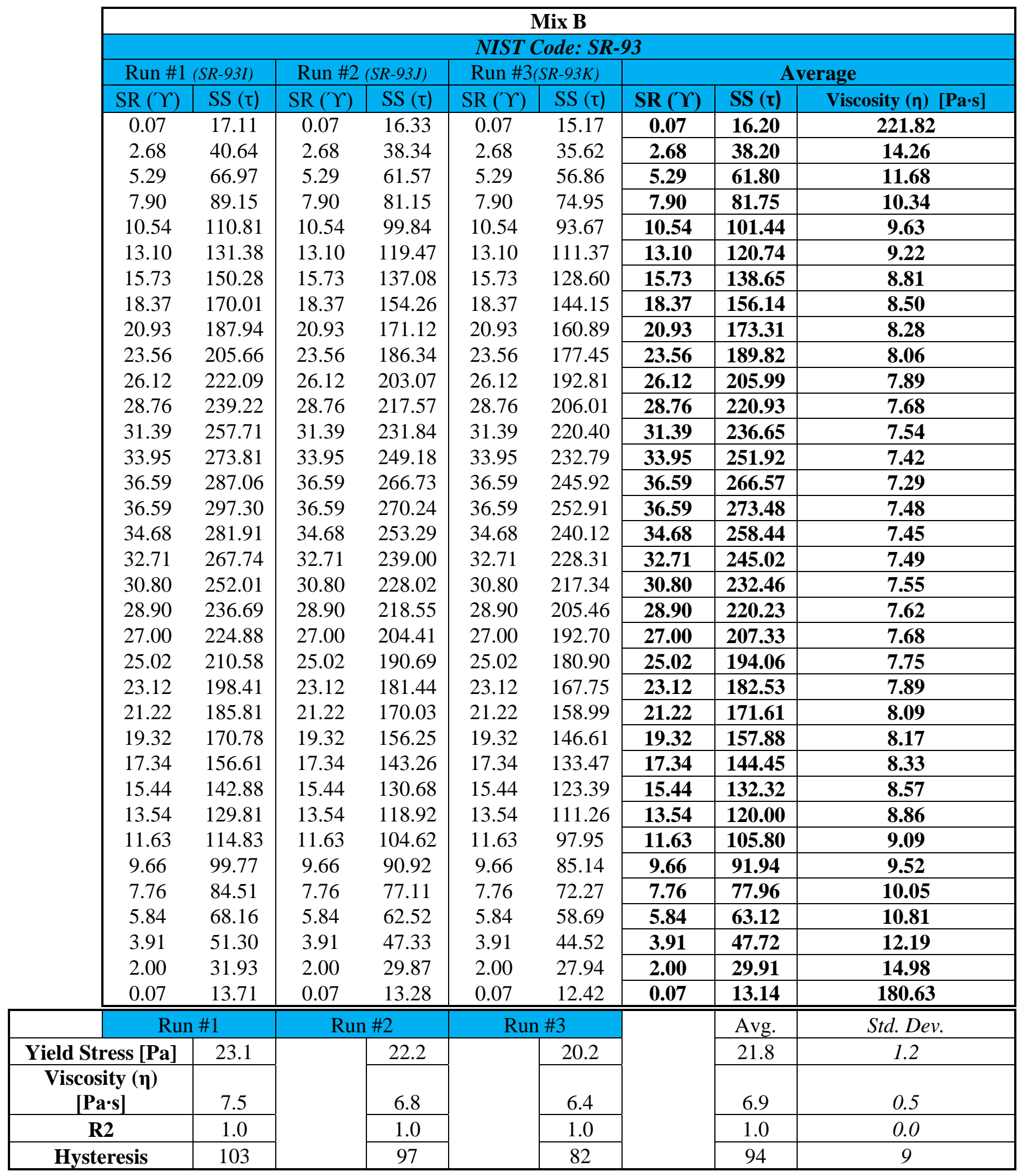




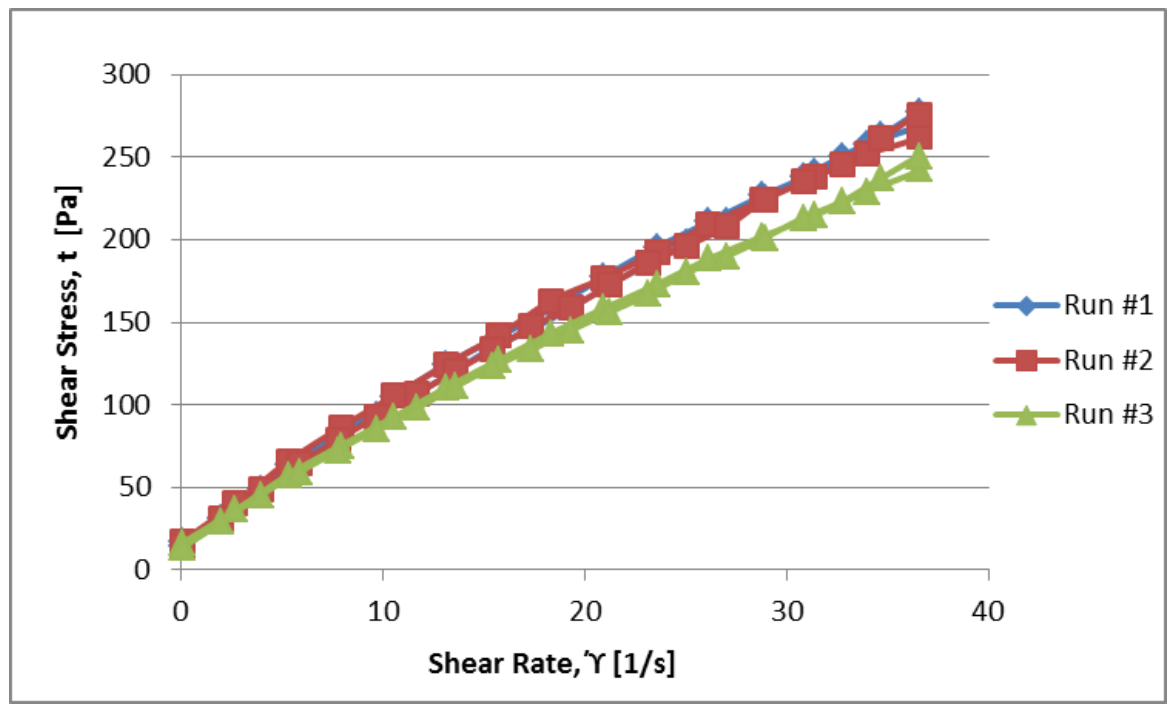

Figure B-4: 1 Day values for Mix B (NIST Code: SR-93)

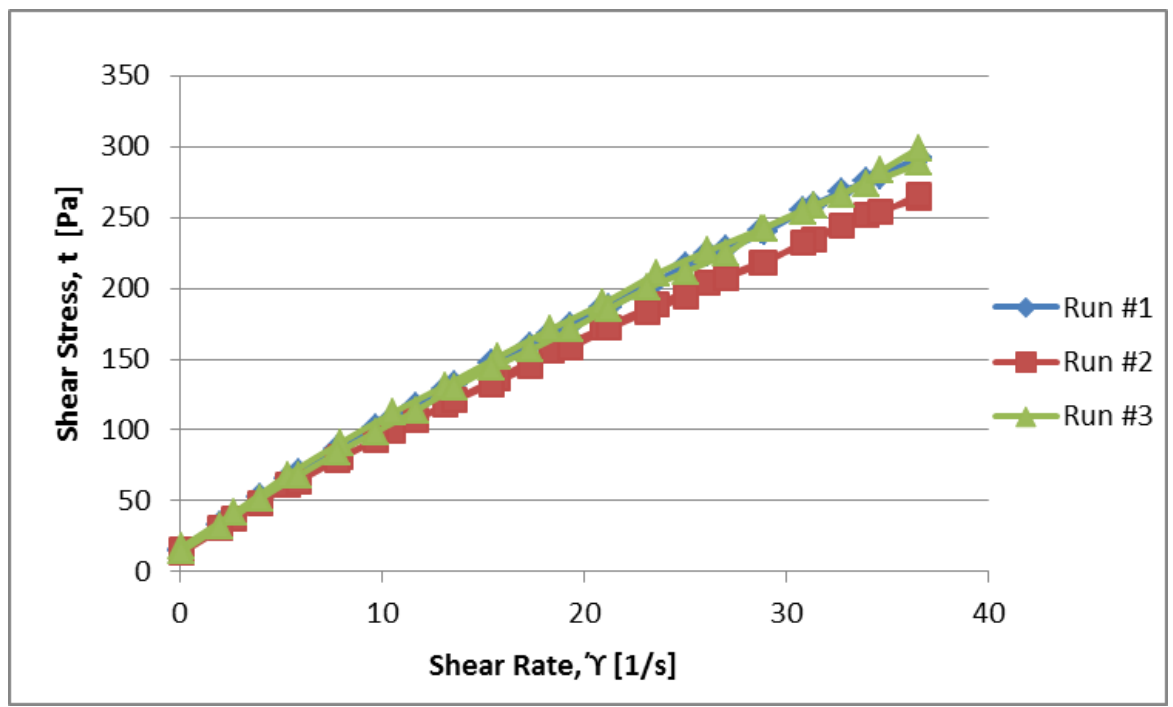

Figure B-5: 3 Day values for Mix B (NIST Code: SR-93)

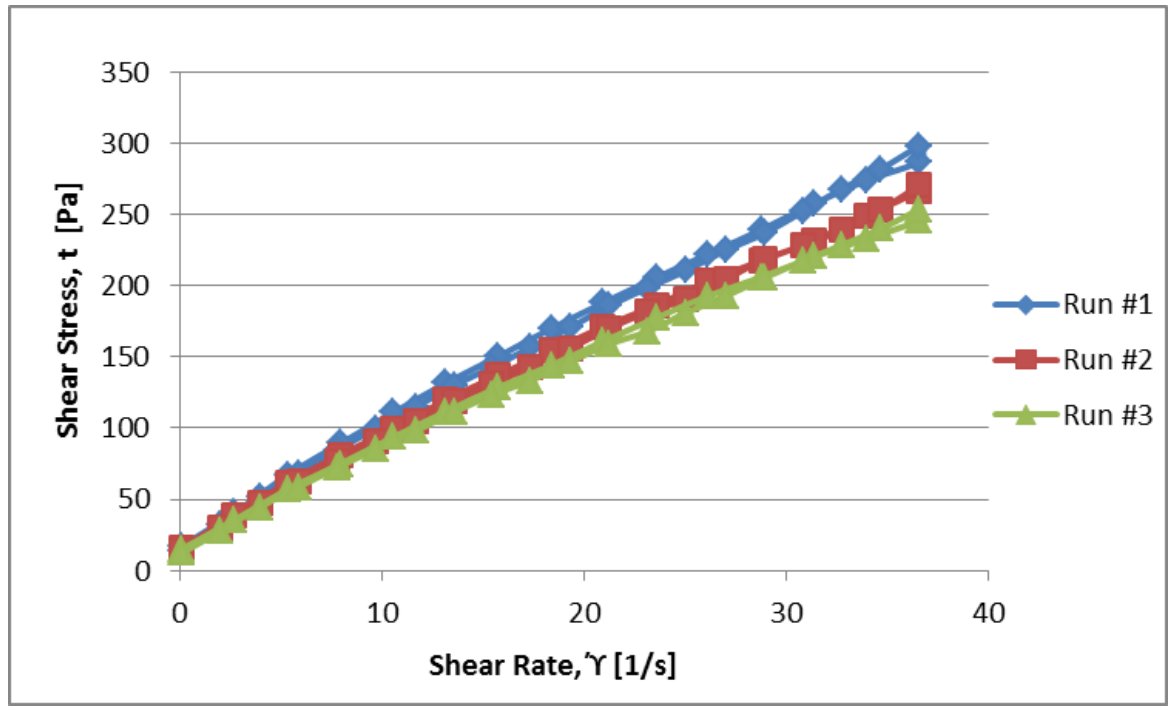

Figure B-6: $\quad$ 7*Day values for Mix B (NIST Code: SR-93)

B - 9 
Table B-7: 1 Day values for Mix C (NIST Code: SR-82)

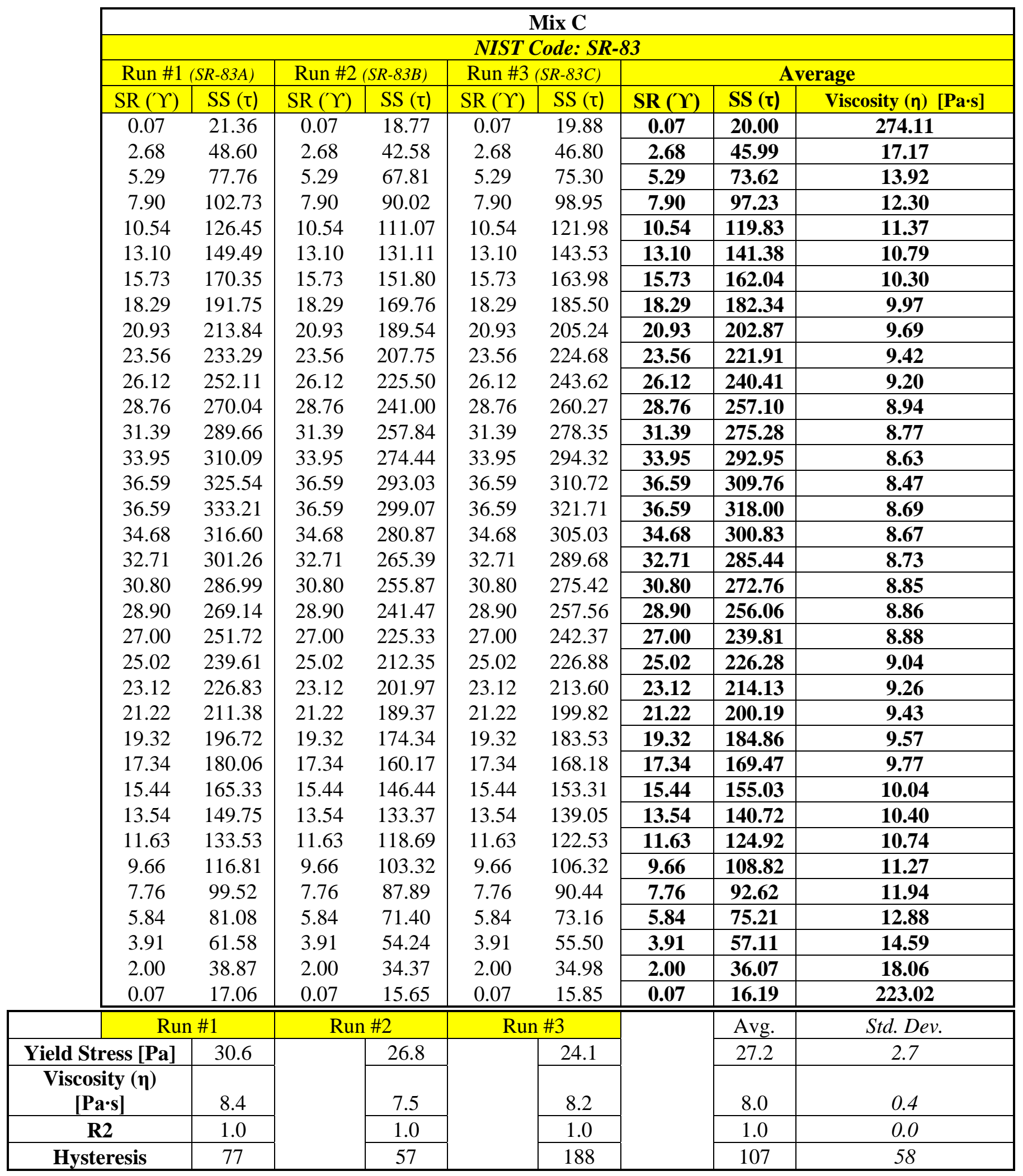


Table B-8: 3 Day values for Mix C (NIST Code: SR-82)

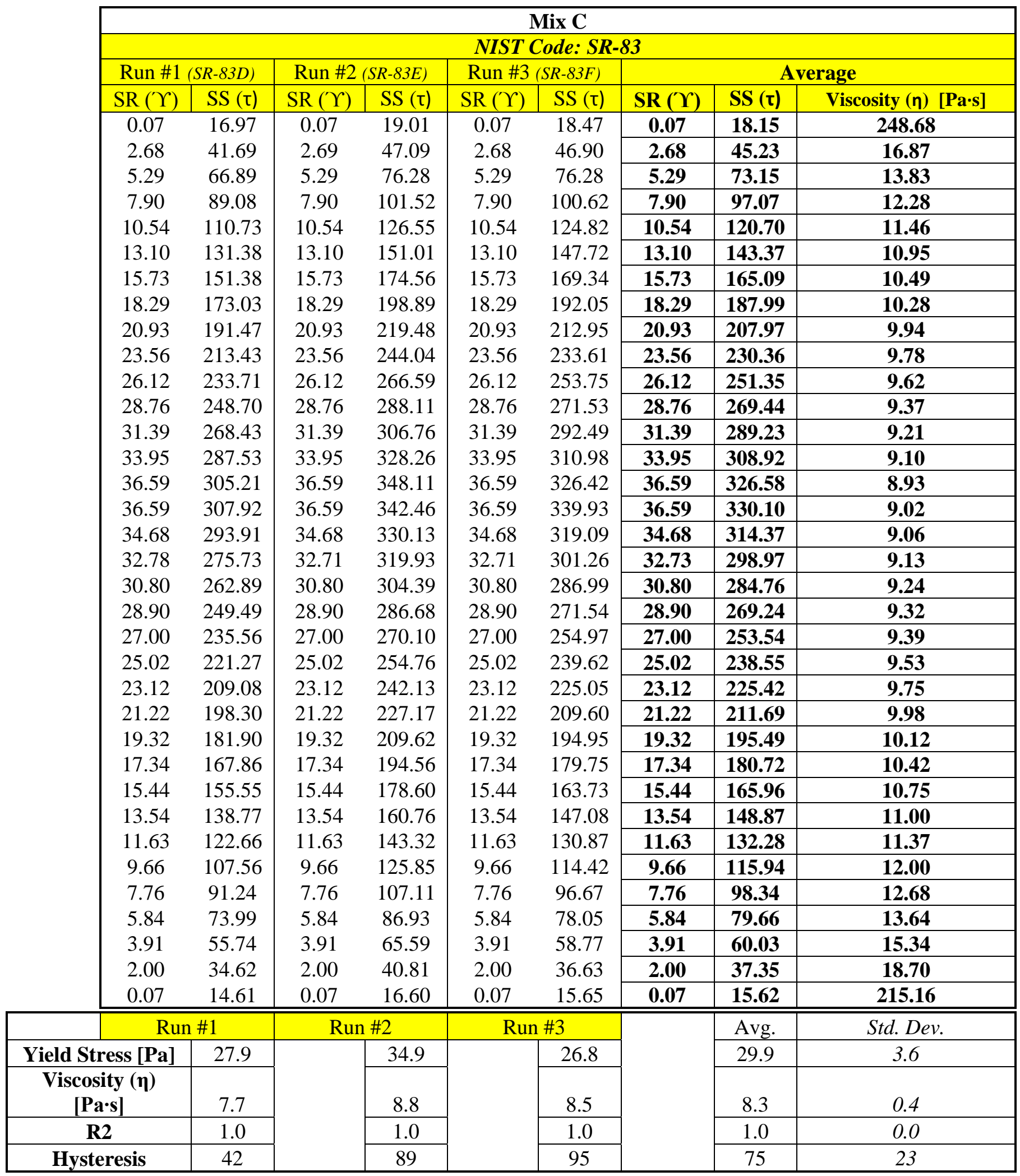


Table B-9: 7 Day values for Mix C (NIST Code: SR-82)

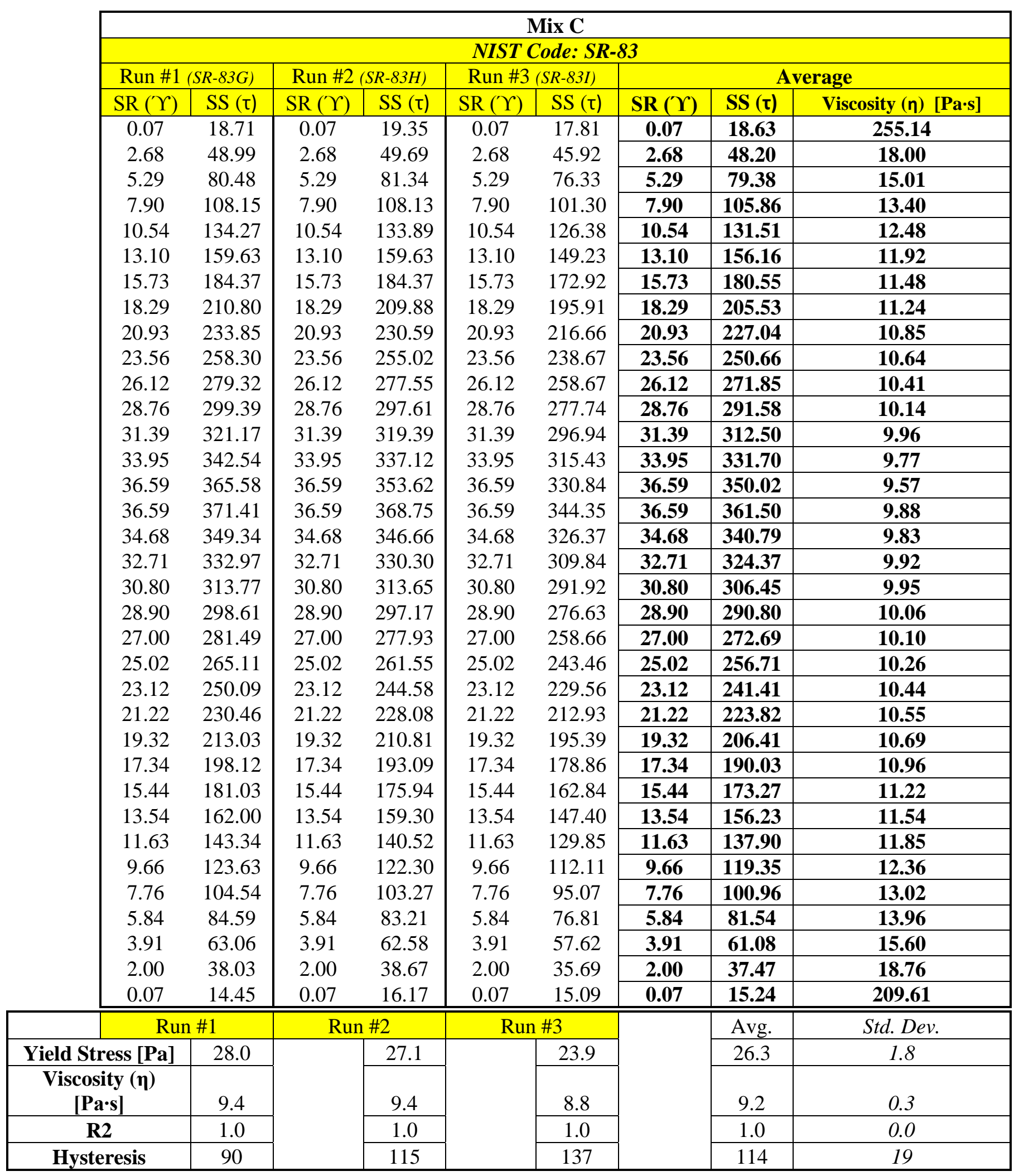




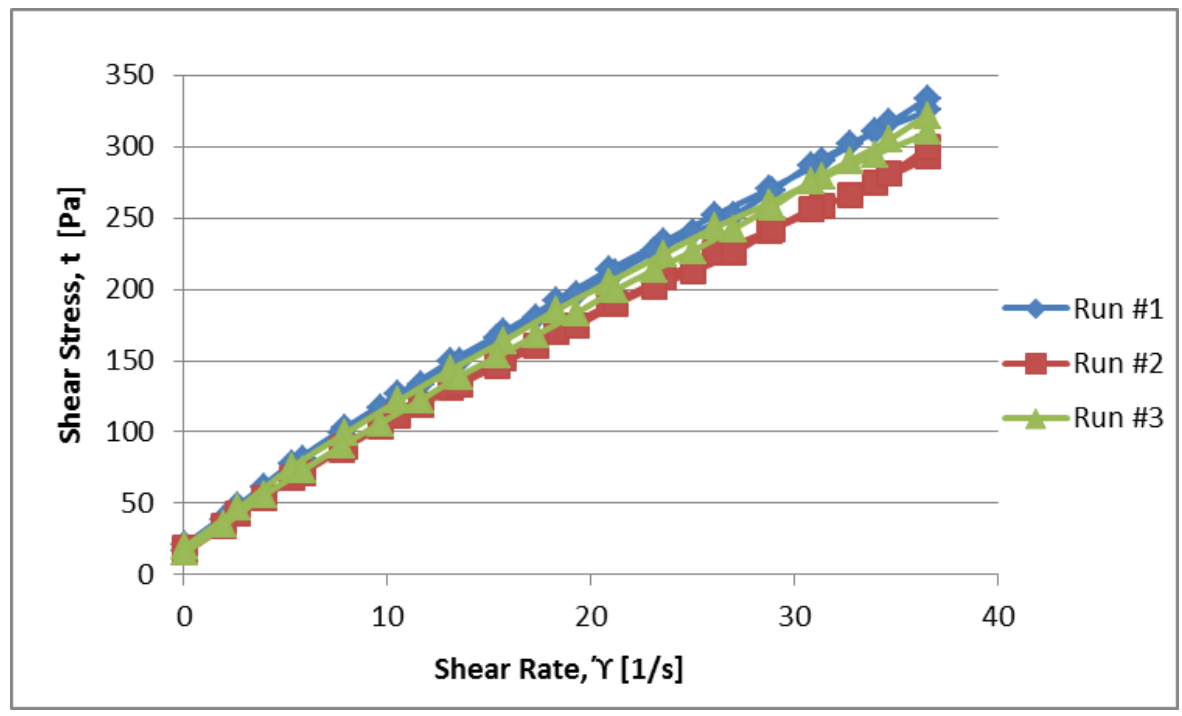

Figure B-7: 1 Day values for Mix C (NIST Code: SR-83)

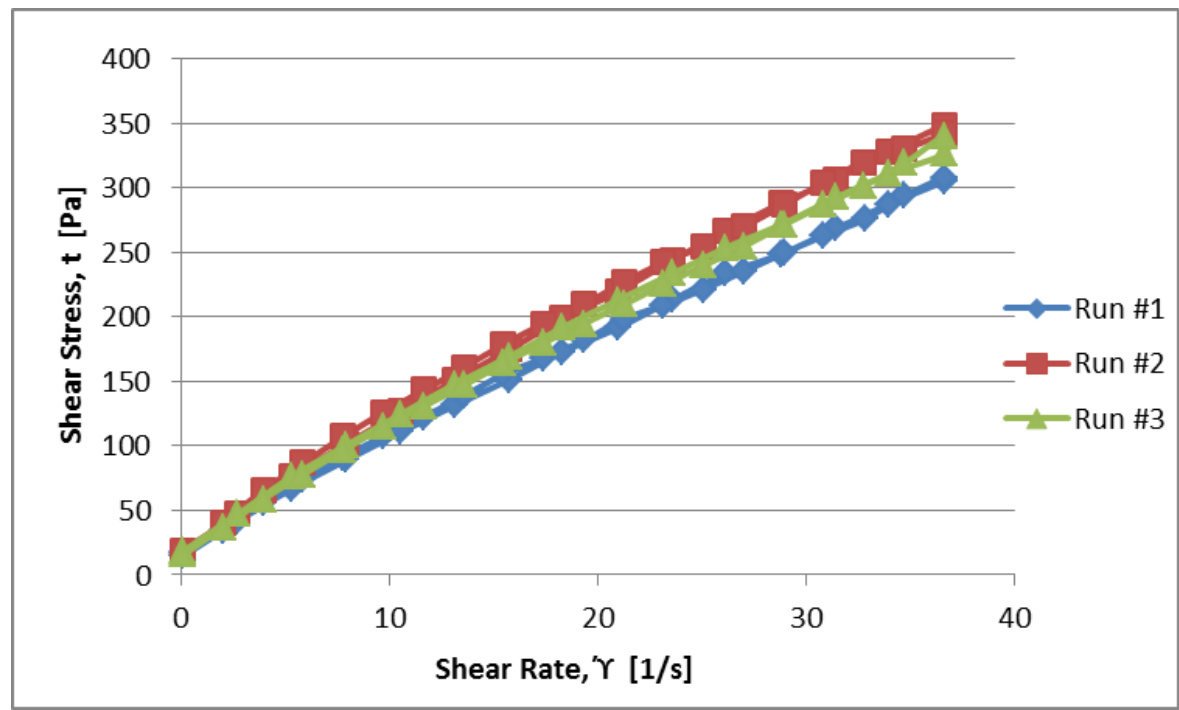

Figure B-8: 3 Day values for Mix C (NIST Code: SR-83)

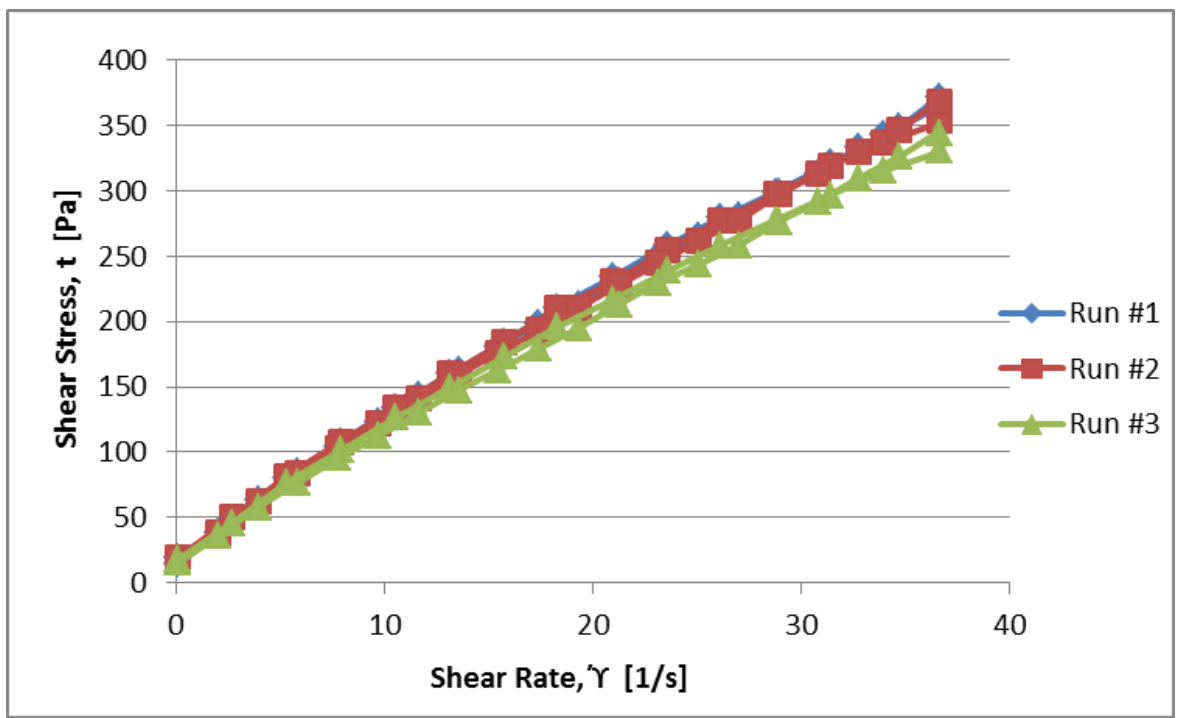

Figure B-9: 7 Day values for Mix C (NIST Code: SR-83)

B - 13 
Table B-10: 1 Day values for Mix D (NIST Code: SR-86)

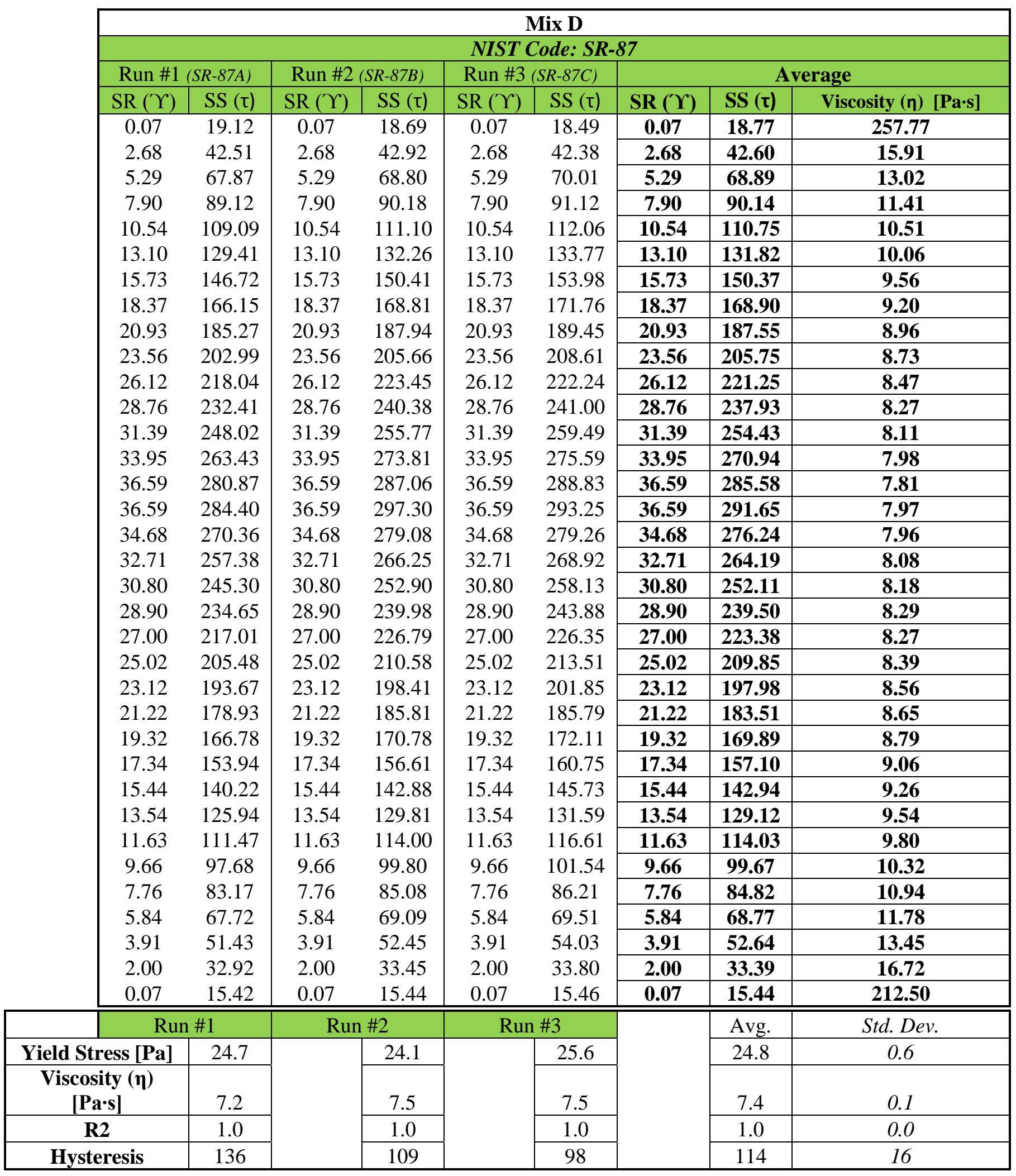


Table B-11: 3 Day values for Mix D (NIST Code: SR-86)

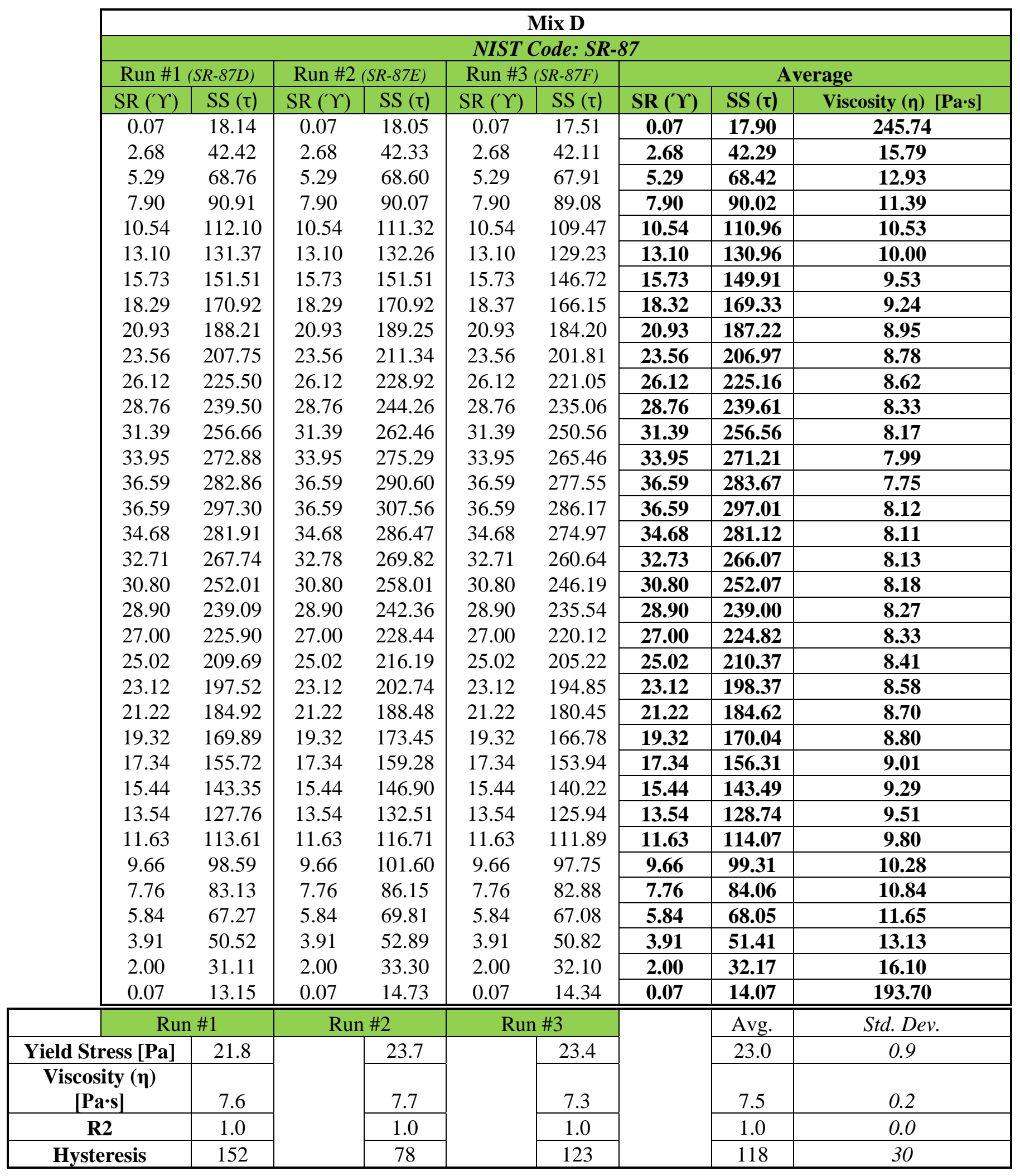


Table B-12: 7 Day values for Mix D (NIST Code: SR-86)

*Data was taken at 8 days due to snow on day 7.

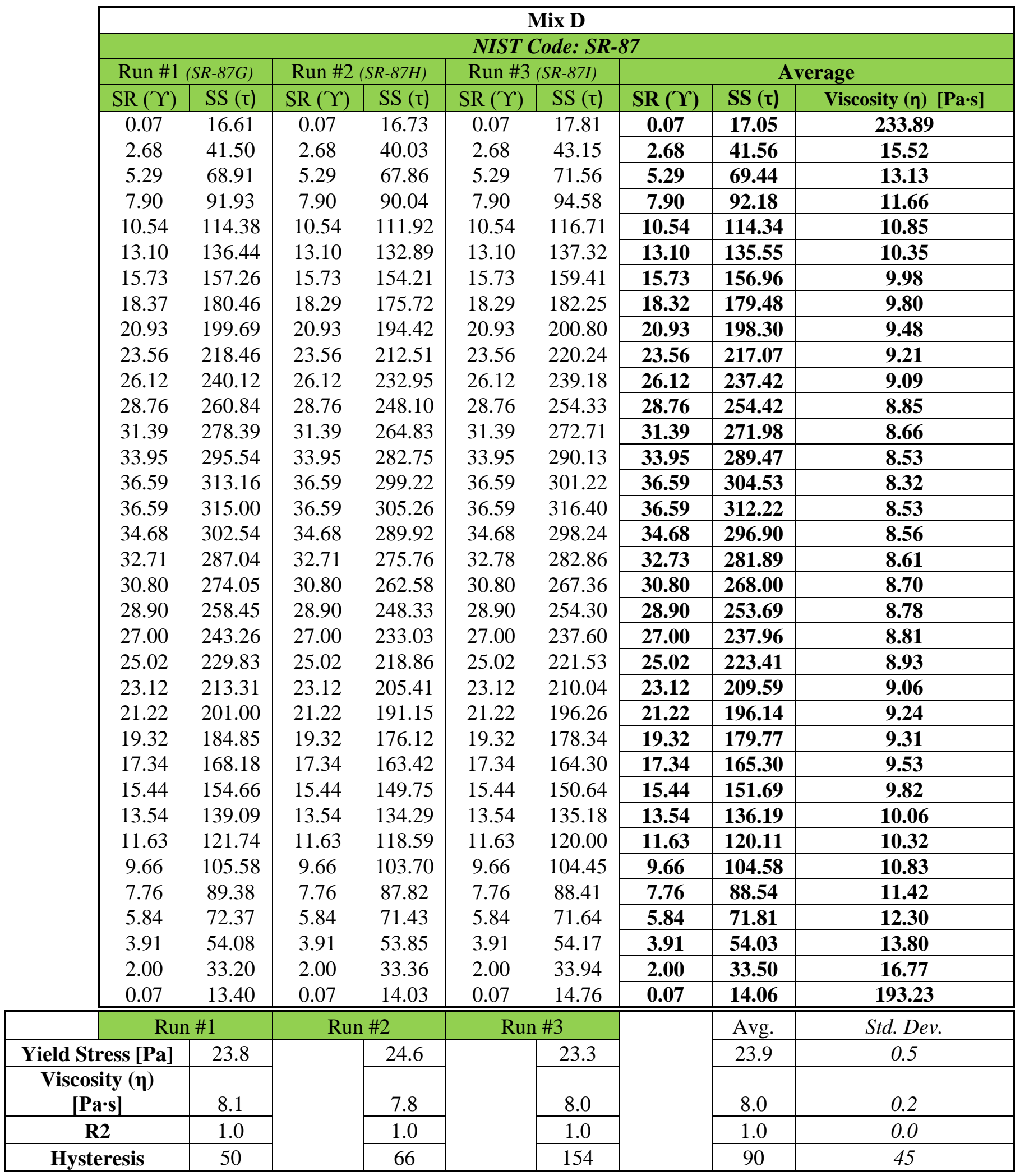




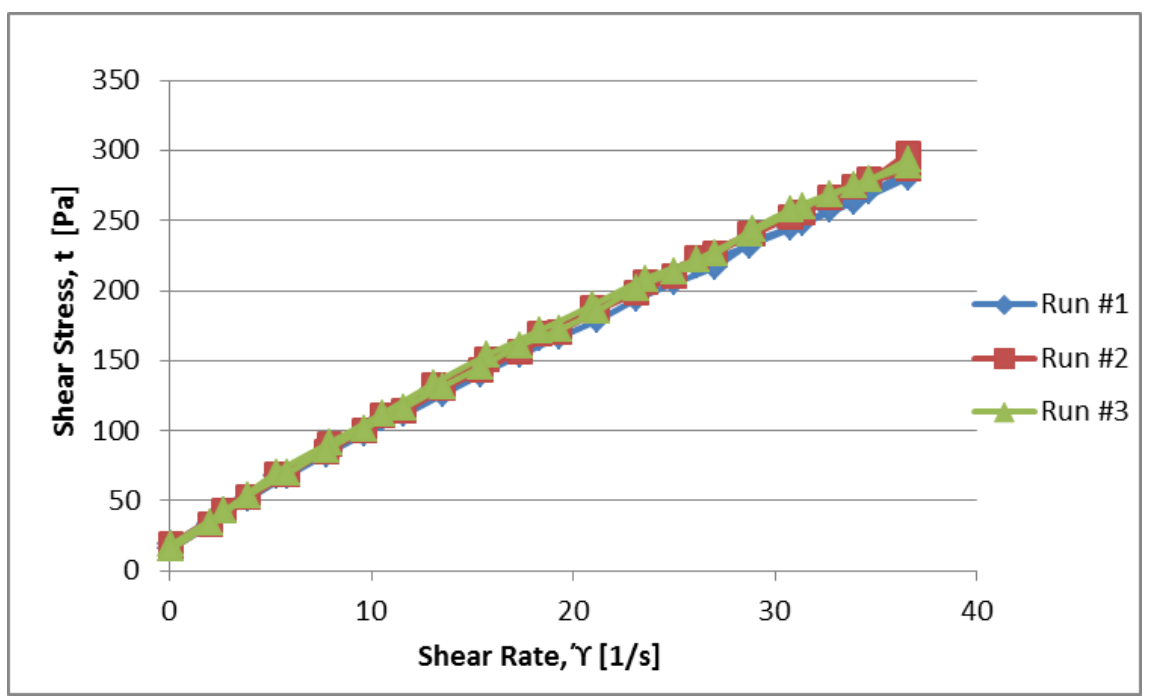

Figure B-10: 1 Day values for Mix D (NIST Code: SR-87)

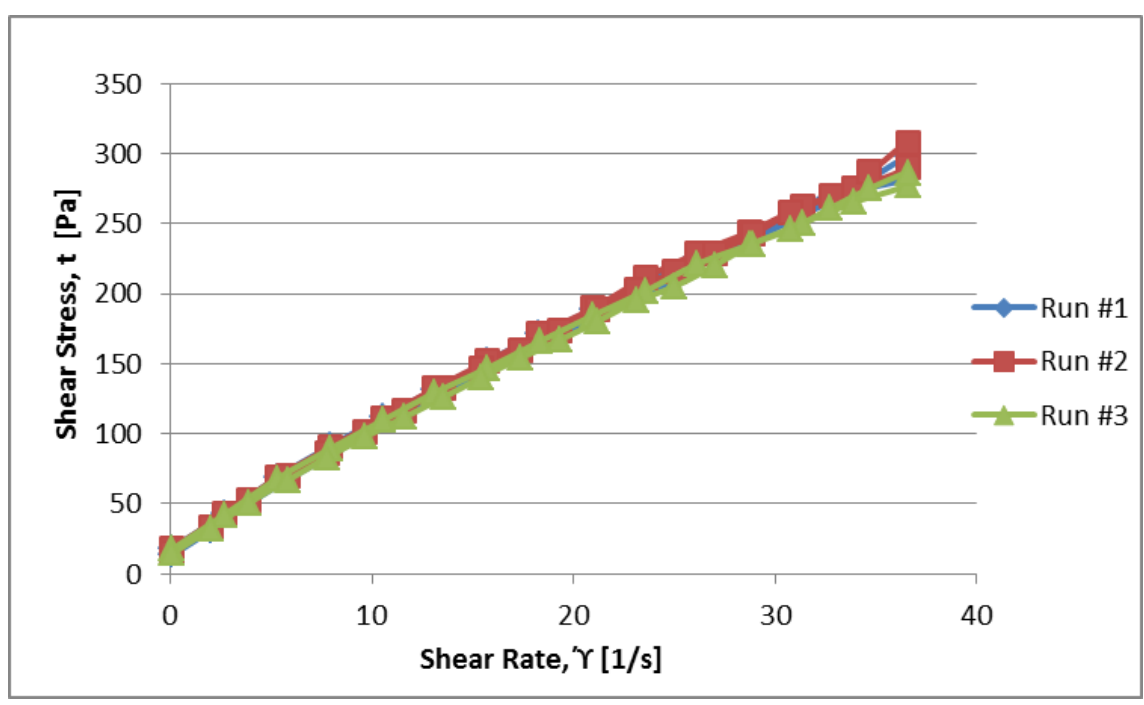

Figure B-11： 3 Day values for Mix D (NIST Code: SR-87)

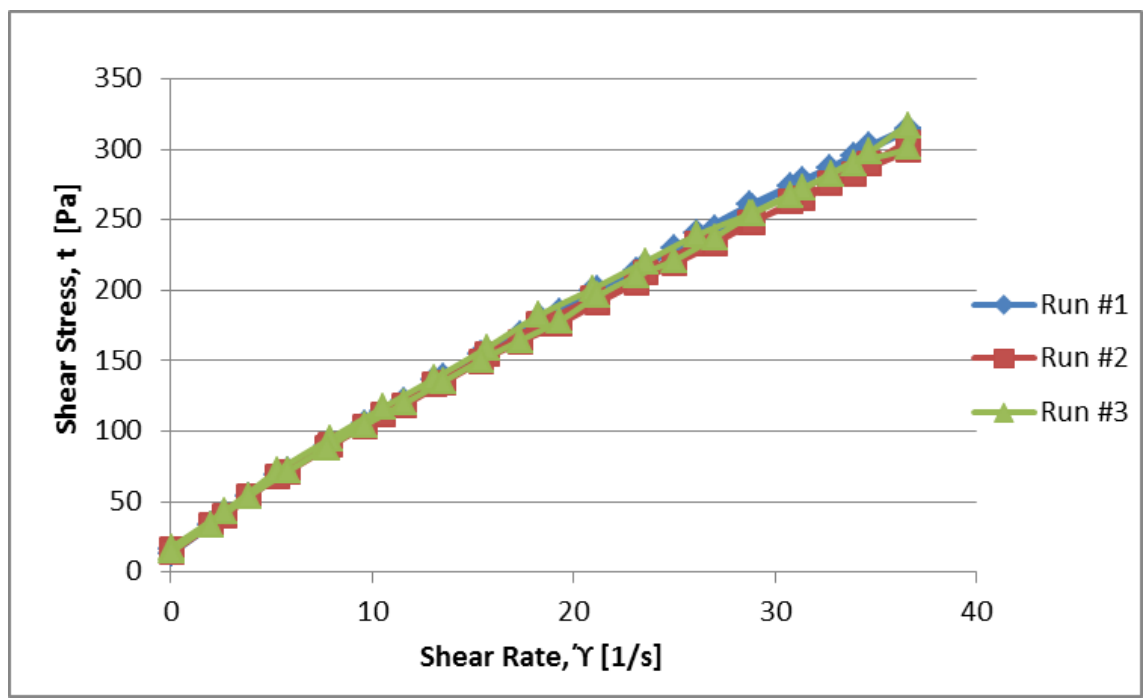

Figure B-12: $7 *$ Day values for Mix D (NIST Code: SR-87)

B - 17 
Table B-13: 1 Day values for Mix E (NIST Code: SR-88)

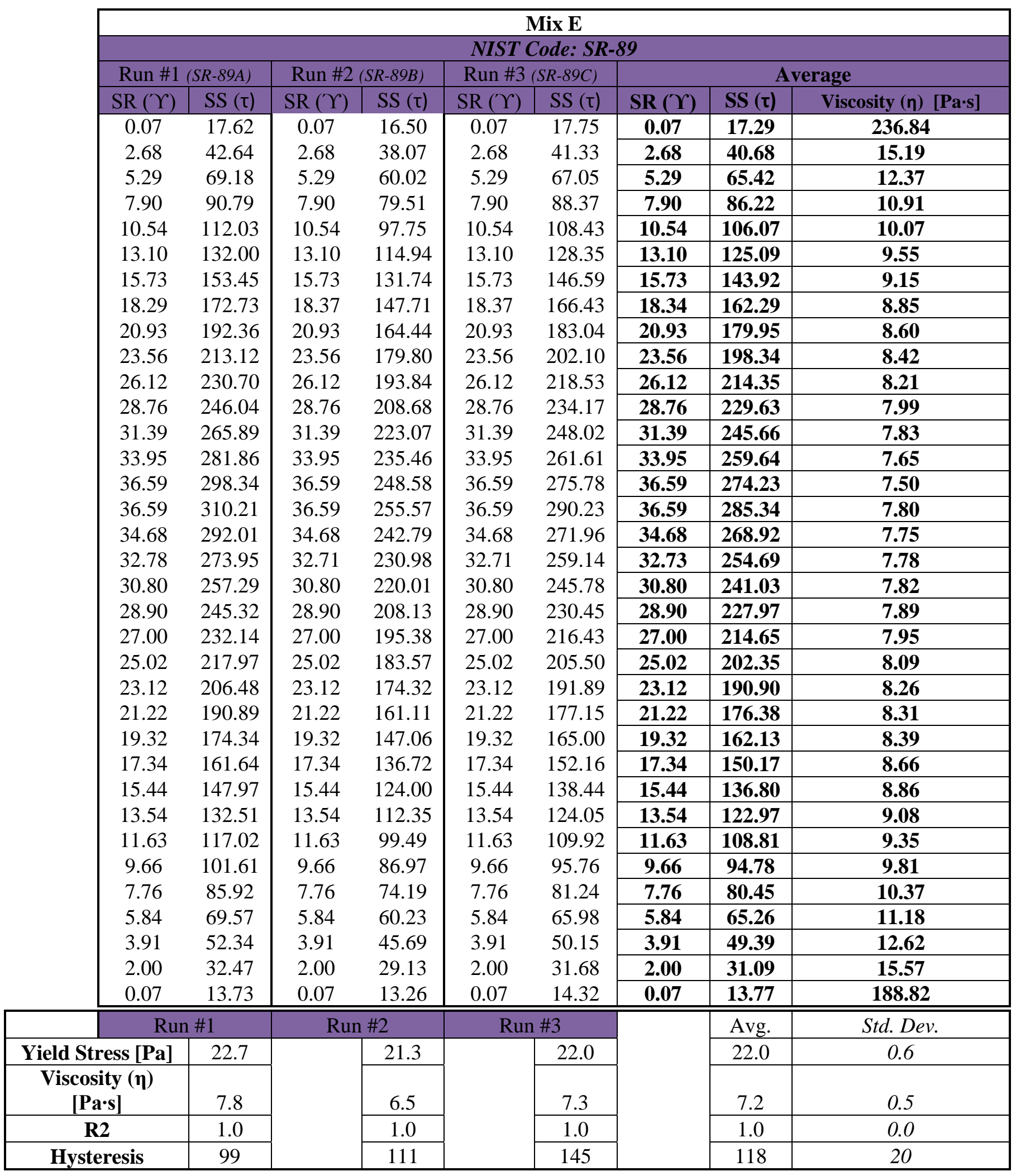


Table B-14: 3 Day values for Mix E (NIST Code: SR-88)

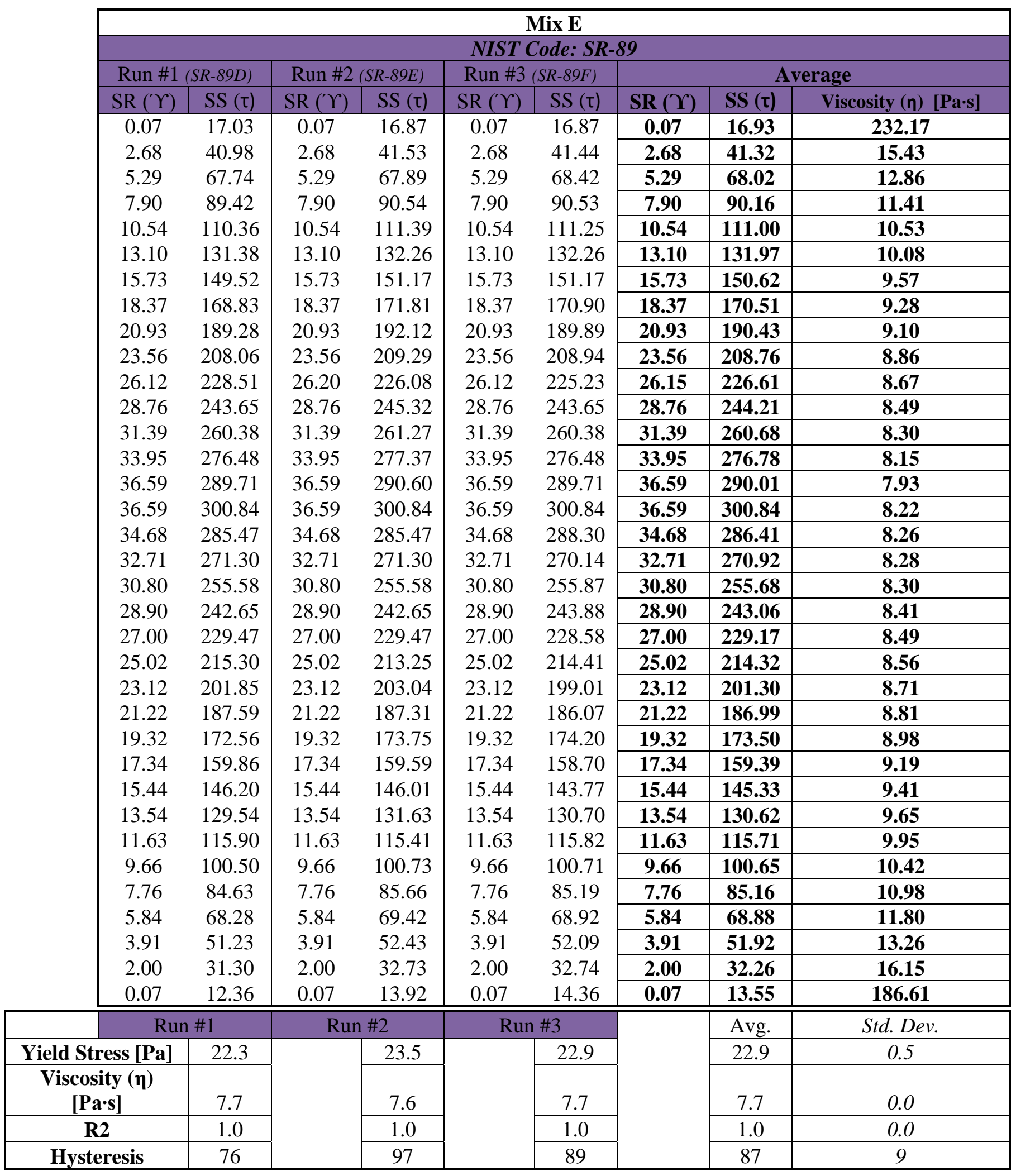


Table B-15: 7 Day values for Mix E (NIST Code: SR-88)

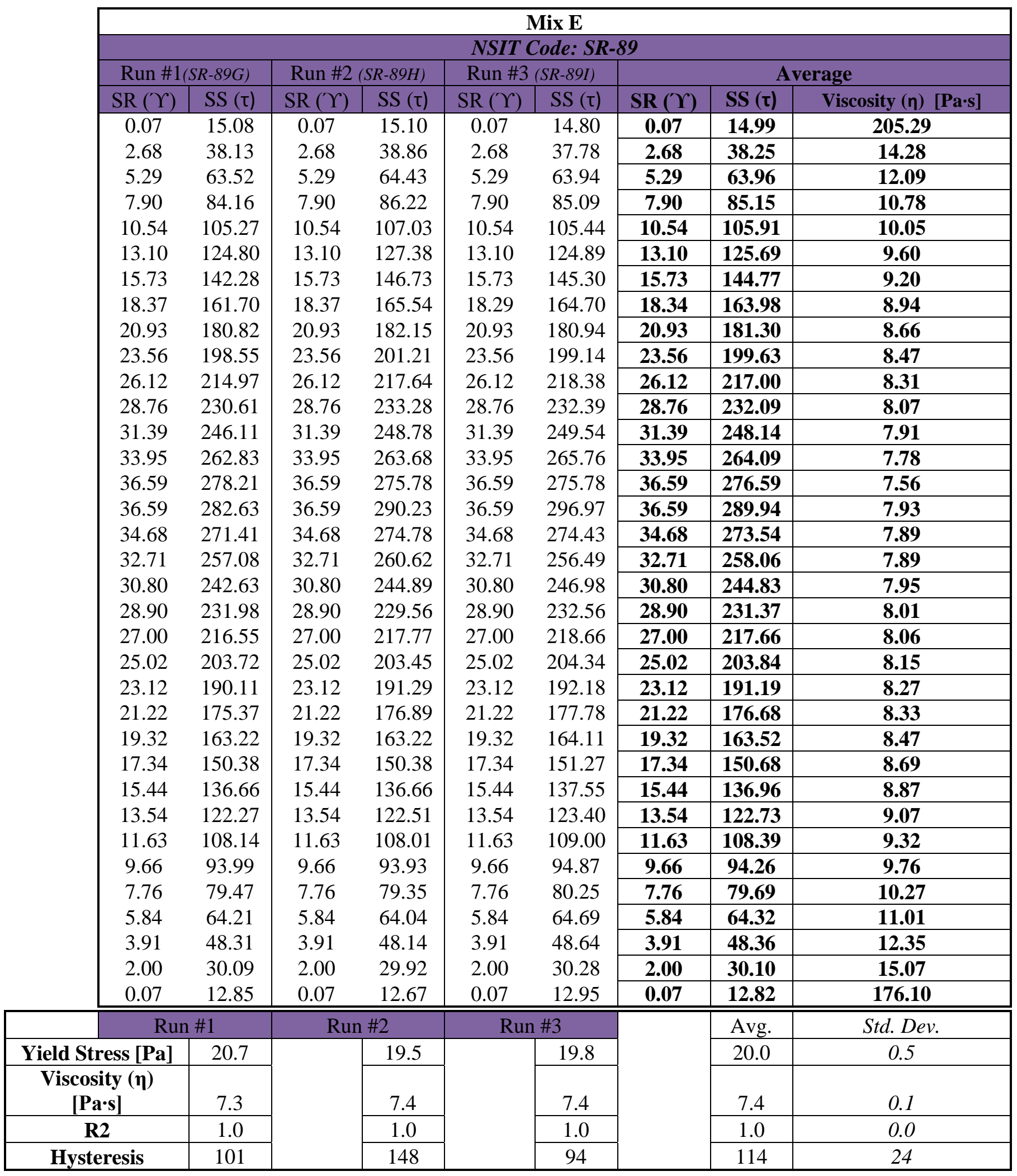




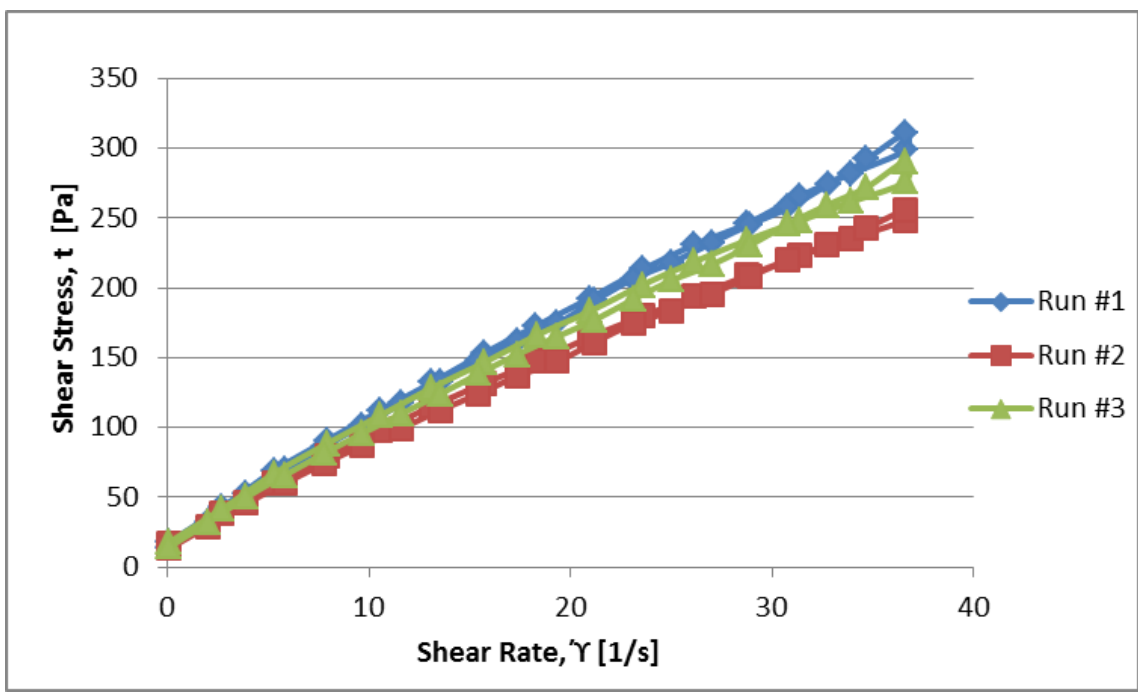

Figure B-13: 1 Day values for Mix E (NIST Code: SR-89)

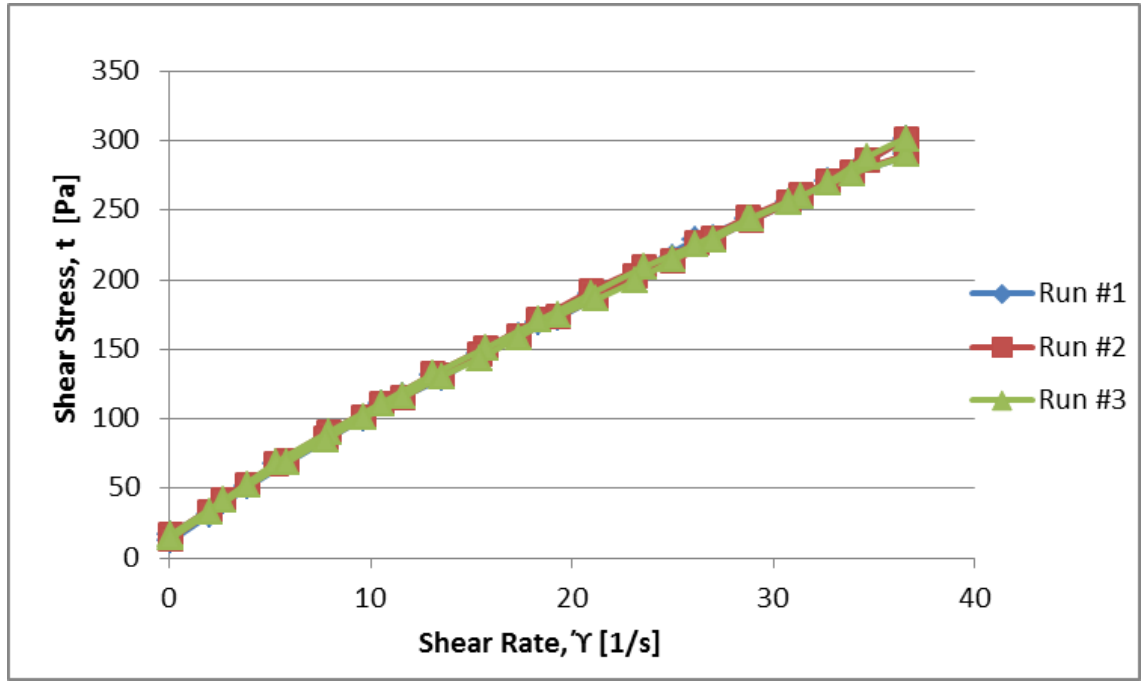

Figure B-14: 3 Day values for Mix E (NIST Code: SR-89)

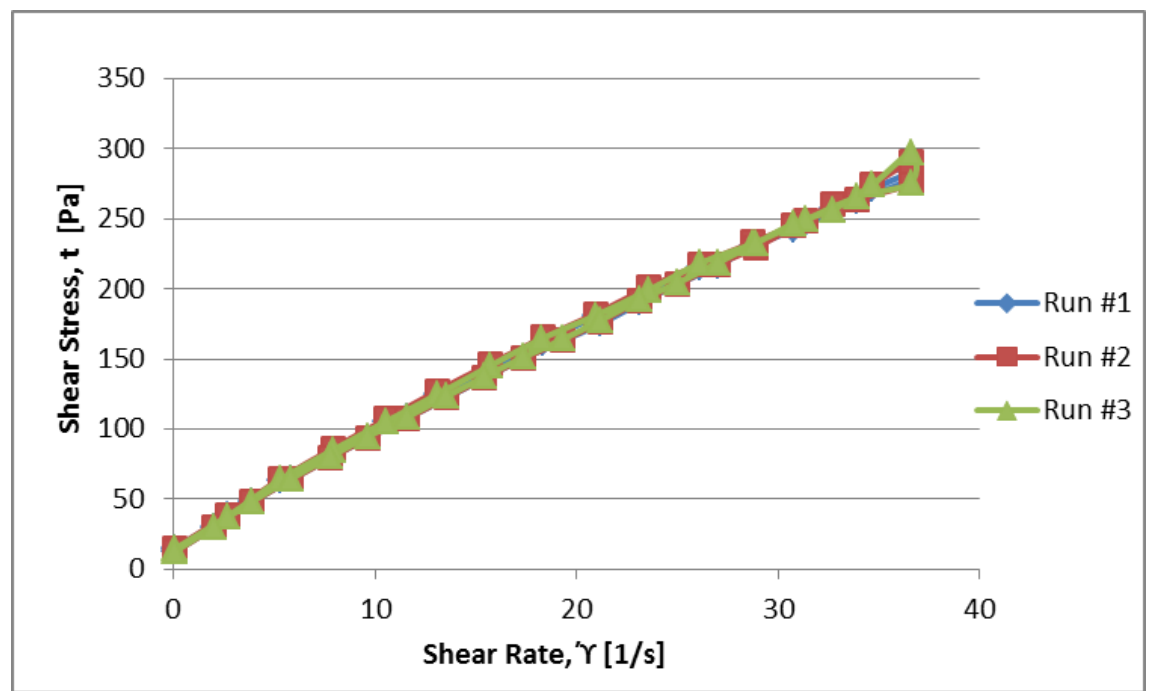

Figure B-15: 7 Day values for Mix E (NIST Code: SR-89) 
Table B-16: 1 Day values for Mix F (NIST Code: SR-80)

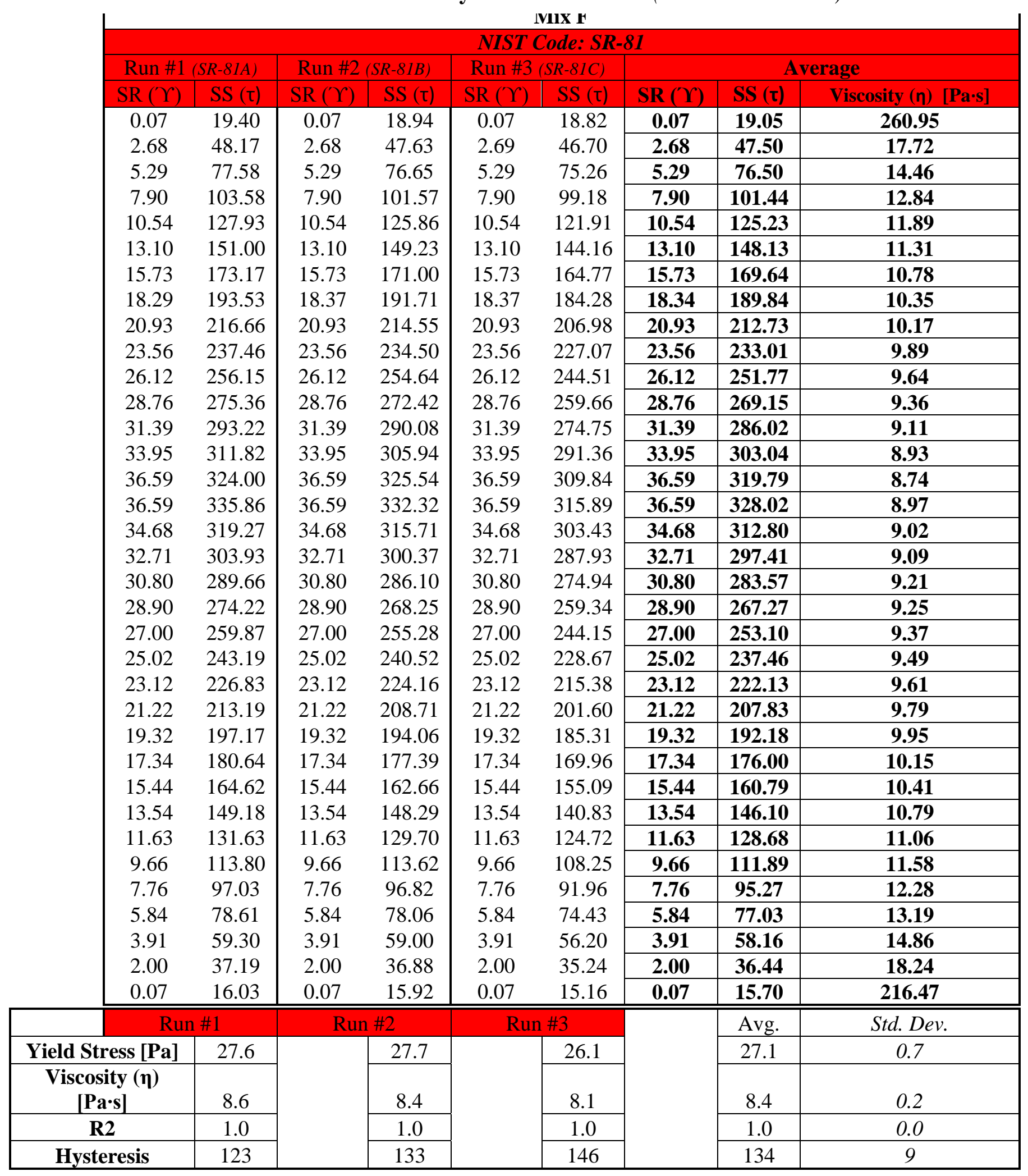


Table B-17: 3 Day values for Mix F (NIST Code: SR-80)

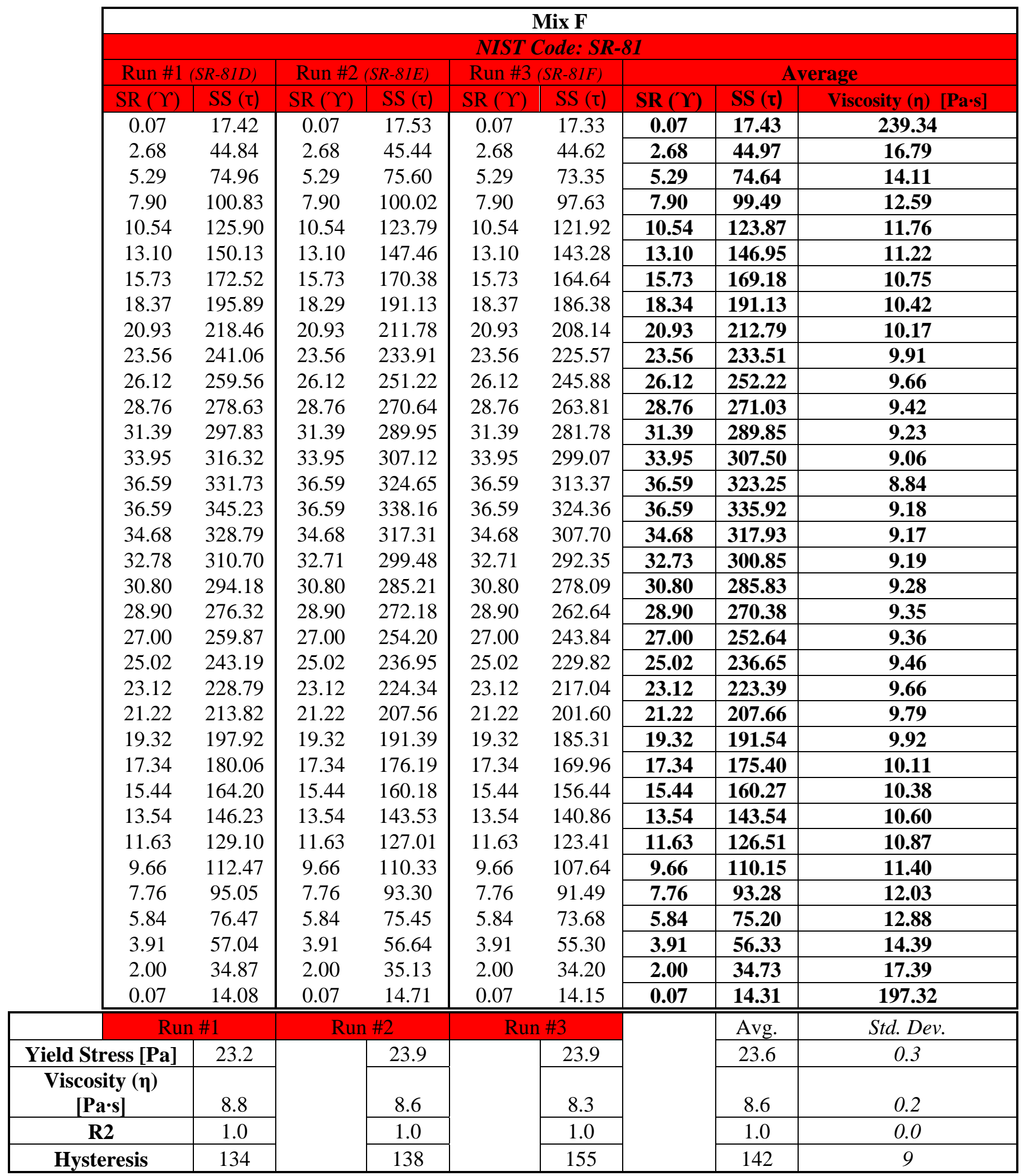


Table B-18: 7 Day values for Mix F (NIST Code: SR-80)

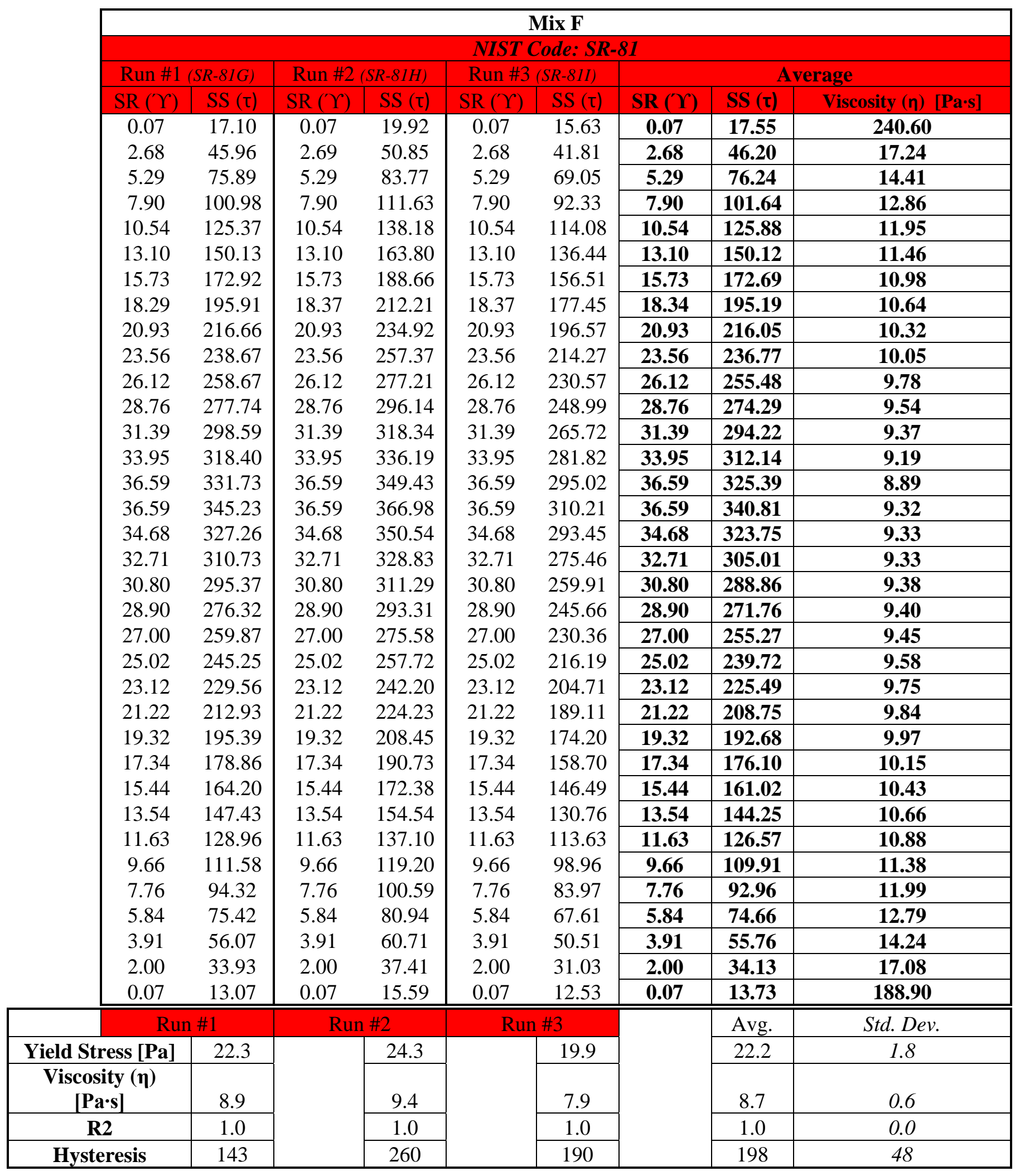




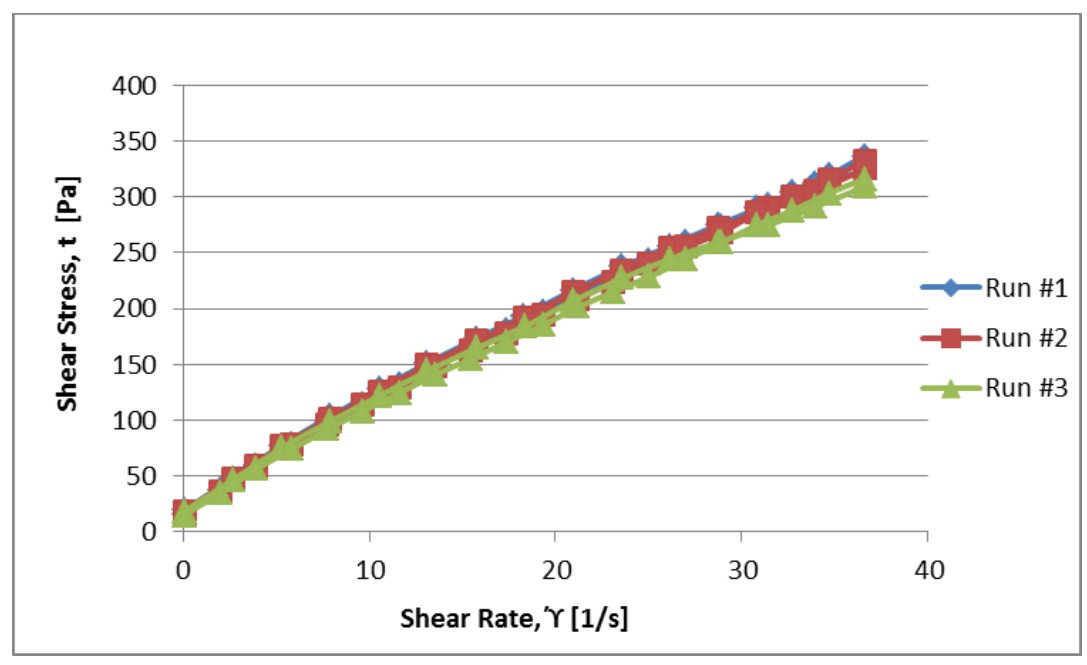

Figure B-16: 1 Day values for Mix F (NIST Code: SR-81)

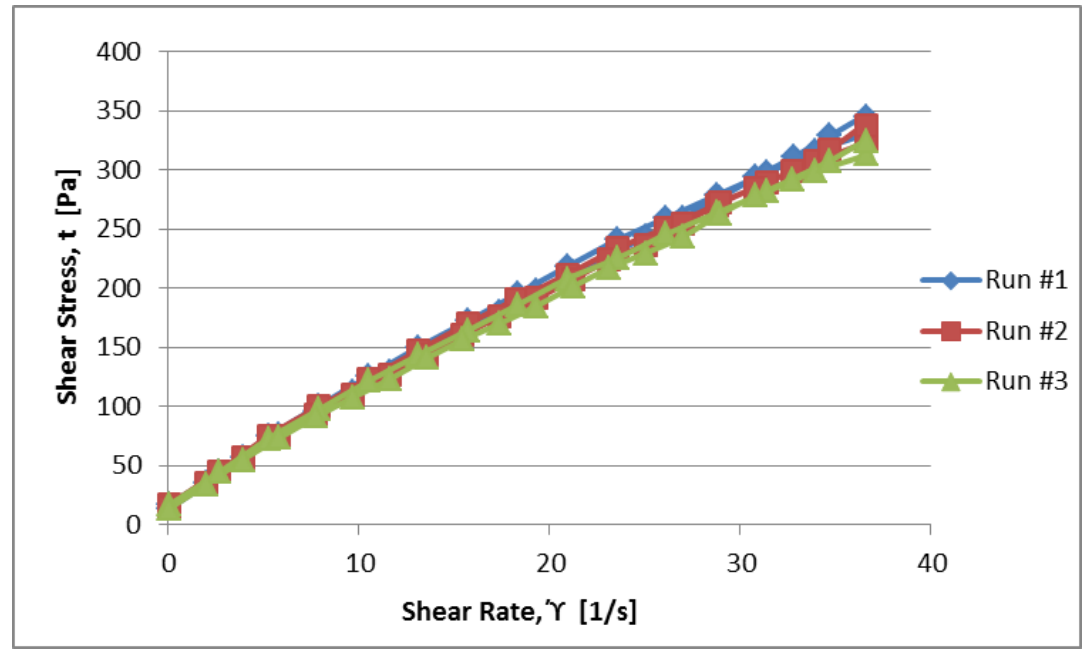

Figure B-17: 3 Day values for Mix F (NIST Code: SR-81)

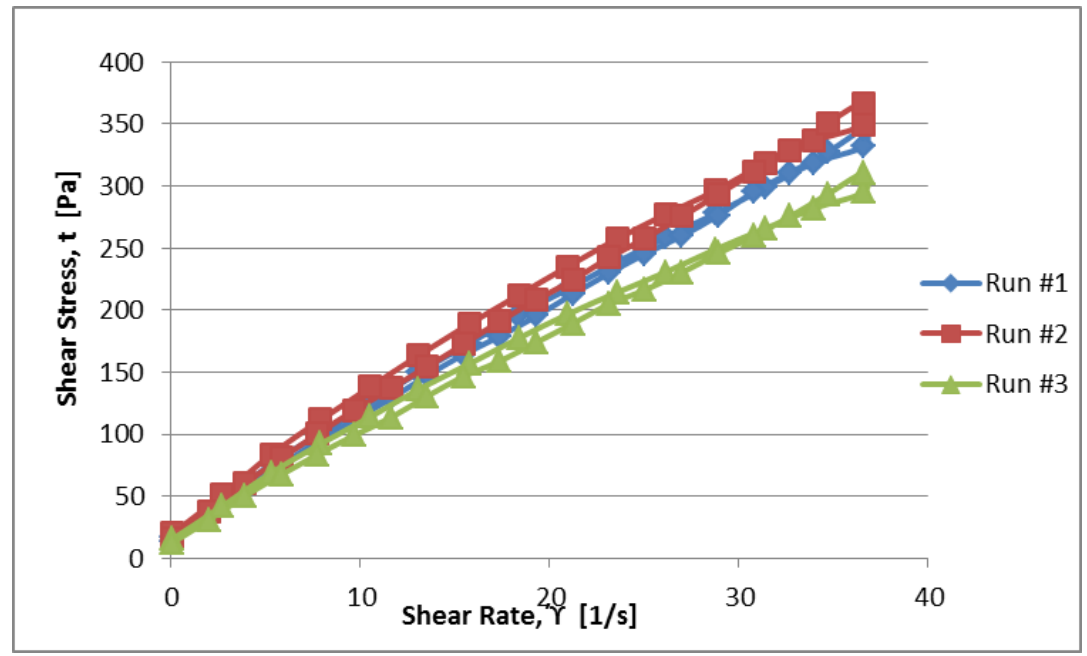

Figure B-18: 7 Day values for Mix F (NIST Code: SR-81) 
Table B-19: 1 Day values for Mix G (NIST Code: SR-78)

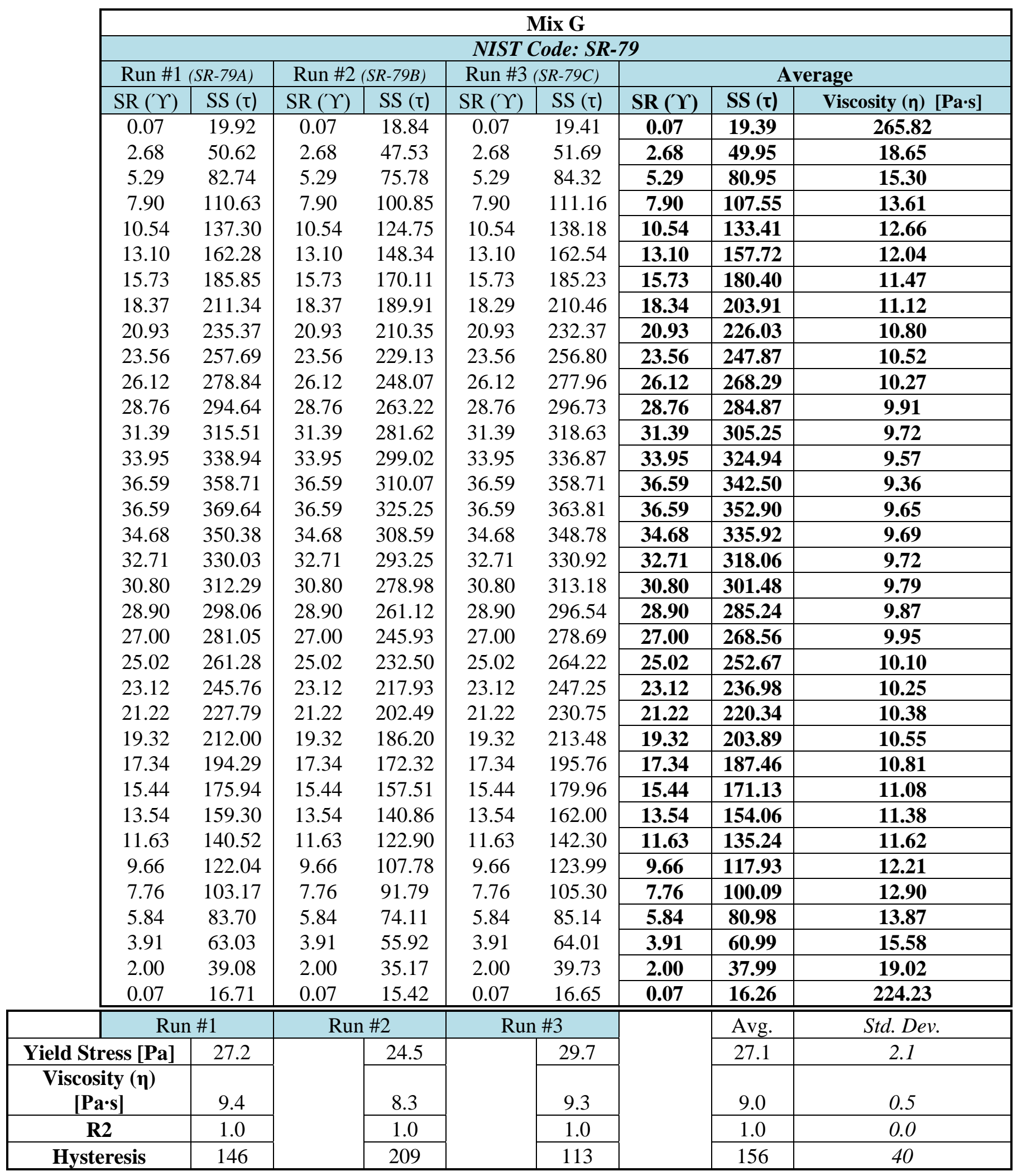


Table B-20: 3 Day values for Mix G Lab Code: SR-79

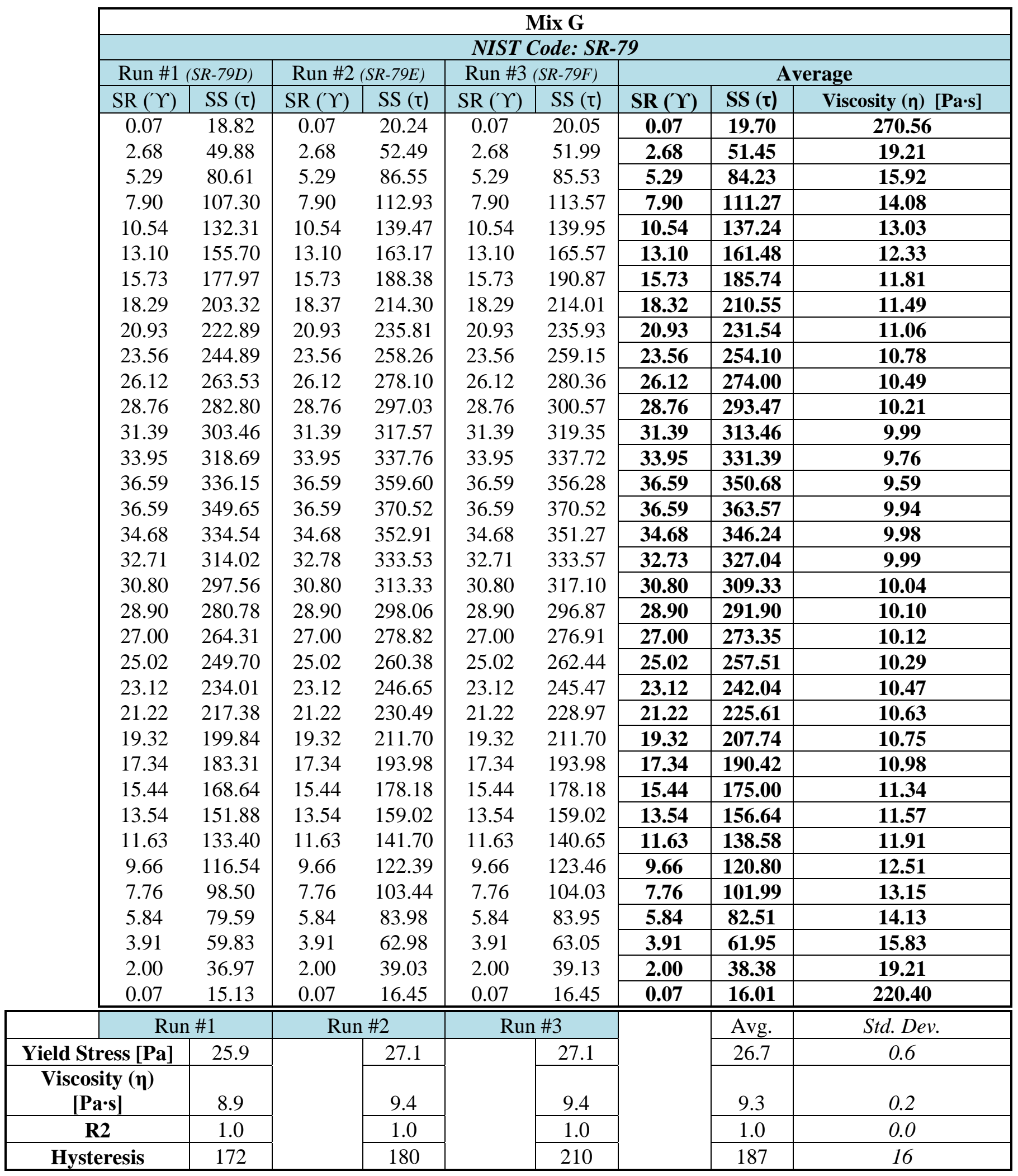


Table B-21: 7 Day values for Mix G Lab Code: SR-79

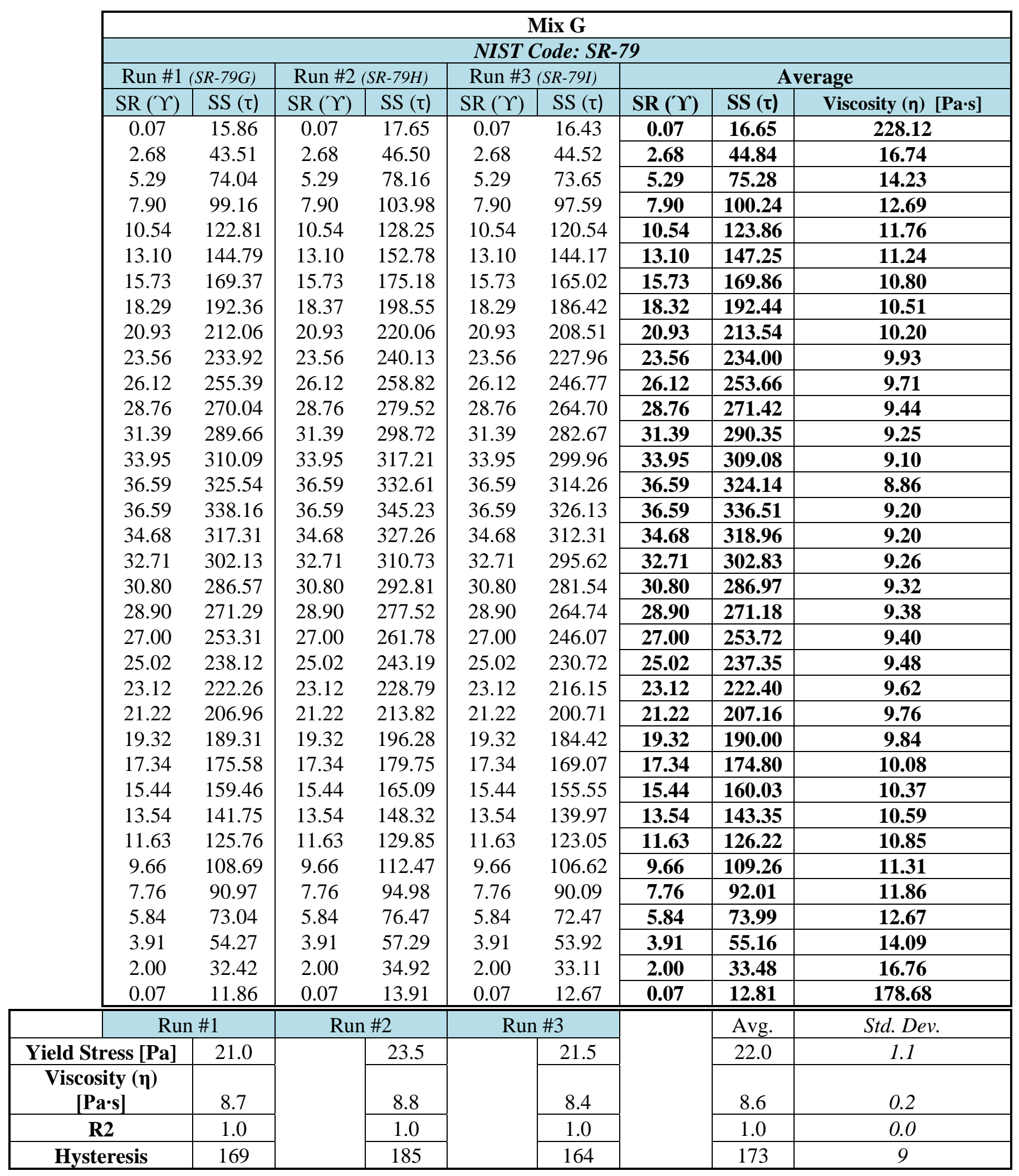




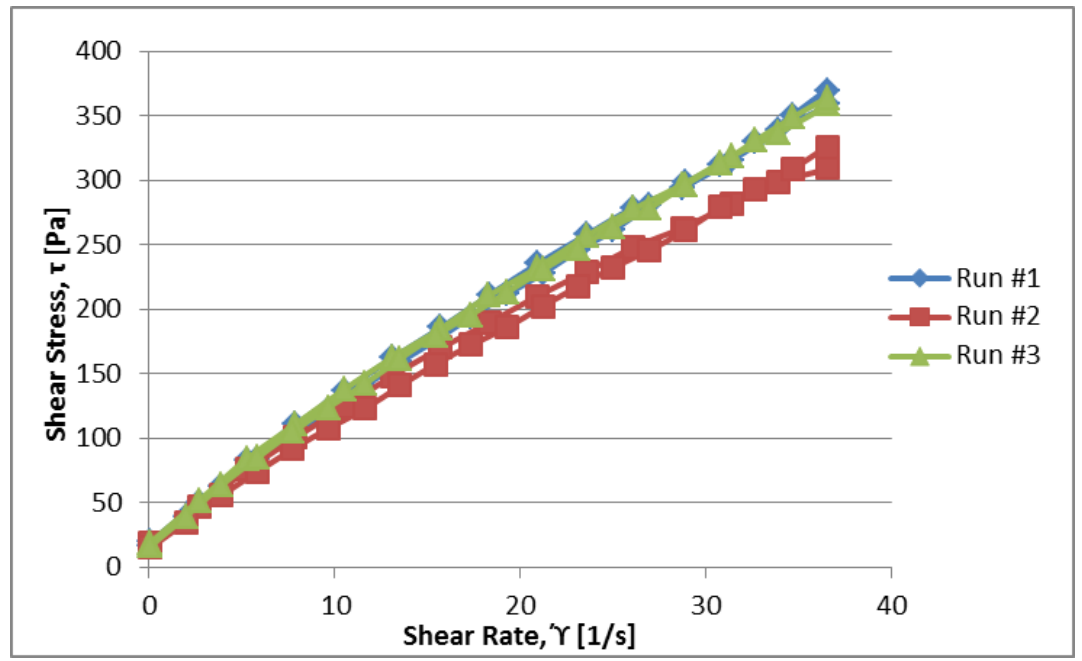

Figure B-19: 1 Day values for Mix G (NIST Code: SR-79)

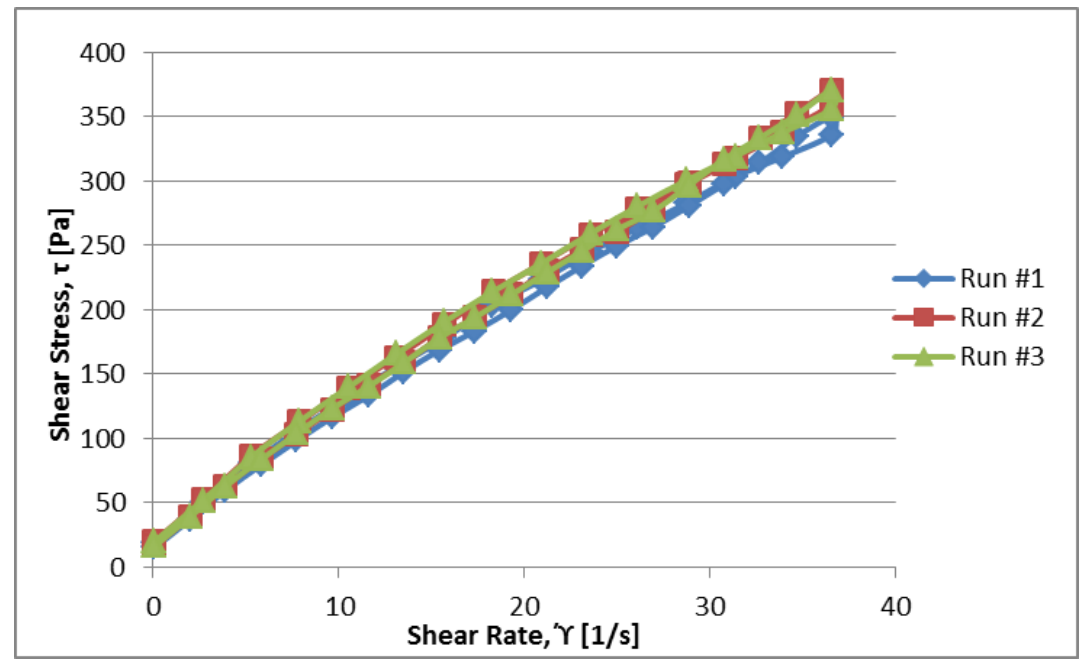

Figure B-20: 3 Day values for Mix G (NIST Code: SR-79)

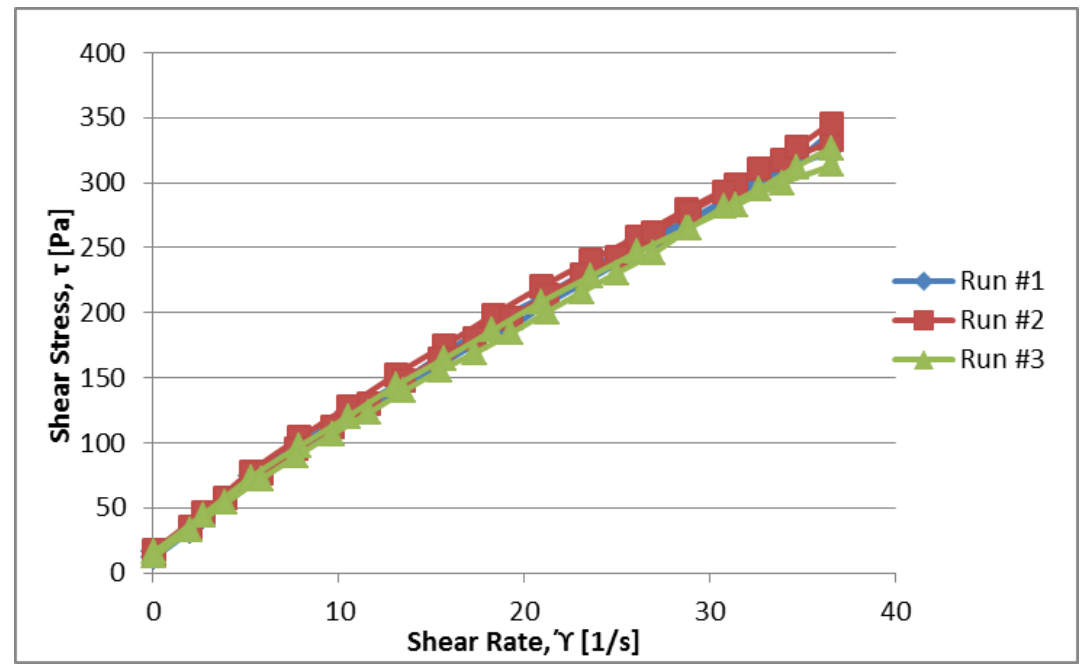

Figure B-21: 7 Day values for Mix G (NIST Code: SR-79) 
Table B-22: 1 Day values for Mix H (NIST Code: SR-98)

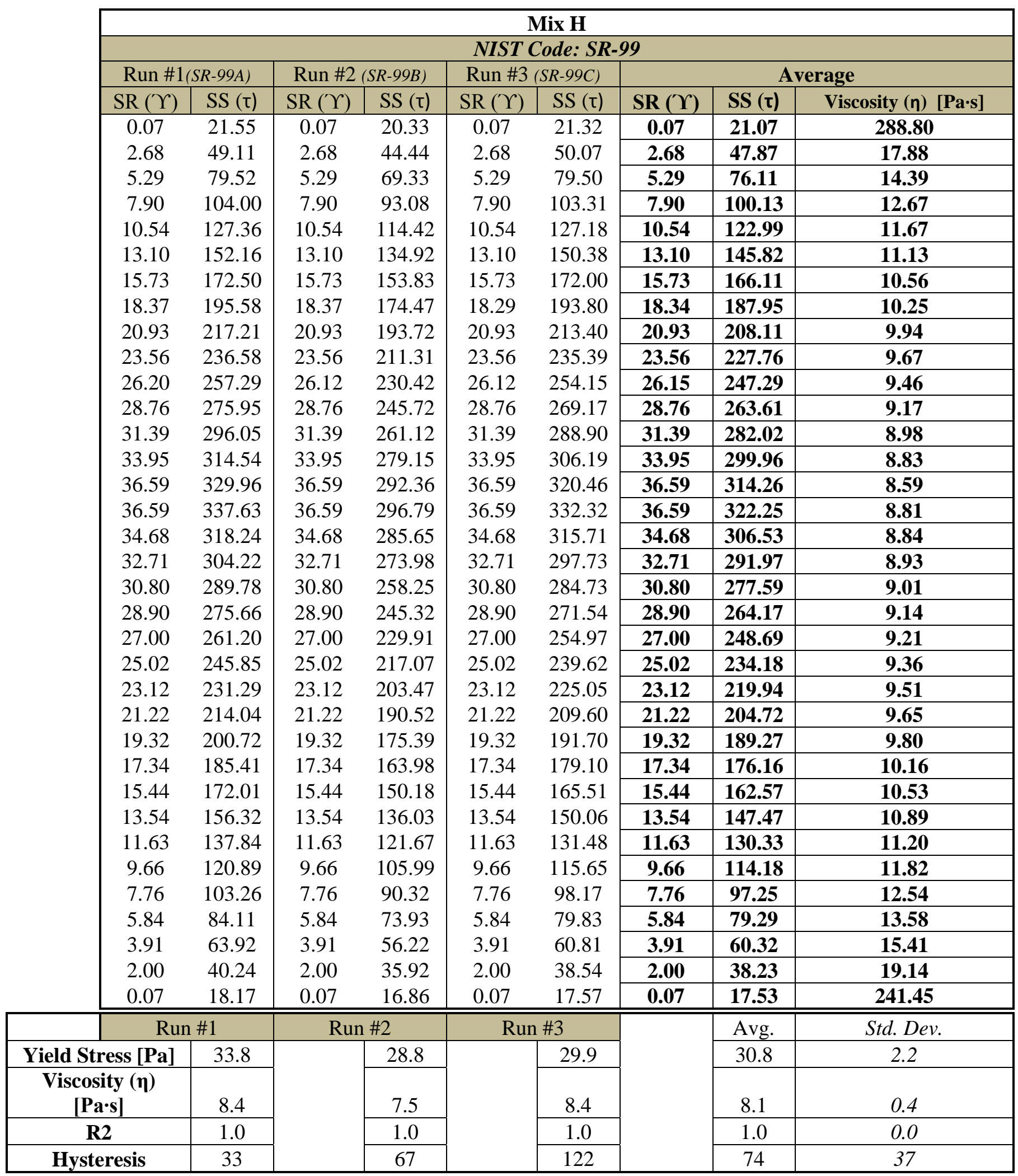


Table B-23: 3 Day values for Mix H (NIST Code: SR-98)

\begin{tabular}{|c|c|c|c|c|c|c|c|c|}
\hline \multicolumn{9}{|c|}{ Mix H } \\
\hline \multicolumn{9}{|c|}{ NIST Code: SR-99 } \\
\hline \multicolumn{2}{|c|}{ Run \#1 (SR-99E) } & \multicolumn{2}{|c|}{ Run \#2 (SR-99F) } & \multicolumn{2}{|c|}{ Run \#3 (SR-99G) } & \multicolumn{3}{|c|}{ Average } \\
\hline SR ('Y) & SS $(\tau)$ & SR ('Y) & $\mathrm{SS}(\tau)$ & SR ('Y) & $\mathrm{SS}(\tau)$ & SR ('T) & SS ( $(\tau)$ & Viscosity ( $\eta)[P a \cdot s]$ \\
\hline 0.07 & 20.72 & 0.07 & 19.43 & 0.07 & 18.95 & 0.07 & 19.70 & 269.96 \\
\hline 2.68 & 48.11 & 2.68 & 43.81 & 2.68 & 42.72 & 2.68 & 44.88 & 16.76 \\
\hline 5.29 & 77.64 & 5.29 & 69.49 & 5.29 & 66.45 & 5.29 & 71.19 & 13.46 \\
\hline 7.90 & 101.61 & 7.90 & 91.73 & 7.90 & 88.12 & 7.90 & 93.82 & 11.87 \\
\hline 10.54 & 125.41 & 10.54 & 112.99 & 10.54 & 108.70 & 10.54 & 115.70 & 10.98 \\
\hline 13.10 & 148.60 & 13.10 & 132.26 & 13.10 & 128.26 & 13.10 & 136.37 & 10.41 \\
\hline 15.73 & 169.46 & 15.73 & 152.06 & 15.73 & 145.83 & 15.73 & 155.78 & 9.90 \\
\hline 18.29 & 189.94 & 18.37 & 171.79 & 18.37 & 165.26 & 18.34 & 175.66 & 9.58 \\
\hline 20.93 & 209.69 & 20.93 & 188.64 & 20.93 & 183.31 & 20.93 & 193.88 & 9.26 \\
\hline 23.56 & 230.34 & 23.56 & 205.05 & 23.56 & 199.72 & 23.56 & 211.70 & 8.99 \\
\hline 26.12 & 249.22 & 26.12 & 222.98 & 26.12 & 216.27 & 26.12 & 229.49 & 8.79 \\
\hline 28.76 & 261.47 & 28.76 & 240.11 & 28.76 & 230.63 & 28.76 & 244.07 & 8.49 \\
\hline 31.39 & 279.97 & 31.39 & 253.64 & 31.39 & 246.24 & 31.39 & 259.95 & 8.28 \\
\hline 33.95 & 297.88 & 33.95 & 265.82 & 33.95 & 259.83 & 33.95 & 274.51 & 8.09 \\
\hline 36.59 & 314.26 & 36.59 & 285.29 & 36.59 & 274.01 & 36.59 & 291.19 & 7.96 \\
\hline 36.59 & 331.97 & 36.59 & 294.65 & 36.59 & 281.74 & 36.59 & 302.79 & 8.28 \\
\hline 34.68 & 312.56 & 34.68 & 277.69 & 34.68 & 270.52 & 34.68 & 286.92 & 8.27 \\
\hline 32.78 & 290.54 & 32.78 & 263.59 & 32.71 & 256.19 & 32.76 & 270.11 & 8.25 \\
\hline 30.80 & 276.53 & 30.80 & 249.27 & 30.80 & 239.19 & 30.80 & 255.00 & 8.28 \\
\hline 28.90 & 264.42 & 28.90 & 237.31 & 28.90 & 227.45 & 28.90 & 243.06 & 8.41 \\
\hline 27.00 & 247.85 & 27.00 & 221.90 & 27.00 & 215.54 & 27.00 & 228.43 & 8.46 \\
\hline 25.02 & 232.50 & 25.02 & 207.00 & 25.02 & 204.61 & 25.02 & 214.71 & 8.58 \\
\hline 23.12 & 215.98 & 23.12 & 194.68 & 23.12 & 189.05 & 23.12 & 199.90 & 8.65 \\
\hline 21.22 & 201.85 & 21.22 & 183.41 & 21.22 & 177.43 & 21.22 & 187.56 & 8.84 \\
\hline 19.32 & 187.09 & 19.32 & 169.89 & 19.32 & 163.81 & 19.32 & 173.60 & 8.99 \\
\hline 17.34 & 171.74 & 17.34 & 155.72 & 17.34 & 150.96 & 17.34 & 159.47 & 9.20 \\
\hline 15.44 & 158.22 & 15.44 & 141.99 & 15.44 & 138.44 & 15.44 & 146.22 & 9.47 \\
\hline 13.54 & 142.64 & 13.54 & 127.72 & 13.54 & 123.93 & 13.54 & 131.43 & 9.71 \\
\hline 11.63 & 125.29 & 11.63 & 113.77 & 11.63 & 109.83 & 11.63 & 116.30 & 10.00 \\
\hline 9.66 & 109.22 & 9.66 & 99.58 & 9.66 & 95.88 & 9.66 & 101.56 & 10.51 \\
\hline 7.76 & 93.11 & 7.76 & 84.60 & 7.76 & 81.27 & 7.76 & 86.33 & 11.13 \\
\hline 5.84 & 75.64 & 5.84 & 68.67 & 5.84 & 66.26 & 5.84 & 70.19 & 12.02 \\
\hline 3.91 & 57.31 & 3.91 & 52.37 & 3.91 & 50.37 & 3.91 & 53.35 & 13.63 \\
\hline 2.00 & 36.11 & 2.00 & 33.25 & 2.00 & 32.22 & 2.00 & 33.86 & 16.95 \\
\hline 0.07 & 16.51 & 0.07 & 15.43 & 0.07 & 15.22 & $\mathbf{0 . 0 7}$ & 15.72 & 216.59 \\
\hline \multicolumn{2}{|c|}{ Run \#1 } & \multicolumn{2}{|c|}{ Run \#2 } & \multicolumn{2}{|c|}{ Run \#3 } & & Avg. & Std. Dev. \\
\hline ess [Pa] & 25.4 & & 24.2 & & 23.6 & & 24.4 & 0.7 \\
\hline ty $(\eta)$ & 8.3 & & 7.4 & & 7.1 & & 7.6 & 0.5 \\
\hline$\underline{z}$ & 1.0 & & 1.0 & & 1.0 & & 1.0 & 0.0 \\
\hline resis & 188 & & 169 & & 156 & & 171 & 13 \\
\hline
\end{tabular}


Table B-24: 7 Day values for Mix H (NIST Code: SR-98)

\begin{tabular}{|c|c|c|c|c|c|c|c|c|}
\hline \multicolumn{9}{|c|}{ Mix H } \\
\hline \multicolumn{9}{|c|}{ NIST Code: SR-99 } \\
\hline \multicolumn{2}{|c|}{ Run \#1 (SR-99I) } & \multicolumn{2}{|c|}{ Run \#2 (SR-99J) } & \multicolumn{2}{|c|}{ Run \#3 (SR-99K) } & \multicolumn{3}{|c|}{ Average } \\
\hline SR $(Y)$ & SS ( $(\tau)$ & SR ('Y) & SS $(\tau)$ & SR ('Y) & SS ( $(\tau)$ & SR ('Y) & SS ( $\tau)$ & Viscosity (n) [Pa·s] \\
\hline 0.07 & 21.30 & 0.07 & 20.80 & 0.07 & 22.05 & 0.07 & 21.38 & 293.51 \\
\hline 2.68 & 49.58 & 2.68 & 47.69 & 2.68 & 50.73 & 2.68 & 49.33 & 18.42 \\
\hline 5.29 & 80.35 & 5.29 & 77.87 & 5.29 & 79.37 & 5.29 & 79.20 & 14.97 \\
\hline 7.90 & 107.01 & 7.90 & 103.35 & 7.90 & 104.89 & 7.90 & 105.08 & 13.30 \\
\hline 10.54 & 132.54 & 10.54 & 128.00 & 10.54 & 128.47 & 10.54 & 129.67 & 12.31 \\
\hline 13.10 & 156.96 & 13.10 & 151.00 & 13.10 & 153.04 & 13.10 & 153.67 & 11.73 \\
\hline 15.73 & 181.83 & 15.73 & 173.93 & 15.73 & 173.78 & 15.73 & 176.51 & 11.22 \\
\hline 18.29 & 205.10 & 18.29 & 195.61 & 18.29 & 195.57 & 18.29 & 198.76 & 10.87 \\
\hline 20.93 & 224.67 & 20.93 & 216.50 & 20.93 & 215.18 & 20.93 & 218.78 & 10.45 \\
\hline 23.56 & 245.46 & 23.56 & 238.37 & 23.56 & 234.75 & 23.56 & 239.53 & 10.17 \\
\hline 26.12 & 264.16 & 26.12 & 257.08 & 26.12 & 250.89 & 26.12 & 257.38 & 9.85 \\
\hline 28.76 & 284.86 & 28.76 & 269.20 & 28.76 & 269.17 & 28.76 & 274.41 & 9.54 \\
\hline 31.39 & 304.06 & 31.39 & 290.68 & 31.39 & 287.25 & 31.39 & 294.00 & 9.37 \\
\hline 33.95 & 322.55 & 33.95 & 307.97 & 33.95 & 305.05 & 33.95 & 311.85 & 9.19 \\
\hline 36.59 & 337.92 & 36.59 & 322.23 & 36.59 & 324.65 & 36.59 & 328.27 & 8.97 \\
\hline 36.59 & 356.38 & 36.59 & 339.04 & 36.59 & 330.55 & 36.59 & 341.99 & 9.35 \\
\hline 34.68 & 334.19 & 34.68 & 318.20 & 34.68 & 316.76 & 34.68 & 323.05 & 9.31 \\
\hline 32.71 & 315.19 & 32.71 & 303.02 & 32.71 & 300.07 & 32.71 & 306.09 & 9.36 \\
\hline 30.80 & 299.82 & 30.80 & 287.46 & 30.80 & 280.87 & 30.80 & 289.39 & 9.39 \\
\hline 28.90 & 283.19 & 28.90 & 272.18 & 28.90 & 266.76 & 28.90 & 274.04 & 9.48 \\
\hline 27.00 & 263.11 & 27.00 & 254.20 & 27.00 & 252.30 & 27.00 & 256.54 & 9.50 \\
\hline 25.02 & 247.91 & 25.02 & 236.95 & 25.02 & 236.95 & 25.02 & 240.60 & 9.61 \\
\hline 23.12 & 234.01 & 23.12 & 222.38 & 23.12 & 222.38 & 23.12 & 226.26 & 9.79 \\
\hline 21.22 & 217.38 & 21.22 & 208.74 & 21.22 & 206.93 & 21.22 & 211.02 & 9.94 \\
\hline 19.32 & 199.84 & 19.32 & 189.46 & 19.32 & 189.03 & 19.32 & 192.78 & 9.98 \\
\hline 17.34 & 183.31 & 17.34 & 175.55 & 17.34 & 176.44 & 17.34 & 178.43 & 10.29 \\
\hline 15.44 & 167.29 & 15.44 & 160.61 & 15.44 & 162.84 & 15.44 & 163.58 & 10.60 \\
\hline 13.54 & 151.84 & 13.54 & 145.27 & 13.54 & 146.19 & 13.54 & 147.77 & 10.92 \\
\hline 11.63 & 134.29 & 11.63 & 131.03 & 11.63 & 129.99 & 11.63 & 131.77 & 11.33 \\
\hline 9.66 & 117.08 & 9.66 & 112.38 & 9.66 & 112.74 & 9.66 & 114.06 & 11.81 \\
\hline 7.76 & 99.62 & 7.76 & 94.86 & 7.76 & 95.77 & 7.76 & 96.75 & 12.47 \\
\hline 5.84 & 80.65 & 5.84 & 77.32 & 5.84 & 78.18 & 5.84 & 78.72 & 13.48 \\
\hline 3.91 & 61.01 & 3.91 & 58.45 & 3.91 & 59.06 & 3.91 & 59.51 & 15.20 \\
\hline 2.00 & 38.35 & 2.00 & 36.79 & 2.00 & 37.20 & 2.00 & 37.45 & 18.75 \\
\hline 0.07 & 17.04 & 0.07 & 16.36 & 0.07 & 16.91 & 0.07 & 16.77 & 230.71 \\
\hline \multicolumn{2}{|c|}{ Run \#1 } & \multicolumn{2}{|c|}{ Run \#2 } & \multicolumn{2}{|c|}{ Run \#3 } & & Avg. & Std. Dev. \\
\hline ess [Pa] & 26.2 & & 25.5 & & 27.6 & & 26.4 & 0.9 \\
\hline ty $(\eta)$ & 8.9 & & 8.5 & & 8.4 & & 8.6 & 0.2 \\
\hline$\underline{z}$ & 1.0 & & 1.0 & & 1.0 & & 1.0 & 0.0 \\
\hline resis & 197 & & 202 & & 219 & & 206 & 9 \\
\hline
\end{tabular}




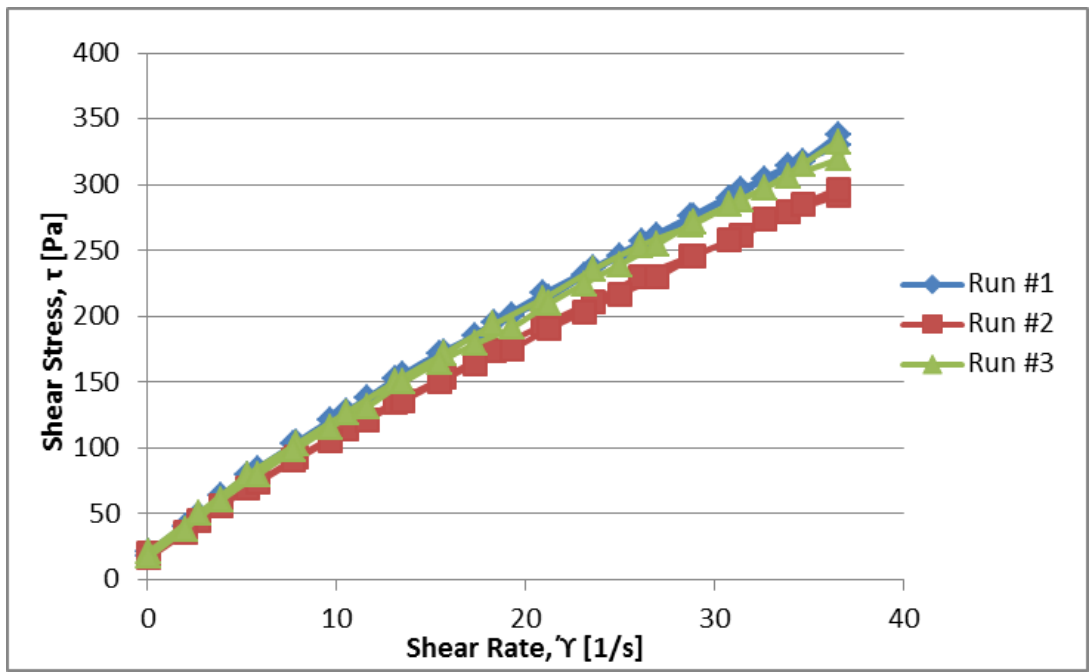

Figure B-22: 1 Day values for Mix H (NIST Code: SR-99)

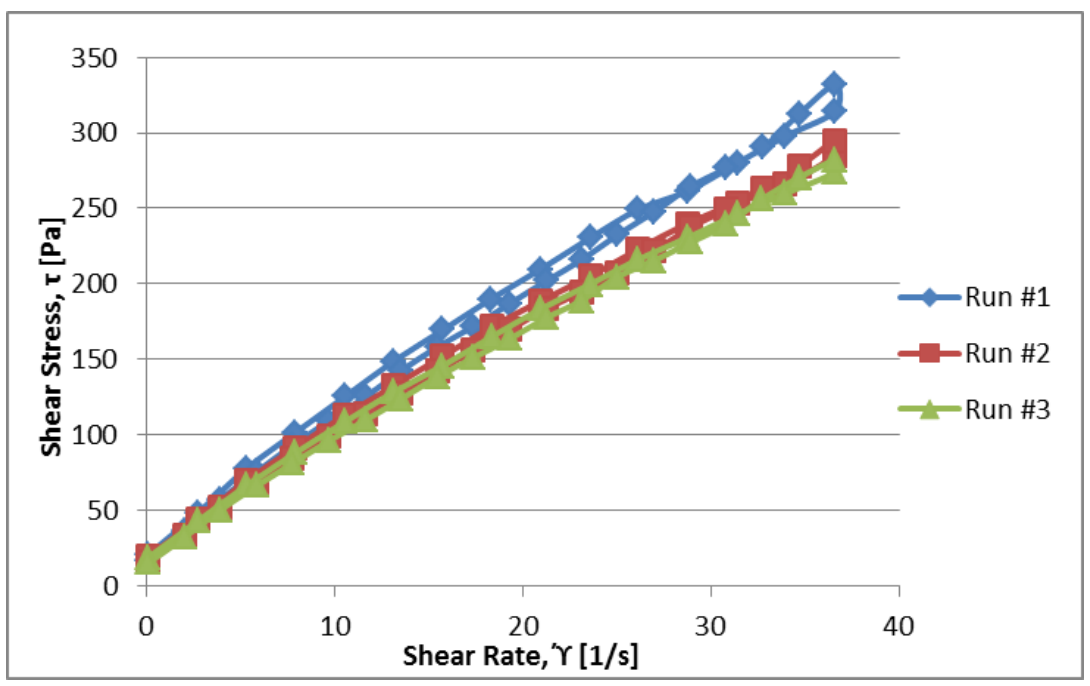

Figure B-23: 3 Day values for Mix H (NIST Code: SR-99)

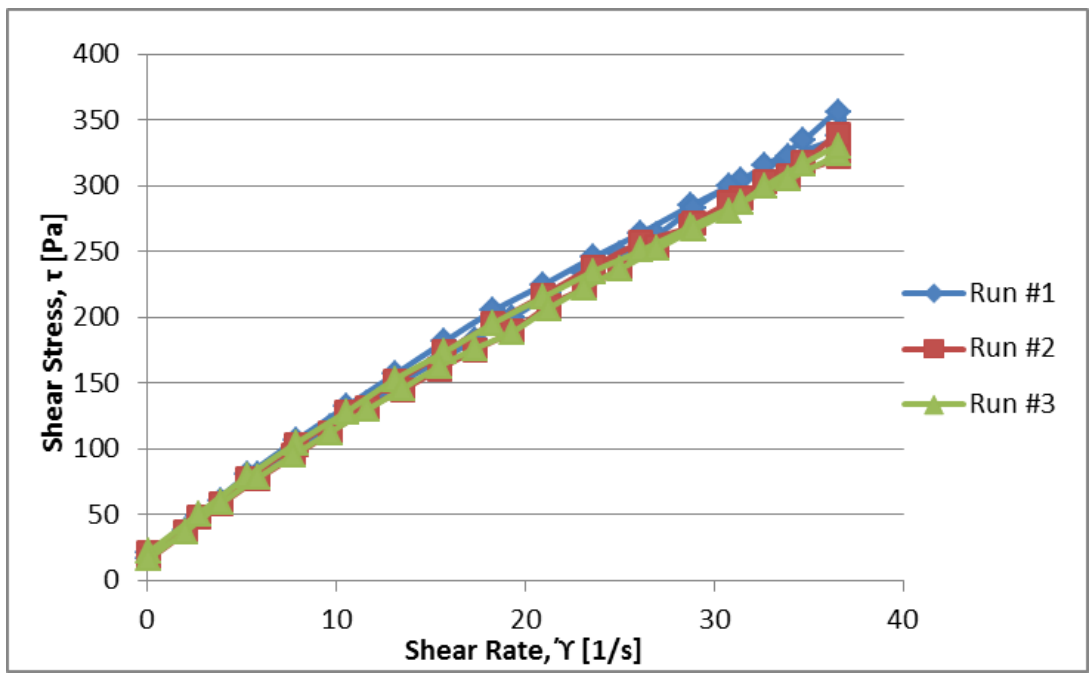

Figure B-24: 7 Day values for Mix H (NIST Code: SR-99)

B - 33 
Table B-25: 1 Day values for Mix I (NIST Code: SR-94)

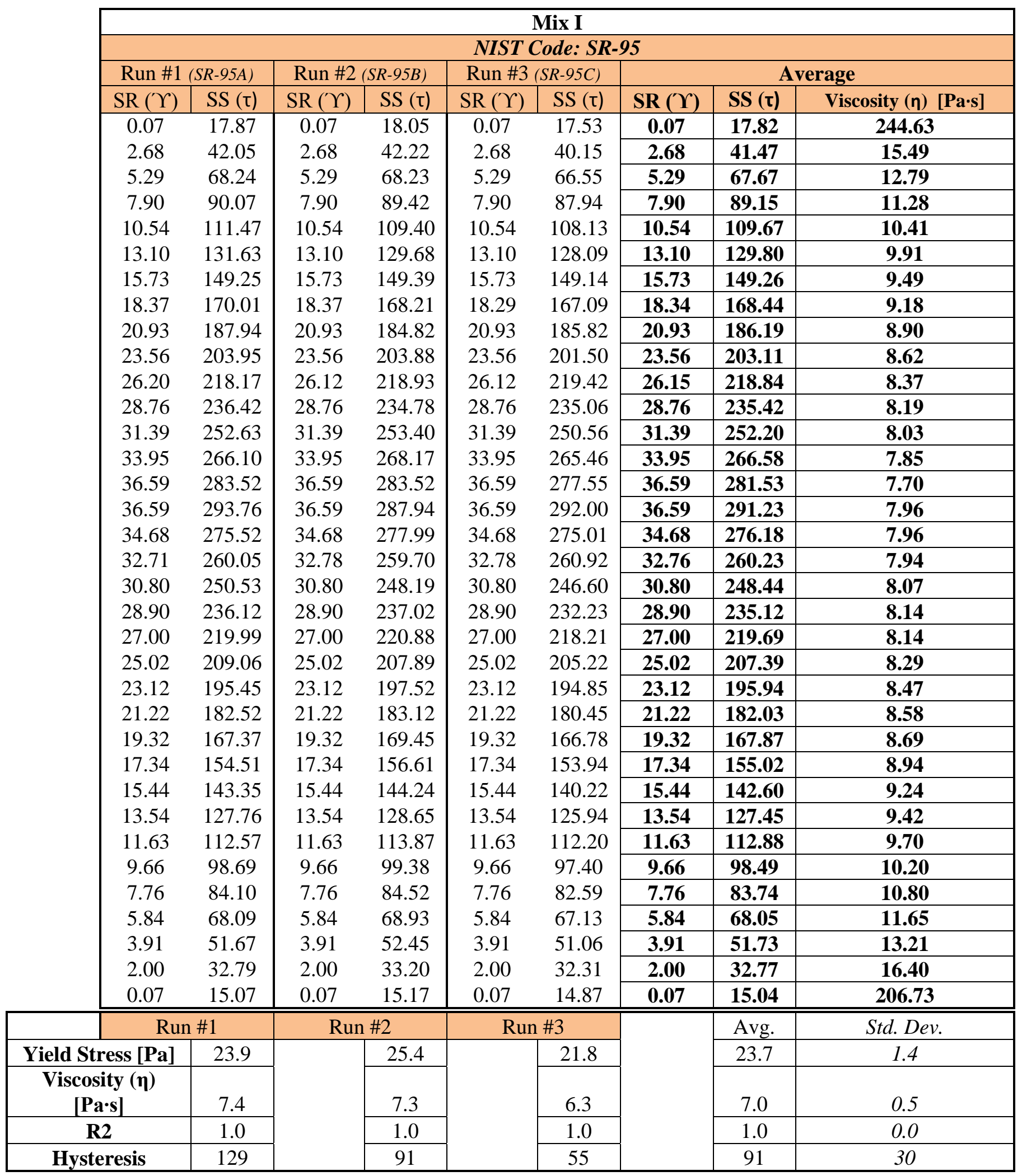


Table B-26: 3 Day values for Mix I (NIST Code: SR-94)

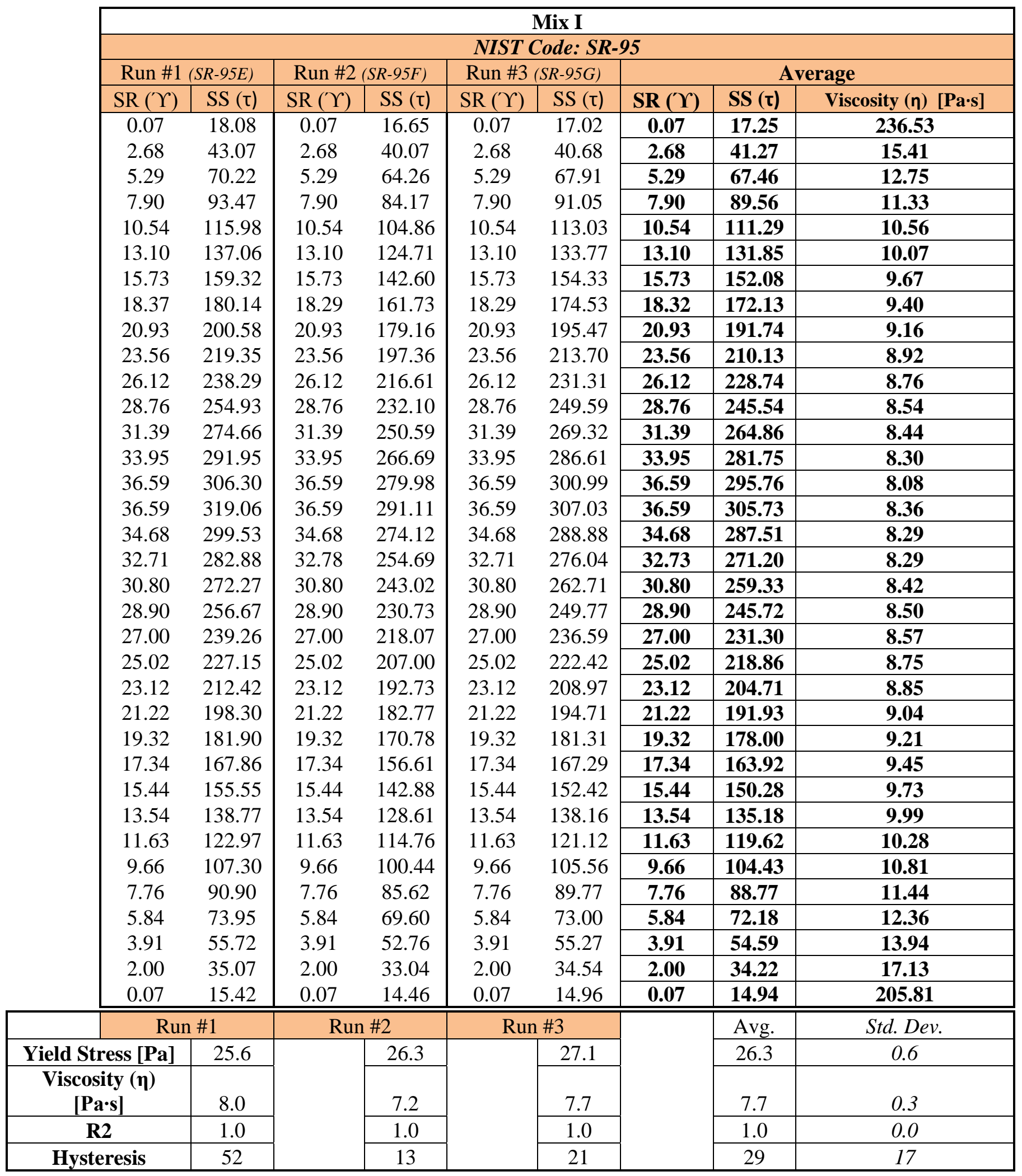


Table B-27: 7 Day values for Mix I (NIST Code: SR-94)

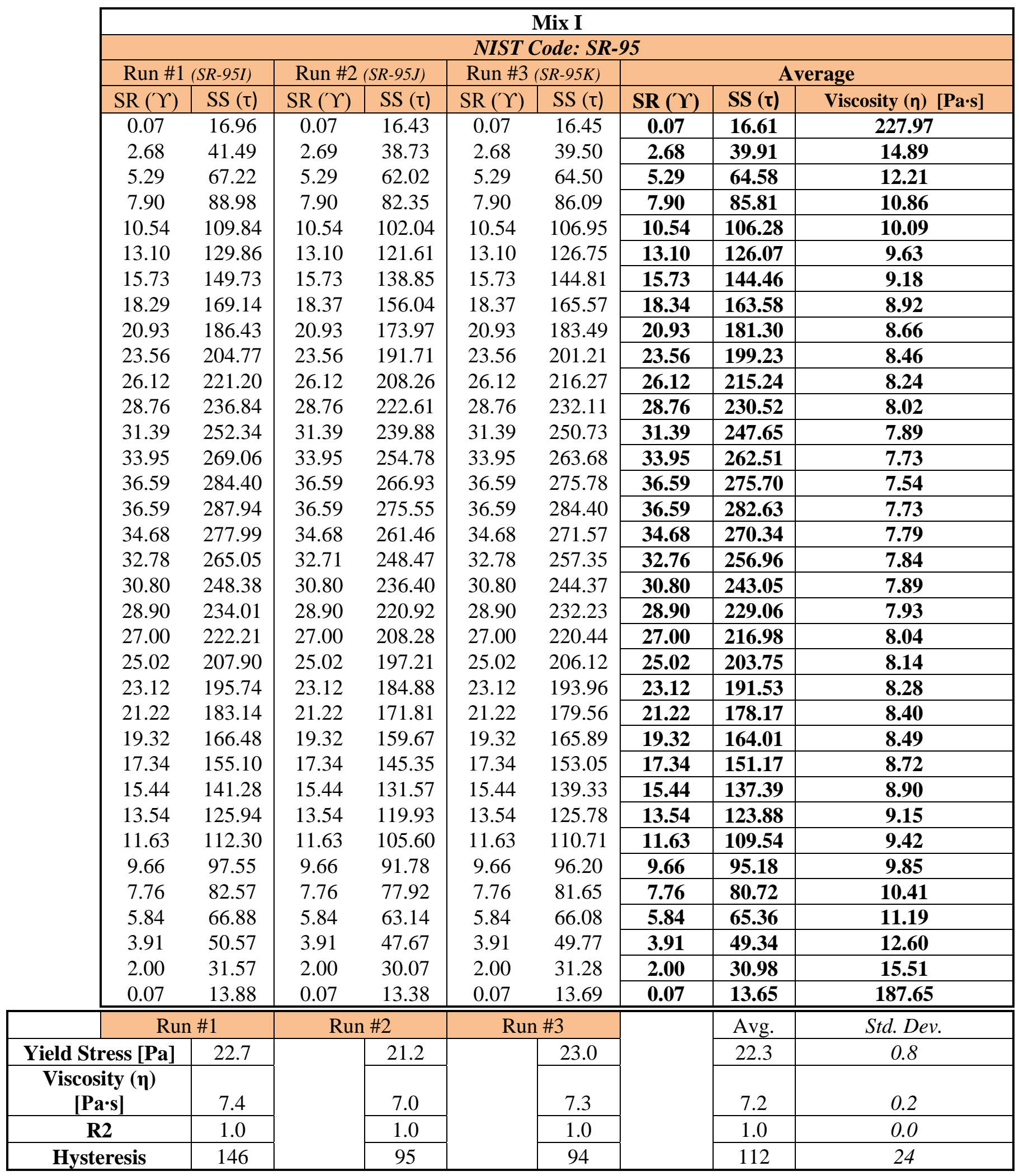




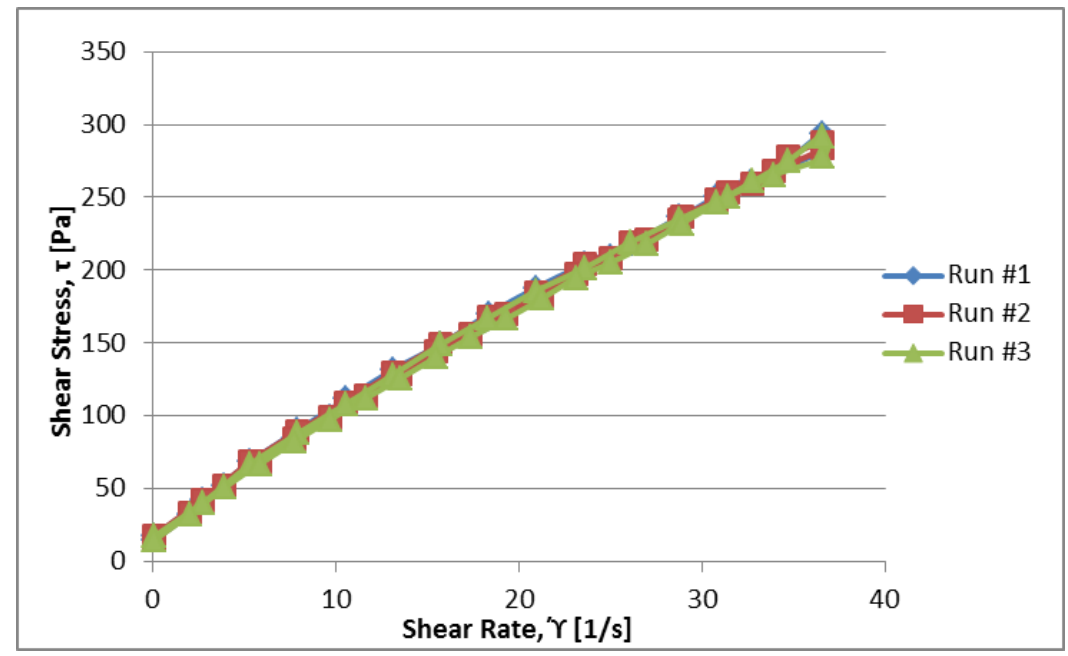

Figure B-25: 1 Day values for Mix I (NIST Code: SR-95)

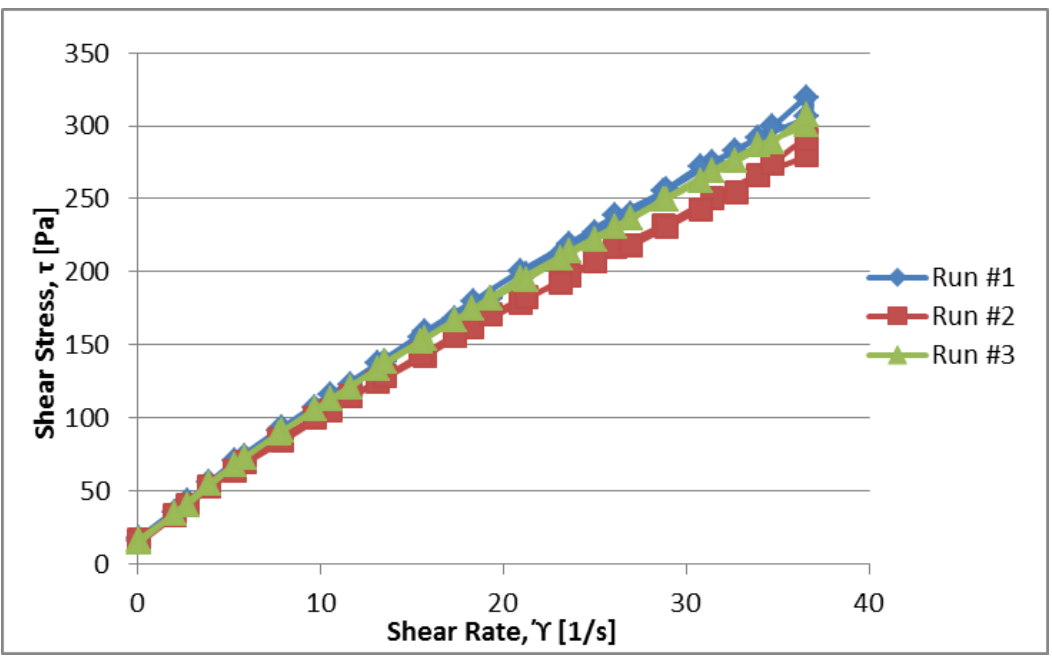

Figure B-26: 3 Day values for Mix I (NIST Code: SR-95)

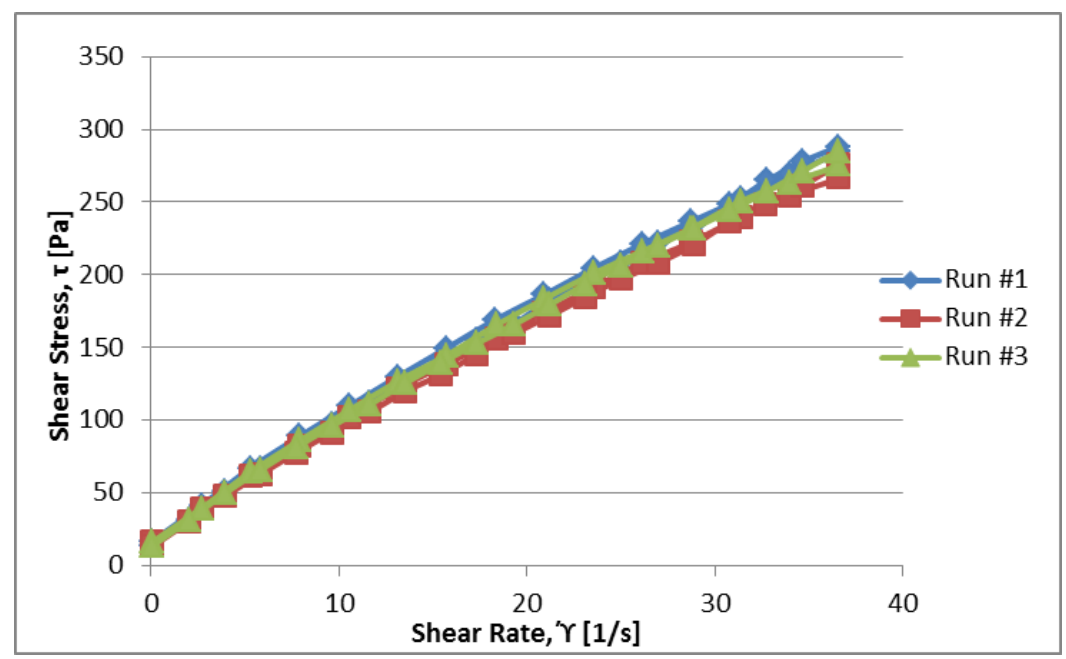

Figure B-27: 7 Day values for Mix I (NIST Code: SR-95) 
Table B-28: 1 Day values for Mix J (NIST Code: SR-96)

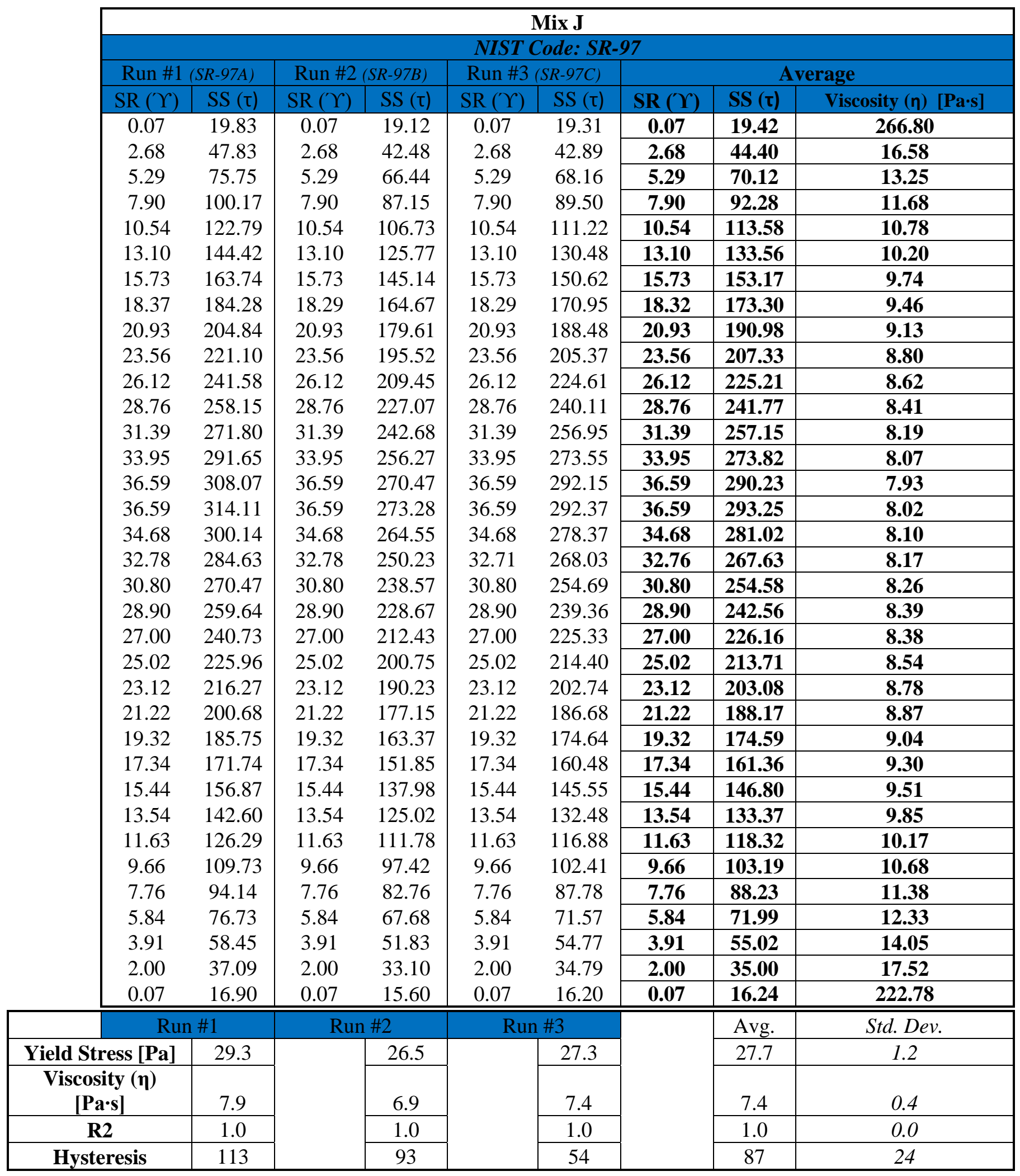


Table B-29: 3 Day values for Mix J (NIST Code: SR-96)

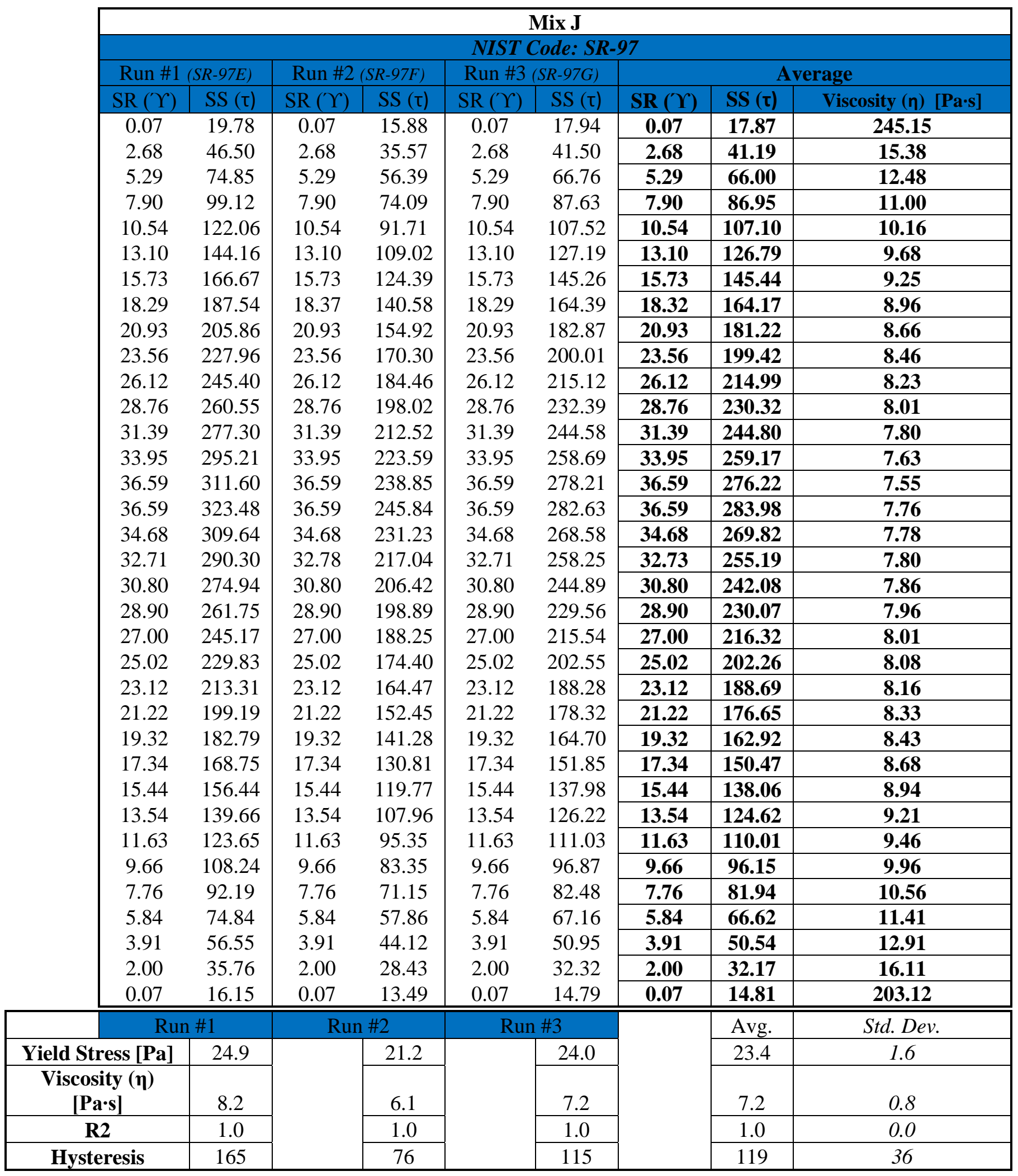


Table B-30: 7 Day values for Mix J (NIST Code: SR-96)

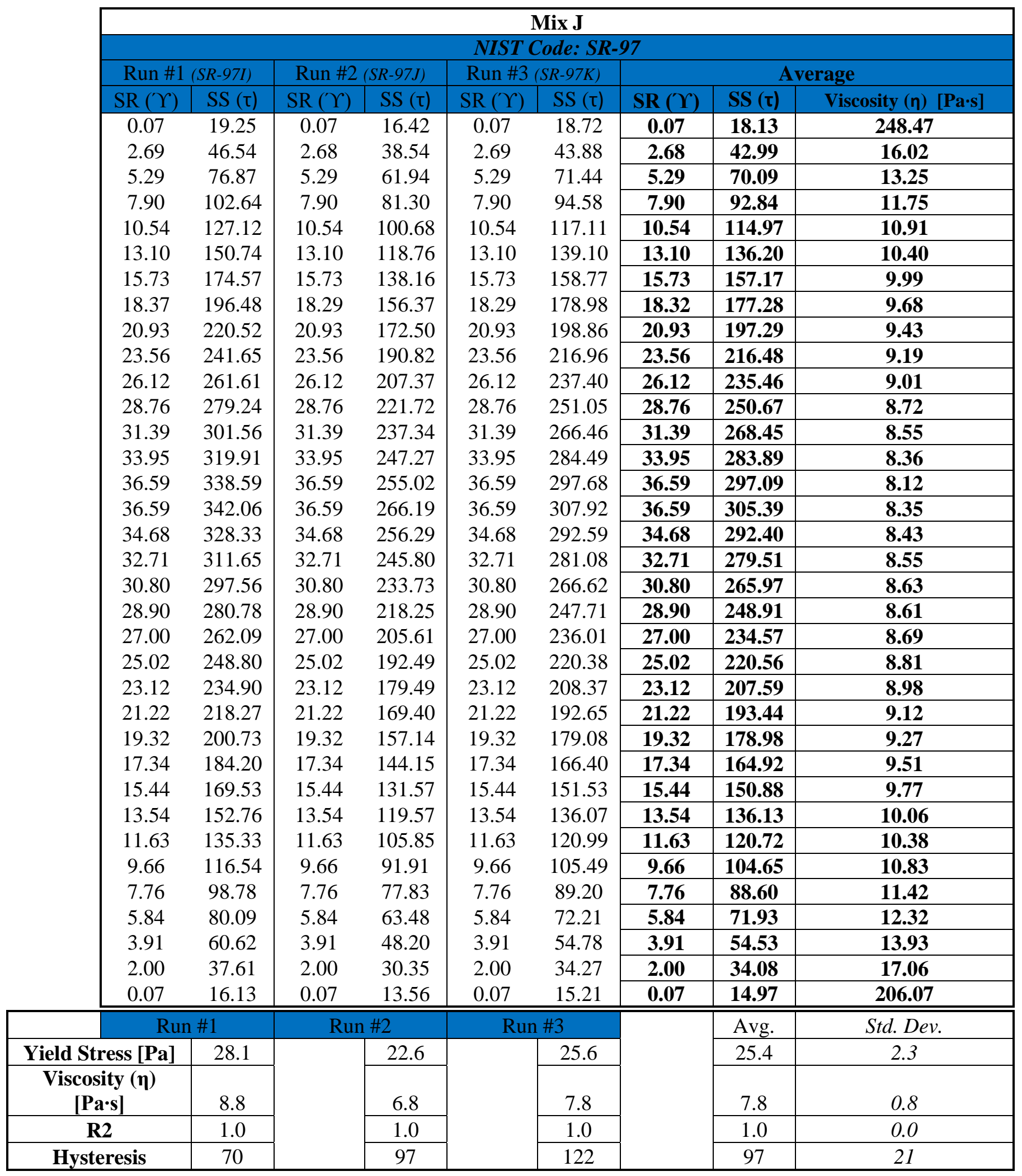




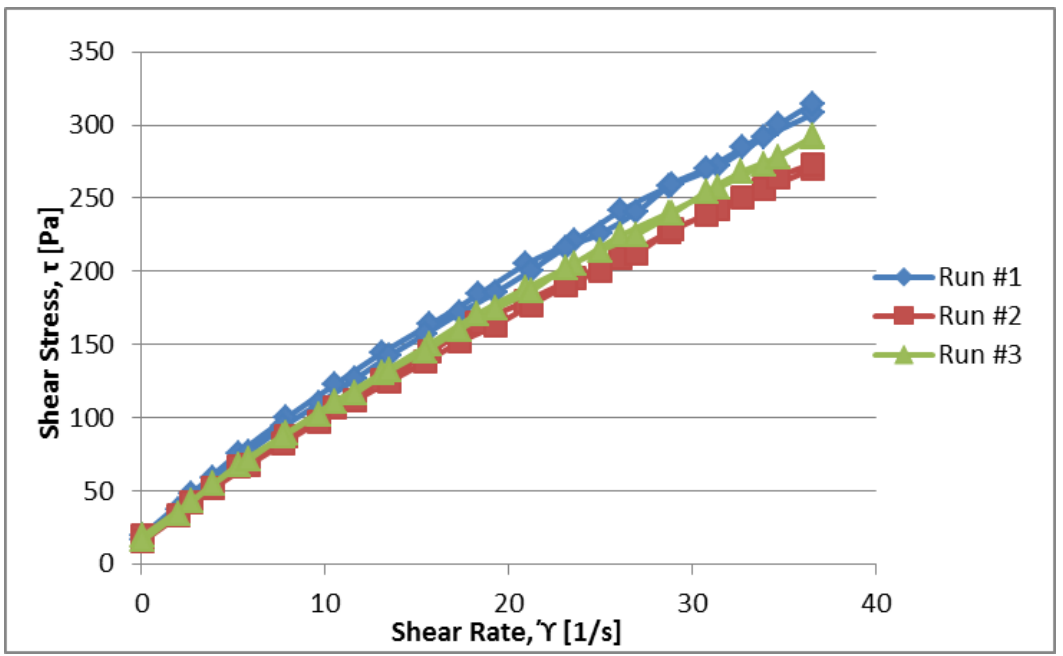

Figure B-28: 1 Day values for Mix J (NIST Code: SR-97)

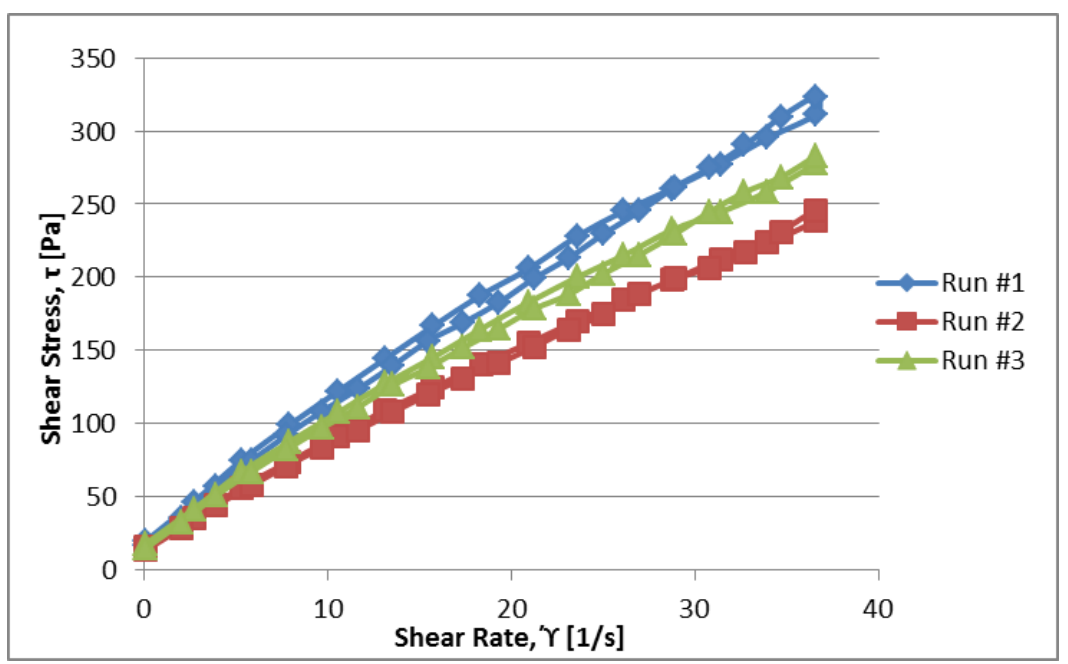

Figure B-29: 3 Day values for Mix J (NIST Code: SR-97)

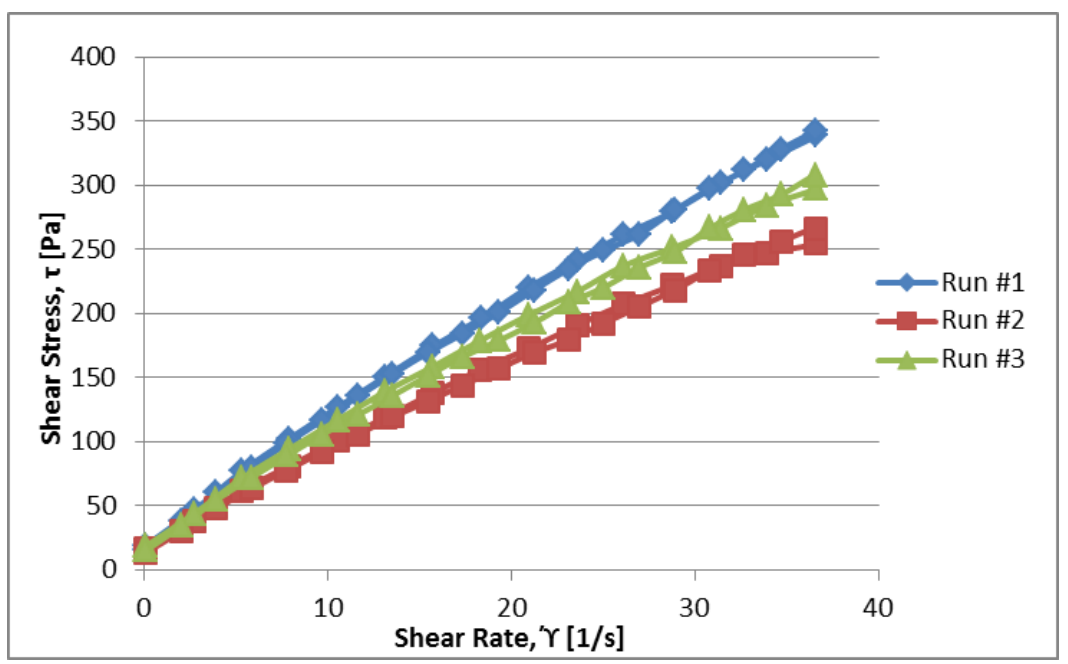

Figure B-30: 7 Day values for Mix J (NIST Code: SR-97) 
Table B-31: 1 Day values for Mix K (NIST Code: SR-90)

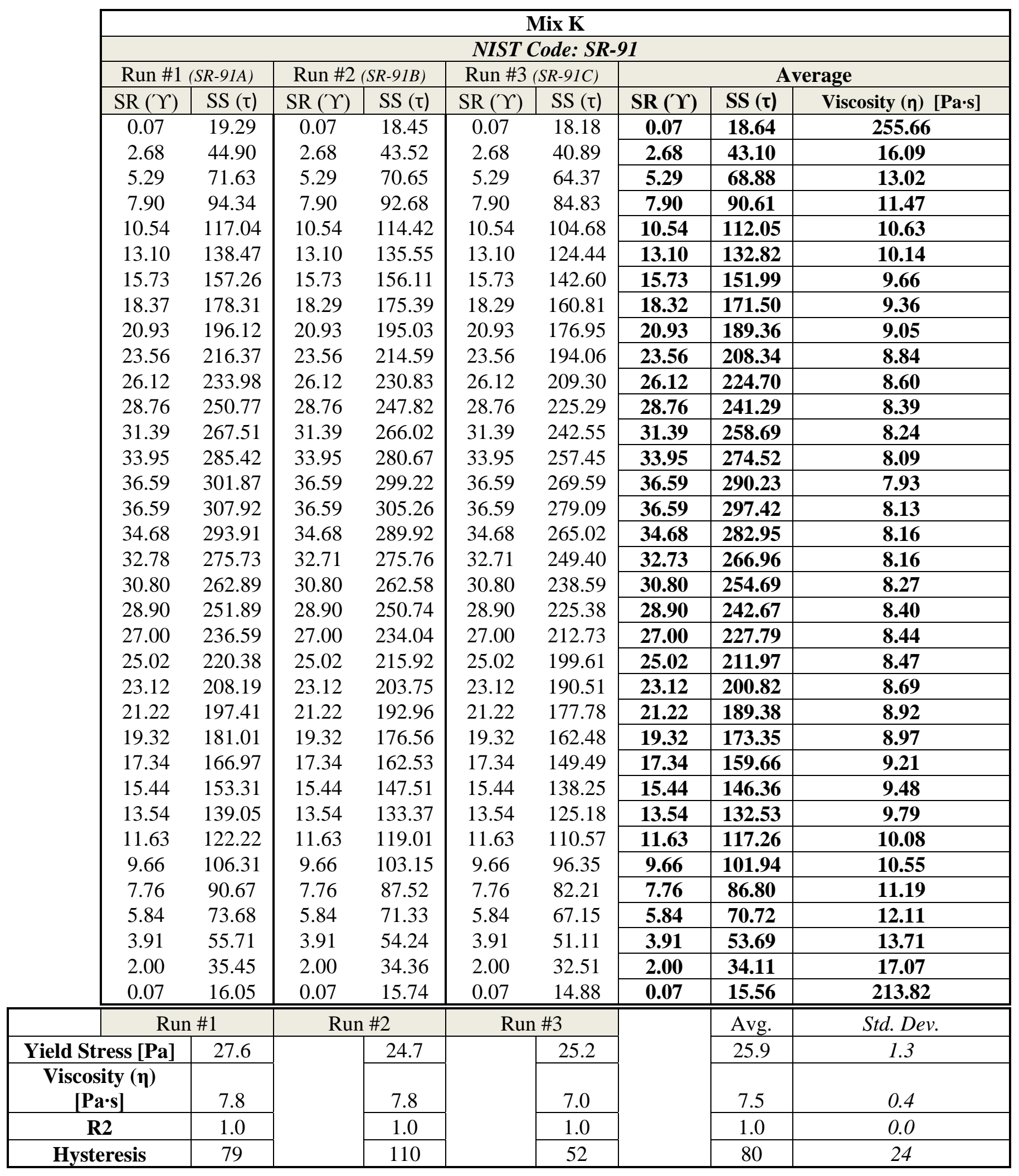


Table B-32: 3 Day values for Mix K (NIST Code: SR-90)

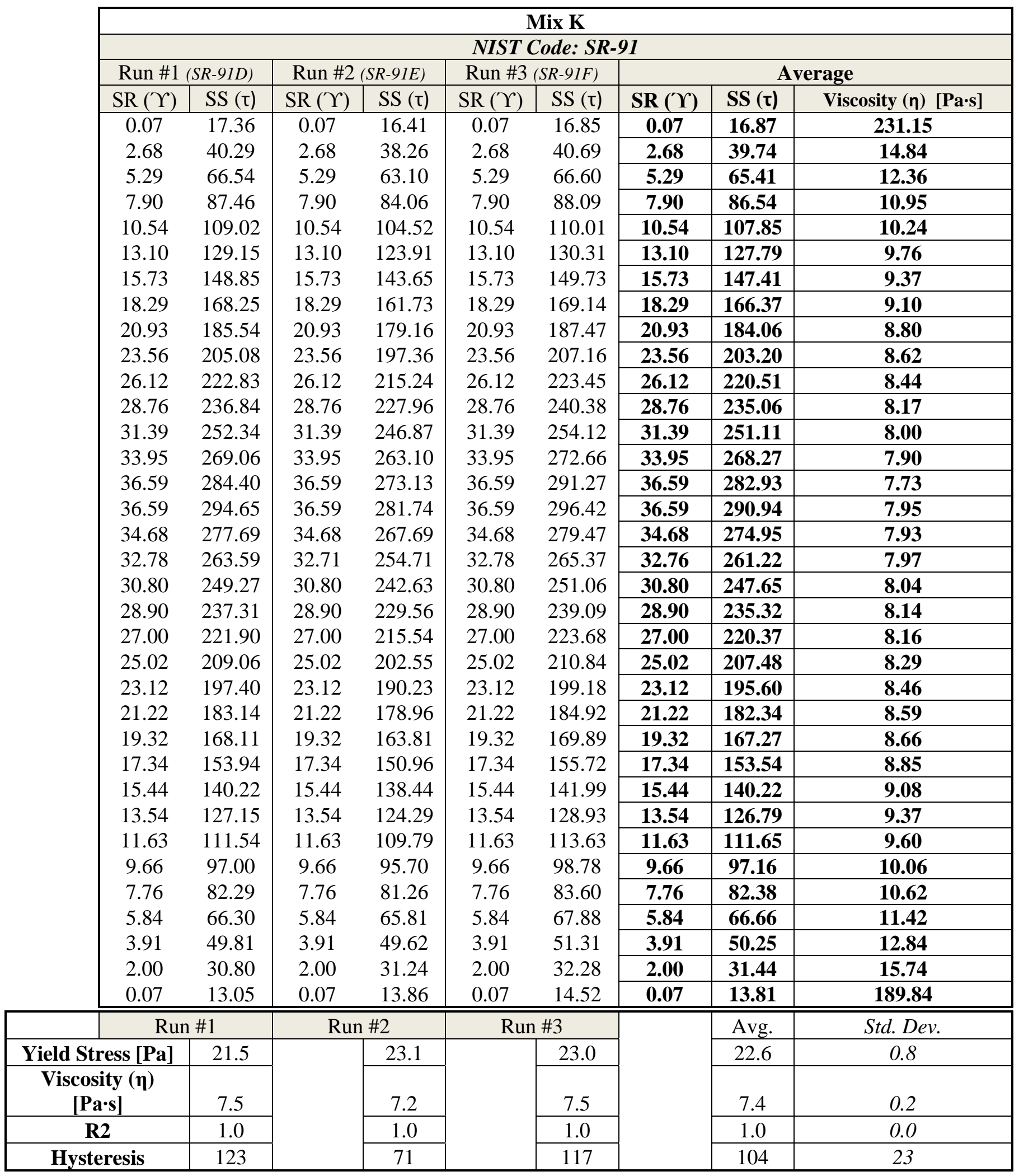


Table B-33: 7 Day values for Mix K (NIST Code: SR-90)

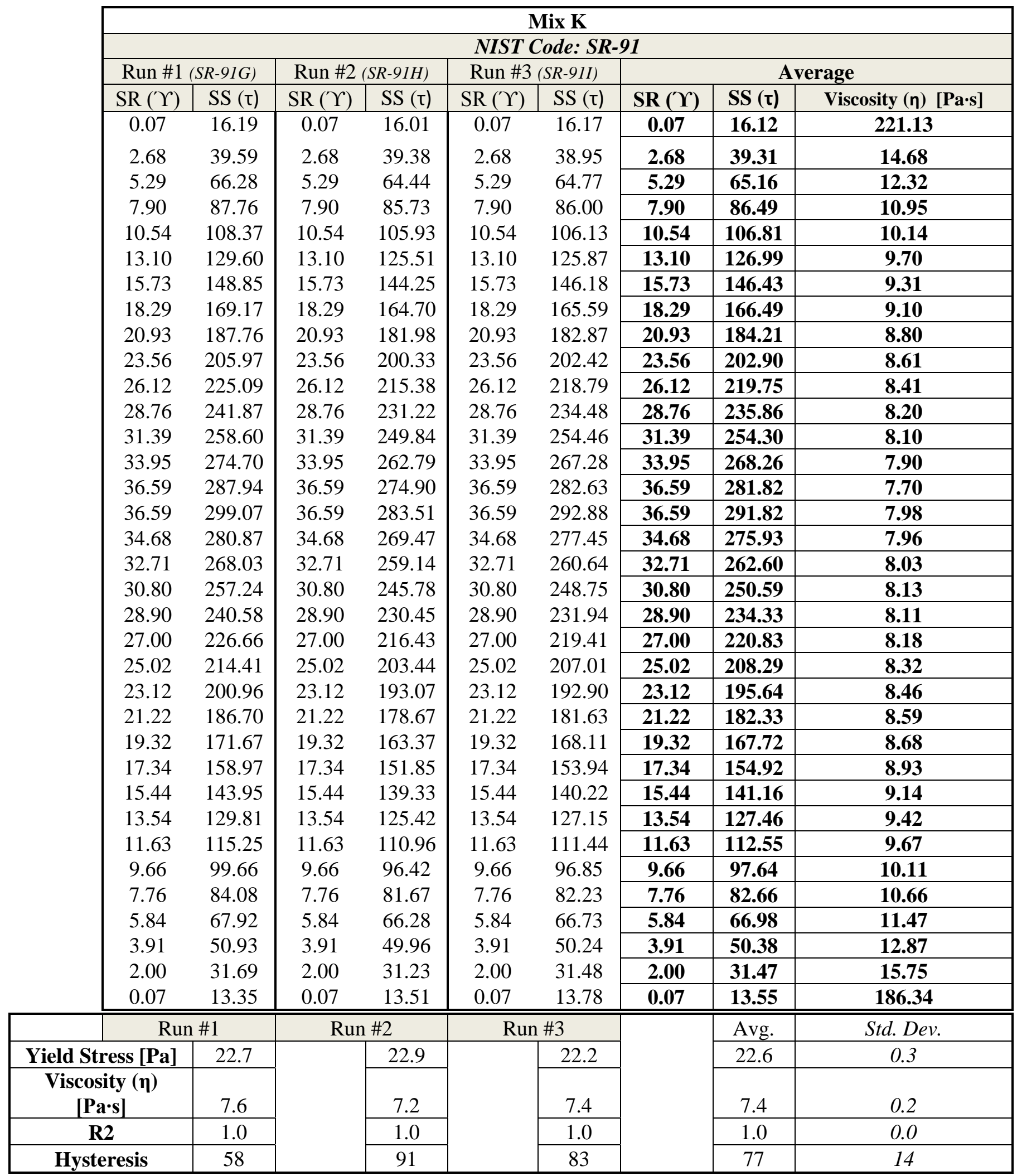




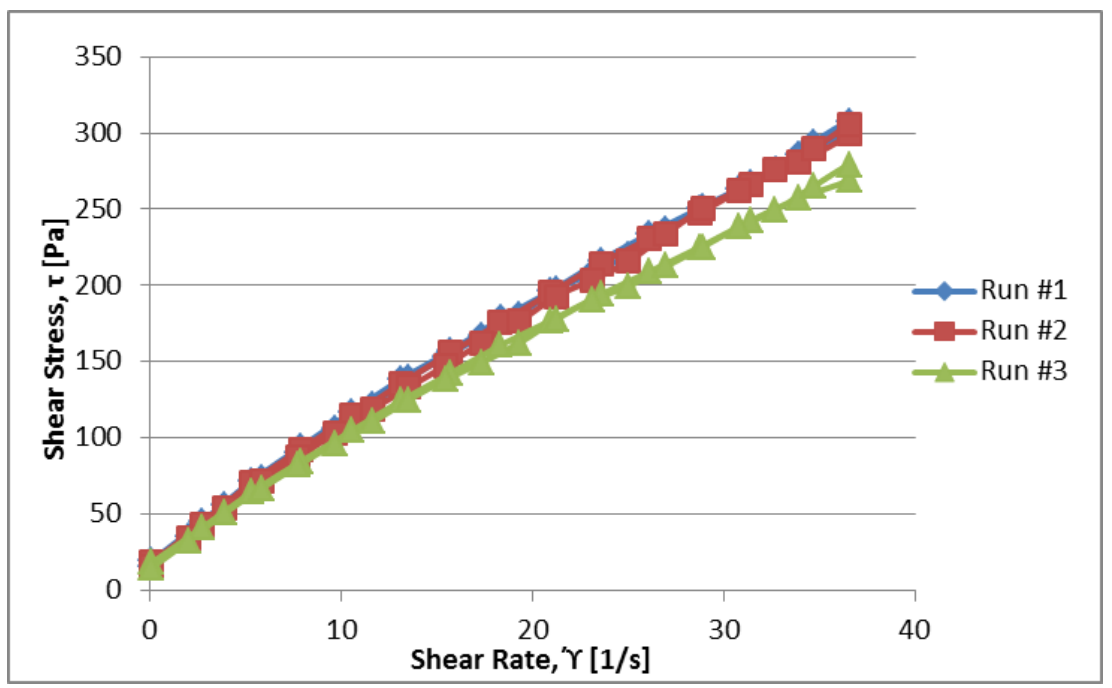

Figure B-31: 1 Day values for Mix K (NIST Code: SR-91)

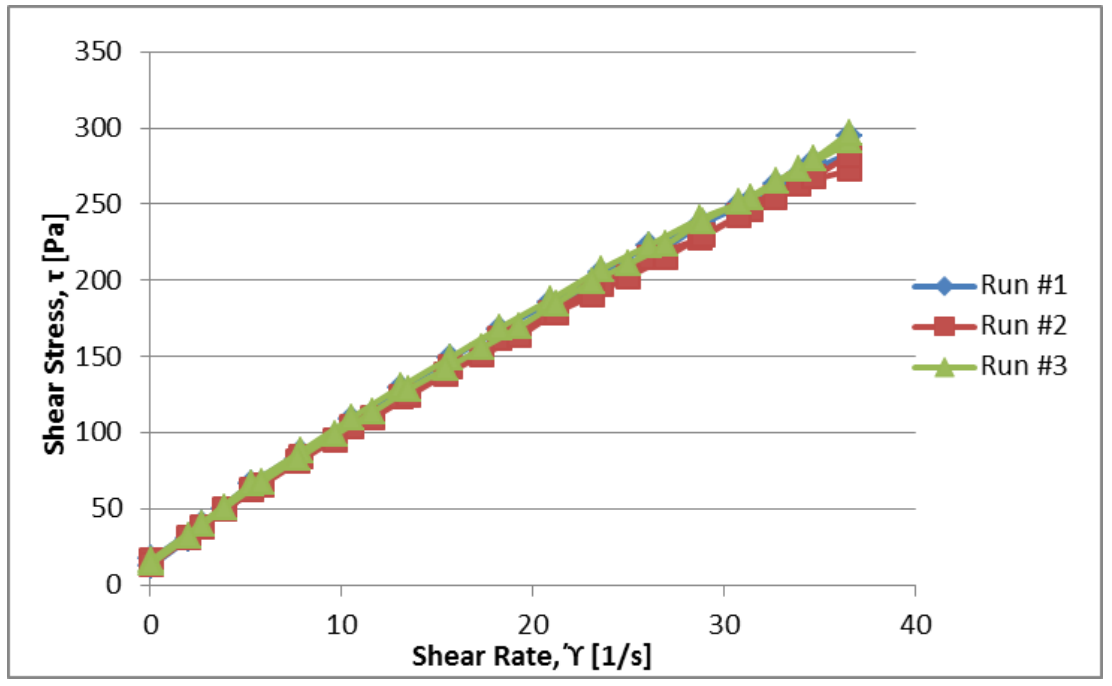

Figure B-32: 3 Day values for Mix K (NIST Code: SR-91)

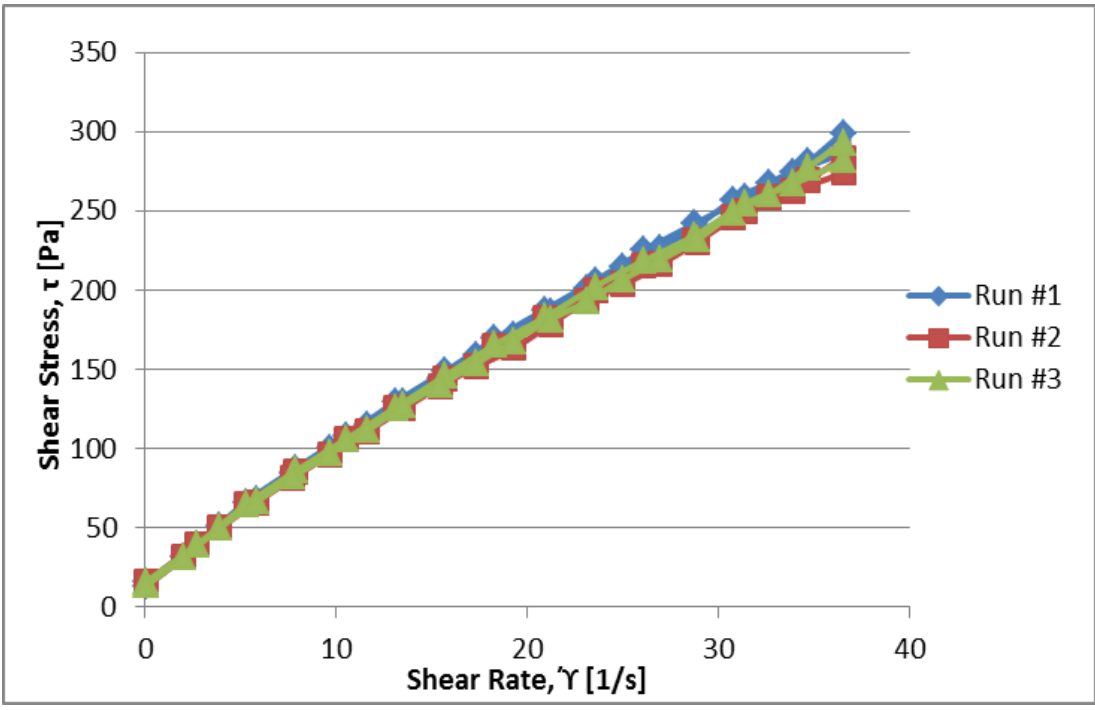

Figure B - 33: 7 Day values for Mix K (NIST Code: SR-91)

B - 45 
Table B-34: 1 Day values for Mix L $\quad$ (NIST Code: SR-100)

\begin{tabular}{|c|c|c|c|c|c|c|c|c|}
\hline \multicolumn{9}{|c|}{ Mix L } \\
\hline \multicolumn{9}{|c|}{ NIST Code: SR-101 } \\
\hline \multicolumn{2}{|c|}{ Run \#1 (SR-101A) } & \multicolumn{2}{|c|}{ Run \#2 (SR-101B) } & \multicolumn{2}{|c|}{ Run \#3 (SR-101C) } & \multicolumn{3}{|c|}{ Average } \\
\hline SR ('Y) & $\mathrm{SS}(\tau)$ & SR $(' \Upsilon)$ & $\mathrm{SS}(\tau)$ & SR (' () & $\mathrm{SS}(\tau)$ & SR ( $\Upsilon)$ & SS ( $\tau)$ & Viscosity $(\eta)[P a \cdot s]$ \\
\hline 0.07 & 22.60 & 0.07 & 21.02 & 0.07 & 20.87 & 0.07 & 21.50 & 294.87 \\
\hline 2.68 & 51.31 & 2.68 & 48.95 & 2.68 & 47.29 & 2.68 & 49.18 & 18.37 \\
\hline 5.29 & 82.48 & 5.29 & 76.94 & 5.29 & 74.26 & 5.29 & 77.89 & 14.72 \\
\hline 7.90 & 108.27 & 7.90 & 100.49 & 7.90 & 97.77 & 7.90 & 102.18 & 12.93 \\
\hline 10.54 & 132.68 & 10.54 & 122.06 & 10.54 & 120.62 & 10.54 & 125.12 & 11.87 \\
\hline 13.10 & 156.59 & 13.10 & 144.42 & 13.10 & 140.87 & 13.10 & 147.29 & 11.25 \\
\hline 15.73 & 177.71 & 15.73 & 164.50 & 15.73 & 161.43 & 15.73 & 167.88 & 10.67 \\
\hline 18.37 & 202.10 & 18.37 & 185.44 & 18.29 & 180.73 & 18.34 & 189.42 & 10.33 \\
\hline 20.93 & 222.55 & 20.93 & 205.64 & 20.93 & 200.36 & 20.93 & 209.52 & 10.01 \\
\hline 23.56 & 240.08 & 23.56 & 224.65 & 23.56 & 219.92 & 23.56 & 228.22 & 9.69 \\
\hline 26.12 & 257.61 & 26.12 & 238.11 & 26.12 & 237.54 & 26.12 & 244.42 & 9.36 \\
\hline 28.76 & 278.65 & 28.76 & 255.24 & 28.76 & 251.33 & 28.76 & 261.74 & 9.10 \\
\hline 31.39 & 296.30 & 31.39 & 273.74 & 31.39 & 265.42 & 31.39 & 278.49 & 8.87 \\
\hline 33.95 & 312.17 & 33.95 & 289.83 & 33.95 & 285.38 & 33.95 & 295.79 & 8.71 \\
\hline 36.59 & 331.73 & 36.59 & 302.99 & 36.59 & 298.56 & 36.59 & 311.09 & 8.50 \\
\hline 36.59 & 344.35 & 36.59 & 319.06 & 36.59 & 307.92 & 36.59 & 323.77 & 8.85 \\
\hline 34.68 & 326.37 & 34.68 & 302.36 & 34.68 & 292.59 & 34.68 & $\mathbf{3 0 7 . 1 0}$ & 8.85 \\
\hline 32.71 & 307.20 & 32.71 & 281.73 & 32.71 & 278.43 & 32.71 & 289.12 & 8.84 \\
\hline 30.80 & 290.55 & 30.80 & 270.00 & 30.80 & 265.26 & 30.80 & 275.27 & 8.94 \\
\hline 28.90 & 277.52 & 28.90 & 256.67 & 28.90 & 251.00 & 28.90 & 261.73 & 9.06 \\
\hline 27.00 & 259.55 & 27.00 & 239.26 & 27.00 & 235.70 & 27.00 & 244.83 & 9.07 \\
\hline 25.02 & 244.35 & 25.02 & 227.15 & 25.02 & 221.53 & 25.02 & 231.01 & 9.23 \\
\hline 23.12 & 230.45 & 23.12 & 212.42 & 23.12 & 210.04 & 23.12 & 217.64 & 9.41 \\
\hline 21.22 & 212.01 & 21.22 & 196.49 & 21.22 & 192.65 & 21.22 & 200.39 & 9.44 \\
\hline 19.32 & 194.21 & 19.32 & 183.09 & 19.32 & 179.08 & 19.32 & 185.46 & 9.60 \\
\hline 17.34 & 180.32 & 17.34 & 169.07 & 17.34 & 166.40 & 17.34 & 171.93 & 9.91 \\
\hline 15.44 & 165.51 & 15.44 & 154.20 & 15.44 & 150.18 & 15.44 & 156.63 & 10.15 \\
\hline 13.54 & 150.06 & 13.54 & 139.94 & 13.54 & 137.23 & 13.54 & 142.41 & 10.52 \\
\hline 11.63 & 132.51 & 11.63 & 122.90 & 11.63 & 121.12 & 11.63 & 125.51 & 10.79 \\
\hline 9.66 & 114.60 & 9.66 & 107.42 & 9.66 & 105.21 & 9.66 & 109.08 & 11.29 \\
\hline 7.76 & 97.80 & 7.76 & 91.73 & 7.76 & 89.79 & 7.76 & 93.10 & 12.00 \\
\hline 5.84 & 79.69 & 5.84 & 74.57 & 5.84 & 73.23 & 5.84 & 75.83 & 12.99 \\
\hline 3.91 & 60.43 & 3.91 & 56.56 & 3.91 & 55.90 & 3.91 & 57.63 & 14.72 \\
\hline 2.00 & 38.22 & 2.00 & 35.91 & 2.00 & 35.61 & 2.00 & 36.58 & 18.31 \\
\hline 0.07 & 17.65 & 0.07 & 16.42 & 0.07 & 16.84 & $\mathbf{0 . 0 7}$ & 16.97 & 233.32 \\
\hline \multicolumn{2}{|c|}{ Run \#1 } & \multicolumn{2}{|c|}{ Run \#2 } & \multicolumn{2}{|c|}{ Run \#3 } & & Avg. & Std. Dev. \\
\hline ess [Pa] & 27.2 & & 26.3 & & 26.7 & & 26.7 & 0.4 \\
\hline ty $(\eta)$ & 8.7 & & 8.0 & & 7.8 & & 8.2 & 0.4 \\
\hline 2 & 1.0 & & 1.0 & & 1.0 & & 1.0 & 0.0 \\
\hline resis & 222 & & 177 & & 177 & & 192 & 21 \\
\hline
\end{tabular}


Table B-35: 3 Day values for Mix L $\quad$ (NIST Code: SR-100)

\begin{tabular}{|c|c|c|c|c|c|c|c|c|}
\hline \multicolumn{9}{|c|}{ Mix L } \\
\hline \multicolumn{9}{|c|}{ NIST Code: SR-101 } \\
\hline \multicolumn{2}{|c|}{ Run \#1 (SR-101E) } & \multicolumn{2}{|c|}{ Run \#2 (SR-101F) } & \multicolumn{2}{|c|}{ Run \#3 (SR-101G) } & \multicolumn{3}{|c|}{ Average } \\
\hline SR ('Y) & $\mathrm{SS}(\tau)$ & SR $(' \Upsilon)$ & $\mathrm{SS}(\tau)$ & SR (' () & $\mathrm{SS}(\tau)$ & SR ( $\Upsilon)$ & SS ( $\tau)$ & Viscosity $(\eta)[P a \cdot s]$ \\
\hline 0.07 & 20.05 & 0.07 & 19.82 & 0.07 & 19.70 & 0.07 & 19.85 & 273.81 \\
\hline 2.68 & 46.46 & 2.69 & 45.08 & 2.69 & 46.51 & 2.68 & 46.02 & 17.15 \\
\hline 5.29 & 75.60 & 5.29 & 71.64 & 5.29 & 74.68 & 5.29 & 73.97 & 13.98 \\
\hline 7.90 & 100.30 & 7.90 & 94.28 & 7.90 & 98.28 & 7.90 & 97.62 & 12.35 \\
\hline 10.54 & 123.42 & 10.54 & 116.56 & 10.54 & 120.32 & 10.54 & 120.10 & 11.40 \\
\hline 13.10 & 146.83 & 13.10 & 136.69 & 13.10 & 140.87 & 13.10 & 141.47 & 10.80 \\
\hline 15.73 & 167.68 & 15.73 & 154.85 & 15.73 & 161.84 & 15.73 & 161.46 & 10.26 \\
\hline 18.29 & 188.17 & 18.37 & 173.26 & 18.37 & 182.78 & 18.34 & 181.40 & 9.89 \\
\hline 20.93 & 207.91 & 20.93 & 192.38 & 20.93 & 201.90 & 20.93 & 200.73 & 9.59 \\
\hline 23.56 & 227.35 & 23.56 & 211.31 & 23.56 & 220.81 & 23.56 & 219.82 & 9.33 \\
\hline 26.12 & 243.54 & 26.12 & 229.06 & 26.12 & 235.68 & 26.12 & 236.09 & 9.04 \\
\hline 28.76 & 257.65 & 28.76 & 243.06 & 28.76 & 248.43 & 28.76 & 249.72 & 8.68 \\
\hline 31.39 & 279.24 & 31.39 & 260.22 & 31.39 & 265.70 & 31.39 & 268.39 & 8.55 \\
\hline 33.95 & 293.39 & 33.95 & 278.26 & 33.95 & 282.42 & 33.95 & 284.69 & 8.39 \\
\hline 36.59 & 306.53 & 36.59 & 291.48 & 36.59 & 297.68 & 36.59 & 298.56 & 8.16 \\
\hline 36.59 & 327.55 & 36.59 & 308.45 & 36.59 & 312.87 & 36.59 & 316.29 & 8.65 \\
\hline 34.68 & 306.62 & 34.68 & 288.84 & 34.68 & 296.12 & 34.68 & 297.19 & 8.57 \\
\hline 32.71 & 288.79 & 32.71 & 269.55 & 32.71 & 278.13 & 32.71 & 278.83 & 8.52 \\
\hline 30.80 & 274.52 & 30.80 & 257.65 & 30.80 & 262.58 & 30.80 & 264.92 & 8.60 \\
\hline 28.90 & 256.67 & 28.90 & 243.25 & 28.90 & 248.33 & 28.90 & 249.42 & 8.63 \\
\hline 27.00 & 243.72 & 27.00 & 229.33 & 27.00 & 235.26 & 27.00 & 236.10 & 8.74 \\
\hline 25.02 & 226.88 & 25.02 & 217.08 & 25.02 & 219.76 & 25.02 & 221.24 & 8.84 \\
\hline 23.12 & 211.82 & 23.12 & 203.63 & 23.12 & 206.48 & 23.12 & 207.31 & 8.97 \\
\hline 21.22 & 196.23 & 21.22 & 187.58 & 21.22 & 189.09 & 21.22 & 190.96 & 9.00 \\
\hline 19.32 & 181.31 & 19.32 & 173.89 & 19.32 & 175.52 & 19.32 & 176.91 & 9.16 \\
\hline 17.34 & 167.29 & 17.34 & 162.53 & 17.34 & 161.37 & 17.34 & 163.73 & 9.44 \\
\hline 15.44 & 153.78 & 15.44 & 148.86 & 15.44 & 147.79 & 15.44 & 150.14 & 9.72 \\
\hline 13.54 & 136.99 & 13.54 & 133.40 & 13.54 & 133.40 & 13.54 & 134.60 & 9.94 \\
\hline 11.63 & 121.09 & 11.63 & 117.29 & 11.63 & 117.91 & 11.63 & 118.76 & 10.21 \\
\hline 9.66 & 105.38 & 9.66 & 102.57 & 9.66 & 102.50 & 9.66 & 103.48 & 10.71 \\
\hline 7.76 & 89.30 & 7.76 & 87.30 & 7.76 & 86.73 & 7.76 & 87.78 & 11.32 \\
\hline 5.84 & 72.04 & 5.84 & 71.07 & 5.84 & 70.39 & 5.84 & 71.17 & 12.19 \\
\hline 3.91 & 54.50 & 3.91 & 53.98 & 3.91 & 53.35 & 3.91 & 53.94 & 13.78 \\
\hline 2.00 & 34.48 & 2.00 & 34.08 & 2.00 & 33.71 & 2.00 & 34.09 & 17.07 \\
\hline 0.07 & 15.66 & 0.07 & 15.56 & 0.07 & 15.28 & $\mathbf{0 . 0 7}$ & 15.50 & 213.00 \\
\hline \multicolumn{2}{|c|}{ Run \#1 } & \multicolumn{2}{|c|}{ Run \#2 } & \multicolumn{2}{|c|}{ Run \#3 } & & Avg. & Std. Dev. \\
\hline ess [Pa] & 22.3 & & 24.8 & & 22.6 & & 23.3 & 1.1 \\
\hline ty $(\eta)$ & 8.2 & & 7.7 & & 7.9 & & 7.9 & 0.2 \\
\hline$\underline{\Sigma}$ & 1.0 & & 1.0 & & 1.0 & & 1.0 & 0.0 \\
\hline resis & 246 & & 118 & & 244 & & 203 & 60 \\
\hline
\end{tabular}


Table B-36: 7 Day values for Mix L $\quad$ (NIST Code: SR-100)

\begin{tabular}{|c|c|c|c|c|c|c|c|c|}
\hline \multicolumn{9}{|c|}{ Mix L } \\
\hline \multicolumn{9}{|c|}{ NIST Code: SR-101 } \\
\hline \multicolumn{2}{|c|}{ Run \#1 (SR-101I) } & \multicolumn{2}{|c|}{ Run \#2 (SR-101J) } & \multicolumn{2}{|c|}{ Run \#3 (SR-101K) } & \multicolumn{3}{|c|}{ Average } \\
\hline SR $(Y)$ & SS $(\tau)$ & SR ('Y) & $\mathrm{SS}(\tau)$ & $\mathrm{SR}(\Upsilon)$ & SS $(\tau)$ & SR ('Y) & SS ( $\tau)$ & Viscosity (n) [Pa·s] \\
\hline 0.07 & 22.08 & 0.07 & 19.55 & 0.07 & 22.09 & $\mathbf{0 . 0 7}$ & 21.24 & 292.50 \\
\hline 2.68 & 48.97 & 2.68 & 50.26 & 2.68 & 52.02 & 2.68 & 50.42 & 18.83 \\
\hline 5.29 & 77.55 & 5.29 & 81.94 & 5.29 & 83.08 & 5.29 & 80.86 & 15.28 \\
\hline 7.90 & 102.73 & 7.90 & 109.58 & 7.90 & 109.72 & 7.90 & 107.34 & 13.58 \\
\hline 10.54 & 125.97 & 10.54 & 136.41 & 10.54 & 135.19 & 10.54 & 132.52 & 12.58 \\
\hline 13.10 & 147.71 & 13.10 & 160.77 & 13.10 & 159.62 & 13.10 & 156.03 & 11.91 \\
\hline 15.73 & 170.22 & 15.73 & 183.45 & 15.73 & 183.31 & 15.73 & 179.00 & 11.38 \\
\hline 18.29 & 192.02 & 18.29 & 207.76 & 18.37 & 205.66 & 18.32 & 201.81 & 11.02 \\
\hline 20.93 & 210.57 & 20.93 & 227.33 & 20.93 & 228.25 & 20.93 & 222.05 & 10.61 \\
\hline 23.56 & 231.23 & 23.56 & 248.12 & 23.56 & 249.62 & 23.56 & 242.99 & 10.31 \\
\hline 26.12 & 250.11 & 26.12 & 265.46 & 26.12 & 265.46 & 26.12 & 260.34 & 9.97 \\
\hline 28.76 & 263.85 & 28.76 & 286.37 & 28.76 & 284.88 & 28.76 & 278.37 & 9.68 \\
\hline 31.39 & 285.34 & 31.39 & 307.02 & 31.39 & 304.19 & 31.39 & 298.85 & 9.52 \\
\hline 33.95 & 302.63 & 33.95 & 322.25 & 33.95 & 321.36 & 33.95 & 315.42 & 9.29 \\
\hline 36.59 & 316.91 & 36.59 & 339.69 & 36.59 & 338.81 & 36.59 & 331.81 & 9.07 \\
\hline 36.59 & 333.74 & 36.59 & 352.31 & 36.59 & 351.42 & 36.59 & 345.82 & 9.45 \\
\hline 34.68 & 315.68 & 34.68 & 335.92 & 34.68 & 333.49 & 34.68 & 328.36 & 9.47 \\
\hline 32.71 & 296.51 & 32.78 & 317.83 & 32.71 & 316.97 & 32.73 & 310.43 & 9.48 \\
\hline 30.80 & 279.87 & 30.80 & 301.30 & 30.80 & 301.60 & 30.80 & 294.26 & 9.55 \\
\hline 28.90 & 264.42 & 28.90 & 288.27 & 28.90 & 284.97 & 28.90 & 279.22 & 9.66 \\
\hline 27.00 & 247.85 & 27.00 & 266.80 & 27.00 & 267.12 & 27.00 & 260.59 & 9.65 \\
\hline 25.02 & 230.45 & 25.02 & 251.75 & 25.02 & 250.59 & 25.02 & 244.26 & 9.76 \\
\hline 23.12 & 217.16 & 23.12 & 234.61 & 23.12 & 234.90 & 23.12 & 228.89 & 9.90 \\
\hline 21.22 & 205.19 & 21.22 & 219.45 & 21.22 & 220.08 & 21.22 & 214.90 & 10.13 \\
\hline 19.32 & 185.90 & 19.32 & 202.05 & 19.32 & 201.16 & 19.32 & 196.37 & 10.17 \\
\hline 17.34 & 172.00 & 17.34 & 184.20 & 17.34 & 183.31 & 17.34 & 179.83 & 10.37 \\
\hline 15.44 & 157.05 & 15.44 & 169.53 & 15.44 & 168.64 & 15.44 & 165.07 & 10.69 \\
\hline 13.54 & 141.71 & 13.54 & 152.76 & 13.54 & 151.88 & 13.54 & 148.79 & 10.99 \\
\hline 11.63 & 125.60 & 11.63 & 135.33 & 11.63 & 133.40 & 11.63 & 131.45 & 11.30 \\
\hline 9.66 & 109.31 & 9.66 & 116.81 & 9.66 & 116.37 & 9.66 & 114.16 & 11.82 \\
\hline 7.76 & 92.76 & 7.76 & 98.44 & 7.76 & 98.36 & 7.76 & 96.52 & 12.44 \\
\hline 5.84 & 75.14 & 5.84 & 80.05 & 5.84 & 79.82 & 5.84 & 78.34 & 13.42 \\
\hline 3.91 & 56.86 & 3.91 & 60.42 & 3.91 & 60.23 & 3.91 & 59.17 & 15.11 \\
\hline 2.00 & 35.93 & 2.00 & 37.71 & 2.00 & 37.76 & 2.00 & 37.13 & 18.59 \\
\hline 0.07 & 16.33 & 0.07 & 16.57 & 0.07 & 16.84 & $\mathbf{0 . 0 7}$ & 16.58 & 228.80 \\
\hline \multicolumn{2}{|c|}{ Run \#1 } & \multicolumn{2}{|c|}{ Run \#2 } & \multicolumn{2}{|c|}{ Run \#3 } & & Avg. & Std. Dev. \\
\hline ess [Pa] & 24.2 & & 26.1 & & 25.9 & & 25.4 & 0.9 \\
\hline ty $(\eta)$ & 8.4 & & 9.0 & & 9.0 & & 8.8 & 0.3 \\
\hline 2 & 1.0 & & 1.0 & & 1.0 & & 1.0 & 0.0 \\
\hline resis & 221 & & 226 & & 239 & & 229 & 7 \\
\hline
\end{tabular}




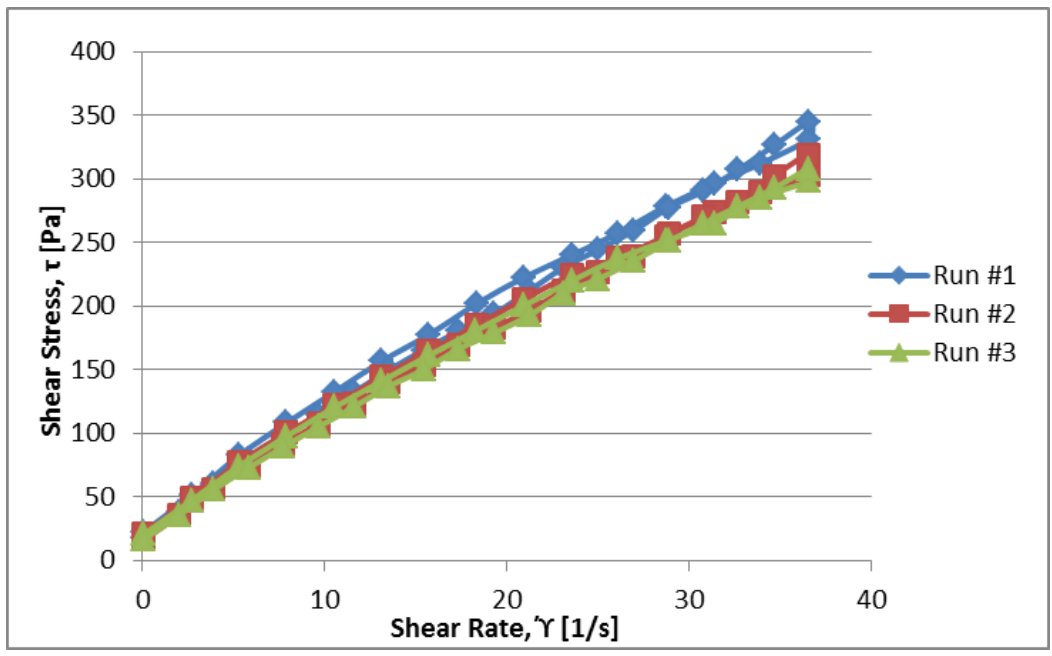

Figure B-34: 1 Day values for Mix L (Lab Code: SR-101)

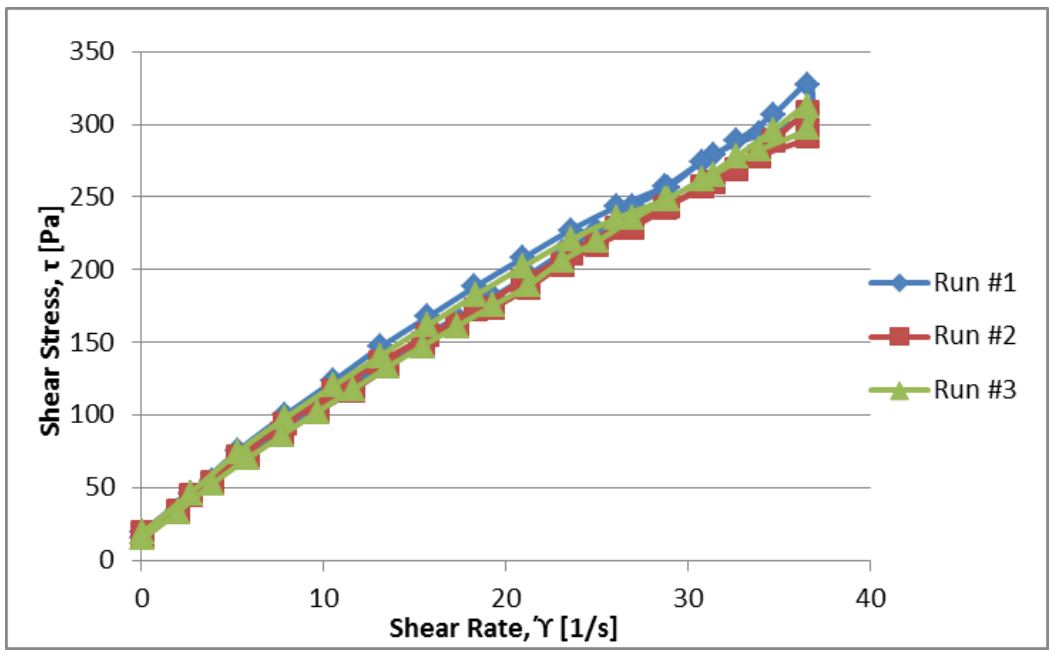

Figure B - 35: 3 Day values for Mix L (NIST Code: SR-101)

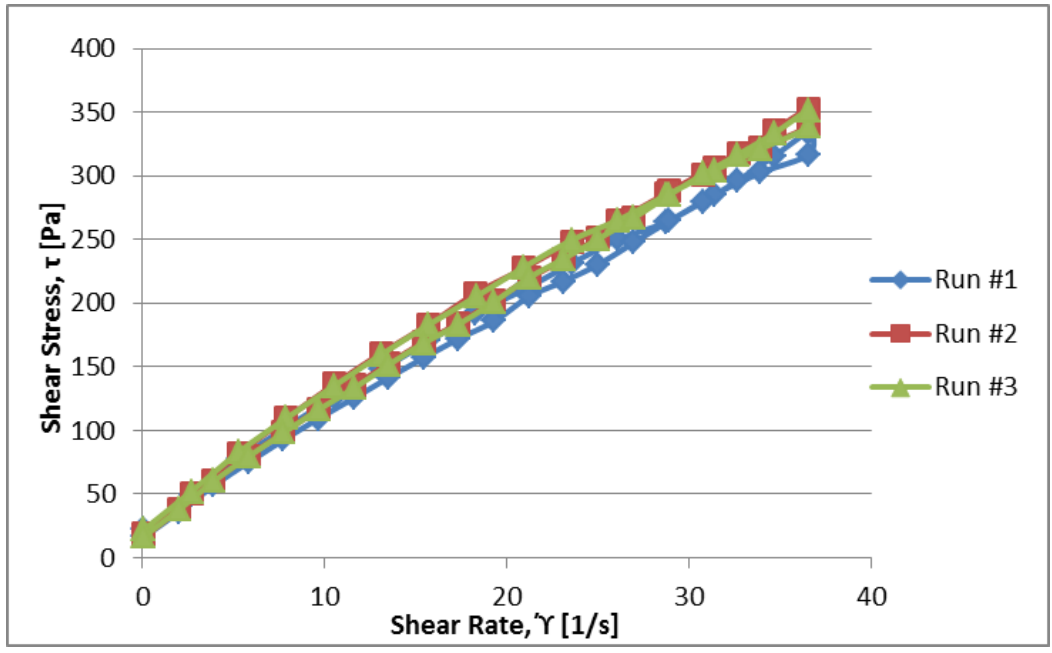

Figure B - 36: 7 Day values for Mix L (NIST Code: SR-101) 


\section{Appendix C: Viscosity curves}

This Appendix provides the viscosity curves (in log scale) for select mixes, and uses the same data as Appendix B for those respective mixes. The curves portray the viscosity of the material at each shear rate, rather than the plastic viscosity found by Bingham approximation.

Notice only select mixes were considered for the generation of viscosity curves, as explained in Section 6. The viscosity curves shown in this appendix are those which were obtained when the rheometer was programmed to record data using a logarithmic scale rather than a linear scale. The log scale data were retrieved as an additional step for the selected mixes, and the certified values were in no way affected by this extra data retrieval.

Each mix was tested at 1, 3 and 7 days; therefore, three graphs for each selected mix are shown in this appendix. The viscosity vs. shear rate data for all 3 days is presented prior to the three graphs for each mix. 
Table C-1: Values measured for Mix B using log-scale data acquisition at 1, 3 \& 7 days. This data was used to form the viscosity curves of Mix $B$.

\begin{tabular}{|c|c|c|c|c|c|c|c|}
\hline \multicolumn{8}{|c|}{ Mix B [SR-93] } \\
\hline \multicolumn{2}{|c|}{ Day 1} & \multicolumn{2}{|c|}{ Day 3} & \multicolumn{2}{|c|}{ Day 7} & \multicolumn{2}{|r|}{ Average } \\
\hline SR ('Y) & Visc. $(\mu)[\mathrm{Pa} \cdot \mathrm{s}]$ & SR (') & Visc. $(\mu)[\mathrm{Pa} \cdot \mathrm{s}]$ & SR ('Y) & Visc. $(\mu)[\mathrm{Pa} \cdot \mathrm{s}]$ & SR ('Y) & Visc. $(\mu)[\mathrm{Pa} \cdot \mathrm{s}]$ \\
\hline 0.07 & 248.00 & 0.07 & 223.10 & 0.07 & 224.32 & 0.07 & 231.81 \\
\hline 0.12 & 163.72 & 0.12 & 146.55 & 0.12 & 147.00 & 0.12 & 152.42 \\
\hline 0.18 & 111.68 & 0.18 & 100.32 & 0.18 & 100.64 & 0.18 & 104.22 \\
\hline 0.28 & 73.93 & 0.28 & 66.88 & 0.28 & 66.53 & 0.28 & 69.11 \\
\hline 0.43 & 51.02 & 0.43 & 46.33 & 0.43 & 45.76 & 0.43 & 47.70 \\
\hline 0.67 & 36.56 & 0.67 & 33.10 & 0.67 & 32.83 & 0.67 & 34.16 \\
\hline 1.05 & 27.51 & 1.05 & 24.81 & 1.05 & 24.64 & 1.05 & 25.65 \\
\hline 1.64 & 21.62 & 1.64 & 19.52 & 1.64 & 19.38 & 1.64 & 20.18 \\
\hline 2.55 & 17.61 & 2.55 & 16.03 & 2.55 & 15.85 & 2.55 & 16.50 \\
\hline 3.97 & 15.03 & 3.97 & 13.75 & 3.97 & 13.63 & 3.97 & 14.13 \\
\hline 6.20 & 13.16 & 6.20 & 12.00 & 6.20 & 11.92 & 6.20 & 12.36 \\
\hline 9.66 & 11.68 & 9.66 & 10.73 & 9.66 & 10.67 & 9.66 & 11.03 \\
\hline 15.07 & 10.47 & 15.07 & 9.62 & 15.07 & 9.64 & 15.07 & 9.91 \\
\hline 23.49 & 9.32 & 23.49 & 8.71 & 23.49 & 8.74 & 23.49 & 8.92 \\
\hline 36.59 & 8.33 & 36.59 & 7.81 & 36.59 & 7.95 & 36.59 & 8.03 \\
\hline 36.59 & 8.44 & 36.59 & 7.87 & 36.59 & 7.96 & 36.59 & 8.09 \\
\hline 26.41 & 8.89 & 26.41 & 8.29 & 26.34 & 8.41 & 26.39 & 8.53 \\
\hline 19.02 & 9.49 & 19.02 & 8.75 & 19.02 & 8.85 & 19.02 & 9.03 \\
\hline 13.68 & 10.19 & 13.68 & 9.40 & 13.68 & 9.41 & 13.68 & 9.67 \\
\hline 9.88 & 10.99 & 9.88 & 10.09 & 9.88 & 10.11 & 9.88 & 10.39 \\
\hline 7.13 & 11.98 & 7.13 & 10.89 & 7.13 & 10.97 & 7.13 & 11.28 \\
\hline 5.14 & 13.18 & 5.14 & 11.99 & 5.14 & 11.99 & 5.14 & 12.39 \\
\hline 3.71 & 14.66 & 3.71 & 13.35 & 3.70 & 13.32 & 3.71 & 13.78 \\
\hline 2.67 & 16.63 & 2.67 & 15.02 & 2.67 & 15.02 & 2.67 & 15.56 \\
\hline 1.92 & 19.13 & 1.92 & 17.39 & 1.92 & 17.26 & 1.92 & 17.93 \\
\hline 1.39 & 22.49 & 1.39 & 20.30 & 1.39 & 20.18 & 1.39 & 20.99 \\
\hline 1.00 & 27.05 & 1.00 & 24.34 & 1.00 & 24.11 & 1.00 & 25.17 \\
\hline 0.72 & 32.84 & 0.72 & 29.58 & 0.72 & 29.21 & 0.72 & 30.54 \\
\hline 0.52 & 41.06 & 0.52 & 36.94 & 0.52 & 36.52 & 0.52 & 38.17 \\
\hline 0.37 & 52.33 & 0.37 & 47.20 & 0.37 & 46.36 & 0.37 & 48.63 \\
\hline 0.27 & 66.93 & 0.27 & 60.69 & 0.27 & 59.19 & 0.27 & 62.27 \\
\hline 0.20 & 86.79 & 0.20 & 77.75 & 0.20 & 76.18 & 0.20 & 80.24 \\
\hline 0.14 & 118.28 & 0.14 & 105.46 & 0.14 & 103.54 & 0.14 & 109.09 \\
\hline 0.10 & 154.53 & 0.10 & 137.97 & 0.10 & 135.37 & 0.10 & 142.62 \\
\hline 0.07 & 209.27 & 0.07 & 187.57 & 0.07 & 183.74 & 0.07 & 193.53 \\
\hline
\end{tabular}


Figure C-1: Viscosity curves for Mix B at (a) 1, (b) 3 and (c) 7 days.

(a)

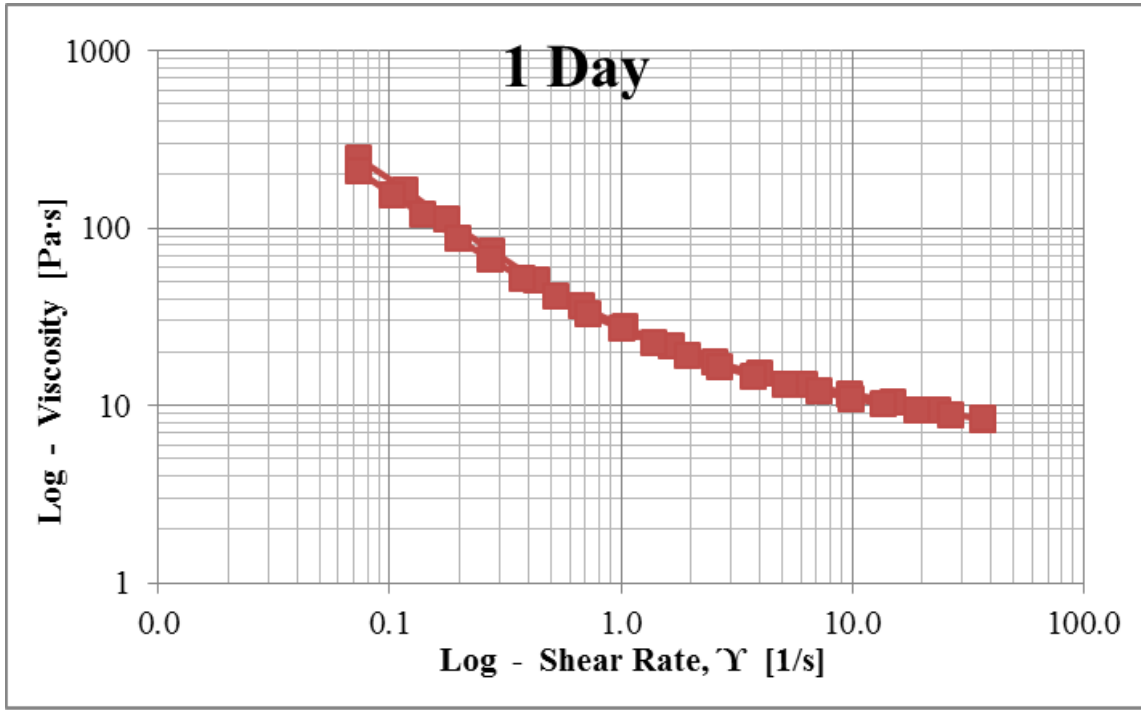

(b)

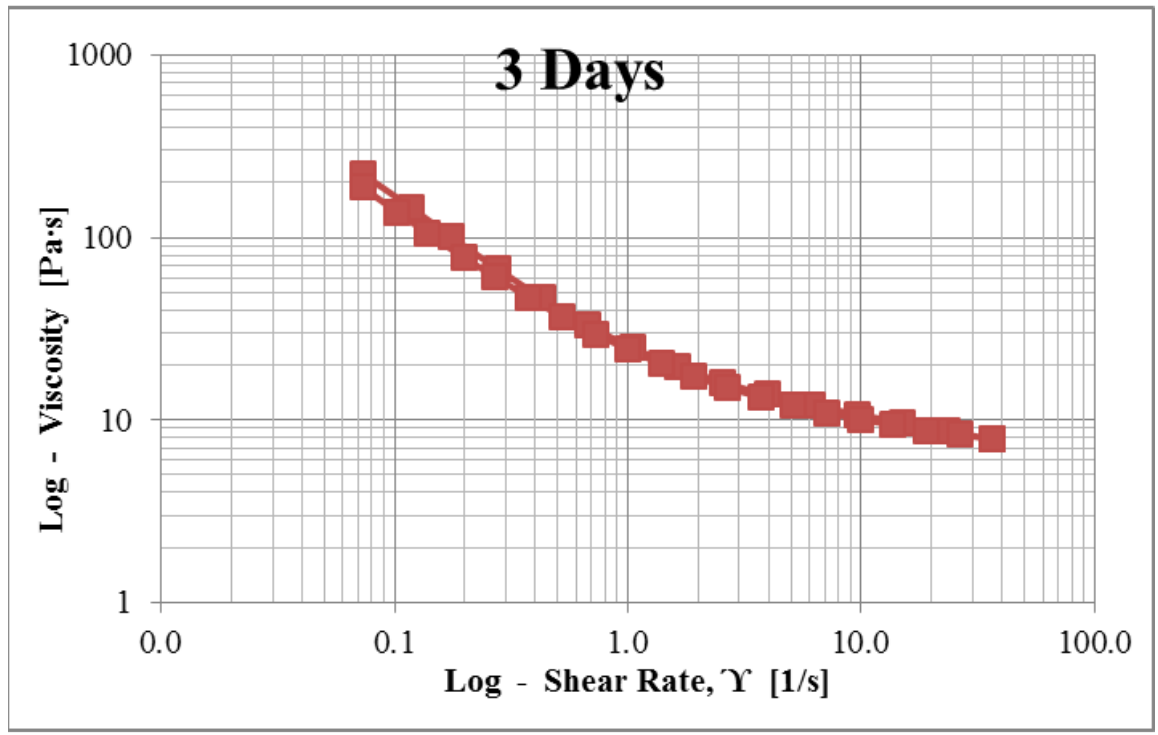

(c)

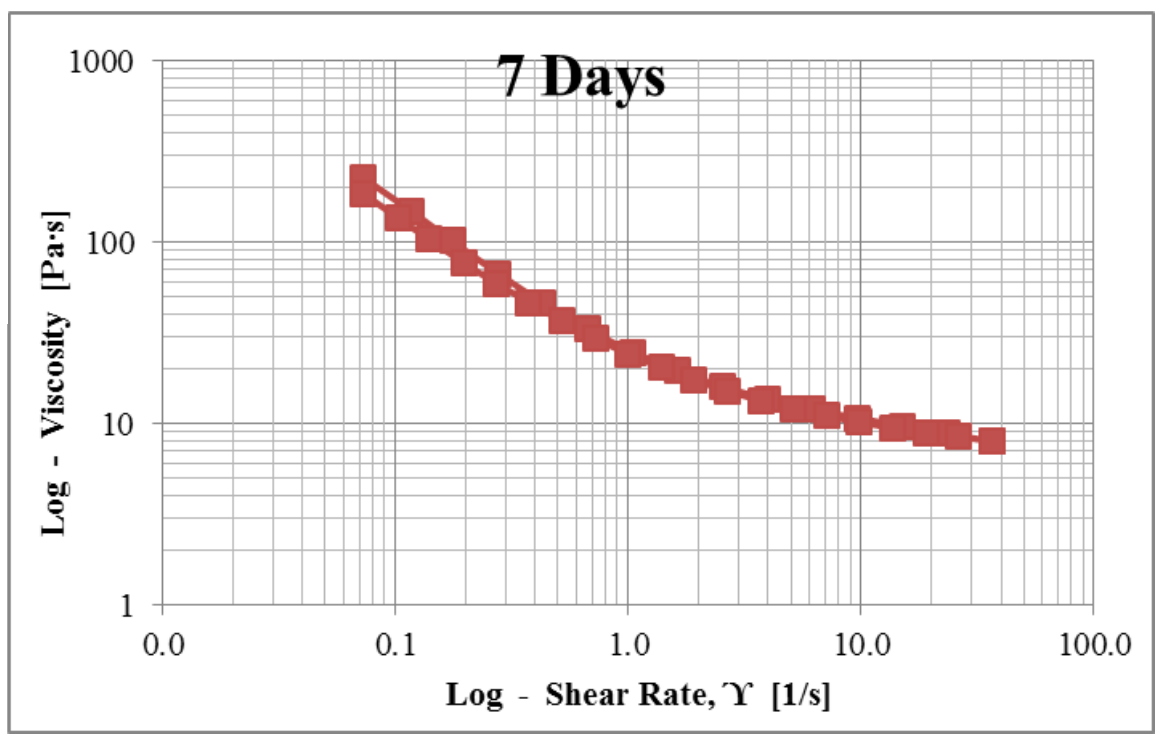

C - 3 
Table C-2: Values measured for Mix $\mathrm{H}$ using log-scale data acquisition at 1,3 \& 7 days. This data was used to form the viscosity curves of Mix $\mathrm{H}$.

\begin{tabular}{|c|c|c|c|c|c|c|c|}
\hline \multicolumn{8}{|c|}{ Mix H [SR-99] } \\
\hline \multicolumn{2}{|c|}{ Day 1} & \multicolumn{2}{|c|}{ Day 3} & \multicolumn{2}{|c|}{ Day 7} & \multicolumn{2}{|c|}{ Average } \\
\hline SR ('Y) & Visc. $(\mu)[\mathrm{Pa} \cdot \mathrm{s}]$ & SR ('Y) & Visc. $(\mu)[\mathrm{Pa} \cdot \mathrm{s}]$ & SR ('Y) & Visc. $(\mu)[\mathrm{Pa} \cdot \mathrm{s}]$ & SR ('Y) & Visc. $(\mu)$ [Pass] \\
\hline 0.07 & 258.59 & 0.07 & 259.81 & 0.07 & 276.93 & 0.07 & 265.11 \\
\hline 0.12 & 169.68 & 0.12 & 169.36 & 0.12 & 181.69 & 0.12 & 173.58 \\
\hline 0.18 & 118.62 & 0.18 & 115.16 & 0.18 & 119.08 & 0.18 & 117.62 \\
\hline 0.28 & 79.79 & 0.28 & 75.60 & 0.28 & 82.31 & 0.28 & 79.23 \\
\hline 0.43 & 55.42 & 0.43 & 52.19 & 0.43 & 56.47 & 0.43 & 54.69 \\
\hline 0.67 & 38.66 & 0.67 & 37.08 & 0.67 & 40.01 & 0.67 & 38.58 \\
\hline 1.05 & 28.34 & 1.05 & 27.42 & 1.05 & 29.75 & 1.05 & 28.50 \\
\hline 1.64 & 21.57 & 1.64 & 20.93 & 1.64 & 23.16 & 1.64 & 21.89 \\
\hline 2.55 & 17.08 & 2.55 & 17.08 & 2.55 & 18.77 & 2.55 & 17.64 \\
\hline 3.97 & 14.13 & 3.97 & 14.43 & 3.97 & 15.93 & 3.97 & 14.83 \\
\hline 6.20 & 12.05 & 6.20 & 12.54 & 6.20 & 13.85 & 6.20 & 12.82 \\
\hline 9.66 & 10.60 & 9.66 & 11.12 & 9.66 & 12.35 & 9.66 & 11.36 \\
\hline 15.07 & 9.40 & 15.07 & 9.98 & 15.07 & 10.97 & 15.07 & 10.12 \\
\hline 23.49 & 8.42 & 23.49 & 9.03 & 23.49 & 9.86 & 23.49 & 9.11 \\
\hline 36.59 & 7.50 & 36.59 & 8.07 & 36.59 & 8.83 & 36.59 & 8.13 \\
\hline 36.59 & 7.56 & 36.59 & 8.12 & 36.59 & 8.83 & 36.59 & 8.17 \\
\hline 26.41 & 7.98 & 26.41 & 8.54 & 26.34 & 9.38 & 26.39 & 8.63 \\
\hline 19.02 & 8.52 & 19.02 & 9.06 & 19.02 & 9.88 & 19.02 & 9.15 \\
\hline 13.68 & 9.18 & 13.68 & 9.65 & 13.68 & 10.59 & 13.68 & 9.81 \\
\hline 9.88 & 9.93 & 9.88 & 10.39 & 9.88 & 11.48 & 9.88 & 10.60 \\
\hline 7.13 & 10.86 & 7.13 & 11.28 & 7.13 & 12.37 & 7.13 & 11.50 \\
\hline 5.14 & 12.03 & 5.14 & 12.36 & 5.14 & 13.54 & 5.14 & 12.64 \\
\hline 3.71 & 13.51 & 3.71 & 13.80 & 3.71 & 15.06 & 3.71 & 14.12 \\
\hline 2.67 & 15.39 & 2.67 & 15.64 & 2.67 & 17.03 & 2.67 & 16.02 \\
\hline 1.92 & 17.96 & 1.92 & 18.12 & 1.92 & 19.62 & 1.92 & 18.57 \\
\hline 1.39 & 21.27 & 1.39 & 21.33 & 1.39 & 23.03 & 1.39 & 21.88 \\
\hline 1.00 & 25.66 & 1.00 & 25.53 & 1.00 & 27.63 & 1.00 & 26.27 \\
\hline 0.72 & 31.68 & 0.72 & 31.32 & 0.72 & 33.58 & 0.72 & 32.19 \\
\hline 0.52 & 40.12 & 0.52 & 39.34 & 0.52 & 42.18 & 0.52 & 40.55 \\
\hline 0.37 & 51.37 & 0.37 & 50.18 & 0.37 & 53.64 & 0.37 & 51.73 \\
\hline 0.27 & 66.11 & 0.27 & 64.46 & 0.27 & 68.94 & 0.27 & 66.50 \\
\hline 0.20 & 85.89 & 0.20 & 83.64 & 0.20 & 88.33 & 0.20 & 85.95 \\
\hline 0.14 & 116.67 & 0.14 & 113.80 & 0.14 & 120.53 & 0.14 & 117.00 \\
\hline 0.10 & 152.75 & 0.10 & 147.97 & 0.10 & 158.01 & 0.10 & 152.91 \\
\hline 0.07 & 208.29 & 0.07 & 200.79 & 0.07 & 214.15 & 0.07 & 207.74 \\
\hline
\end{tabular}


Figure C-2: Viscosity curves for Mix $\mathrm{H}$ at (a) 1, (b) 3 and (c) 7 days.

(a)

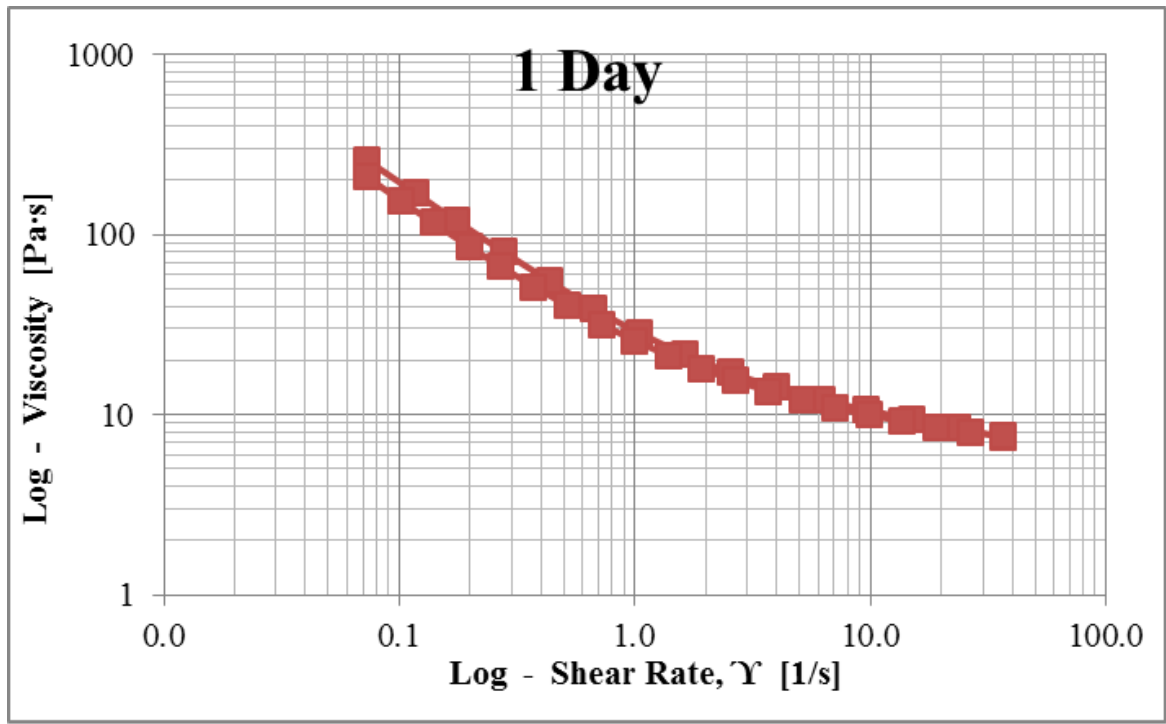

(b)

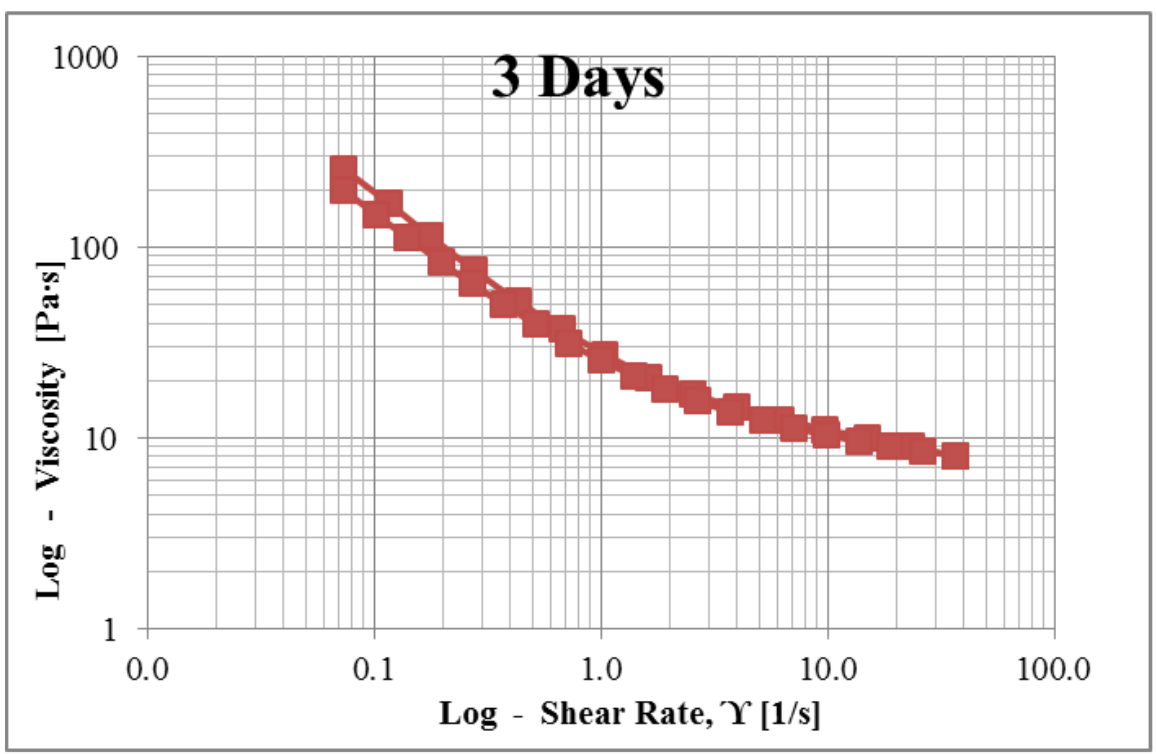

(c)

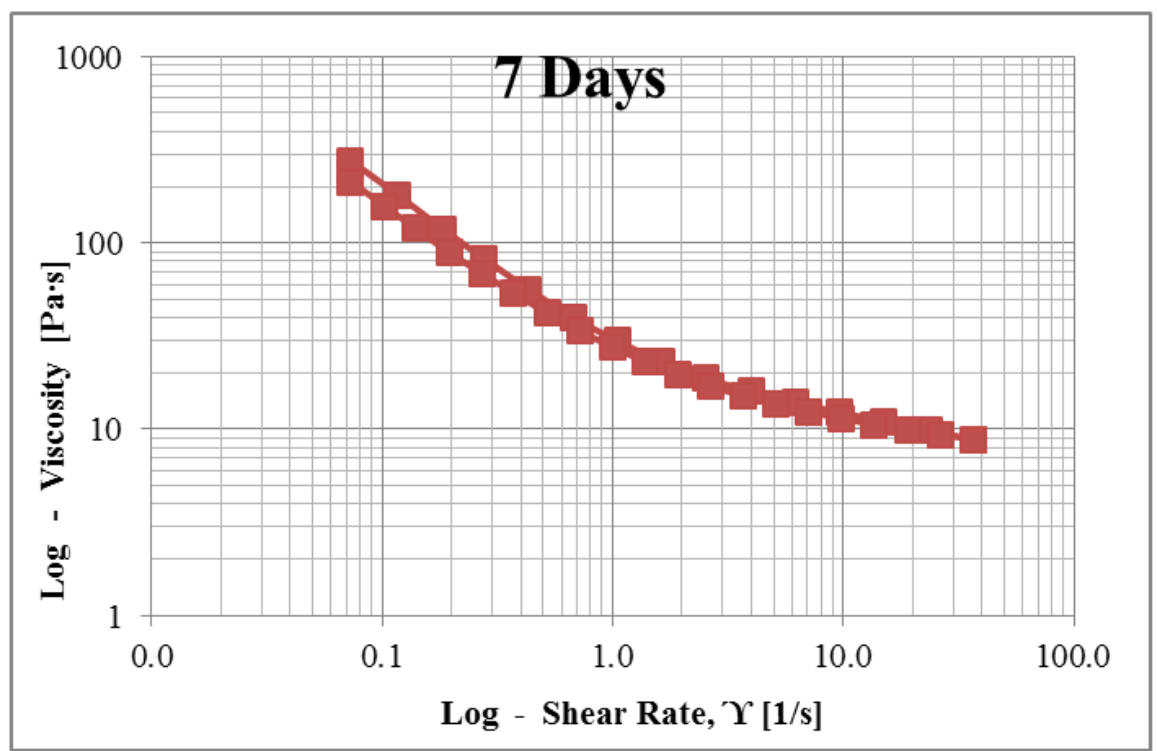

C - 5 
Table C-3: Values measured for Mix I using log-scale data acquisition at 1, 3 \& 7 days. This data was used to form the viscosity curves of Mix I.

\begin{tabular}{|c|c|c|c|c|c|c|c|}
\hline \multicolumn{8}{|c|}{ Mix I [SR-95] } \\
\hline \multicolumn{2}{|c|}{ Day 1} & \multicolumn{2}{|c|}{ Day 3} & \multicolumn{2}{|c|}{ Day 7} & \multicolumn{2}{|c|}{$\begin{array}{l}\text { Average } \\
\end{array}$} \\
\hline SR ('Y) & Visc. $(\mu)[\mathrm{Pa} \cdot \mathrm{s}]$ & SR ('Y) & Visc. $(\mu)[\mathrm{Pa} \cdot \mathrm{s}]$ & SR $(' Y)$ & Visc. $(\mu)[\mathrm{Pa} \cdot \mathrm{s}]$ & SR ('Y) & Visc. $(\mu)[$ Pa:s] \\
\hline 0.07 & 241.63 & 0.07 & 226.36 & 0.07 & 211.91 & 0.07 & 226.63 \\
\hline 0.12 & 159.62 & 0.12 & 148.29 & 0.12 & 139.13 & 0.12 & 149.01 \\
\hline 0.18 & 108.95 & 0.18 & 100.25 & 0.18 & 94.86 & 0.18 & 101.35 \\
\hline 0.28 & 71.88 & 0.28 & 66.86 & 0.28 & 63.34 & 0.28 & 67.36 \\
\hline 0.43 & 49.85 & 0.43 & 46.76 & 0.43 & 44.35 & 0.43 & 46.99 \\
\hline 0.67 & 35.87 & 0.67 & 33.65 & 0.67 & 31.77 & 0.67 & 33.76 \\
\hline 1.05 & 26.68 & 1.05 & 25.05 & 1.05 & 23.82 & 1.05 & 25.18 \\
\hline 1.64 & 20.65 & 1.64 & 19.40 & 1.64 & 18.49 & 1.64 & 19.51 \\
\hline 2.55 & 16.70 & 2.55 & 16.12 & 2.55 & 15.07 & 2.55 & 15.96 \\
\hline 3.97 & 14.11 & 3.97 & 13.71 & 3.97 & 12.74 & 3.97 & 13.52 \\
\hline 6.20 & 12.18 & 6.20 & 12.04 & 6.20 & 11.07 & 6.20 & 11.76 \\
\hline 9.66 & 10.81 & 9.66 & 10.72 & 9.66 & 9.84 & 9.66 & 10.45 \\
\hline 15.07 & 9.66 & 15.07 & 9.65 & 15.07 & 8.89 & 15.07 & 9.40 \\
\hline 23.49 & 8.70 & 23.49 & 8.85 & 23.49 & 8.05 & 23.49 & 8.53 \\
\hline 36.59 & 7.86 & 36.59 & 7.95 & 36.59 & 7.24 & 36.59 & 7.68 \\
\hline 36.59 & 7.93 & 36.59 & 7.99 & 36.59 & 7.25 & 36.59 & 7.72 \\
\hline 26.34 & 8.34 & 26.41 & 8.42 & 26.34 & 7.71 & 26.37 & 8.16 \\
\hline 19.02 & 8.86 & 19.02 & 8.89 & 19.02 & 8.13 & 19.02 & 8.63 \\
\hline 13.68 & 9.48 & 13.68 & 9.49 & 13.68 & 8.67 & 13.68 & 9.21 \\
\hline 9.88 & 10.19 & 9.88 & 10.19 & 9.88 & 9.31 & 9.88 & 9.90 \\
\hline 7.13 & 11.07 & 7.13 & 11.06 & 7.13 & 10.08 & 7.13 & 10.74 \\
\hline 5.14 & 12.17 & 5.14 & 12.11 & 5.14 & 11.07 & 5.14 & 11.78 \\
\hline 3.70 & 13.62 & 3.71 & 13.49 & 3.70 & 12.30 & 3.70 & 13.14 \\
\hline 2.67 & 15.43 & 2.67 & 15.24 & 2.67 & 13.94 & 2.67 & 14.87 \\
\hline 1.92 & 17.89 & 1.92 & 17.64 & 1.92 & 16.08 & 1.92 & 17.20 \\
\hline 1.39 & 21.11 & 1.39 & 20.65 & 1.39 & 18.86 & 1.39 & 20.21 \\
\hline 1.00 & 25.31 & 1.00 & 24.74 & 1.00 & 22.60 & 1.00 & 24.21 \\
\hline 0.72 & 30.81 & 0.72 & 30.07 & 0.72 & 27.55 & 0.72 & 29.48 \\
\hline 0.52 & 38.75 & 0.52 & 37.72 & 0.52 & 34.63 & 0.52 & 37.03 \\
\hline 0.37 & 49.46 & 0.37 & 48.16 & 0.37 & 44.46 & 0.37 & 47.36 \\
\hline 0.27 & 63.65 & 0.27 & 61.51 & 0.27 & 56.71 & 0.27 & 60.63 \\
\hline 0.20 & 81.81 & 0.20 & 78.65 & 0.20 & 73.51 & 0.20 & 77.99 \\
\hline 0.14 & 111.23 & 0.14 & 107.07 & 0.14 & 99.04 & 0.14 & 105.78 \\
\hline 0.10 & 146.27 & 0.10 & 139.27 & 0.10 & 129.72 & 0.10 & 138.42 \\
\hline 0.07 & 198.31 & 0.07 & 188.61 & 0.07 & 176.43 & 0.07 & 187.79 \\
\hline
\end{tabular}


Figure C-3: Viscosity curves for Mix I at (a) 1, (b) 3 and (c) 7 days.

(a)

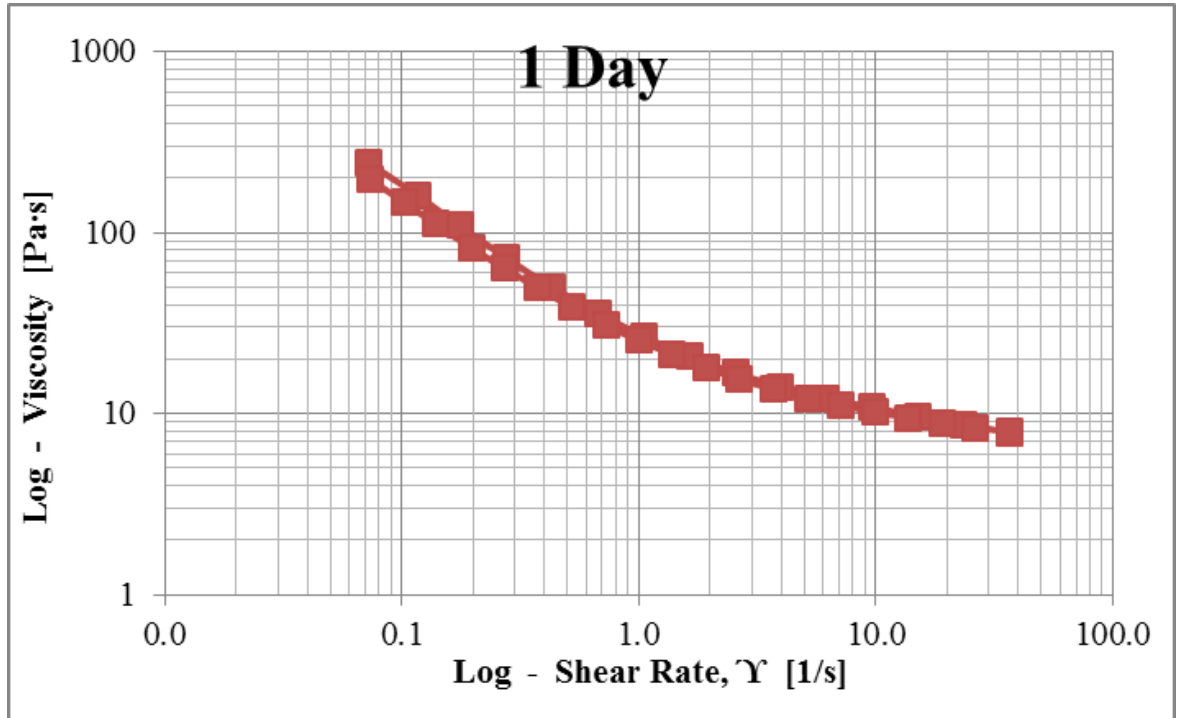

(b)

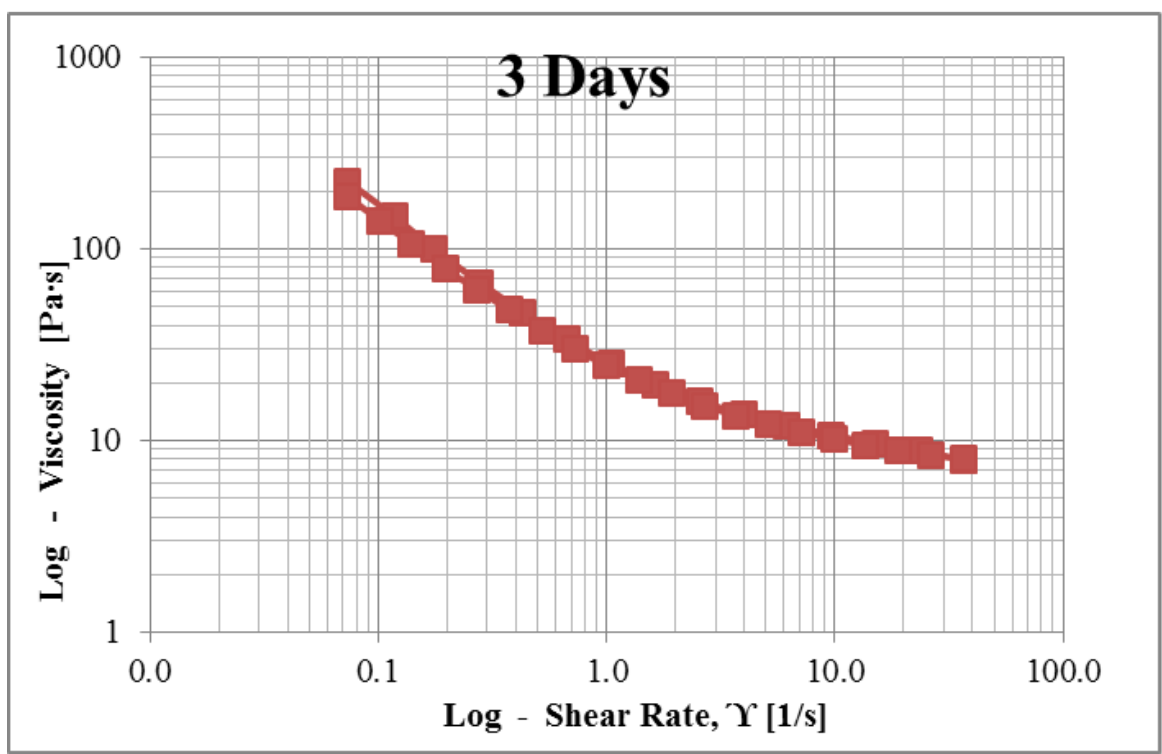

(c)

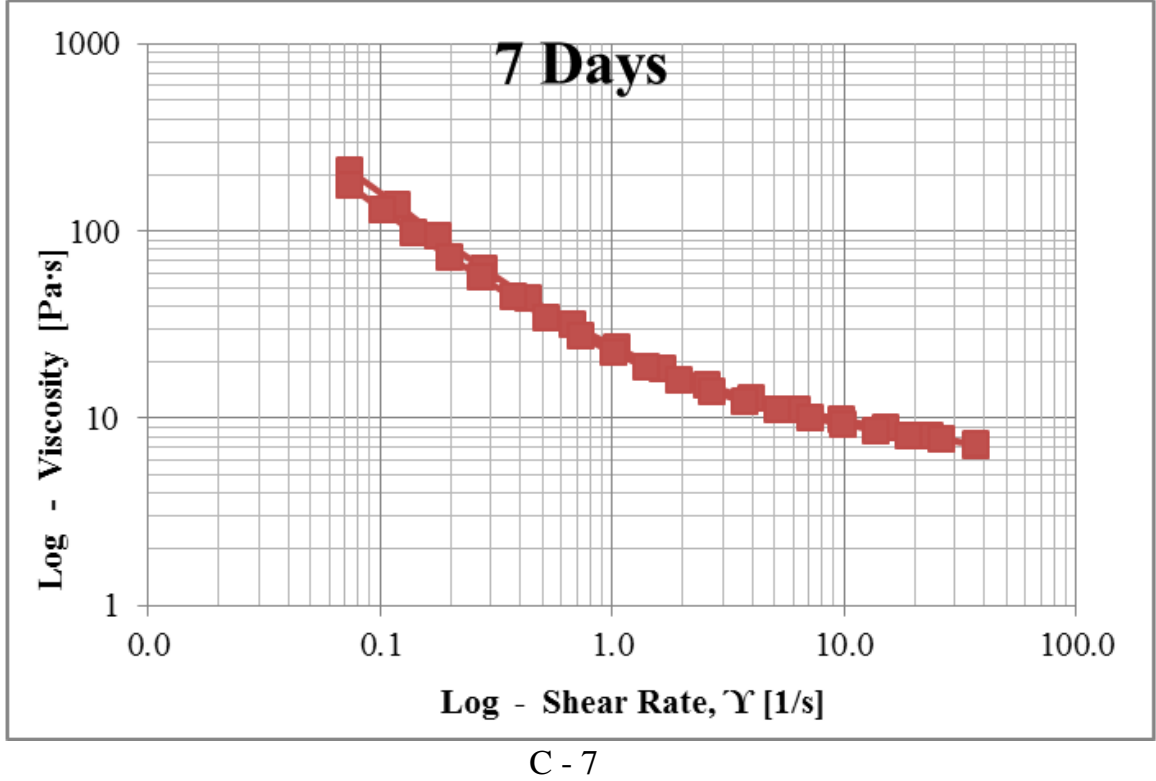


Table C-4: Values measured for Mix J using log-scale data acquisition at 1, 3 \& 7 days. This data was used to form the viscosity curves of Mix $J$.

\begin{tabular}{|c|c|c|c|c|c|c|c|}
\hline \multicolumn{8}{|c|}{ Mix J [SR-97] } \\
\hline \multicolumn{2}{|c|}{ Day 1} & \multicolumn{2}{|c|}{ Day 3} & \multicolumn{2}{|c|}{ Day 7} & \multicolumn{2}{|r|}{ Average } \\
\hline SR ('Y) & Visc. $(\mu)[\mathrm{Pa} \cdot \mathrm{s}]$ & SR $(' \Upsilon)$ & Visc. $(\mu)[\mathrm{Pa} \cdot \mathrm{s}]$ & SR ('Y) & Visc. $(\mu)[\mathrm{Pa} \cdot \mathrm{s}]$ & SR ('Y) & Visc. $(\mu)$ [Pa:s] \\
\hline 0.07 & 273.17 & 0.07 & 234.50 & 0.07 & 227.17 & 0.07 & 244.95 \\
\hline 0.12 & 179.13 & 0.12 & 154.48 & 0.12 & 148.21 & 0.12 & 160.61 \\
\hline 0.18 & 121.63 & 0.18 & 105.21 & 0.18 & 101.65 & 0.18 & 109.50 \\
\hline 0.28 & 80.45 & 0.28 & 69.64 & 0.28 & 67.39 & 0.28 & 72.49 \\
\hline 0.43 & 55.51 & 0.43 & 48.12 & 0.43 & 46.67 & 0.43 & 50.10 \\
\hline 0.67 & 39.58 & 0.67 & 34.10 & 0.67 & 33.13 & 0.67 & 35.60 \\
\hline 1.05 & 29.45 & 1.05 & 25.41 & 1.05 & 24.59 & 1.05 & 26.48 \\
\hline 1.64 & 22.75 & 1.64 & 19.71 & 1.64 & 18.89 & 1.64 & 20.45 \\
\hline 2.55 & 18.48 & 2.55 & 16.10 & 2.55 & 15.43 & 2.55 & 16.67 \\
\hline 3.97 & 15.65 & 3.97 & 13.60 & 3.97 & 13.08 & 3.97 & 14.11 \\
\hline 6.20 & 13.60 & 6.20 & 11.81 & 6.20 & 11.38 & 6.20 & 12.26 \\
\hline 9.66 & 12.11 & 9.66 & 10.49 & 9.66 & 10.13 & 9.66 & 10.91 \\
\hline 15.07 & 10.75 & 15.07 & 9.37 & 15.07 & 9.11 & 15.07 & 9.74 \\
\hline 23.49 & 9.68 & 23.49 & 8.45 & 23.49 & 8.28 & 23.49 & 8.80 \\
\hline 36.59 & 8.69 & 36.59 & 7.55 & 36.59 & 7.36 & 36.59 & 7.86 \\
\hline 36.59 & 8.77 & 36.59 & 7.62 & 36.59 & 7.43 & 36.59 & 7.94 \\
\hline 26.41 & 9.21 & 26.41 & 7.99 & 26.34 & 7.81 & 26.39 & 8.34 \\
\hline 19.02 & 9.79 & 19.02 & 8.52 & 19.02 & 8.33 & 19.02 & 8.88 \\
\hline 13.68 & 10.52 & 13.68 & 9.23 & 13.68 & 8.92 & 13.68 & 9.55 \\
\hline 9.88 & 11.32 & 9.88 & 9.90 & 9.88 & 9.56 & 9.88 & 10.26 \\
\hline 7.13 & 12.33 & 7.13 & 10.72 & 7.13 & 10.40 & 7.13 & 11.15 \\
\hline 5.14 & 13.58 & 5.14 & 11.80 & 5.14 & 11.43 & 5.14 & 12.27 \\
\hline 3.71 & 15.16 & 3.71 & 13.16 & 3.71 & 12.74 & 3.71 & 13.69 \\
\hline 2.67 & 17.23 & 2.67 & 14.96 & 2.67 & 14.46 & 2.67 & 15.55 \\
\hline 1.92 & 20.10 & 1.92 & 17.33 & 1.92 & 16.76 & 1.92 & 18.06 \\
\hline 1.39 & 23.60 & 1.39 & 20.37 & 1.39 & 19.66 & 1.39 & 21.21 \\
\hline 1.00 & 28.29 & 1.00 & 24.47 & 1.00 & 23.53 & 1.00 & 25.43 \\
\hline 0.72 & 34.70 & 0.72 & 29.90 & 0.72 & 28.85 & 0.72 & 31.15 \\
\hline 0.52 & 43.54 & 0.52 & 37.46 & 0.52 & 36.35 & 0.52 & 39.11 \\
\hline 0.37 & 55.81 & 0.37 & 47.92 & 0.37 & 46.48 & 0.37 & 50.07 \\
\hline 0.27 & 71.73 & 0.27 & 61.50 & 0.27 & 59.34 & 0.27 & 64.19 \\
\hline 0.20 & 91.94 & 0.20 & 79.58 & 0.20 & 76.87 & 0.20 & 82.80 \\
\hline 0.14 & 125.98 & 0.14 & 107.70 & 0.14 & 104.49 & 0.14 & 112.72 \\
\hline 0.10 & 164.52 & 0.10 & 140.58 & 0.10 & 138.02 & 0.10 & 147.70 \\
\hline 0.07 & 222.88 & 0.07 & 191.23 & 0.07 & 187.35 & 0.07 & 200.48 \\
\hline
\end{tabular}


Figure C-4: Viscosity curves for Mix $\mathrm{J}$ at (a) 1, (b) 3 and (c) 7 days.

(a)

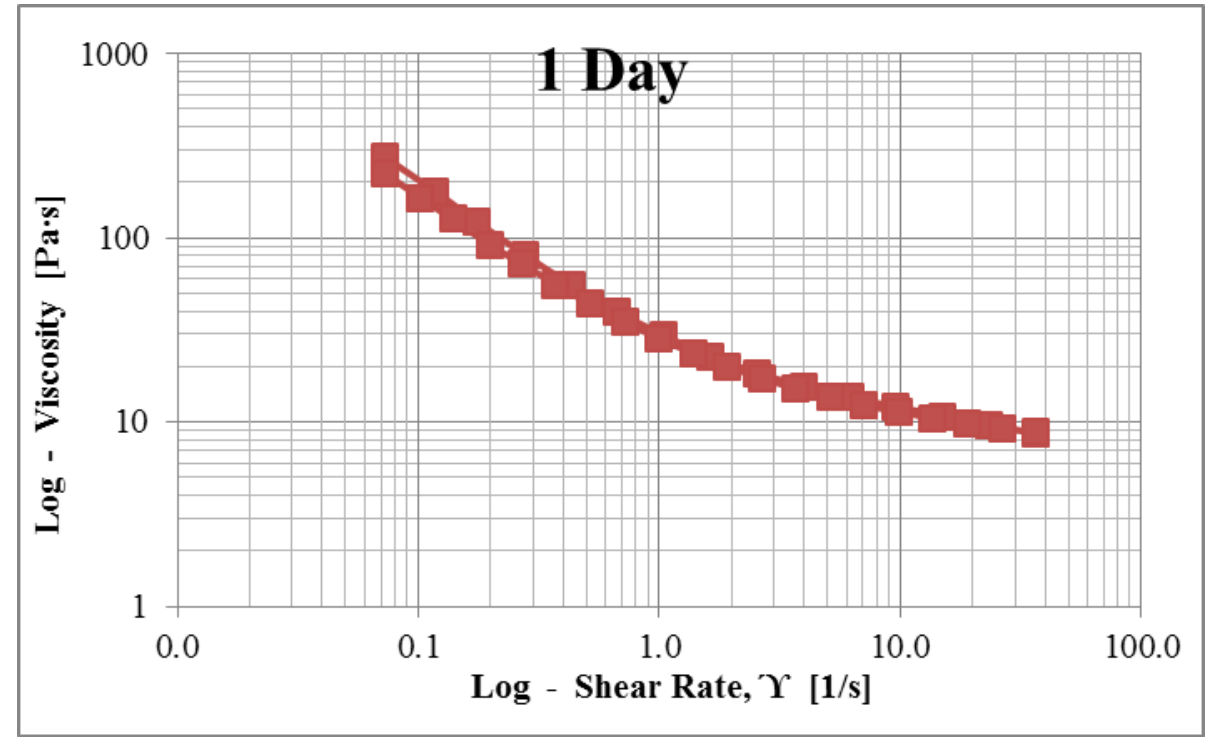

(b)

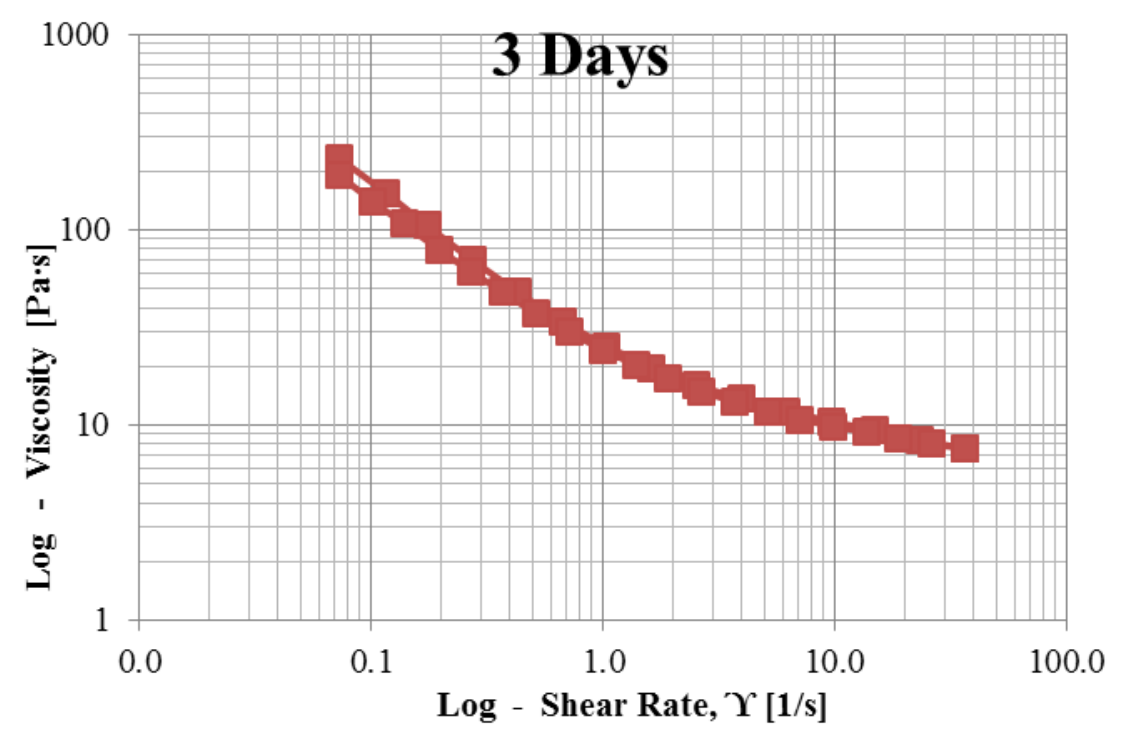

(c)

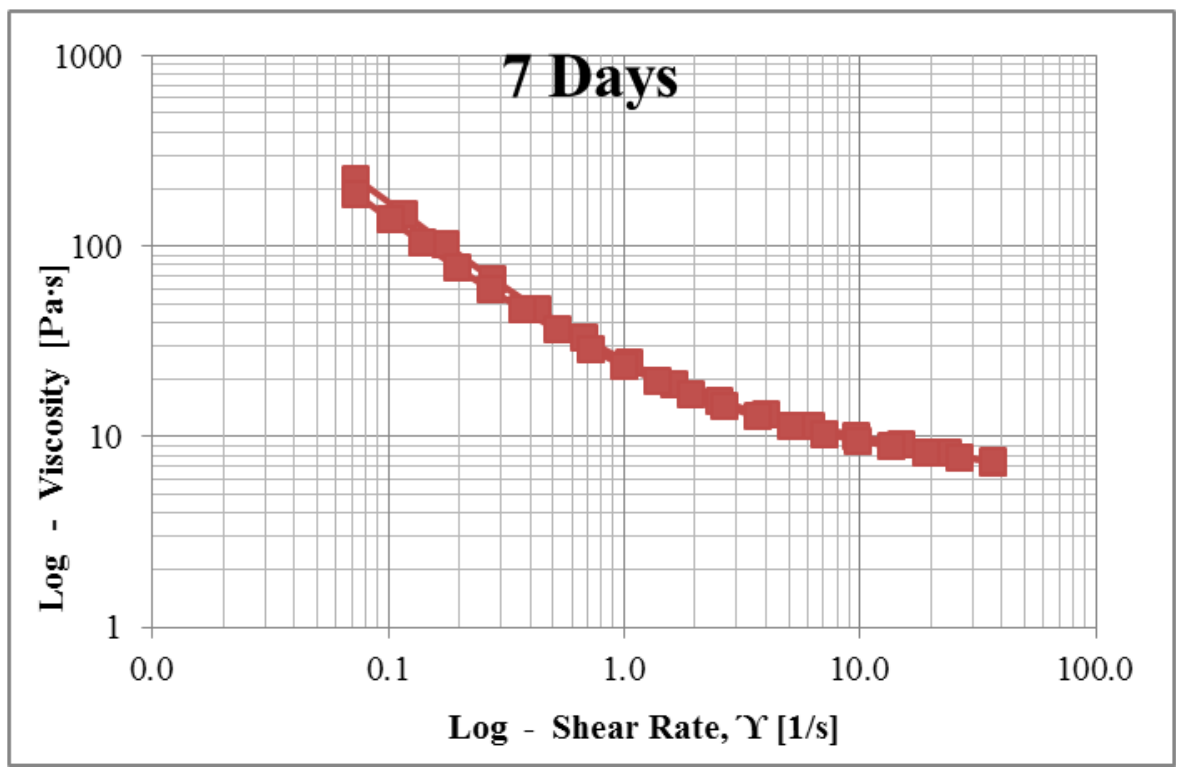

C -9 
Table C-5: Values measured for Mix $L$ using log-scale data acquisition at $1,3 \& 7$ days. This data was used to form the viscosity curves of Mix $L$.

\begin{tabular}{|c|c|c|c|c|c|c|c|}
\hline \multicolumn{8}{|c|}{ Mix L [SR-101] } \\
\hline \multicolumn{2}{|c|}{ Day 1} & \multicolumn{2}{|c|}{ Day 3} & \multicolumn{2}{|c|}{ Day 7} & \multicolumn{2}{|c|}{ Average } \\
\hline SR ('Y) & Visc. $(\mu)[\mathrm{Pa} \cdot \mathrm{s}]$ & SR $(\Upsilon)$ & Visc. $(\mu)[$ Pa·s $]$ & $\mathrm{SR}(\Upsilon)$ & Visc. $(\mu)[\mathrm{Pa} \cdot \mathrm{s}]$ & SR ('T) & Visc. $(\mu)[$ Pa:s] \\
\hline 0.07 & 265.68 & 0.07 & 274.99 & 0.07 & 264.05 & 0.07 & 268.24 \\
\hline 0.12 & 173.72 & 0.12 & 180.45 & 0.12 & 173.00 & 0.12 & 175.72 \\
\hline 0.18 & 119.49 & 0.18 & 122.85 & 0.18 & 118.09 & 0.18 & 120.14 \\
\hline 0.28 & 78.96 & 0.28 & 81.20 & 0.28 & 77.76 & 0.28 & 79.31 \\
\hline 0.43 & 54.48 & 0.43 & 56.43 & 0.43 & 53.93 & 0.43 & 54.94 \\
\hline 0.67 & 38.21 & 0.67 & 40.62 & 0.67 & 38.61 & 0.67 & 39.15 \\
\hline 1.05 & 28.39 & 1.05 & 30.29 & 1.05 & 28.45 & 1.05 & 29.04 \\
\hline 1.64 & 21.65 & 1.64 & 23.53 & 1.64 & 21.80 & 1.64 & 22.33 \\
\hline 2.55 & 17.32 & 2.55 & 19.26 & 2.55 & 18.00 & 2.55 & 18.19 \\
\hline 3.97 & 14.57 & 3.97 & 16.26 & 3.97 & 15.29 & 3.97 & 15.37 \\
\hline 6.20 & 12.51 & 6.20 & 14.20 & 6.20 & 13.29 & 6.20 & 13.33 \\
\hline 9.66 & 10.98 & 9.66 & 12.61 & 9.66 & 11.80 & 9.66 & 11.80 \\
\hline 15.07 & 9.78 & 15.07 & 11.41 & 15.07 & 10.69 & 15.07 & 10.63 \\
\hline 23.49 & 8.75 & 23.49 & 10.28 & 23.49 & 9.74 & 23.49 & 9.59 \\
\hline 36.59 & 7.81 & 36.59 & 9.26 & 36.59 & 8.78 & 36.59 & 8.62 \\
\hline 36.59 & 7.91 & 36.59 & 9.32 & 36.59 & 8.81 & 36.59 & 8.68 \\
\hline 26.41 & 8.33 & 26.34 & 9.80 & 26.34 & 9.29 & 26.37 & 9.14 \\
\hline 19.02 & 8.90 & 19.02 & 10.30 & 19.02 & 9.71 & 19.02 & 9.64 \\
\hline 13.68 & 9.52 & 13.68 & 11.05 & 13.68 & 10.45 & 13.68 & 10.34 \\
\hline 9.88 & 10.32 & 9.88 & 11.82 & 9.88 & 11.22 & 9.88 & 11.12 \\
\hline 7.13 & 11.27 & 7.13 & 12.79 & 7.13 & 12.10 & 7.13 & 12.05 \\
\hline 5.14 & 12.48 & 5.14 & 14.06 & 5.14 & 13.27 & 5.14 & 13.27 \\
\hline 3.71 & 13.95 & 3.70 & 15.64 & 3.71 & 14.74 & 3.71 & 14.78 \\
\hline 2.67 & 15.91 & 2.67 & 17.62 & 2.67 & 16.66 & 2.67 & 16.73 \\
\hline 1.92 & 18.51 & 1.92 & 20.25 & 1.92 & 19.23 & 1.92 & 19.33 \\
\hline 1.39 & 21.91 & 1.39 & 23.74 & 1.39 & 22.58 & 1.39 & 22.74 \\
\hline 1.00 & 26.52 & 1.00 & 28.38 & 1.00 & 27.09 & 1.00 & 27.33 \\
\hline 0.72 & 32.54 & 0.72 & 34.44 & 0.72 & 33.03 & 0.72 & 33.34 \\
\hline 0.52 & 41.15 & 0.52 & 43.21 & 0.52 & 41.40 & 0.52 & 41.92 \\
\hline 0.37 & 52.94 & 0.37 & 54.71 & 0.37 & 52.81 & 0.37 & 53.49 \\
\hline 0.27 & 67.92 & 0.27 & 70.25 & 0.27 & 67.77 & 0.27 & 68.65 \\
\hline 0.20 & 88.15 & 0.20 & 90.61 & 0.20 & 87.46 & 0.20 & 88.74 \\
\hline 0.14 & 120.21 & 0.14 & 122.12 & 0.14 & 118.92 & 0.14 & 120.42 \\
\hline 0.10 & 156.67 & 0.10 & 160.65 & 0.10 & 155.39 & 0.10 & 157.57 \\
\hline 0.07 & 212.97 & 0.07 & 218.15 & 0.07 & 210.69 & 0.07 & 213.93 \\
\hline
\end{tabular}


Figure C-5: Viscosity curves for Mix L at (a) 1, (b) 3 and (c) 7 days.

(a)

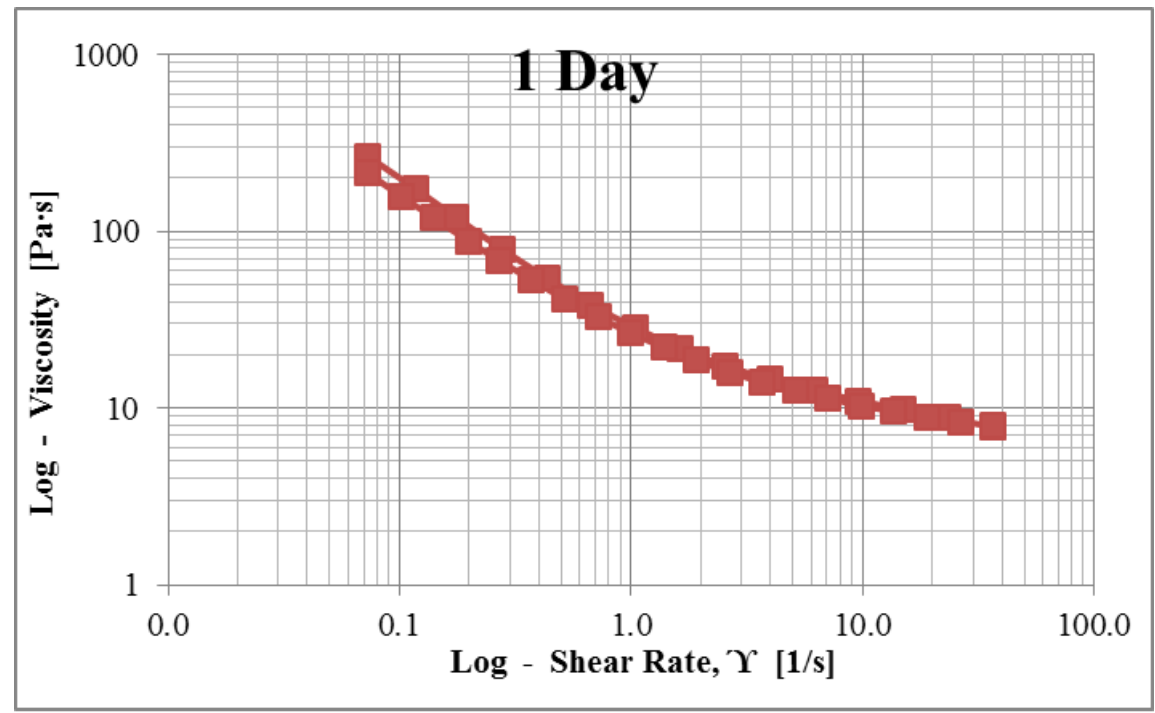

(b)

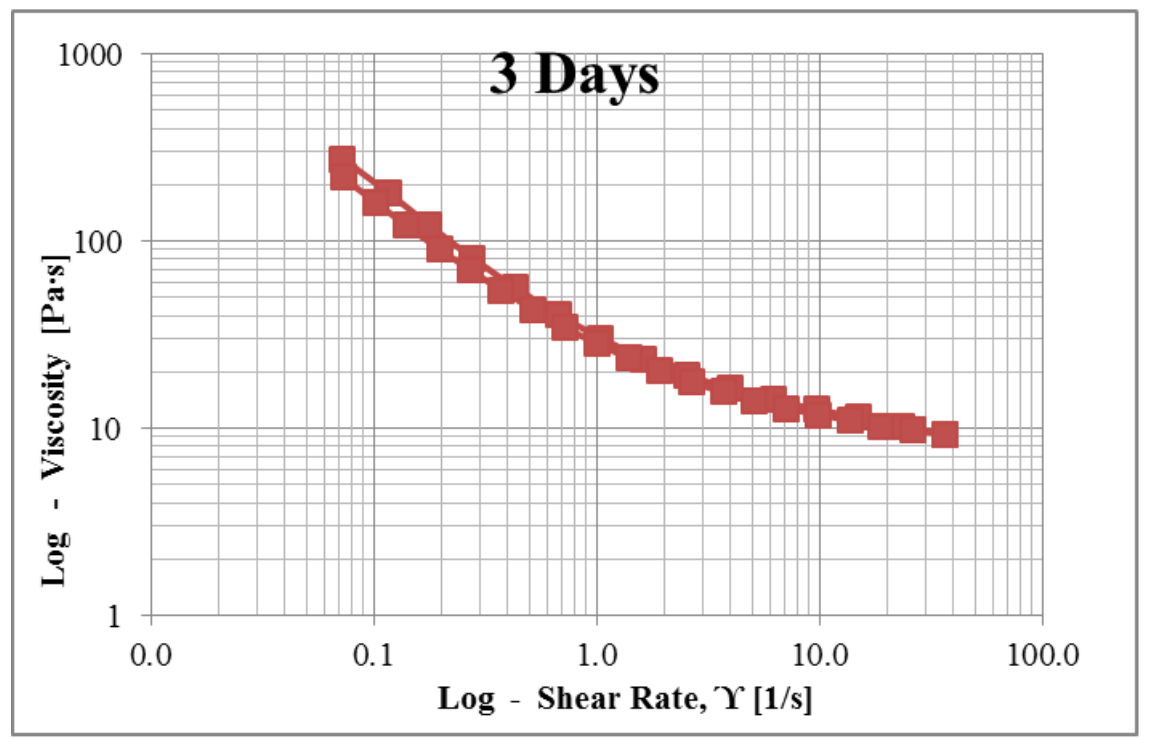

(c)

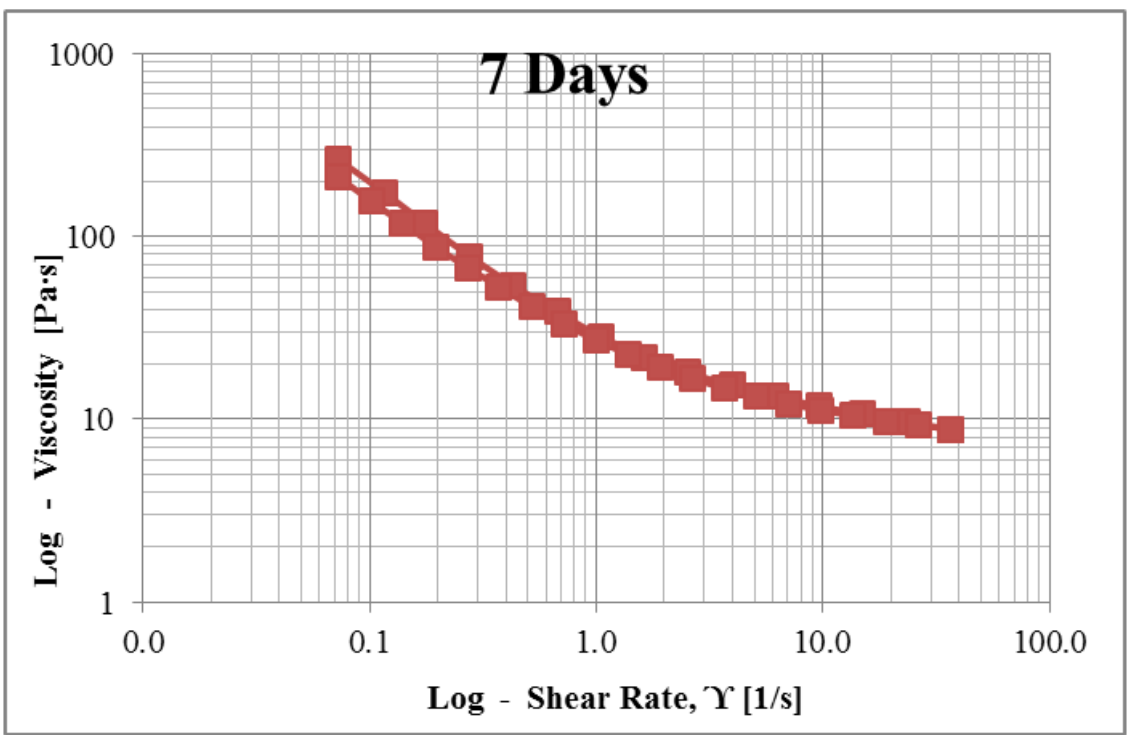

C - 11 


\section{Appendix D: Viscosity Curve Certified and Reference Values}

The tables in this appendix provide the statistical results of the viscosity curve analysis for select mixes (See appendix C). As in Appendix C, these curves portray the viscosity of the material at each shear rate, rather than the plastic viscosity found by Bingham approximation.

The values associated with sample ages for which measurements were made (i.e. $1 \mathrm{~d}, 3 \mathrm{~d}$ and $7 \mathrm{~d}$ ) are considered to be certified values. The values for the other sample ages (i.e. $2 \mathrm{~d}$, $4 \mathrm{~d}, 5 \mathrm{~d}, 6 \mathrm{~d}$ ) are considered to be reference values. However, all values were predicted from the same statistical models describing the relationship between shear rate and viscosity. 
Table D-1: Certified Values for Samples at an Age of $1 \mathrm{~d}$

\begin{tabular}{|c|c|c|c|c|}
\hline $\begin{array}{c}\text { Shear Rate } \\
1 / \mathrm{s} \\
\end{array}$ & $\begin{array}{c}\text { Viscosity } \\
\mathrm{Pa} \cdot \mathrm{s}\end{array}$ & $\begin{array}{c}\text { Viscosity } \\
\text { Standard } \\
\text { Uncertainty } \\
\text { Pa.s } \\
\end{array}$ & $\begin{array}{c}\text { Coverage Factor } \\
\text { (95\% Confidence) } \\
1.000 \\
\end{array}$ & $\begin{array}{c}\text { Viscosity } \\
\text { Expanded } \\
\text { Uncertainty } \\
\mathrm{Pa} \cdot \mathrm{S} \\
\end{array}$ \\
\hline 0.100 & 168.527 & 11.924 & 2.015 & 24.024 \\
\hline 0.103 & 163.838 & 11.734 & 2.035 & 23.877 \\
\hline 0.107 & 159.082 & 11.595 & 2.027 & 23.502 \\
\hline 0.110 & 154.122 & 11.100 & 2.003 & 22.228 \\
\hline 0.114 & 149.277 & 10.891 & 2.010 & 21.895 \\
\hline 0.119 & 144.355 & 10.569 & 2.022 & 21.367 \\
\hline 0.123 & 139.263 & 10.168 & 2.032 & 20.661 \\
\hline 0.129 & 134.355 & 9.843 & 2.052 & 20.198 \\
\hline 0.134 & 129.328 & 9.458 & 2.022 & 19.124 \\
\hline 0.140 & 124.294 & 8.993 & 2.043 & 18.374 \\
\hline 0.147 & 119.303 & 8.653 & 2.031 & 17.571 \\
\hline 0.154 & 114.252 & 8.293 & 2.023 & 16.780 \\
\hline 0.162 & 109.060 & 7.965 & 2.042 & 16.265 \\
\hline 0.171 & 103.957 & 7.549 & 2.032 & 15.343 \\
\hline 0.181 & 98.739 & 7.162 & 2.032 & 14.551 \\
\hline 0.192 & 93.497 & 6.794 & 2.014 & 13.685 \\
\hline 0.205 & 88.390 & 6.428 & 2.011 & 12.929 \\
\hline 0.219 & 83.193 & 6.054 & 2.021 & 12.234 \\
\hline 0.235 & 78.004 & 5.660 & 2.024 & 11.457 \\
\hline 0.255 & 72.871 & 5.345 & 2.025 & 10.827 \\
\hline 0.277 & 67.720 & 4.904 & 2.013 & 9.870 \\
\hline 0.305 & 62.549 & 4.536 & 2.029 & 9.203 \\
\hline 0.338 & 57.373 & 4.157 & 2.026 & 8.421 \\
\hline 0.379 & 52.333 & 3.731 & 2.027 & 7.564 \\
\hline 0.431 & 47.235 & 3.326 & 2.040 & 6.783 \\
\hline 0.500 & 42.127 & 2.946 & 2.057 & 6.060 \\
\hline 0.596 & 37.011 & 2.536 & 2.058 & 5.219 \\
\hline 0.737 & 31.881 & 2.139 & 2.023 & 4.326 \\
\hline 0.966 & 26.782 & 1.730 & 2.076 & 3.592 \\
\hline 1.402 & 21.659 & 1.357 & 2.069 & 2.808 \\
\hline 2.550 & 16.554 & 1.104 & 2.055 & 2.268 \\
\hline 5.000 & 13.353 & 0.944 & 2.050 & 1.936 \\
\hline 10.000 & 10.966 & 0.777 & 2.049 & 1.591 \\
\hline 15.000 & 9.972 & 0.722 & 2.038 & 1.471 \\
\hline 20.000 & 9.349 & 0.676 & 2.045 & 1.382 \\
\hline 25.000 & 8.925 & 0.655 & 2.042 & 1.338 \\
\hline 30.000 & 8.601 & 0.620 & 2.023 & 1.255 \\
\hline 35.000 & 8.354 & 0.617 & 2.056 & 1.268 \\
\hline
\end{tabular}


Table D-2: Reference Values for Samples at an Age of 2 d

\begin{tabular}{|c|c|c|c|c|}
\hline $\begin{array}{c}\text { Shear Rate } \\
1 / \mathrm{s} \\
\end{array}$ & $\begin{array}{c}\text { Viscosity } \\
\text { Pa.s }\end{array}$ & $\begin{array}{c}\text { Viscosity } \\
\text { Standard } \\
\text { Uncertainty } \\
\text { Pa.s } \\
\end{array}$ & $\begin{array}{c}\text { Coverage Factor } \\
\text { (95\% Confidence) } \\
1.000 \\
\end{array}$ & $\begin{array}{c}\text { Viscosity } \\
\text { Expanded } \\
\text { Uncertainty } \\
\text { Pa.s } \\
\end{array}$ \\
\hline 0.100 & 166.603 & 11.927 & 2.032 & 24.238 \\
\hline 0.103 & 161.871 & 11.616 & 2.031 & 23.587 \\
\hline 0.107 & 157.618 & 11.450 & 2.016 & 23.081 \\
\hline 0.110 & 152.548 & 11.065 & 2.013 & 22.270 \\
\hline 0.114 & 147.772 & 10.819 & 2.031 & 21.970 \\
\hline 0.119 & 142.790 & 10.463 & 2.013 & 21.063 \\
\hline 0.123 & 137.920 & 10.047 & 2.019 & 20.283 \\
\hline 0.129 & 133.031 & 9.795 & 2.024 & 19.826 \\
\hline 0.134 & 127.990 & 9.404 & 2.029 & 19.076 \\
\hline 0.140 & 123.006 & 9.034 & 2.049 & 18.514 \\
\hline 0.147 & 118.075 & 8.619 & 2.056 & 17.716 \\
\hline 0.154 & 113.019 & 8.268 & 2.043 & 16.892 \\
\hline 0.162 & 107.912 & 7.959 & 2.038 & 16.220 \\
\hline 0.171 & 102.809 & 7.482 & 2.037 & 15.242 \\
\hline 0.181 & 97.700 & 7.200 & 2.037 & 14.668 \\
\hline 0.192 & 92.525 & 6.724 & 2.016 & 13.554 \\
\hline 0.205 & 87.492 & 6.486 & 2.029 & 13.156 \\
\hline 0.219 & 82.256 & 6.017 & 2.029 & 12.209 \\
\hline 0.235 & 77.159 & 5.690 & 2.024 & 11.516 \\
\hline 0.255 & 72.169 & 5.275 & 2.017 & 10.642 \\
\hline 0.277 & 67.036 & 4.879 & 2.029 & 9.900 \\
\hline 0.305 & 61.977 & 4.534 & 2.025 & 9.181 \\
\hline 0.338 & 56.924 & 4.126 & 2.019 & 8.330 \\
\hline 0.379 & 51.800 & 3.743 & 2.016 & 7.545 \\
\hline 0.431 & 46.754 & 3.384 & 2.009 & 6.797 \\
\hline 0.500 & 41.710 & 2.940 & 2.039 & 5.994 \\
\hline 0.596 & 36.691 & 2.530 & 2.036 & 5.151 \\
\hline 0.737 & 31.634 & 2.140 & 2.064 & 4.416 \\
\hline 0.966 & 26.603 & 1.729 & 2.052 & 3.546 \\
\hline 1.402 & 21.538 & 1.357 & 2.071 & 2.811 \\
\hline 2.550 & 16.496 & 1.092 & 2.040 & 2.228 \\
\hline 5.000 & 13.348 & 0.938 & 2.059 & 1.930 \\
\hline 10.000 & 10.981 & 0.776 & 2.046 & 1.588 \\
\hline 15.000 & 9.997 & 0.713 & 2.039 & 1.455 \\
\hline 20.000 & 9.371 & 0.682 & 2.048 & 1.397 \\
\hline 25.000 & 8.956 & 0.645 & 2.040 & 1.317 \\
\hline 30.000 & 8.624 & 0.623 & 2.049 & 1.276 \\
\hline 35.000 & 8.383 & 0.610 & 2.046 & 1.247 \\
\hline
\end{tabular}


Table D-3: Certified Value for Samples at an Age of $3 \mathrm{~d}$

\begin{tabular}{|c|c|c|c|c|}
\hline $\begin{array}{c}\text { Shear Rate } \\
1 / \mathrm{s}\end{array}$ & $\begin{array}{c}\text { Viscosity } \\
\mathrm{Pa} \cdot \mathrm{s}\end{array}$ & $\begin{array}{c}\text { Viscosity } \\
\text { Standard } \\
\text { Uncertainty } \\
\text { Pa.s } \\
\end{array}$ & $\begin{array}{c}\text { Coverage Factor } \\
\text { (95\% Confidence) } \\
1.000 \\
\end{array}$ & $\begin{array}{c}\text { Viscosity } \\
\text { Expanded } \\
\text { Uncertainty } \\
\text { Pa.s }\end{array}$ \\
\hline 0.100 & 164.967 & 11.933 & 2.011 & 23.995 \\
\hline 0.103 & 160.319 & 11.475 & 2.027 & 23.258 \\
\hline 0.107 & 155.767 & 11.355 & 2.004 & 22.758 \\
\hline 0.110 & 150.844 & 10.979 & 2.013 & 22.102 \\
\hline 0.114 & 146.085 & 10.817 & 2.020 & 21.851 \\
\hline 0.119 & 141.245 & 10.509 & 2.037 & 21.412 \\
\hline 0.123 & 136.273 & 10.174 & 2.025 & 20.603 \\
\hline 0.129 & 131.649 & 9.702 & 2.041 & 19.798 \\
\hline 0.134 & 126.632 & 9.453 & 2.047 & 19.347 \\
\hline 0.140 & 121.713 & 9.042 & 2.044 & 18.478 \\
\hline 0.147 & 116.715 & 8.631 & 2.031 & 17.527 \\
\hline 0.154 & 111.808 & 8.231 & 2.048 & 16.854 \\
\hline 0.162 & 106.675 & 7.877 & 2.032 & 16.006 \\
\hline 0.171 & 101.709 & 7.541 & 2.028 & 15.294 \\
\hline 0.181 & 96.699 & 7.199 & 2.028 & 14.597 \\
\hline 0.192 & 91.558 & 6.698 & 2.026 & 13.572 \\
\hline 0.205 & 86.586 & 6.386 & 2.038 & 13.011 \\
\hline 0.219 & 81.426 & 6.068 & 2.042 & 12.391 \\
\hline 0.235 & 76.356 & 5.609 & 2.035 & 11.417 \\
\hline 0.255 & 71.390 & 5.274 & 2.021 & 10.657 \\
\hline 0.277 & 66.370 & 4.854 & 2.019 & 9.801 \\
\hline 0.305 & 61.330 & 4.497 & 2.027 & 9.116 \\
\hline 0.338 & 56.339 & 4.113 & 2.017 & 8.299 \\
\hline 0.379 & 51.337 & 3.723 & 2.019 & 7.518 \\
\hline 0.431 & 46.342 & 3.333 & 2.026 & 6.752 \\
\hline 0.500 & 41.343 & 2.969 & 2.035 & 6.041 \\
\hline 0.596 & 36.361 & 2.525 & 2.031 & 5.130 \\
\hline 0.737 & 31.384 & 2.133 & 2.027 & 4.324 \\
\hline 0.966 & 26.409 & 1.720 & 2.051 & 3.528 \\
\hline 1.402 & 21.411 & 1.362 & 2.067 & 2.814 \\
\hline 2.550 & 16.428 & 1.070 & 2.047 & 2.191 \\
\hline 5.000 & 13.315 & 0.924 & 2.059 & 1.902 \\
\hline 10.000 & 10.993 & 0.765 & 2.041 & 1.561 \\
\hline 15.000 & 10.012 & 0.714 & 2.054 & 1.467 \\
\hline 20.000 & 9.403 & 0.680 & 2.042 & 1.389 \\
\hline 25.000 & 8.985 & 0.649 & 2.039 & 1.322 \\
\hline 30.000 & 8.659 & 0.628 & 2.043 & 1.284 \\
\hline 35.000 & 8.422 & 0.615 & 2.047 & 1.258 \\
\hline
\end{tabular}


Table D-4: Reference Values for Samples at an Age of 4 d

\begin{tabular}{|c|c|c|c|c|}
\hline $\begin{array}{c}\text { Shear Rate } \\
1 / \mathrm{s}\end{array}$ & $\begin{array}{c}\text { Viscosity } \\
\mathrm{Pa} \cdot \mathrm{s}\end{array}$ & $\begin{array}{c}\text { Viscosity } \\
\text { Standard } \\
\text { Uncertainty } \\
\text { Pa.s } \\
\end{array}$ & $\begin{array}{c}\text { Coverage Factor } \\
\text { (95\% Confidence) } \\
1.000 \\
\end{array}$ & $\begin{array}{c}\text { Viscosity } \\
\text { Expanded } \\
\text { Uncertainty } \\
\text { Pa.s }\end{array}$ \\
\hline 0.1000 & 163.0821 & 11.8218 & 2.0345 & 24.0510 \\
\hline 0.1032 & 158.4471 & 11.5844 & 2.0075 & 23.2552 \\
\hline 0.1065 & 154.0894 & 11.4604 & 2.0417 & 23.3982 \\
\hline 0.1103 & 149.3031 & 11.0238 & 2.0200 & 22.2685 \\
\hline 0.1143 & 144.4133 & 10.7745 & 2.0269 & 21.8385 \\
\hline 0.1187 & 139.6814 & 10.5158 & 2.0445 & 21.4997 \\
\hline 0.1234 & 134.8451 & 10.1903 & 2.0394 & 20.7820 \\
\hline 0.1285 & 130.0087 & 9.7303 & 2.0402 & 19.8516 \\
\hline 0.1341 & 125.1284 & 9.4205 & 2.0385 & 19.2039 \\
\hline 0.1401 & 120.4082 & 9.0122 & 2.0343 & 18.3339 \\
\hline 0.1467 & 115.4065 & 8.6446 & 2.0417 & 17.6493 \\
\hline 0.1539 & 110.5026 & 8.2081 & 2.0275 & 16.6418 \\
\hline 0.1619 & 105.6063 & 7.9176 & 2.0390 & 16.1443 \\
\hline 0.1709 & 100.5740 & 7.5487 & 2.0269 & 15.3005 \\
\hline 0.1808 & 95.5844 & 7.1098 & 2.0334 & 14.4570 \\
\hline 0.1919 & 90.5623 & 6.7396 & 2.0321 & 13.6955 \\
\hline 0.2045 & 85.6299 & 6.3052 & 2.0435 & 12.8846 \\
\hline 0.2189 & 80.5662 & 6.0081 & 2.0220 & 12.1484 \\
\hline 0.2355 & 75.6022 & 5.6686 & 2.0288 & 11.5006 \\
\hline 0.2547 & 70.6604 & 5.2661 & 2.0402 & 10.7437 \\
\hline 0.2774 & 65.6387 & 4.8871 & 2.0232 & 9.8876 \\
\hline 0.3046 & 60.7592 & 4.5402 & 2.0152 & 9.1497 \\
\hline 0.3376 & 55.7926 & 4.0776 & 2.0357 & 8.3007 \\
\hline 0.3787 & 50.8628 & 3.7702 & 2.0160 & 7.6006 \\
\hline 0.4311 & 45.9177 & 3.3183 & 2.0229 & 6.7125 \\
\hline 0.5004 & 40.9998 & 2.9376 & 2.0440 & 6.0044 \\
\hline 0.5962 & 36.0336 & 2.5413 & 2.0346 & 5.1705 \\
\hline 0.7375 & 31.1489 & 2.1401 & 2.0492 & 4.3854 \\
\hline 0.9665 & 26.2159 & 1.7240 & 2.0542 & 3.5416 \\
\hline 1.4016 & 21.2571 & 1.3418 & 2.0747 & 2.7838 \\
\hline 2.5496 & 16.3623 & 1.0935 & 2.0645 & 2.2576 \\
\hline 5.0000 & 13.3131 & 0.9283 & 2.0510 & 1.9039 \\
\hline 10.0000 & 11.0018 & 0.7786 & 2.0471 & 1.5938 \\
\hline 15.0000 & 10.0377 & 0.7039 & 2.0528 & 1.4449 \\
\hline 20.0000 & 9.4316 & 0.6762 & 2.0605 & 1.3932 \\
\hline 25.0000 & 9.0242 & 0.6532 & 2.0362 & 1.3300 \\
\hline 30.0000 & 8.6960 & 0.6263 & 2.0516 & 1.2849 \\
\hline 35.0000 & 8.4582 & 0.6147 & 2.0351 & 1.2510 \\
\hline
\end{tabular}


Table D-5: Reference Values for Samples at an Age of 5 d

\begin{tabular}{|c|c|c|c|c|}
\hline $\begin{array}{c}\text { Shear Rate } \\
1 / \mathrm{s}\end{array}$ & $\begin{array}{c}\text { Viscosity } \\
\mathrm{Pa} \cdot \mathrm{s}\end{array}$ & $\begin{array}{c}\text { Viscosity } \\
\text { Standard } \\
\text { Uncertainty } \\
\text { Pa.s } \\
\end{array}$ & $\begin{array}{c}\text { Coverage Factor } \\
\text { (95\% Confidence) } \\
1.000 \\
\end{array}$ & $\begin{array}{c}\text { Viscosity } \\
\text { Expanded } \\
\text { Uncertainty } \\
\text { Pa.s }\end{array}$ \\
\hline 0.100 & 161.248 & 11.919 & 2.023 & 24.109 \\
\hline 0.103 & 156.813 & 11.696 & 2.021 & 23.642 \\
\hline 0.107 & 152.271 & 11.479 & 2.034 & 23.349 \\
\hline 0.110 & 147.644 & 11.090 & 2.009 & 22.278 \\
\hline 0.114 & 142.944 & 10.746 & 2.033 & 21.845 \\
\hline 0.119 & 138.146 & 10.481 & 2.020 & 21.167 \\
\hline 0.123 & 133.337 & 10.163 & 2.037 & 20.703 \\
\hline 0.129 & 128.732 & 9.759 & 2.022 & 19.735 \\
\hline 0.134 & 123.716 & 9.395 & 2.030 & 19.075 \\
\hline 0.140 & 118.990 & 8.931 & 2.037 & 18.193 \\
\hline 0.147 & 114.157 & 8.740 & 2.037 & 17.807 \\
\hline 0.154 & 109.345 & 8.230 & 2.029 & 16.702 \\
\hline 0.162 & 104.381 & 7.932 & 2.036 & 16.152 \\
\hline 0.171 & 99.486 & 7.494 & 2.023 & 15.162 \\
\hline 0.181 & 94.566 & 7.160 & 2.033 & 14.560 \\
\hline 0.192 & 89.708 & 6.719 & 2.044 & 13.731 \\
\hline 0.205 & 84.744 & 6.445 & 2.039 & 13.142 \\
\hline 0.219 & 79.741 & 6.055 & 2.031 & 12.294 \\
\hline 0.235 & 74.833 & 5.670 & 2.023 & 11.468 \\
\hline 0.255 & 69.901 & 5.285 & 2.016 & 10.654 \\
\hline 0.277 & 65.090 & 4.881 & 2.008 & 9.802 \\
\hline 0.305 & 60.091 & 4.485 & 2.008 & 9.006 \\
\hline 0.338 & 55.240 & 4.137 & 2.032 & 8.407 \\
\hline 0.379 & 50.342 & 3.712 & 2.039 & 7.569 \\
\hline 0.431 & 45.480 & 3.348 & 2.040 & 6.829 \\
\hline 0.500 & 40.620 & 2.931 & 2.045 & 5.993 \\
\hline 0.596 & 35.738 & 2.532 & 2.040 & 5.164 \\
\hline 0.737 & 30.873 & 2.110 & 2.048 & 4.323 \\
\hline 0.966 & 26.024 & 1.734 & 2.052 & 3.557 \\
\hline 1.402 & 21.150 & 1.361 & 2.091 & 2.847 \\
\hline 2.550 & 16.307 & 1.088 & 2.050 & 2.231 \\
\hline 5.000 & 13.290 & 0.930 & 2.050 & 1.907 \\
\hline 10.000 & 11.003 & 0.776 & 2.074 & 1.609 \\
\hline 15.000 & 10.053 & 0.717 & 2.058 & 1.476 \\
\hline 20.000 & 9.454 & 0.682 & 2.059 & 1.404 \\
\hline 25.000 & 9.049 & 0.652 & 2.040 & 1.330 \\
\hline 30.000 & 8.720 & 0.625 & 2.055 & 1.284 \\
\hline 35.000 & 8.490 & 0.612 & 2.020 & 1.237 \\
\hline
\end{tabular}


Table D-6: Reference Values for Samples at an Age of $6 \mathrm{~d}$

\begin{tabular}{|c|c|c|c|c|}
\hline $\begin{array}{c}\text { Shear Rate } \\
1 / \mathrm{s} \\
\end{array}$ & $\begin{array}{c}\text { Viscosity } \\
\mathrm{Pa} \cdot \mathrm{s}\end{array}$ & $\begin{array}{c}\text { Viscosity } \\
\text { Standard } \\
\text { Uncertainty } \\
\text { Pa.s } \\
\end{array}$ & $\begin{array}{c}\text { Coverage Factor } \\
\text { (95\% Confidence) } \\
1.000 \\
\end{array}$ & $\begin{array}{c}\text { Viscosity } \\
\text { Expanded } \\
\text { Uncertainty } \\
\mathrm{Pa} \cdot \mathrm{s} \\
\end{array}$ \\
\hline 0.100 & 159.498 & 11.984 & 2.023 & 24.238 \\
\hline 0.103 & 155.021 & 11.693 & 2.039 & 23.845 \\
\hline 0.107 & 150.612 & 11.396 & 2.022 & 23.046 \\
\hline 0.110 & 145.979 & 10.981 & 2.022 & 22.207 \\
\hline 0.114 & 141.379 & 10.845 & 2.016 & 21.866 \\
\hline 0.119 & 136.665 & 10.497 & 2.039 & 21.404 \\
\hline 0.123 & 131.899 & 10.189 & 2.034 & 20.725 \\
\hline 0.129 & 127.277 & 9.721 & 2.051 & 19.935 \\
\hline 0.134 & 122.516 & 9.513 & 2.030 & 19.312 \\
\hline 0.140 & 117.715 & 9.091 & 2.039 & 18.541 \\
\hline 0.147 & 112.997 & 8.648 & 2.026 & 17.519 \\
\hline 0.154 & 108.074 & 8.332 & 2.058 & 17.149 \\
\hline 0.162 & 103.286 & 7.922 & 2.035 & 16.125 \\
\hline 0.171 & 98.362 & 7.484 & 2.034 & 15.222 \\
\hline 0.181 & 93.455 & 7.119 & 2.032 & 14.466 \\
\hline 0.192 & 88.588 & 6.792 & 2.033 & 13.808 \\
\hline 0.205 & 83.717 & 6.454 & 2.035 & 13.136 \\
\hline 0.219 & 78.848 & 6.059 & 2.018 & 12.226 \\
\hline 0.235 & 74.041 & 5.722 & 2.012 & 11.511 \\
\hline 0.255 & 69.160 & 5.297 & 2.038 & 10.795 \\
\hline 0.277 & 64.363 & 4.853 & 2.020 & 9.802 \\
\hline 0.305 & 59.573 & 4.543 & 2.035 & 9.246 \\
\hline 0.338 & 54.725 & 4.119 & 2.009 & 8.277 \\
\hline 0.379 & 49.832 & 3.776 & 2.014 & 7.604 \\
\hline 0.431 & 45.078 & 3.339 & 2.016 & 6.731 \\
\hline 0.500 & 40.258 & 2.963 & 2.023 & 5.995 \\
\hline 0.596 & 35.440 & 2.539 & 2.030 & 5.154 \\
\hline 0.737 & 30.637 & 2.124 & 2.024 & 4.298 \\
\hline 0.966 & 25.828 & 1.727 & 2.037 & 3.519 \\
\hline 1.402 & 21.023 & 1.372 & 2.063 & 2.832 \\
\hline 2.550 & 16.236 & 1.094 & 2.056 & 2.249 \\
\hline 5.000 & 13.265 & 0.934 & 2.034 & 1.899 \\
\hline 10.000 & 11.026 & 0.784 & 2.057 & 1.612 \\
\hline 15.000 & 10.071 & 0.722 & 2.058 & 1.486 \\
\hline 20.000 & 9.482 & 0.684 & 2.040 & 1.395 \\
\hline 25.000 & 9.078 & 0.657 & 2.050 & 1.347 \\
\hline 30.000 & 8.754 & 0.631 & 2.044 & 1.289 \\
\hline 35.000 & 8.522 & 0.618 & 2.059 & 1.273 \\
\hline
\end{tabular}


Table D-7: Certified Values for Samples at an Age of 7 d

\begin{tabular}{|c|c|c|c|c|}
\hline $\begin{array}{c}\text { Shear Rate } \\
1 / \mathrm{s}\end{array}$ & $\begin{array}{c}\text { Viscosity } \\
\mathrm{Pa} \cdot \mathrm{s}\end{array}$ & $\begin{array}{c}\text { Viscosity } \\
\text { Standard } \\
\text { Uncertainty } \\
\text { Pa.s } \\
\end{array}$ & $\begin{array}{c}\text { Coverage Factor } \\
\text { (95\% Confidence) } \\
1.000 \\
\end{array}$ & $\begin{array}{c}\text { Viscosity } \\
\text { Expanded } \\
\text { Uncertainty } \\
\text { Pa.s }\end{array}$ \\
\hline 0.100 & 157.841 & 12.043 & 2.011 & 24.221 \\
\hline 0.103 & 153.249 & 11.682 & 2.025 & 23.659 \\
\hline 0.107 & 148.870 & 11.540 & 2.029 & 23.418 \\
\hline 0.110 & 144.284 & 11.068 & 2.010 & 22.246 \\
\hline 0.114 & 139.791 & 10.887 & 2.011 & 21.888 \\
\hline 0.119 & 135.040 & 10.512 & 2.011 & 21.144 \\
\hline 0.123 & 130.382 & 10.089 & 2.014 & 20.325 \\
\hline 0.129 & 125.832 & 9.968 & 2.016 & 20.095 \\
\hline 0.134 & 121.049 & 9.520 & 2.034 & 19.366 \\
\hline 0.140 & 116.447 & 9.092 & 2.018 & 18.350 \\
\hline 0.147 & 111.688 & 8.741 & 2.034 & 17.779 \\
\hline 0.154 & 106.895 & 8.334 & 2.022 & 16.855 \\
\hline 0.162 & 102.161 & 7.974 & 2.032 & 16.203 \\
\hline 0.171 & 97.312 & 7.590 & 2.011 & 15.264 \\
\hline 0.181 & 92.469 & 7.190 & 2.035 & 14.631 \\
\hline 0.192 & 87.671 & 6.849 & 2.036 & 13.946 \\
\hline 0.205 & 82.793 & 6.442 & 2.034 & 13.104 \\
\hline 0.219 & 78.028 & 6.078 & 2.030 & 12.335 \\
\hline 0.235 & 73.183 & 5.713 & 2.024 & 11.564 \\
\hline 0.255 & 68.460 & 5.284 & 2.023 & 10.692 \\
\hline 0.277 & 63.689 & 4.888 & 2.043 & 9.984 \\
\hline 0.305 & 58.860 & 4.516 & 2.024 & 9.142 \\
\hline 0.338 & 54.159 & 4.138 & 2.019 & 8.353 \\
\hline 0.379 & 49.409 & 3.763 & 2.028 & 7.631 \\
\hline 0.431 & 44.646 & 3.362 & 2.045 & 6.878 \\
\hline 0.500 & 39.900 & 2.950 & 2.020 & 5.961 \\
\hline 0.596 & 35.121 & 2.564 & 2.044 & 5.239 \\
\hline 0.737 & 30.350 & 2.139 & 2.051 & 4.386 \\
\hline 0.966 & 25.634 & 1.730 & 2.063 & 3.570 \\
\hline 1.402 & 20.873 & 1.374 & 2.055 & 2.823 \\
\hline 2.550 & 16.185 & 1.090 & 2.066 & 2.252 \\
\hline 5.000 & 13.252 & 0.938 & 2.037 & 1.911 \\
\hline 10.000 & 11.032 & 0.789 & 2.052 & 1.619 \\
\hline 15.000 & 10.103 & 0.720 & 2.040 & 1.468 \\
\hline 20.000 & 9.514 & 0.688 & 2.029 & 1.396 \\
\hline 25.000 & 9.105 & 0.650 & 2.045 & 1.330 \\
\hline 30.000 & 8.793 & 0.629 & 2.054 & 1.292 \\
\hline 35.000 & 8.553 & 0.624 & 2.055 & 1.283 \\
\hline
\end{tabular}

